Hernán Salas Quintanal

María Leticia Rivermar Pérez

editores

\title{
Nativitas, Tlaxcala.
}

\section{La construcción en el tiempo de un territorio rural}

近政lícacton delos signos.

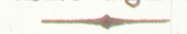

- Cuidad Copitat

- Cabecera de Partido

- Rueblas

- Haciencetas

$\triangle$ Racickos

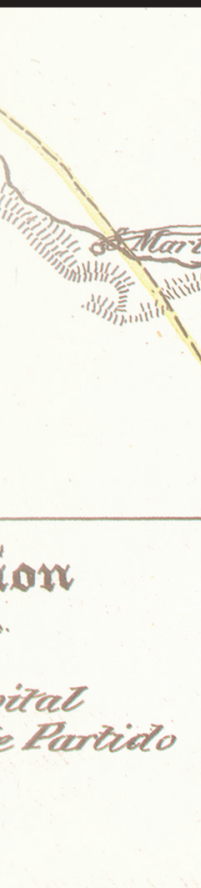

os. Peatro Popeatlanz Marió oS. Fetipe Tia.Trinto

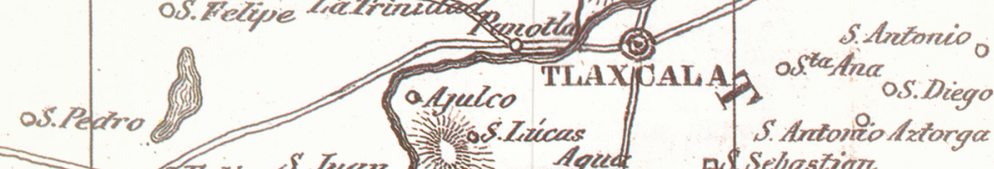
S. Antorico on of Oblep is of. Truan Misco " s.menguel del off.Migurel i mingatiago ostalsabel Tepoy ropoyizing

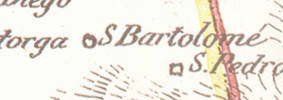

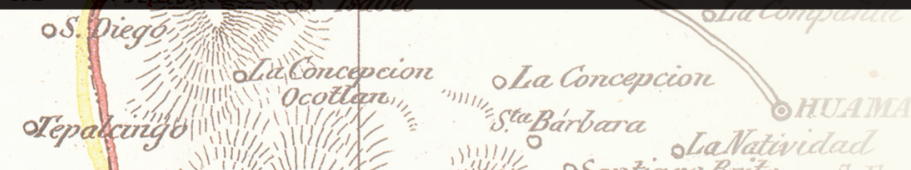

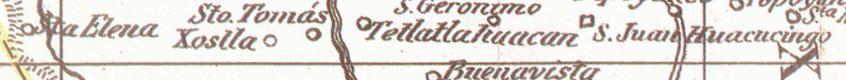

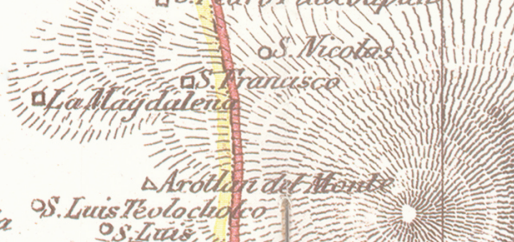
1"

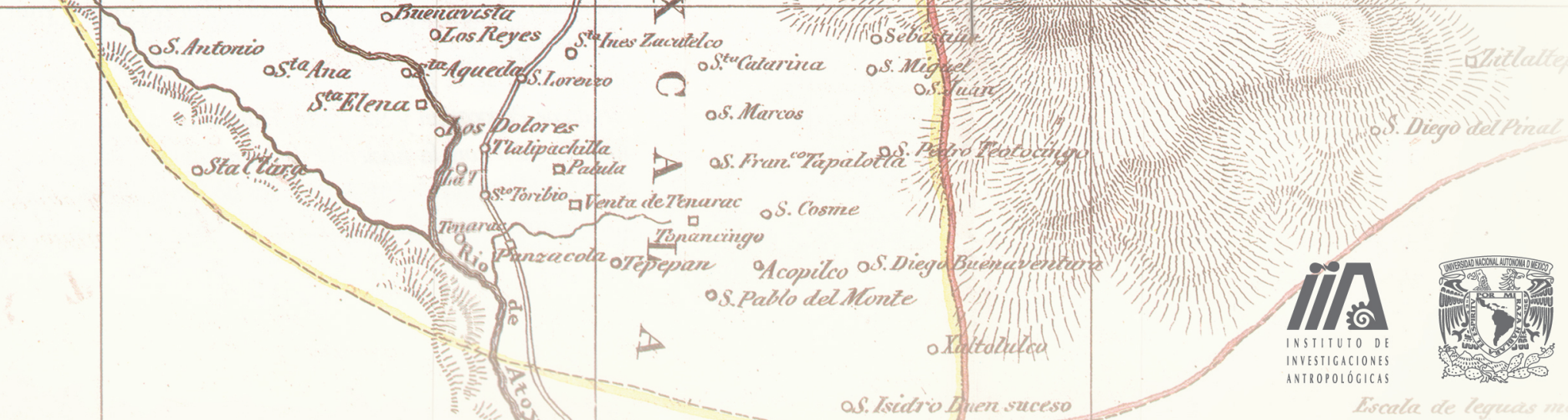




\section{Nativitas, Tlaxcala La construcción en el tiempo de un territorio rural}




\section{Nativitas, Tlaxcala La construcción en el tiempo de un territorio rural}


Nativitas, Tlaxcala : la construcción en el tiempo de un territorio rural / editores Hernán Salas Quintanal, María Leticia Rivermar Pérez. -- Primera edición. -- México : UNAM, Instituto de Investigaciones Antropológicas, 2014. 312 páginas : ilustraciones ; $27 \mathrm{~cm}$.

Bibliografía: páginas 273-306

ISBN versión impresa 978-607-02-5543-4

ISBN versión electróinca 978-607-02-6647-8

1. Nativitas (Tlaxcala) - Condiciones rurales - Historia. 2. Tenencia de la tierra - Tlaxcala - Nativitas - Historia. 3. Ejidos - Tlaxcala - Nativitas. 4. Agricultura - Tlaxcala - Nativitas. I. Salas Quintanal, Hernán, editor. II. Rivermar Pérez, María Leticia, editor. III. Universidad Nacional Autónoma de México. Instituto de Investigaciones Antropológicas.

338.109724835-scdd21 Biblioteca Nacional de México

Primera edición impresa: junio 2014

Primera edición electrónica: junio 2015

Término de la edición electrónica: 9 de junio de 2015

D.R. 2015 @ Universidad Nacional Autónoma de México Ciudad Universitaria, C. P. 04510, Coyoacán, México, Distrito Federal.

Instituto De Investigaciones Antropológicas www.iia.unam.mx

Agradecemos el apoyo por parte del Programa de Apoyo a Proyectos de Investigación e Innovación Tecnológica (UNAM-PAPIIT) al proyecto IN302709 y del Consejo Nacional de Ciencia y Tecnología (Conacyt) al proyecto 98651, para la impresión de la presente publicación.

IISBN versión impresa 978-607-02-5543-4

ISBN versión electróinca 978-607-02-6647-8

Diseño de interiores y portada: Flor Moyao Gutiérrez

Prohibida la reproducción total o parcial por cualquier medio sin la autorización escrita del titular de los derechos patrimoniales.

Derechos reservados conforme a la ley

Hecho en México

Made in Mexico 


\section{ÍNDICE}

9 Agradecimientos

11 INTRODUCCIÓN. SOBRE EL TERRITORIO RURAL Y SUS HABITANTES Hernán Salas Quintanal

María Leticia Rivermar Pérez

21 TERRITORIO Y SISTEMA HÍDRICO DE LA PLANICIE DEL SUROESTE DE TLAXCALA A TRAVÉS DEL TIEMPO

Esther Galicia Hernández

37 La CONFORMación del Sistema de Riego del Valle de TeXmeluCAN, EN LA CUENCA DEL ALTO ATOYAC, DURANTE EL SIGLO XVII Davison G. Mazabel Dominguez

59 CONFORMACIÓN HISTÓRICO-TERRITORIAL Y PRODUCTIVA EN LA SEGUNDA MITAD DEL SIGLO XIX EN NATIVITAS

Guillermo Paleta Pérez

73 El REPARTO AGRARIO EN NATIVITAS, RESUlTADO DE LUCHAS SOCIALES EN LAS PRIMERAS DÉCADAS DEL SIGLO XX

Óscar Gerardo Hernández Lara

95 El EJIDO EN NATIVITAS: PASADO, PRESENTE Y FUTURO Hernán Salas Quintanal

Rubén Luna Castillo

115 Repensando el pasado agrícola para entender el pResente RURAL Paola Velasco Santos 
LOS EFECTOS SOCIOAMBIENTALES DE LA CONTAMINACIÓN

DEL RÍO ATOYAC EN NATIVITAS

Hernán Salas Quintanal

Paola Velasco Santos

ESTRATEGIAS SOCIOLABORALES Y ECONÓMICAS

DE LOS EJIDATARIOS DE NATIVITAS

Hernán Salas Quintanal

Íñigo González de la Fuente

LA MIGRACIÓN CON FINES LABORALES EN EL CONTEXTO DE LA DIVERSIFICACIÓN DE ACTIVIDADES ECONÓMICAS ENTRE LOS NATIVITEÑOS

María Leticia Rivermar Pérez

ESTRATEGIAS COMUNITARIAS EN NATIVITAS.

UNA PLURALIDAD DE PROCESOS SOCIALES

Íñigo González de la Fuente

\section{CARTOGRAFIA DE NATIVITAS}

Celia López Miguel

269 INDICE DE FIGURAS, CUADROS Y MAPAS

273 BIBLIOGRAFÍA

307 SOBRE LOS AUTORES 


\section{AGRADECIMIENTOS}

$\mathrm{E}$

ste libro es resultado de los proyectos colectivos de investigación titulados "Continui-

dades y transformaciones socioeconómicas y culturales en el municipio de Nativitas, Tlaxcala. ¿Hacia la conformación de una nueva ruralidad?" (IN 302709), financiado por la Dirección General de Asuntos del Personal Académico (DGAPA) de la Universidad Nacional Autónoma de México, a través del Programa de Apoyo a Proyectos de Investigación e Innovación Tecnológica (PAPIIT); y "Repensar lo rural y el concepto de nueva ruralidad como propuesta para entender las transformaciones contemporáneas en el valle Puebla-Tlaxcala", sufragado por el Consejo Nacional de Ciencia y Tecnología (clave CB-98651), a través del programa de Ciencia Básica. Los resultados de esta obra se presentaron y discutieron en el seminario "Antropología y nuevas ruralidades".

Agradecemos el apoyo recibido por la Dirección de Catastro Rural del Registro Agrario Nacional (RAN), de la Delegación Estatal del RAN en Tlaxcala, de los Archivos Histórico del Estado de Tlaxcala, Parroquial de Santa María Nativitas, Histórico del Agua y General de la Nación.

A los habitantes del municipio de Nativitas, Tlaxcala, en especial de las comunidades de Jesús Tepactepec, Santa María Nativitas, San Miguel del Milagro, Santiago Michac y San Miguel Xochitecatitla, queremos agradecer su apoyo, generosidad y paciencia, que fueron imprescindibles para la realización de las investigaciones que se presentan en este libro. Por sus enseñanzas y generosidad a don Joaquín Contreras ( $\dagger$ ) y familia.

Por último, agradecemos las sugerencias y comentarios de quienes dictaminaron esta obra, así como las facilidades otorgadas para llevar a cabo nuestra investigación por el personal que labora en el Instituto de Investigaciones Antropológicas de la UNAM. 


\section{INTRODUCCIÓN. SOBRE EL TERRITORIO RURAL Y SUS HABITANTES}

Hernán Salas Quintanal

$\mathrm{C}$ on la lógica de la cultura industrial occidental, moderna y urbana que predomina en las sociedades contemporáneas, el término "campesino" ha sido asociado con formas productivas diferentes, algunas veces definido como opuesto a las de la modernidad. Esta generalización envuelve diferentes aspectos de la vida campesina que es oportuno revisar. El campesino ha sido caracterizado desde el punto de vista económico como un productor agrícola que labora con fuerza de trabajo familiar, su producción se destina principalmente al autoconsumo y una porción secundaria al mercado y a los diversos tipos de intercambio. Desde la perspectiva social el campesinado se ha definido por su integración y solidaridad, como un grupo que establece relaciones sociales con base en el intercambio material y simbólico y la reciprocidad comunitaria y familiar. En la esfera cultural ha sido considerado un resabio de tradiciones y creencias que organizan, y a veces determinan, la vida cotidiana y las interacciones sociales. Desde la perspectiva académica y las investigaciones sobre el campesinado, algunos autores han puesto el énfasis en uno u otro aspecto.

En algunas de las definiciones más rigurosas de "campesino", como las que dieron Wolf (1955) o Redfield (1960), se excluye explícita o implícitamente toda actividad no agrícola. En tanto Wolf enfatiza el tema de las estructuras de poder -del Estado- en las que se inserta el campesinado, Redfield se centra en la transición hacia la modernidad. En la actualidad, Bryceson (2007: 2) delimita cuatro criterios fundamentales para una definición de campesinos: 1) farm, la búsqueda de la agricultura de subsistencia combina la producción de subsistencia con la de productos básicos; 2) family, una organización social interna basada en el trabajo familiar, mediante la cual la familia es unidad de producción, consumo, reproducción, socialización, bienestar y minimización de riesgos; 3 ) class, la subordinación al Estado y a los mercados regionales o interna- 
cionales, lo que genera la extracción de excedentes y la diferenciación de clases; 4) community, asentamiento en pueblos y actitudes tradicionales. Por su parte, Kearney (1996) pone el acento en una condición que, según sus estudios, es generalizada: la capacidad de los campesinos para moverse en diferentes mercados laborales y espacios migratorios, sea en los límites del Estado nación o fuera de ellos. En anteriores publicaciones (Salas y Rivermar 2011) hemos insistido en un contexto campesino que se define por la pérdida de centralidad de la agricultura, donde el acceso a diversos mercados laborales y la movilidad poblacional histórica y contemporánea es generalizada.

En términos generales, podemos decir que una figura como la de campesino, compleja en su dimensión histórica, ha intentado ser reducida a un simple productor agrícola: pequeño productor agrícola, minifundista, productores simples de pequeñas agriculturas, productores familiares de subsistencia; todos juegos de palabras que reflejan un proceso de transformación que en ningún caso puede ser lineal. Contrariamente a esta idea observamos que la inexistencia de direcciones inmutables del cambio y el comportamiento humano continuamente dan lugar a nuevos patrones. Uno de estos procesos se discute en este libro: los múltiples tipos de movimientos poblacionales y de mano de obra campesina de pequeñas agriculturas familiares hacia sectores urbanos o rurales no agrícolas, en el interior del país o en el extranjero; se puede hablar de un proceso que ha significado el tránsito desde el campo hacia otros sectores de la economía. En el microespacio social analizado se da cuenta de diversas respuestas de los grupos domésticos rurales a la contracción de la agricultura frente a la industria, el comercio y los servicios.

A diferencia de la descampesinización que observamos en los años setenta y ochenta del siglo $\mathrm{xx}$, cuando se describía y explicaba cómo esta mano de obra transitaba hacia el asalaramiento, hoy, tal como lo ha apuntado Bryceson (2007), la descampesinización se combina con los procesos de desagrarización que se venían gestando desde los setenta, fenómeno que implica la disminución de la superficie agrícola cultivada, la pérdida de valor de la producción agrícola y un menor peso de la agricultura en los ingresos de las familias rurales. Esta situación obliga a preguntarse si la viabilidad de los medios de subsistencia de los campesinos y su vitalidad cultural persistirá en la era posindustrial del siglo xxi. La reflexión en torno a este importante cuestionamiento precisa tomar en consideración dos elementos: la descampesinización ha significado la creación de un amplio contingente de mano de obra rural disponible, fundamental en la etapa de expansión del capitalismo en el agro, otorgando a la sociedad rural un carácter bimodal que combinaba la existencia de la agricultura comercial capitalizada -inserta en grandes circuitos mundiales de comercio, centrados en cultivos de exportación- con pequeñas producciones familiares, cuya producción no alcanzaba para satisfacer las necesida- 
des del grupo familiar, por lo que sus miembros se veían obligados a contratarse como trabajadores asalariados en campos agrícolas de corte empresarial.

De esta manera, nuevas transformaciones acompañaron la debilitada unidad campesina de producción y consumo. La descampesinización abrió la puerta a la generalización del trabajo asalariado, lo que en las últimas décadas ha lanzado a los campesinos fuera de los límites del mercado laboral agrícola. Paralela a la disminución de la superficie cultivada, se observa una creciente incorporación de poblaciones rurales en empleos poco calificados en las industrias, los servicios y el comercio. Esta situación ha intensificado el multiempleo, la precariedad laboral, el acceso simultáneo a mercados de trabajo en diferentes sectores y en la informalidad, la participación en la economía subterránea, complementariedad de ingresos y centralidad del mercado como regulador de la vida social y de la supervivencia de estas poblaciones.

Cabe preguntarse cómo ha afectado a las poblaciones rurales su incorporación a un mercado laboral precario, flexible, frágil, movible, intermitente, inestable y sin reglas claras. La desarticulación de formas históricas de organización de la producción, de la sociedad, la cultura y la economía ha generado una población rural descampesinizada, migrante, sometida a diversos procesos de asalarización. Estamos frente al fracaso de los paradigmas laborales que buscaban la especialización de la mano de obra para lograr una mayor productividad y de un proyecto histórico de nación que buscaba la autosuficiencia alimentaria con base en la consolidación de un aparato productivo.

Interesados por la problemática rural, ha llamado nuestra atención en las últimas décadas estudiar los efectos de las políticas de ajuste estructural y de corte neoliberal aplicadas en el campo latinoamericano, específicamente en el mexicano. Este análisis se ha realizado desde diversas perspectivas teóricas, entre las que destaca la conocida como "nueva ruralidad", cuyos argumentos centrales son la pérdida de centralidad de la agricultura como forma de vida de las poblaciones rurales, el incremento del multiempleo y la pluriactividad en el interior de los grupos domésticos y, con ello, del trabajo asalariado tanto en los lugares de origen como en el interior del país y más allá de las fronteras nacionales, lo que ha traído aparejada la reorganización de la vida familiar y comunitaria. De acuerdo con los hallazgos de nuestras investigaciones, podemos afirmar, junto con Bryceson (2007), que en la actualidad las poblaciones rurales se definen por su dualidad: son limitadamente autónomas en tanto mantienen pequeñas producciones para el autoconsumo y, al mismo tiempo, son muy vulnerables en la medida que están sometidas a debilitados mercados de trabajo.

En el año 2008 nos reunimos un grupo de investigadores y estudiantes con el fin de darnos a la tarea de documentar con un estudio de caso, y siguiendo la propuesta de la nueva ruralidad, los efectos de la reestructuración del campo en la vida de las poblaciones rurales y las 
formas que estas poblaciones han adoptado para responder a las nuevas demandas del capitalismo global. Para tal efecto, se eligió el municipio de Nativitas, ubicado en el sur del estado de Tlaxcala, en el valle Puebla-Tlaxcala. Por su localización estratégica, casi en el centro del valle, la historia contemporánea de este municipio ha sido dramáticamente afectada desde la construcción en sus inmediaciones de la autopista México-Puebla, un corredor industrial y un aeropuerto, lo que hace de Nativitas un espacio privilegiado para estudiar los efectos de las políticas gubernamentales de reestructuración del campo mexicano sobre la vida de los habitantes de este municipio y las respuestas que han dado a los profundos cambios acontecidos en su entorno en las últimas décadas.

Asimismo, la antigüedad del poblamiento del territorio en el que se asienta Nativitas, por lo menos de dos mil años, permite suponer una muy temprana conformación de una sociedad agrícola que, desde sus inicios, hizo un uso racional de importantes recursos naturales: tierra de alta feracidad y agua en abundancia - proveniente de los ríos Atoyac y Zahuapan y del subsuelo- y que son el sustento de la vida material, ritual y espiritual y, por tanto, de la identidad de las poblaciones que ahí habitan, temas todos que también han sido de interés para nuestra investigación.

Para dar cuenta de la historia agrícola del municipio de Nativitas, de los cambios habidos en las últimas décadas y de las respuestas de sus habitantes, iniciamos el proyecto "Continuidades y transformaciones socioeconómicas y culturales en el municipio de Nativitas Tlaxcala. ¿Hacia la conformación de una nueva ruralidad?", apoyado por la Universidad Nacional Autónoma de México. Paralelamente, pusimos en marcha el proyecto "Repensar lo rural y el concepto de nueva ruralidad como propuesta para entender las transformaciones contemporáneas en el valle Puebla-Tlaxcala", financiado por el Consejo Nacional de Ciencia y Tecnología.

En ambas investigaciones nos planteamos como objetivo central caracterizar los trastrocamientos habidos en el municipio de Nativitas desde mediados del siglo xIx hasta el último tercio del xx con el fin de conocer las transformaciones en las esferas de lo económico, lo social y lo cultural y explicar las bases de la reproducción material y simbólica de los habitantes contemporáneos de este municipio. Para tal fin indagamos sobre el sistema de hacienda y el proceso que derivó en la reforma agraria y en torno a la industrialización de la región y sus consecuencias, entre las que destacan los cambios en el uso de la tierra, el desplazamiento de la centralidad económica de las actividades agropecuarias, las transformaciones del mercado laboral, el deterioro y contaminación de los recursos naturales -tierra y agua y, en general, del medio ambiente-, los cambios en la organización del grupo doméstico, las identidades colectivas, los modos de vida, la organización política y religiosa y las instituciones de compadrazgo. 
Desde el comienzo de la investigación, a la vez que se emprendió la recolección de información etnográfica, cartográfica y de archivos históricos, se conformó el Seminario permanente "Antropología y nuevas ruralidades", con sede en el Instituto de Investigaciones Antropológicas de la UNAM con el objetivo central de discutir los avances de la investigación, de las tesis que se vienen realizando bajo el cobijo del proyecto y de la bibliografía sobre el tema. Asimismo, se ha invitado a colegas que comparten intereses a exponer los resultados de sus estudios y discutir con los miembros del seminario sus propuestas. Cabe resaltar la organización de cuatro coloquios de investigación - uno en las instalaciones de la BUAP en la ciudad de Puebla en 2010, otro en las de la UnAm en San Manuel Marcom, Tlaxcala, en 2011, el tercero en la ENES de la UNAM en León, Guanajuato, en 2012 y el cuarto en 2013 en la UNAM, Jiquilpan, Michoacán- que tuvieron como finalidad la presentación de los resultados preliminares del proyecto y los de colegas que trabajan temas afines en diversas regiones del país. La discusión académica ha fortalecido ideas comunes que como equipo de investigación hemos presentado en ponencias, artículos, capítulos de libros y tesis. Asimismo, hemos organizado simposios y mesas redondas en diversos congresos nacionales e internacionales y publicado resultados tanto de la investigación colectiva como de las individuales ( $c f r$. Salas 2010; Rodríguez y Salas 2010; Salas et al. 2011; González 2011a, 2011b; González y Salas 2012).

Desde un inicio asumimos que la propuesta de nuevas ruralidades implicaba el trabajo interdisciplinario, de manera que el equipo de trabajo se ha conformado con especialistas y estudiantes de diferentes niveles y con diversas formaciones y disciplinas, como la antropología, la etnohistoria, la geografía, los estudios regionales, la agronomía, la sociología y la gestión intercultural, lo que ha redundado en el entendimiento global de la problemática estudiada y en el análisis estructural e histórico, que se manifiesta en los capítulos que conforman el presente texto. Este punto de partida también ha permitido analizar tópicos que comúnmente no son estudiados en investigaciones de este corte: la contaminación de suelos y aguas, el problema de los recursos hídricos (tanto subterráneos como superficiales), la organización histórica de la tenencia de la tierra, por sólo citar algunos. Este libro, resultado de las reflexiones colectivas alude, como indica el título, a la construcción de un territorio rural a través del tiempo, considerando las variables geográficas, sociológicas y antropológicas, hasta llegar a las características actuales, con referencia a un pasado en el sentido de hechos que imprimen rasgos específicos a las condiciones económicas, sociales y políticas que encontramos hoy en Nativitas y que se abordan en esta obra.

Contra todo pronóstico, el país aún cuenta con pequeños productores que continúan trabajando sus tierras ejidales o de propiedad privada, con producción para el autoconsumo, la cría de animales de traspatio para el consumo familiar o para un mercado local o regional, 
actividades que se articulan con otras en el seno familiar y en un mismo individuo. Sin el afán de regresar a la discusión sobre el futuro del campesinado, la continuidad de estos productores y la forma en la que se han enfrentado a la globalización neoliberal merece especial atención y nos obliga a preguntarnos no sólo cómo se han transformado las sociedades rurales, sino cómo y por qué los pequeños productores siguen cultivando en el contexto de un sistema capitalista cada vez más flexible. Con el objetivo de trascender las explicaciones parciales o inmediatas que resultarían de un análisis del contexto actual, en este libro se opta por ofrecer un panorama histórico profundo que permita redimensionar el neoliberalismo y entenderlo como la prolongación de relaciones, discursos y prácticas propias del capitalismo. El conjunto de trabajos aquí presentados parte de la premisa de que no es posible explicar el presente sin entender el pasado, ni comprender las problemáticas actuales de Nativitas sin considerar sus transformaciones territoriales.

El presente libro se ha organizado tomando en cuenta varios aspectos: el cronológico, desde la Colonia hasta la actualidad, con énfasis en el siglo xx; el territorial, la planicie, el valle Puebla-Tlaxcala y el Alto Atoyac, hasta la escala municipal y de comunidades (agencias auxiliares); el de las problemáticas actuales que afectan a la población de Nativitas, con la producción agrícola y pecuaria, ejidal y en pequeñas propiedades, el deterioro ambiental y social, los procesos laborales y migratorios y las organizaciones comunitarias. Muchos aspectos de la ruralidad del municipio quedan pendientes; sin embargo, este volumen busca regresar a las poblaciones la información generada con la esperanza de que su socialización permita generar procesos de mejoramiento de sus condiciones de vida.

El libro abre con el trabajo de Esther Galicia, el cual identifica y caracteriza de manera general los elementos y las condiciones "originales" de funcionamiento del sistema hídrico en la planicie de Tlaxcala, inscrito en la subcuenca Puebla-Tlaxcala de la cuenca alta del río Atoyac (Alto Atoyac). En este capítulo se reconstruye, desde una perspectiva histórica ambiental, el estado físico-natural de dos de los principales factores condicionantes del funcionamiento del sistema hídrico en la planicie: topografía y geología. Se caracterizan algunos rasgos tangibles del territorio que fueron producto y manifestación del funcionamiento de los sistemas de flujo de agua subterránea: manantiales, lagos, humedales-pantanos, niveles freáticos someros, flora y fauna acuáticos, y se analiza su impacto en continuas etapas de la vida social de los pueblos de la planicie. Para tal fin se consultaron diversos archivos y mapas históricos, información que se procesó y analizó con un Sistema de Información Geográfica.

En el segundo capítulo, Davison Mazabel analiza el proceso de apropiación del agua y el carácter de los conflictos suscitados alrededor de este recurso en el valle de Texmelucan, Puebla, concretamente en el Alto Atoyac, durante el siglo xvir. Se analiza el control que las haciendas 
que se establecieron en la región tuvieron sobre el agua y el territorio y sus efectos en la conformación del sistema de riego de la microcuenca del río Cotzala. Con base en los registros de los diezmos del obispado poblano se colige que las disputas por el vital líquido coinciden con la inserción de la región en la dinámica del desarrollo agrícola del valle poblano-tlaxcalteca. Otro elemento que también se considera en este trabajo es el repartimiento de aguas de 1673, que sentó un precedente legal para los futuros repartimientos y para el ordenamiento, manejo y aprovechamiento del agua en Texmelucan y, por consiguiente, en el valle poblano tlaxcalteca.

En el tercer capítulo, Guillermo Paleta caracteriza la estructuración territorial del municipio de Nativitas desde una perspectiva de larga duración. El autor parte del marco contextual del sistema de haciendas agropecuarias del siglo xIx. La idea central del texto refiere la conformación territorial a la luz de la explotación de los recursos naturales por parte de las haciendas locales. Desde una perspectiva de larga data, el análisis nos permite entender la reconfiguración del territorio rural actual inmerso en complejidades tanto locales como extralocales a lo largo del tiempo. Nativitas ilustra de manera interesante el devenir de una región privilegiada por el acceso a recursos naturales abundantes; su configuración social, del paisaje y territorial ha sido moldeada por la organización de la producción económica. Asimismo, se estudian las relaciones contenciosas que se generaron a la luz del establecimiento de haciendas pecuarias, propiedad de población española, con la población local como consecuencia de la explotación intensiva y extensiva de los recursos naturales y de la mano de obra.

A partir de una revisión de fuentes históricas y bibliográficas que develan la historia del municipio de Nativitas durante las primeras décadas del siglo $\mathrm{xx}$, en el cuarto capítulo, Óscar Hernández describe el proceso que dio origen al fraccionamiento de tierras y, con ello, al sistema ejidal, cuyo resultado fueron situaciones sin precedentes, tales como orden, justicia y relaciones sociales y económicas, arraigo y organización comunitaria. No sólo indaga las luchas, eventos y movimientos, sino también los actores, contextos y consecuencias que tocan y modifican distintas esferas de la vida rural. Para tal fin centra su atención en el caso de la hacienda Segura Michac a partir del cual se propone entender de manera diversa e integral el reparto agrario, que se entiende como resultado directo de las luchas que se llevaron a cabo en la región. La identificación de los líderes agrarios y los actores involucrados permite visualizar dicho reparto como un proceso político y social dinámico en cuyo desenlace fue central la movilización social.

En el quinto capítulo, Hernán Salas y Rubén Luna analizan la importancia del reparto agrario en el fortalecimiento del aparato gubernamental, la reconstrucción de la economía rural y la búsqueda de justicia social para los campesinos. Se describe el reparto agrario y la creación de los ejidos en Nativitas, las formas como se ha conducido la vida productiva, la distribución y 
el acceso a los recursos naturales -agua y tierra-, la organización social, territorial y política del municipio y la forma como los ejidos han conformado patrones de residencia. A partir de indagar el origen de los ejidos del municipio, este capítulo se plantea como objetivo dar cuenta de la situación social en la que se encuentran los ejidos en la actualidad.

En el sexto capítulo, Paola Velasco explica las dinámicas socioeconómicas que han permitido a los ejidatarios y pequeños productores reconfigurar el trabajo agrícola frente a sus otras actividades y, con ello, enfrentar condiciones adversas, tales como el estado de deterioro ambiental en el que se encuentra su principal fuente de riego y la negligencia del Estado y las clases hegemónicas en materia agrícola y de bienestar social. En el texto se sugiere que los habitantes de Nativitas han entretejido complejos arreglos socioeconómicos familiares e individuales que no son producto unívoco del neoliberalismo ni tampoco son resultado de una decisión libre y racionalizada individualmente, son más bien formas de negociar, resistir y adaptarse al contexto ambiental, social y político en el que están insertos y en donde las relaciones desiguales de poder son evidentes.

En el séptimo capítulo, Hernán Salas y Paola Velasco describen el ambiente socionatural del municipio con el objetivo de mostrar cómo los cambios ambientales, fundamentalmente expresados en la contaminación del río Atoyac, principal fuente de agua para las labores agropecuarias, industriales y domésticas del municipio de Nativitas, han afectado sistemas productivos históricos en una región definida por su vocación agrícola. Para lo cual se hace una descripción física e histórica del río Atoyac y del valle de Tlaxcala, enfatizando en la historia del uso del agua del río, los asentamientos en sus riberas y la infraestructura para su aprovechamiento. Enseguida, se da cuenta del proceso de deterioro ambiental del Atoyac y de los pueblos que han utilizado sus aguas como resultado de la actividad industrial y el crecimiento urbano. Finalmente, se analizan las consecuencias que la contaminación ha tenido en la calidad de vida de las poblaciones.

En el capítulo octavo, con el fin de entender la desagrarización y sus efectos en la sociedad rural, Hernán Salas e Îñigo González analizan tres momentos de las transformaciones sociales del municipio que corresponden a estrategias laborales y económicas adoptadas por sus pobladores, lo que permite entender las transformaciones de las instituciones que han regulado la vida socioeconómica del lugar y sus efectos en el modo de vida de la población del municipio. El caso de Nativitas es un ejemplo de cómo se ha transformado la economía y la sociedad rural en toda América Latina en décadas recientes a partir de la incorporación de la agricultura y la producción de alimentos a los mercados de la economía mundial, a formas de modernización que han beneficiado a grupos agroindustriales y a empresarios agrícolas capitalistas. El objetivo es conocer las diversas formas de ruralidad, pasando de una centrada en las actividades 
agropecuarias de las unidades campesinas a otra donde la diversificación de labores es cada vez mayor, se propone el concepto de "nuevas ruralidades", identificado como un proceso de desagrarización sin desruralización, que busca generar nuevas reflexiones en torno a lo rural.

A partir de la premisa de que las migraciones contemporáneas son resultado de las demandas de un mercado laboral muy flexibilizado, en el capítulo noveno Leticia Rivermar da cuenta de los desplazamientos de los habitantes del municipio. Reúne información cuantitativa y etnográfica para caracterizar los flujos migratorios de los pobladores de la entidad, tanto internos como a Canadá y a Estados Unidos. También delinea las características de la migración hacia Estados Unidos de las poblaciones del municipio de estudio y discute críticamente las cifras oficiales sobre la migración interna e internacional de tlaxcaltecas y de nativiteños.

En el décimo capítulo, Ínigo González describe, analiza y reflexiona sobre las formas de organización comunitaria en la localidad de Jesús Tepactepec. Parte de la idea de que el sistema de cargos alimenta una serie de mecanismos que rigen la vida comunitaria bajo las siguientes premisas: son prácticas que permiten entrar y "jugar" al mayor número del total de agentes en una pluralidad de campos; son prácticas que se repiten con frecuencia, cuyas "reglas de juego" aseguran la distribución rotatoria de las posiciones sociales (aunque solamente de determinados grupos de agentes) y, por tanto, la de los diferentes tipos de capital cuya posesión condiciona el acceso a las recompensas específicas de cada campo.

El capítulo final de la obra expone la cartografía elaborada por Celia López. Su objetivo es utilizar los mapas -a escala estatal (Tlaxcala) y municipal (Nativitas)- para mostrar temáticas, cambios multitemporales y reconstrucciones históricas. Las principales fuentes de información son del Instituto Nacional de Estadística y Geografía (Escala 1:250 000 y 1:50 000), Registro Agrario Nacional, cartografía histórica y recorridos de campo. Los materiales y herramientas que se utilizaron fueron: cartografía vectorial digital (curvas de nivel, áreas urbanas, hidrografía, vías de comunicación, localidades, geología, agua subterránea, agua superficial, cuencas), ortofotos, mapas impresos, datos de campo obtenidos con el GPS (Sistema Global de Posicionamiento); toda la información fue procesada y editada dentro de dos Sistemas de Información Geográfica (sIG), Ilwis 3.x y ArcGIS 10. Para observar los cambios de las divisiones políticas administrativas a nivel estatal se trabajó el periodo de 1848 a 2010, y para el caso del municipio de Nativitas se trabajó de 1999 al presente. Los temas de las haciendas y de las industrias se trabajaron tanto con cartografía histórica como con recorridos de campo e información bibliográfica. La información bibliográfica se convirtió en mapa por medio de georeferenciación, corrección geométrica y digitización, dentro del sig. Durante todo el libro se hace referencia a estos mapas, de manera que han sido numerados para facilitar su consulta y apoyar la argumentación de cada capítulo. 


\title{
TERRITORIO Y SISTEMA HÍDRICO DE LA PLANICIE DEL SUROESTE DE TLAXCALA A TRAVÉS DEL TIEMPO
}

\author{
Esther Galicia Hernández
}

INTRODUCCIÓN ${ }^{1}$

$\mathrm{D}$ sde que el hombre hace su aparición en la tierra empieza una historia de apropiación de la naturaleza, sin embargo, la relación hombre-naturaleza no siempre se ha dado bajo las mismas formas ni en la misma intensidad, mucho menos los resultados han sido similares. Con la aparición de la agricultura y el concomitante sedentarismo, se inicia un proceso de interacción con el medio natural a través del cual el hombre se convierte en un agente transformador de su entorno.

La conquista española de lo que hoy conocemos como el territorio mexicano implicó cambios profundos en la relación hombre-naturaleza. Antes de la Colonia, la apropiación de la naturaleza dependió esencialmente de formas de organización social colectivas y del uso de herramientas rudimentarias. En contraste, la economía novohispana se sustentó en una división del trabajo más compleja y en el uso de herramientas y técnicas de cultivo más sofisticadas que produjeron importantes modificaciones del medio natural. Actividades como la minería y el establecimiento de las nuevas ciudades demandaron grandes cantidades de materiales de construcción (cantera y madera), con lo que se iniciaron procesos como la deforestación de bosques, erosión de suelos, transformación de la topografía, entre otros (Marín et al. s/f).

${ }^{1}$ El trabajo cartográfico ha sido posible gracias al valioso apoyo brindado por Edgardo Trejo (Mapoteca de la Benemérita Universidad Autónoma de Puebla) y Crescencio C. Ariza Simón (Instituto Nacional de Estadística y Geografía en Puebla). 
Más contemporáneamente, el desarrollo de la sociedad ha conllevado mayores requerimientos de productos agrícolas, materias primas (entre ellas forestales e hídricas), áreas para viviendas, equipamiento (escuelas, hospitales, industrias, comercios, etcétera) e infraestructura urbana y rural (carreteras, caminos, calles, acueductos, oleoductos, etcétera). Las transformaciones socioeconómicas han implicado más y nuevas necesidades que han repercutido en cambios en el uso del suelo y en las formas de apropiación de los recursos naturales en general $y$, al mismo tiempo, han modificado las condiciones "originales" del medio natural.

El objetivo principal de este capítulo es identificar y caracterizar los elementos y las condiciones "originales" de funcionamiento del sistema hídrico en la planicie del suroeste de Tlaxcala, inserta en la subregión/subcuenca Puebla-Tlaxcala; ${ }^{2}$ conocer en términos generales el estado físico-natural en el que se encontraban los diversos factores que determinaron el funcionamiento del sistema hídrico y, en particular, reconocer algunas manifestaciones ambientales de los sistemas de flujo de agua subterránea y su impacto sobre el territorio. ${ }^{3}$ Estos

${ }^{2}$ La cuenca denominada Alto Atoyac está conformada por dos grandes subcuencas o subregiones (en este trabajo utilizamos estos términos como sinónimos): Atlangatepec y Puebla-Tlaxcala. La primera se ubica al norte, en el estado de Tlaxcala, su red hidrográfica alimenta al río Zahuapan, la más importante corriente superficial y uno de los principales afluentes del río Atoyac. La subregión Puebla-Tlaxcala, como su nombre lo indica, comprende municipios de ambos estados y una pequeña extensión del estado de México: su red hidrográfica es, en extensión y volumen de agua, la más importante de la cuenca y el río Atoyac es su principal corriente superficial. A esta subregión la divide el denominado Bloque Tlaxcala (Galicia 2009: 28, 29). De acuerdo con la división de subcuencas realizada por la Comisión Nacional del Agua, la planicie del suroeste de Tlaxcala se ubica al este de la subcuenca del río Atoyac y al suroeste de la subcuenca del río Zahuapan (mapa 18). Esta última delimitación no fue tomada como base de análisis para el presente estudio debido a que su definición se sustenta únicamente en las formas de escurrimiento y distribución del agua superficial (cuencas superficiales), que no siempre coinciden con el funcionamiento de los sistemas de flujos de agua subterránea, aunque ambas sean componentes del mismo sistema general; para el estudio de este sistema hídrico se optó por utilizar la primera delimitación-regionalización propuesta (Galicia 2009: 28, 29).

${ }^{3}$ El énfasis en el agua subterránea no significa que ésta tenga mayor o menor importancia que la superficial o que funcione como un componente aislado del sistema hídrico. Por el contario, se reconoce que ambas fuentes son elementos del mismo continuo hidrológico y que interactúan en una variedad de paisajes fisiográficos y climáticos (Sophocleous 2002: 53). En esta interacción diferenciada en el territorio se busca comprender el impacto del agua subterránea en el ambiente acuático de la planicie del suroeste de Tlaxcala en tanto el funcionamiento de esta última se ha estudiado sólo parcialmente y poco se ha profundizado en aspectos como su interacción con ecosistemas y su relación con las condiciones físico-ambientales del territorio. La mayoría de los estudios geohidrológicos que se han realizado han sido a nivel de subcuenca (o parte de ella, denominándole "valle de Puebla") y se han centrado, en términos muy generales, en conocer algunas 
antecedentes servirán para construir un marco de referencia que permita una mayor comprensión del funcionamiento del agua superficial-subterránea y que aporte elementos para la reconstrucción de una memoria hídrica.

Para entender el funcionamiento de los sistemas de flujo de agua subterránea, se tomó como base la teoría de sistemas de flujo que, a partir de considerar el movimiento del agua a través de formaciones rocosas, la ubica como un importante agente geológico (Tóth 2000: 9-26). El agua se mueve, viaja en el subsuelo a través de formaciones geológicas con las que interactúa a lo largo de todo su recorrido generando y, al mismo tiempo, siendo afectada por diversos procesos físico-químicos. En general, un sistema hidrogeológico se desarrolla sobre la base de dos fenómenos fundamentales: el primero es la interacción entre agua y medio natural y el segundo, la naturaleza jerárquica y sistematizada de los flujos de agua subterránea (Tóth 2000: 11).

Ubicar cada uno de los elementos del sistema hídrico de la planicie Tlaxcala existentes en épocas históricas precedentes es una tarea gigante en tiempo y esfuerzo, sin embargo, no garantiza una comprensión completa del funcionamiento del sistema. Además, la heterogeneidad de la información histórica existente sólo permite profundizar en ciertos lugares y características específicas. Tomando en cuenta estas consideraciones, abarcamos algunos rasgos físicos asociados con la presencia de flujos de agua subterránea (manantiales, humedales, flora y fauna acuática, suelos con alto nivel de humedad y salinidad) y con la descripción general de dos de los factores naturales fundamentales para entender su funcionamiento: topografía y geología.

Para la concentración, procesamiento y análisis de datos, se utilizó un Sistema de Información Geográfica (SIG) construido en el marco de un proyecto más amplio que abarca la cuenca denominada Alto Atoyac. La retroalimentación de la base de datos y de la cartografía empleada se hizo a partir de la consulta de textos derivados de investigaciones históricas y de la revisión de documentos y mapas del Archivo Histórico de Tlaxcala y del Archivo Histórico del Agua (AHA). Los niveles freáticos existentes en la planicie durante el siglo xx se obtuvieron a partir de la consulta del estudio geohidrológico realizado en 1973 por la empresa Agrogeología, auspiciado por la entonces Secretaría de Recursos Hidráulicos.

características geológicas e hidráulicas de las unidades acuíferas, realizar balances hídricos y determinar el volumen de agua "disponible" para su aprovechamiento-extracción (Agrogeología y SRH 1973; Lesser 1982; EXYCO 1990; Geotecnología 1997). Otros estudios han tenido como objetivo determinar el funcionamiento del acuífero y definir sus zonas de recarga y descarga a partir de la composición química del agua (Hernández y Maldonado 1991) y algunos más han centrado sus esfuerzos en la aplicación de modelos conceptualesmatemáticos para explicar el funcionamiento del agua subterránea (Geotecnología 1997; Jiménez 2005). 
La subcuenca Puebla-Tlaxcala está integrada por municipios de los estados de Tlaxcala y Puebla (mapa 17). Su evolución ha estado ligada a la historia económica, política, social, cultural y ambiental de los municipios de ambas entidades que geográficamente la conforman. La planicie del suroeste de Tlaxcala constituye la parte baja de esta subcuenca y la integran los municipios de Tepetitla de Lardizábal, Ixtacuixtla de Mariano Matamoros, San Damián Texóloc, Panotla, Nativitas, Santa Apolonia Teacalco, Tetlatlahuca, Tepeyanco, San Lorenzo Axocomanitla, Zacatelco y Xicohtzinco. La mayoría de estos municipios son del estado de Tlaxcala, conforman el área norte de la subcuenca Puebla-Tlaxcala, que se prolonga hacia el sur, abarcando algunos municipios del estado de Puebla.

Los sistemas de flujo de agua subterránea que convergen en la planicie de Tlaxcala están determinados, preponderantemente, por factores naturales definidos a escala de subregión/ subcuenca: topografía, geología y clima (mapa 18). En este trabajo no analizamos con detalle cada uno de esos factores; construimos un marco general de las condiciones "originales" de funcionamiento de los sistemas de flujo de agua subterránea en la planicie (mapas 19 y 20) mediante mapas de aguas subterráneas de la cuenca y del municipio de Nativitas; enfatizamos en la ubicación y características de algunas de sus principales manifestaciones físicasterritoriales: manantiales, cuerpos de agua, humedales, flora y fauna acuáticos, rasgos edáficos característicos y el impacto de diversas acciones antropogénicas sobre las anteriores y viceversa. Para la construcción histórica de dichas condiciones se tomó como referencia la división territorial política vigente durante las últimas décadas del siglo XIX, que se conformaba por seis distritos, subdivididos en 33 municipalidades ${ }^{4}$ (cuadro 1). En relación con la extensión y número de distritos, es necesario señalar que existen algunas diferencias entre las fuentes $\operatorname{consultadas}^{5}$ (mapa 11).

Los principales cuerpos de agua que existieron en periodos remotos fueron las lagunas del Rosario y Acuitlapilco. Los remanentes de la laguna o lago del Rosario (San Juan Molino o Atoyac) se ubicaban al suroeste del estado de Tlaxcala, en los distritos de Hidalgo y Zaragoza,

${ }^{4}$ El concepto de municipalidad es una categoría político-administrativa empleada para dividir el territorio y es utilizada en este trabajo como sinónimo de municipio; sin embargo, no corresponde exactamente a la actual delimitación físico-territorial de los municipios, pues la mayoría abarca otros pueblos o localidades; no obstante, la ubicación en general es la misma.

${ }^{5}$ Fundamentalmente entre la Carta del Estado de Tlaxcala (1881) y el documento de Velasco (1998). 


\begin{tabular}{|c|c|c|c|c|}
\hline Distritos & Municipalidades & Hombres & Mujeres & Total \\
\hline \multirow[t]{3}{*}{ Ocampo } & Calpulalpam & 5760 & 5610 & 11370 \\
\hline & Españita & 1547 & 1301 & 2848 \\
\hline & Hueyotlipan & 1676 & 1611 & 3287 \\
\hline \multirow[t]{3}{*}{ Morelos } & Tlaxco & 7335 & 4244 & 11579 \\
\hline & Tetla & 2367 & 2345 & 4712 \\
\hline & Atlangatepec & 1348 & 1596 & 2944 \\
\hline \multirow[t]{8}{*}{ Juárez } & Huamantla & 5935 & 6440 & 12375 \\
\hline & Ixtenco & 2013 & 2034 & 4047 \\
\hline & Zitlaltepec & 1263 & 1220 & 2483 \\
\hline & Cuapiaxtla & 1678 & 1733 & 3411 \\
\hline & El Carmen & 1227 & 1213 & 2440 \\
\hline & Alzayanca & 2100 & 2330 & 4430 \\
\hline & Terrenate & 1150 & 1032 & 2182 \\
\hline & Tzompantepec & 1665 & 1633 & 3298 \\
\hline \multirow[t]{7}{*}{ Zaragoza } & Zacatelco & 3717 & 3869 & 7586 \\
\hline & Tepeyanco & 1612 & 1731 & 3343 \\
\hline & Teolocholco & 1525 & 1573 & 3098 \\
\hline & Tetlatlahuca & 1773 & 1862 & 3635 \\
\hline & Nativitas & 3017 & 3301 & 6318 \\
\hline & San Pablo del Monte & 2079 & 2121 & 4200 \\
\hline & Xicohténcatl & 1868 & 1926 & 3794 \\
\hline \multirow[t]{7}{*}{ Hidalgo } & Tlaxcala & 4466 & 5562 & 10028 \\
\hline & Apetatitlán & 1141 & 1272 & 2413 \\
\hline & Chiautempan & 3930 & 4232 & 8162 \\
\hline & Contla & 1988 & 1979 & 3967 \\
\hline & Ixtacuixtla & 3123 & 2988 & 6111 \\
\hline & Lardizábal & 1244 & 1131 & 2375 \\
\hline & Panotla & 1418 & 1008 & 2426 \\
\hline
\end{tabular}




\begin{tabular}{llccc}
\hline \multirow{2}{*}{ Distritos } & \multicolumn{1}{c}{ Municipalidades } & Hombres & Mujeres & Total \\
\hline \multirow{2}{*}{ Cuauhtémoc } & Barron-Escandón & 2073 & 1458 & 3531 \\
\cline { 2 - 5 } & Xaltocan & 1973 & 1781 & 3754 \\
\hline & Yauhquemehcan & 1753 & 1626 & 3379 \\
\hline Santa Cruz Tlaxcala & 1765 & 1347 & 3112 \\
\hline & San Cosme Xalóxtoc & 1140 & 1093 & 2233 \\
\hline
\end{tabular}

específicamente en la parte norte de la municipalidad de Nativitas y en los límites de Lardizábal, al occidente del cerro Xochitécatl y al norte del río Atoyac, el cual no tenía desagüe natural. Su superficie se extendía por 252 hectáreas y estaba conformada por los desagües de la hacienda La Compañía y del rancho La Soledad. La laguna del Rosario, que en los textos históricos se describe como de agua salobre a cuyas orillas crecía muy buen tule, comenzó a desecarse en 1886 (Velasco 1998: 18, 80). Trautmann (1981: 7) señala que los pantanos ubicados al sur de Santa Inés Tecuexcomac constituían los restos de la antigua laguna del Rosario, que todavía existía en 1849. En 1931 se reconoció que el agua de la laguna San Juan Molino o Atoyac o del Rosario tenía su origen en los manantiales localizados en el vaso del mismo lago. Su producción fue de tal magnitud que derramaba el agua en el arroyo Michapamitl, que la conducía de manera permanente al río Atoyac. Sólo parte del caudal era aprovechado por el pueblo de San Miguel Xochitecatitla ubicado tierras abajo, en la municipalidad de Nativitas. ${ }^{6}$ Otro lago que se ubicaba cerca de Tecuexcomac fue conocido en el siglo xvir con el nombre de laguna de Tlaxicotla. Este cuerpo de agua fue desecado por algunos hacendados en 1661 mediante la intercepción de los afluentes que alimentaban la ciénega. Fue drenado de tal manera que el antiguo fondo de la laguna podía usarse como empastada o, en parte, como terrenos de cultivo (Trautmann 1981: 173).

Al oriente de la subcuenca Puebla-Tlaxcala, al finalizar el piedemonte poniente de la Malinche, se localizaba el lago o laguna de Acuitlapilco. La parte norte de la laguna se ubicaba en la municipalidad de Tepeyanco, en el distrito de Zaragoza; la otra parte se localizaba en la municipalidad de Tlaxcala, distrito de Hidalgo. Sus aguas se unían al río Zahuapan en la hacienda de Los Reyes, su superficie era para 1890 de 105 hectáreas, dividida en dos secciones denominadas Taza Grande y Taza Chica. La parte norte de la laguna de Acuitlapilco era la de mayor profun-

${ }^{6}$ De acuerdo con el oficio No. 1873 remitido por la Secretaría de Agricultura y Fomento al director de Aguas, Tierras y Colonización en la ciudad de México, el día 27 de julio de 1931 (Tello et al. 2010: 178). 
didad y extensión: en 1896 se reportó que medía 2800 metros de longitud y 1300 metros de latitud, su mayor profundidad alcanzó los diez metros, lo que la hacía navegable en pequeñas canoas (González 1999: 200-203).

Los manantiales fueron la principal fuente de abastecimiento de agua para la población durante la Colonia. Junto con las lluvias, eran la única fuente de abastecimiento del vital líquido en algunas partes de la subcuenca Puebla-Tlaxcala. Por ejemplo, en la municipalidad de Hueyotlipan, dentro del distrito de Ocampo, "si faltan los ríos y arroyos, abundan los manantiales, las presas, los aljibes y las ollas, de donde se proveen de agua los habitantes [...] En esta zona en que falta el agua, y que solo fertilizan las lluvias, crecen asombrosamente los agaves y sólo se descubren las extensas magueyeras y uno que otro sembradío" (Velasco 1998: 47). En otras zonas, especialmente en los distritos de Hidalgo y Zaragoza, además de consumir agua de manantial de manera generalizada, sus habitantes utilizaban ríos y pozos someros como fuentes de abastecimiento. Las zonas inundables y pantanosas se ubicaban principalmente en el distrito de Zaragoza (Velasco 1998: 80, 93), en la parte baja de la subcuenca, cerca de donde se unen los ríos Atoyac y Zahuapan, donde destacaban los humedales de Nativitas y de los municipios del centro de la planicie del suroeste de Tlaxcala.

Las condiciones climáticas, topográficas y geológicas de la subcuenca Puebla-Tlaxcala determinan que esta planicie funcione como una zona de descarga de flujos de agua subterránea y superficial, generando con ello paisajes acuáticos característicos. Los gigantes estratovolcanes Iztaccíhuatl y Malinche, al poniente y oriente de la planicie respectivamente, han sido fundamentales para generar una importante zona de confluencia de flujos de agua en esta parte baja de la subcuenca. Una de sus principales manifestaciones desde tiempos remotos y hasta la primera mitad del siglo xx fue la presencia somera del nivel freático, que en diversos lugares de las llanuras de Tecuexcomac y Nativitas rebasaba el del suelo formando pantanos; en otros sitios cercanos se encontraba muy próximo al suelo, como más adelante se detallará.

A dichas condiciones topográficas hay que agregar que la planicie está delimitada al norte e interrumpida al oriente por diversos cerros, lomeríos y mesetas cubiertos por tobas (mapa 18). En general se trata de grandes bloques de depósitos lacustres del Plioceno (Tpl) cuya composición es limo-arcillosa, integrada fundamentalmente de arcilla lacustre y horizontes de diatomitas, lo que los hace una unidad litológica prácticamente impermeable que sobresale hoy a las planicies de aluvión reciente (Qal) a consecuencia del tectonismo (Geotecnología 1997). Dichos depósitos han conformado barreras naturales que obstaculizan el movimiento horizontal de los flujos de agua que contribuyeron en el pasado a generar constantes inundaciones.

La configuración edafológica de la planicie también es expresión del funcionamiento y distribución de los sistemas de flujo de agua subterránea y superficial. Las importantes extensiones 
de suelos gleysoles en la planicie de Tlaxcala son resultado del dominio de niveles freáticos someros, principal situación que definió las características de este tipo de suelo, que se formó por las condiciones estables de humedad. Un suelo gleysol se distingue por tener horizontes de colores azulosos en todo el perfil, resultado de formas de hierro reducido causadas por la dificultad para asimilar el oxígeno (Lugo et al. 1989). En general, este tipo de suelo se compone de sedimentos aluviales recientes, légamo arenoso fino a arenoso fino-arcilloso humoso. Son suelos poco desarrollados, profundos, con predominio de agua freática en sus horizontes y con diferente nivel de salinización dependiendo de su ubicación (Aeppli 1972).

Un ejemplo significativo de condiciones edáficas especiales es la llanura de Tecuexcomac, la cual se ha caracterizado por tener suelos húmedos que en algunos sitios dieron lugar a suelos salinos (tequixquite). La concentración de canales de drenaje trazados regularmente es un indicador de que la llanura estuvo en gran parte cubierta por pantanos o lagos poco profundos en épocas históricas, como actualmente puede observarse en el lugar en el que se ubicaba la laguna del Rosario (Trautmann 1981: 14-15) (figuras 1 y 2). Aparentemente la constante humedad en el sector de las raíces de las plantas favorece el rendimiento de los terrenos; sin embargo, la estructura capilar y la gran evaporación que se producen constituyen un peligro de salinidad para los suelos, como ha sucedido especialmente al norte de Santa Ana Nopalucan (Trautmann 1981: 8).

Otra característica importante a destacar es que tanto en el distrito de Zaragoza como en el de Hidalgo, ambos señalados por los cronistas de la Colonia como zonas con pantanos, también existían manantiales clasificados en aquel entonces como termales, específicamente los ubicados en los municipios de Ixtacuixtla (Atotonilco y El Porvenir), Tepeyanco (Molino de Flores de Santa Ana), Huactzinco, Santa Cruz Tlaxcala y Amaxac de Guerrero (también denominado Atotonilco). En el caso de los manantiales de Huactzinco, sus aguas también fueron clasificadas como minerales (Trautmann 1981: 15) (figura 1).

\section{APROPIACIÓN DE LOS RECURSOS FLORA, FAUNA Y AGUA DE LA PLANICIE DEL SUROESTE DE TLAXCALA}

A la diversidad de ambientes acuáticos de la planicie del suroeste de Tlaxcala correspondió una abundancia de formas vegetales adaptadas a este medio. Las hidrófitas son plantas que viven total o parcialmente sumergidas en el agua: pantanos, marismas y ciénegas son su hábitat natural, por lo que se adaptan fácilmente a suelos que contienen niveles de agua que serían superiores al óptimo para las plantas promedio. El agua en sí misma no es dañina, "pero la
Figura 1. Sitios de canales, lagunas, chinampas y manantiales termales en la planicie del suroeste de Tlaxcala. Subcuenca Puebla-Tlaxcala. Época prehispánica-siglo xıx. Fuente: elaborado con base en datos de Velasco (1998), González (1999), Trautmann (1981), Carta del Estado de Tlaxcala (1881), base cartográfica (INEGI 1996), INEGI (1999). 


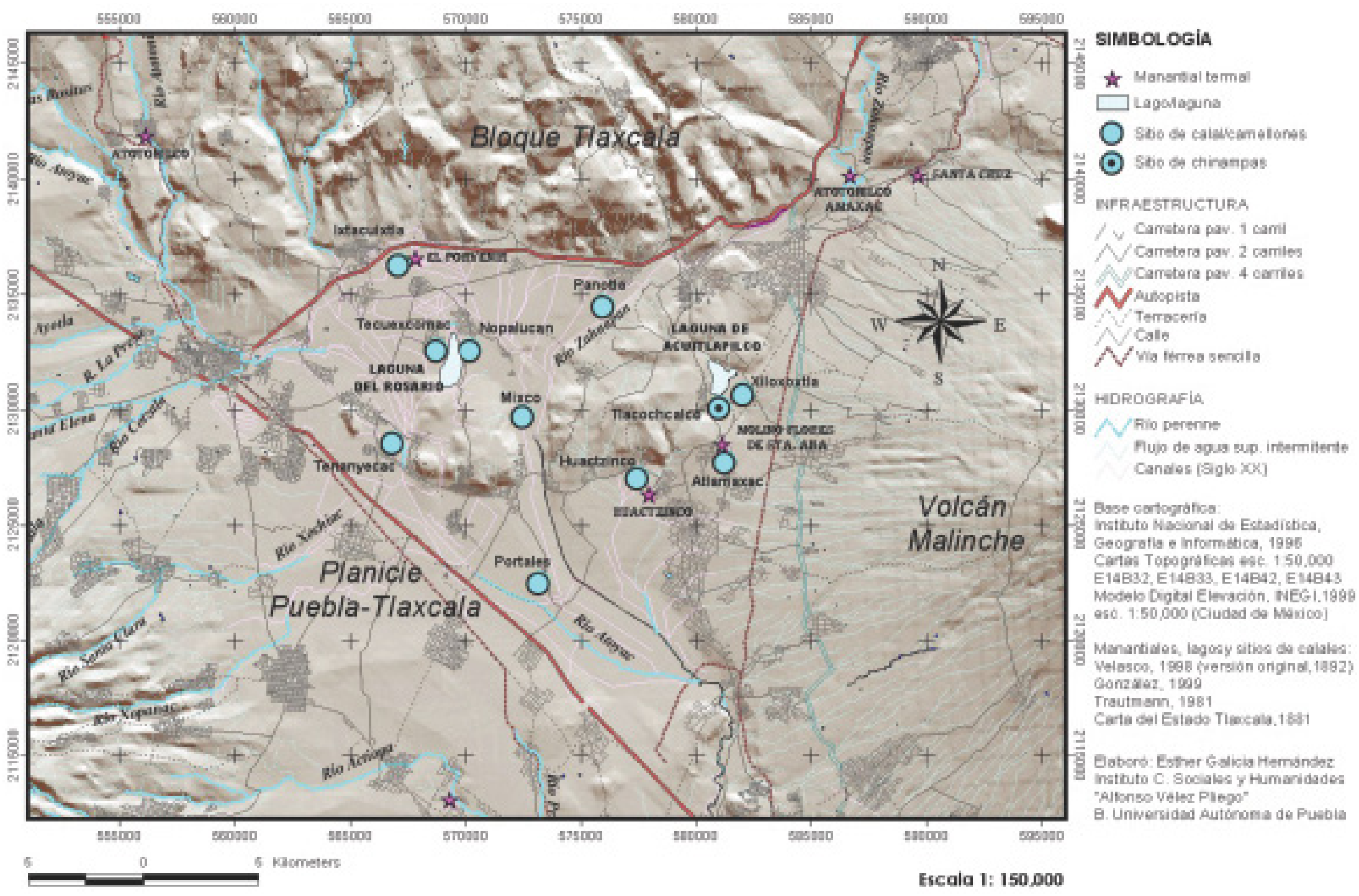




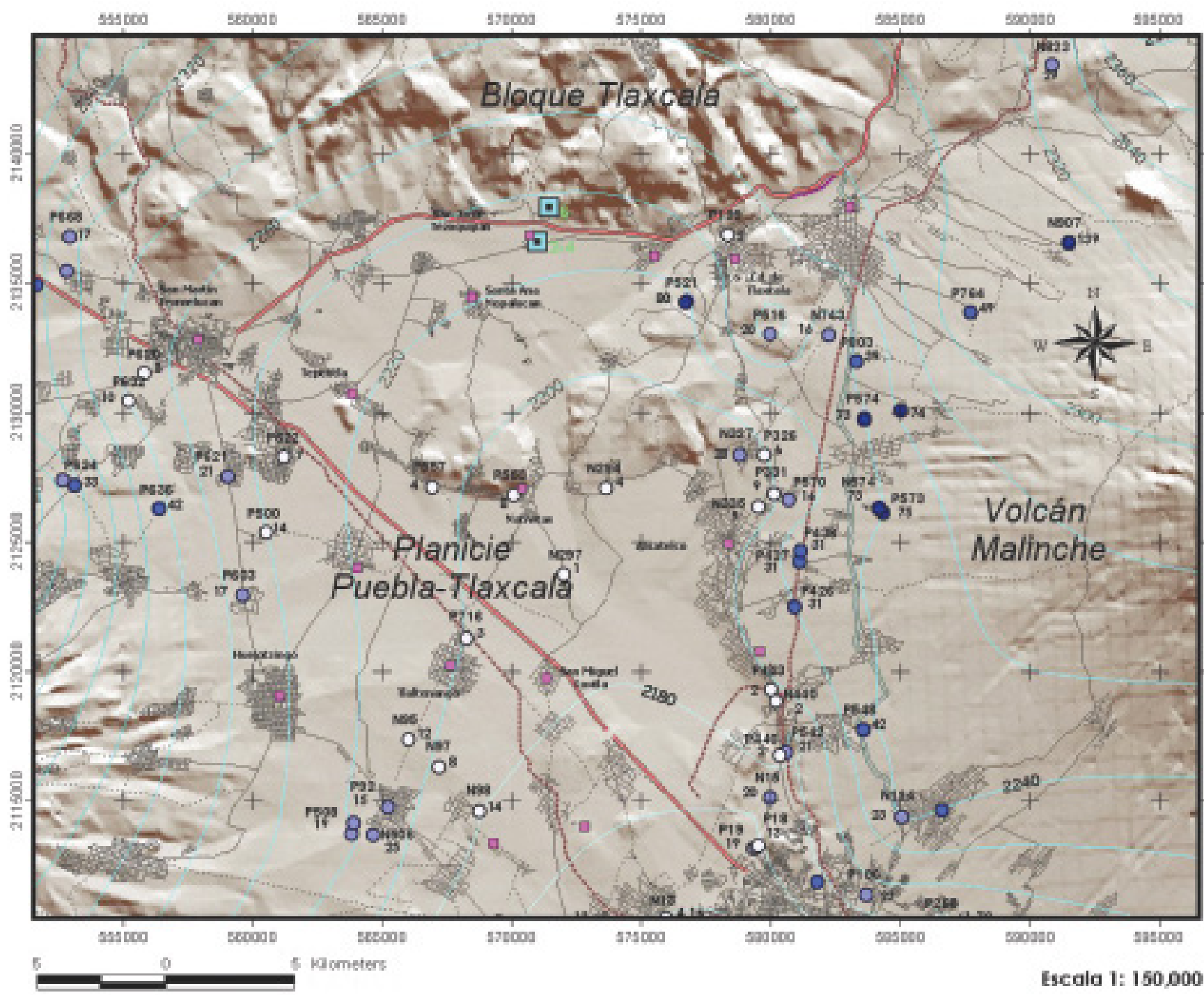

SIMBOLOGia

- Cudadesipuebion

- Prof. al nivel reabico en 1051 Aschiwo Hiatorico del Apyal Prof. al nivel freatico (m) 1973

O $1-14.2$

- $15-2999$

- $30-5990$

- $60-150$

leolineas nivel frestice (monm) 19T3

$$
\begin{array}{r}
1900-2099 \\
2100-2199 \\
2200-2200 \\
2300-2399 \\
2400-2500
\end{array}
$$

NFRAESTRUCTURA

/ V Carretora pav. 1 caml

A. Cametera pav. 2 camil

A Cametera pav 4 camios

Nenespista

$$
\text { Terroceria }
$$

Cale

A via werres sencila

N294 [ollave de pocos y norias, 1973 ;

- 4 iprof. al nivol treatico_m, 1073)

Base cortografica

insthuto Nasional de Estudistica.

Geoprafia e informatica |IINEGII, 1990

Catas Topograficas easc 150.000

E14B32, E14833, E14R42, E14843,

Andelo Digtal Eleración. NUEG1.1999

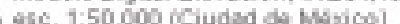

Pozos ynorias (nivel frestecos):

Agrogo diogia 8 A A

Sacretaris Recurnes Hid suliogs, 1973

Eaboro: Esther Gavicia Homandez

Insthuto C. Sociales y Humaridades

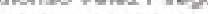

Unwersidsd Auttonons de Puebles

Escala 1: 150,000 
Figura 2. Profundidad del nivel freático y dirección de los flujos de agua subterránea. Subcuenca Puebla-Taxcala, 1972-1973. Fuente: profundidad al nivel estático del agua subterránea en la planicie Tlaxcala, 1973, subcuenca PueblaTlaxcala (elaborado con base en datos tomados de Agrogeología y Secretaría de Recursos Hidráulicos 1973; INEGI 1996, 1999). extrema lentitud a la cual se disuelve y difunde el oxígeno en el agua o en el suelo saturado produce un conjunto de condiciones críticas, que las plantas sólo pueden afrontar si están lo suficientemente especializadas" (Granados y Tapia 1990: 71).

La existencia de humedales, ríos, lagos, manantiales, etcétera, en la planicie del suroeste de Tlaxcala estuvo asociada con la presencia de flora y fauna particulares que definieron entornos naturales característicos de lugares con abundante agua. Entre la flora (González 2002: 210) se encontraban varios tipos de sauces: acuático (Salix caprea), blanco (S. alba), colorado ( $S$. purpurea), de hojas grandes (S. grandiflora), lanceolado (S. lanceolata), llorón (S. babilónica); algunos tipos de fresnos: fresno (Fraxinus sambuccifolia), blanco (F. americana), azul (F. quadranculata); jara blanca, ahuehuete o sabino, ahilite, varios tipos de álamo, tres variedades de tule, carrizo y carricillo. ${ }^{7}$

En relación con la fauna asociada a zonas inundables, había gallina de agua, gallareta, gallinita de agua, garzas, martín pescador, varios tipos de patos, pelícano o alcatraz, culebra de agua, ajolote o axólotl, dos tipos de rana y sapos, dos tipos de peces (juil y pescado blanco). También existían otros animales de menores dimensiones, como pólipos, anillados, arácnidos, insectos, etcétera. Algunos animales acuáticos de la zona eran parte de la dieta humana, por ejemplo, los acosiles y atempolocates en Santa Inés Tecuexcómac. En Santa María Acuitlapilco y en otros lugares de la subcuenca en donde existían canales se consumía el pez denominado charal (González 2002: 211).

Además de delinear entornos naturales característicos, la presencia de pantanos y cuerpos de agua determinó algunas actividades económicas de las poblaciones prehispánicas y coloniales. Varios pueblos se habían especializado en el tratamiento de plantas no domesticadas además del cultivo agrícola, entre ellas destacaba la manufactura de petates de tule (Stirpus lacustris) utilizados con fines domésticos y de culto. A principios de la Colonia, estas plantas silvestres crecían en ciénegas de superficies considerables las cuales se fueron desecando poco a poco, lo que redujo las zonas en donde crecía el tule y, en consecuencia, afectó seriamente la economía de los pueblos. Sin embargo, hasta finales del siglo xx todavía se cultivaba el tule en algunas fosas húmedas en las márgenes de los campos, como sucedía en Santa Ana Nopalucan (Trautmann 1981: 52). En Santa María Acuitlapilco los pobladores tejían petates o esteras de tule que tenían un amplio mercado en las industrias textiles de la región, en donde se empleaban para el embalaje de telas. Sillas, canastos y cestos también fueron importantes productos elabo-

${ }^{7}$ En las regiones húmedas entre los ríos Atoyac y Zahuapan se encuentran restos de un antiguo bosque con Fraxinus, Salix y Alnus arguta. Su alineación a lo largo de los diques de los ríos y de la red de drenaje refleja una fuerte influencia antrópica (Trautmann 1981: 8). 
rados con esta peculiar planta. Otras actividades que desarrollaron los habitantes de aquellos ambientes acuáticos fueron la pesca, la recolección de crustáceos, batracios, huevos de insecto, la cacería de patos y otras aves acuáticas para su venta en los mercados vecinos de Santa Ana Chiautempan, Tlaxcala y Puebla (Velasco 1998: 21, 30, 34, 38).

Los ambientes acuáticos dominaron los paisajes de varios lugares de la planicie del suroeste de Tlaxcala y condicionaron las formas de apropiación del suelo y el agua. Estas características particulares la hicieron una zona de difícil manejo humano, dados los requerimientos de fuerza de trabajo para construir y mantener los distintos sistemas para el control del agua (que mantuvieron un equilibrio delicado entre la fertilidad y las inundaciones), sus tierras no fueron utilizadas todo el tiempo. Durante la época prehispánica sólo se ocupó para actividades agrícolas a finales del Clásico. Los pueblos se ubicaban en los lugares más elevados y las tierras bajas, generalmente inundadas, se drenaban para cultivarse o se utilizaban para pesca, caza y obtención de productos como el tule o el otate, como se describió anteriormente. Desde la época prehispánica se utilizó un sistema agrícola denominado calal, que en náhuatl significa "casa junto al agua". Es una denominación local utilizada por los campesinos del suroeste tlaxcalteca para referirse a un sistema agrícola que se practicó en zonas inundables o pantanosas y que consistió en un conjunto de plataformas y canales organizados en forma reticular. En las plataformas se cultivaba y a través de los canales se conducía el agua del sistema, incluso en algunos de ellos era posible el transporte de canoas y el cultivo de plantas acuáticas, como el tule.

El historiador Trautmann (1981) clasificó a los camellones dentro del tipo de cultivos de humedad (sistema conformado por plataformas y canales alargados) indicando que, para la segunda mitad del siglo XVI, se les encontraba en Quautlan, Panotla, Ocotelulco, Huactzinco, Tecuescamas, El Porvenir, Temazolco, Ixtacuixtla, Tenexyacac, Nopalucan, Portales y Mixteco (González 2002: 205, 206). También existieron camellones en la orilla oriental de la laguna de Acuitlapilco, que pertenecieron a Santa Isabel Xiloxotla, y una zona de chinampas que fue parte de Santiaguito Tlacochcalco. En Tepeyanco había plataformas de forma reticular, es decir, con zonas cuadradas bordeadas por canales menores y zanjas (al parecer una variación del calal). En Atlamajac -anteriormente barrio de Tepeyanco- se desarrolló un sistema de camellones con plataformas alargadas, bordeadas por canales menores y árboles como el ailite (Alnus spp.) y álamo blanco (Populus alba L.) que protegían la zona interna de la plataforma (figura 1).

En estos sitios de humedales la apropiación del suelo para uso agrícola estuvo condicionada por la existencia de agua en abundancia, producto tanto de escurrimientos superficiales como del afloramiento de flujos de agua subterránea. El trabajo humano ha sido el factor principal para la apropiación de este suelo y el que ha remodelado el paisaje natural mediante la canalización de los ríos, la construcción de bordos, redes de canales y zanjas para controlar el 
curso y nivel del agua y permitir el cultivo en las plataformas con suelos formados mediante la aplicación de légamos y/o la construcción de desagües para drenarla. Durante el periodo prehispánico e inicios de la Colonia, las obras para control del agua obedecieron a situaciones estrictamente locales que tomaban en consideración condiciones ambientales de naturaleza particular, ajustándose a las variaciones anuales. En su mayoría, estas obras se hacían de tierra acumulada, piedras y palos que podían moverse rápidamente en caso de aguaceros torrenciales que amenazaran con inundar las zonas cultivadas, o podían incrementarse en volumen agregándoles hileras o montones de costales o sacos rellenos de arena (González 1999: 193195). Dicha interacción no modificaba sustancialmente las condiciones del medio natural ni cambiaba en esencia su naturaleza. Las actividades agrícolas se adaptaban a las características de un ambiente acuático, sin alterarlo drásticamente para su aprovechamiento.

Tal situación parece haberse prolongado hasta el siglo xIx, cuando los hacendados construyeron la mayoría de las obras que estuvieron destinadas a controlar el agua en la planicie o a drenarla de manera "permanente" o semipermanente. Estas obras, normalmente, fueron de mampostería o construidas con materiales durables, incluidos canales, drenes, muros de contención, infraestructura para sostener compuertas y represas. Dada la imposibilidad de removerse rápidamente o de modificar su curso en las temporadas anuales de lluvias torrenciales, algunas de esas obras hidráulicas propiciaron inundaciones en las zonas cercanas a las poblaciones o en sus terrenos de cultivo. En general, dichas construcciones fueron coordinadas por los distintos propietarios de fincas, lo que implicó formas de participación y organización más amplias que las estrictamente individuales y locales. La remodelación de estos suelos conllevó un cambio en la escala de la configuración territorial pues incluyó varias propiedades y, en algunos casos, alcanzó una dimensión regional (González 1999: 194).

En este contexto, se puede afirmar que el proceso de apropiación del medio natural, condicionado por la presencia o ausencia de agua superficial y subterránea, también ha conllevado formas y dinámicas particulares de uso-manejo, integración o desintegración del territorio natural y construido. Es decir, la distribución del agua en la subcuenca, en general, además de definir una gama de paisajes naturales, ha restringido la ubicación de la población y condicionado sus actividades económicas. Después del movimiento armado de 1910, especialmente a partir del reparto agrario, en el país se suscitaron cambios políticos-jurídicos e ideológicos que impulsaron nuevas formas de distribución y usos del suelo y agua (Gayol 1994: 144). Ahí donde las grandes haciendas tenían el control de las fuentes y corrientes de agua, el reparto agrario iniciado en 1917, al provocar su disolución y dejarlas en manos de nuevos propietarios o ejidatarios, conllevó nuevos conflictos por el uso y distribución del agua (Aboites 1999: 188). Fueron también condiciones causantes de cambios significativos en las escalas de producción y tipos 
de cultivo; hubo, por lo tanto, nuevos impactos al entorno natural, modificaciones al ambiente acuático, importante soporte material del desarrollo de la subcuenca hasta esos momentos.

Dichos cambios no transformaron radicalmente el ambiente acuático de la planicie del suroeste de Tlaxcala. Todo parece indicar que se desarrolló una agricultura híbrida pues el sistema de camellones subsistió hasta casi mediados del siglo xx. Fue en la década de los cuarenta cuando inició un rápido proceso de alteración permanente del medio natural de la planicie. Como parte de importantes cambios de orden político-administrativo y técnico en el Distrito de Riego Atoyac-Zahuapan (056), ${ }^{8}$ se puso en marcha un nuevo sistema de control de agua a través de una amplia red de canales hechos a base de cemento cuya función fue expulsar el agua de las zonas de inundación de la planicie (figura 1), sobreponiendo-imponiendo un nuevo sistema de drenaje permanente en el sistema de calales/camellones cuyo principio había sido utilizar el agua existente en la planicie a partir de su control-dosificación (González 2002: 207).

Los resultados de este largo proceso histórico han sido diversos y diferentes para cada lugar y pueblo de la planicie, dependen fundamentalmente de su ubicación con respecto a los sitios de descarga de flujos de agua subterránea y superficial; empero, con estas últimas afectaciones al medio natural se aceleraron tendencias generales, como el descenso del nivel freático, cuyas manifestaciones principales fueron la disminución o desecación de pantanos, aunque varios de ellos ya habían disminuido o desaparecido mucho antes. Como se señaló en párrafos anteriores, a consecuencia de la desecación, paulatinamente siguieron menguando o se extinguieron la fauna y flora acuáticas, cuyo resultado, puede inferirse, fue la disminución de actividades económicas, como la confección de petates y cestos y la pesca (figura 2).

En este contexto, como consecuencia del descenso del nivel freático en diferentes zonas de la subcuenca, ${ }^{9}$ la Secretaría de Recursos Hidráulicos impulsó en los primeros años de la década

${ }^{8}$ Hay notables diferencias entre algunos autores sobre el año de creación y transferencia del Distrito de Riego Atoyac-Zahuapan (056): González (2002: 207) señala que fue creado por la Secretaría de Agricultura y Recursos Hidráulicos (SARH) en 1947; Tello et al. (2010: 174) refieren que fue establecido durante el periodo presidencial de Manuel Ávila Camacho (1940-46) y que el 19 de diciembre de 1947 fue entregado por la Secretaría de Agricultura y Ganadería a las Juntas de Agua de Puebla y Tlaxcala para su operación y administración por los siguientes trece años; en 1960 la Secretaría de Recursos Hidráulicos reasumiría la administración, operación y conservación del Distrito de Riego. Palerm y Martínez (2009: 301) señalan que en 1947 la Secretaría de Agricultura y Ganadería entregó el Distrito a los usuarios (lo cual coincide con la información de Tello et al. 2010).

${ }^{9}$ Hacia el sur del estado de Tlaxcala la planicie continúa abarcando extensas áreas de territorio poblano. En esas áreas también se manifestó un descenso del nivel freático que provocó la disminución del caudal de sus manantiales. Los manantiales que abastecieron a San Mateo Cuanalá, localidad del municipio de Juan C. 
de los cincuenta del siglo xx estudios geohidrológicos en la planicie del suroeste de Tlaxcala con el objeto de extraer agua subterránea para riego agrícola. Con tales estudios técnicos se pudo constatar que no existía ningún pozo profundo en esta parte de la subcuenca hasta esos momentos: "no se sabe si existen acuíferos confinados, con aguas ascendentes a mayor profundidad, ya que no hay ninguna perforación profunda en esta región, confirmando o desechando tal posibilidad". ${ }^{10}$ En esos estudios también se describía un panorama general del nivel freático en diferentes puntos: "en la parte norte de este valle el agua estaba a una profundidad de doce a quince metros; en la parte sur, conforme iba descendiendo el nivel del terreno, subía el nivel del agua para llegar a formar hasta pantanos, de manera que en esta parte pantanosa hay que drenar para sembrar". ${ }^{11}$ En aquellos años se registraron variaciones del nivel freático en diferentes lugares de la franja norte de la planicie que colinda con el Bloque Tlaxcala; específicamente en San Jorge Tezoquipan, municipio de Panotla, en donde el agua se encontraba entre dos y cuatro metros de distancia con respecto al nivel del suelo, mientras que en Jesús Acatitla, pueblo vecino de Santa Cruz Techachalco, el agua se localizaba aproximadamente a ocho metros de profundidad (figura 2).

En la parte sur, la más baja de la planicie de Tlaxcala, a pesar de que en los años cuarenta del siglo xx se impuso el sistema de drenaje superficial de sus aguas, todavía a principios de la década de los cincuenta se reportaba en estos estudios técnicos la existencia de lugares pantanosos, lo cual demuestra el impacto e importancia de los flujos de agua subterránea en esta parte de planicie. A partir de las referencias señaladas y con el apoyo del estudio geohidrológico realizado por Agrogeología y la Secretaría de Recursos Hidráulicos (1973) en la subcuenca Puebla-Tlaxcala durante los primeros años de la década de los setenta, se puede establecer que fue aproximadamente en la década anterior cuando inició en esta subcuenca la perforación de pozos profundos para la extracción de agua subterránea, aunque, como se puede observar en la figura 2, en la planicie Tlaxcala fue mínimo el número de pozos registrados en dicho estudio. Tomando como base los datos de la noria (N297) censada por Agrogeología (1973) en el sitio denominado Portales, se puede constatar la disminución del nivel freático en la parte sur de la

Bonilla, son un ejemplo significativo de dicha situación: el gasto registrado en 1953 fue menor de un litro por segundo, cuando en años anteriores habían presentado un "gasto considerable" (Archivo Histórico del Agua [AHA], 1951, Fondo Consultivo Técnico, caja 584, exp. 5464).

${ }^{10}$ Dictamen acerca de las condiciones geohidrológicas en el valle de Tlaxcala, estado de Tlaxcala, emitido por el Ing. Harold Von Kuegelgen en 1951 a petición de la Secretaría de Recursos Hidráulicos (AHA 1951, Fondo Consultivo Técnico, caja 835, exp. 7894, foja 5).

${ }^{11}$ AHA 1951, Fondo Consultivo Técnico, caja 835, exp. 7894, fojas 5 y 6. 
planicie; en dicha noria se registró, en un lugar que en el pasado fue zona pantanosa, el nivel del agua subterránea un metro abajo con respecto al nivel del suelo (figuras 1 y 2). Con el inicio de la perforación de pozos profundos en la subcuenca dio comienzo una nueva etapa en la transformación radical del ambiente natural en general y en específico del sistema hídrico del suroeste de la planicie de Tlaxcala.

\section{CONCLUSIONES}

La construcción del territorio de la planicie del suroeste de Tlaxcala ha sido resultado de un largo proceso histórico de interacción sociedad-naturaleza en el que el sistema hídrico ha tenido un papel central como parte de las condiciones-soportes materiales que han sustentado su desarrollo. La configuración del territorio, la distribución de los usos del suelo y sus paisajes naturales pasados y presentes han sido expresión fundamental de la presencia diferenciada de agua. El ambiente acuático característico de la planicie del suroeste de Tlaxcala fue (es todavía, pero alterado) resultado de la convergencia de distintos flujos de agua subterránea y superficial en esta parte baja de la subcuenca. Esta condición ha generado a lo largo de su historia formas y dinámicas particulares de manejo, aprovechamiento o desocupación y división o integración del territorio.

La construcción de un marco histórico-conceptual de las condiciones "originales" de funcionamiento del sistema hídrico en la planicie es fundamental para recuperar/reconocer los elementos del sistema que alienten la reconstrucción de una memoria hídrica. Conforma, además, un marco de referencia que permite visualizar a nivel del territorio las alteraciones que ha sufrido en la actualidad, de tal manera que sea posible hacer una evaluación real de las diferentes acciones antropogénicas efectuadas sobre dicho sistema en distintos momentos que contribuya a la construcción de una plataforma de información sustentada en el conocimiento de los procesos hídricos. En suma, es necesario reorientar la gestión del agua en la planicie del suroeste de Tlaxcala, que tenga como premisas centrales un marco hídrico-histórico, el funcionamiento integral del sistema general (agua superficial y subterránea) y la interaccióninterdependencia que existe entre sistemas naturales y sociales. 


\section{LA CONFORMACIÓN DEL SISTEMA DE RIEGO DEL VALLE DE TEXMELUCAN, EN LA CUENCA DEL ALTO ATOYAC, DURANTE EL SIGLO XVII}

Davison G. Mazabel Domínguez

\section{INTRODUCCIÓN}

$\mathrm{E}$ n este trabajo se destaca la importancia del recurso hídrico en el surgimiento de un sistema de riego de la microcuenca del valle de Puebla, del río Cotzala, producto de la colonización española y la conformación de un espacio agrícola regional. En ambos procesos las disputas por el agua constituyeron el meollo del proceso agrario.

La microcuenca del río Cotzala, en el Alto Atoyac, se localiza en la porción noroeste del estado de Puebla, concretamente en el valle de Texmelucan. Los conflictos por el agua en esta microcuenca se articulan alrededor de dos ejes: 1) el predominio de tierras en manos de algunos propietarios, lo que supone, al mismo tiempo, su capacidad de concentración de los recursos naturales, sustentada en los derechos que se establecieron a partir de las "mercedes primigenias" entre los siglos XVI-XVII y de las propiedades fundadas en el área central del territorio; 2) el marcado interés en la producción cerealera durante buena parte del siglo XVII, que contribuyó significativamente a la intensificación de los conflictos por agua, de tal suerte que, con el repartimiento de aguas de $1673^{12}$ se consolidó una tendencia a la expansión de la frontera agrícola, dando lugar al surgimiento de pequeños productores o pegujaleros que, instalados

${ }^{12}$ Los repartimientos de agua en la época colonial constituían una forma de ordenamiento del recurso hídrico, ejecutados por un funcionario local -corregidor o alcalde mayor o el teniente de alcalde mayor- o virreinal -un juez u oidor encargado para tal efecto. Los usuarios o interesados en acceder a la repartición debían demostrar, mediante título o concesión, el derecho al agua en cuestión. 
en medio o en la periferia de las grandes propiedades, fueron paulatinamente incrementando la demanda de agua.

Dos son las razones de la relación de la microcuenca del río Cotzala con la región de Tlaxcala, de la que Nativitas forma parte. En primer lugar, la microcuenca del río Cotzala en el Alto Atoyac forma parte de las laderas de volcán Iztaccíhuatl, es decir, de la franja de faldas superiores de la subcuenca Puebla-Tlaxcala a la que tanto la región de Nativitas como el valle de Texmelucan pertenecen, de tal suerte que la dinámica de flujos hidráulicos afectan como un continuo a ambos territorios (mapa 21). La segunda razón tiene que ver con el hecho de que los estudios de larga duración -desde la perspectiva de la antropología histórica- que estamos realizando sobre el valle de Texmelucan, al que concebimos como zona de frontera entre el antiguo señorío de Huejotzingo y el de Tlaxcala, y las relaciones sociohistóricas que se gestaron durante el periodo colonial, han servido para entender parte del comportamiento socioterritorial de la región de Nativitas respecto a los procesos de colonización y conformación de espacios agrícolas regionales y la construcción de las nuevas territorialidades que se configuraron a partir de la conquista y colonización española.

El punto de arranque decisivo del proceso colonizador español sobre el valle Puebla-Tlaxcala fue la fundación de la ciudad de Puebla en el año de 1531, concebida como espacio estratégico de comunicación entre la ciudad de México y el puerto de Veracruz. En tanto región intermedia que serviría de apoyo logístico y productor de alimentos en un área clave del sistema colonial, la ciudad de Puebla garantizaría la seguridad y el abasto alimentario. Con el paso del tiempo, fueron constituyéndose espacios productivos en torno a ella, donde no sólo los recursos naturales ofrecían mejores oportunidades, también la oferta de mano de obra indígena facilitaría el rápido desarrollo agrícola de la región. Uno de estos centros se situó en el valle de Texmelucan, en los alrededores de San Martín Texmelucan, Puebla (mapas 16 y 17).

Aunque de diversas maneras el valle se encuentra articulado a la zona montañosa o de laderas del Iztaccíhuatl, hay que destacar que la oferta hídrica es mucho más generosa en la planicie, que fue precisamente donde se solicitaron las primeras y grandes mercedes tanto de tierra -a fines del siglo XVI- como de agua -durante las primeras décadas del siglo XVII- y en donde se establecieron las principales haciendas de la región. Fueron los propietarios de estas haciendas quienes adquirieron lo que denominamos las "mercedes centrales" o "derechos primigenios" sobre los que se fundó una nueva territorialidad u organización territorial a través de un dominio y control geográficamente estratégico sobre los recursos de la región, particularmente el agua.

Este territorio puede definirse como una microcuenca que se despliega alrededor del río Cotzala y su tributario el río Santa Elena, en torno a los cuales se despliega una serie de veneros 
que bajan de la sierra Nevada y a los que se suman los flujos de manantiales y ojos de agua que se encuentran en la región. El agua, de la que se dispone con relativa abundancia, es conducida a los campos para el riego mediante sistemas de canales que, como refiere Miehlich (1988: 15), son de origen prehispánico, ${ }^{13}$ por lo cual fue posible obtener varias cosechas al año. De ahí que la topografía, los suelos y los recursos hídricos favorezcan al valle superior del Atoyac y a las laderas inferiores del Iztaccíhuatl, convirtiendo las comarcas ahí localizadas y el valle de Atlixco en la tierra preferida de asentamiento de la colonización española en el valle de Puebla (Miehlich 1988: 18).

\section{TERRITORIO Y COLONIZACIÓN}

Durante la época colonial la Corona se constituyó en uno de los actores principales de la delimitación espacial. En una formación social tal, el territorio fue sujeto de múltiples actuaciones y territorialidades. No obstante, la producción de un orden territorial y poblacional institucionalizado fue estructurándose paulatinamente con base en las ordenanzas y disposiciones reales que definieron los límites político-administrativos (reinos, corregimientos y alcaldías mayores, etcétera), así como los tipos de propiedad (individual, social, pública).

Las leyes, en tanto estructuras formales de autoridad, generan órdenes territoriales y poblacionales que, a su vez, producen pautas o normas de acción y comportamiento social, que a pesar de ser la estructura de las instituciones, sólo tienen existencia real cuando la gente se apropia de ellas en un tiempo y lugar específicos (North 1990). En este sentido, la apropiación y aplicación de dichas leyes y disposiciones tuvo que pasar por el tamiz de las realidades locales. La ambigüedad que se derivó de las propias disposiciones reales cuando se decretaron modos de vida en repúblicas de indios y de españoles generó un sinfín de contrariedades que estuvieron supeditadas, sobre todo en el caso de los pueblos de indios, ${ }^{14}$ al derecho consuetudinario, derivado del derecho indígena local.

La producción del espacio es un proceso que se lleva a cabo en todo momento a través de prácticas sociales e institucionales; el tiempo, así como el lugar, asignan marcas de especificidad a la territorialidad producida. De manera que podemos hablar de territorialidades, en plural, para señalar su carácter histórico y social (Torres 2009). Es importante resaltar que

${ }^{13}$ Miehlich (1988) los sitúa desde un periodo tan antiguo como el Preclásico, pero no precisa fechas.

${ }^{14}$ Para los propósitos de este trabajo se ha usado el término "pueblo de indios" que fue el más utilizado en la documentación colonial. 
la empresa de colonización española, si bien estaba orientada en lo general a la política de la Corona, en la práctica se dio, por lo menos durante la primera etapa del régimen colonial, conforme a las características de los territorios y de las poblaciones con las que los españoles interactuaron. Es en ese sentido que al menos ciertas estructuras políticas y socioeconómicas de origen indígena fueron tomadas en cuenta tanto para fines organizativos como de tributo, asimismo algunas formas de habitabilidad -e incluso de territorialidad indígena- se permitieron o toleraron en gran medida por razones estratégicas.

Durante gran parte del periodo colonial, el hinterland ${ }^{15}$ de la zona montañosa del Iztaccíhuatl continuó siendo un espacio de acceso a los diversos grupos humanos asentados en la planicie y zona de laderas, surtía de materia prima a los colonizadores españoles y era un espacio de abastecimiento de recursos materiales y de reproducción simbólica para los pueblos de indios. Es hasta entrado el siglo XVIII cuando empiezan a aparecer en la documentación colonial quejas y disputas por los recursos maderables y del monte por parte de los pueblos de la región.

Al respecto se puede plantear de manera puntual que en el proceso de cambio social, los rasgos estructurales específicos de las poblaciones conquistadas constituyeron un factor decisivo, incluso parecen haber determinado la rapidez o lentitud de las transformaciones. Cabe señalar que la organización política y administrativa colonial, durante el primer siglo, se basó en las estructuras previas a la dominación española. Instituciones como el tlahtocayo ${ }^{16}$ han sido identificadas en diversos puntos de la región poblana, como en el señorío de Tepeaca (Martínez 1984). Pudiera inferirse el peso de esta institución en las declaraciones de los principales de Huejotzingo durante el siglo Xvi sobre las tasaciones de tributo. ${ }^{17}$

Cuando se ha identificado el tlahtocayotl ha sido considerado como el núcleo de la estructura social y de la compleja organización económica y política; se caracterizó por un régimen

${ }^{15}$ La palabra hinterland proviene del idioma alemán y significa literalmente "tierra posterior" (a una ciudad, un puerto, río, etcétera). En un sentido más amplio el término se refiere a la esfera de influencia de un asentamiento. Es el área para la cual el asentamiento central es el nexo comercial (Encyclopaedia Britanica 2012). Este término comenzó a utilizarse en el contexto portuario como la región económicamente vinculada a un puerto hace más de un siglo (Chisholm 1888). En el caso que exponemos se refiere al área contigua e interconectada con el sistema montañoso en términos de la conformación fisiográfica y el área cultural asociada a éste.

${ }^{16}$ Se refiere a la casa señorial que dependía de un señor o teuhtli. En la documentación de archivo sobre Xochimilco, éste posee las características que Carrasco utiliza para definir el tecalli (Carrasco 1976: 21, 22) y las que refiere Martínez sobre los tlahtocayotl de Tepeaca (Martínez 1984).

${ }^{17}$ Ver Matrícula de Huejotzingo y el Códice Guillermo Tovar de Huejotzingo. Asimismo puede revisarse el trabajo de Landa (1987). 
de tenencia de la tierra basado en la propiedad territorial de los tlahtoque, lo que garantizaba a su vez un control directo sobre la población tributaria. De manera que las unidades sociales de producción continuaron siendo controladas durante la mayor parte del siglo xvI en primera instancia por los pipiltin o clase noble indígena. ${ }^{18}$ La territorialidad indígena construida en el periodo previo al contacto estaba sustentada en la organización espacial del altepet ${ }^{19} \mathrm{y}$ de los calpullis $^{20}$ (al nivel de las tierras comunales).

Es importante señalar que, respecto a la división prehispánica de la tenencia indígena de la tierra en Huejotzingo, no podemos descartar la idea de que ésta era de facto dominada por la nobleza, por lo que las estructuras calpullalli-pillalli, si bien están sugeridas en la literatura sobre este señorío, como lo destaca Prem (1988), parece que de una manera más tangible debió haberse dado una situación parecida a la encontrada en otras zonas del área poblano-tlaxcalteca, donde la estructura del tecalli ${ }^{21}$ y la institución del tlahtocayotl eran predominantes.

En ese sentido, la categoría calpullalli, según las declaraciones expresas de la nobleza con motivo de la acción de repartición de la tierra de 1554, aunque logran identificar la mayor parte de los barrios con sus respectivos calpullis, parece que ya no están tan presentes en términos del dominio territorial, ya que los principales pretenden haber sido los propietarios únicos de toda la tierra. Lo que sí destaca es una cantidad importante de terrazgueros ${ }^{22}$-en 1560 se menciona la cifra de 5396 (Brito 2011). Pareciera entonces que la supervivencia de los calpulli en el territorio se hubieran reducido a la presencia de los diseminados pueblos o comunidades en un

${ }^{18}$ En cuanto a la estructura social de origen prehispánico, encontramos en los documentos coloniales, para la región, los nobles teteuctin, quienes se agrupaban en casas llamadas tecalli o "casa de mayorazgo", y pipiltin, en la "casa solariega". Estas "casas señoriales" constituían una corporación dentro de las estructuras económicas y políticas y a ellas estaban adscritos pipiltin, macehualtin y bienes: casas habitación y tierras (Limón 1991).

${ }^{19} \mathrm{El}$ altepetl o huey altepetl, alude a la "gran ciudad" prehispánica, que comprendía a su vez a varios altepeme (plural de altepetl), ya fuera bajo la jurisdicción de uno jerárquicamente superior o como parte de una confederación, de acuerdo con la jerarquía sociopolítica y territorial de su propio modelo de asentamiento (Bernal y García 2006).

${ }^{20}$ El calpolli era una institución muy compleja que incluía el control de un territorio determinado dentro del altepetl. A menudo se convirtió en pueblo sujeto al mismo altepetl al que pertenecía (Bernal y García 2006).

${ }^{21} \mathrm{El}$ tecalli era una entidad que dependía de un señor y ante todo comprendía las tierras de la casa, con sus dependientes y el título de su señor, uno de los dirigentes en la organización política del señorío (Vargas 1995).

${ }^{22}$ Los terrazgueros eran, desde la época prehispánica, indios sin tierras propias que trabajaban las que pertenecían a los nobles, en contraste con los macehuales, quienes labraban las de su propiedad. Al otorgarles tierra a los terrazgueros, la Corona los convirtió en macehuales con obligación de pagar tributo al gobierno español y no a los señores indígenas (Rendón 1996). 
extenso territorio que, sucesivamente, fue ocupado por la colonización española, particularmente con fines de aprovechamiento agrícola, sobre todo en el territorio al que hacemos referencia en nuestro estudio: el valle de Texmelucan. ${ }^{23}$ Es importante señalar que si bien el valle de Texmelucan perteneció o formó parte del antiguo señorío huexotzinca, al mismo tiempo tenemos que el carácter de frontera imprimió una huella en sus determinantes territoriales, es decir, esta condición puede brindarnos una pista en términos de cómo se construyó la territorialidad antes de la llegada de los españoles a la región (figura 3).
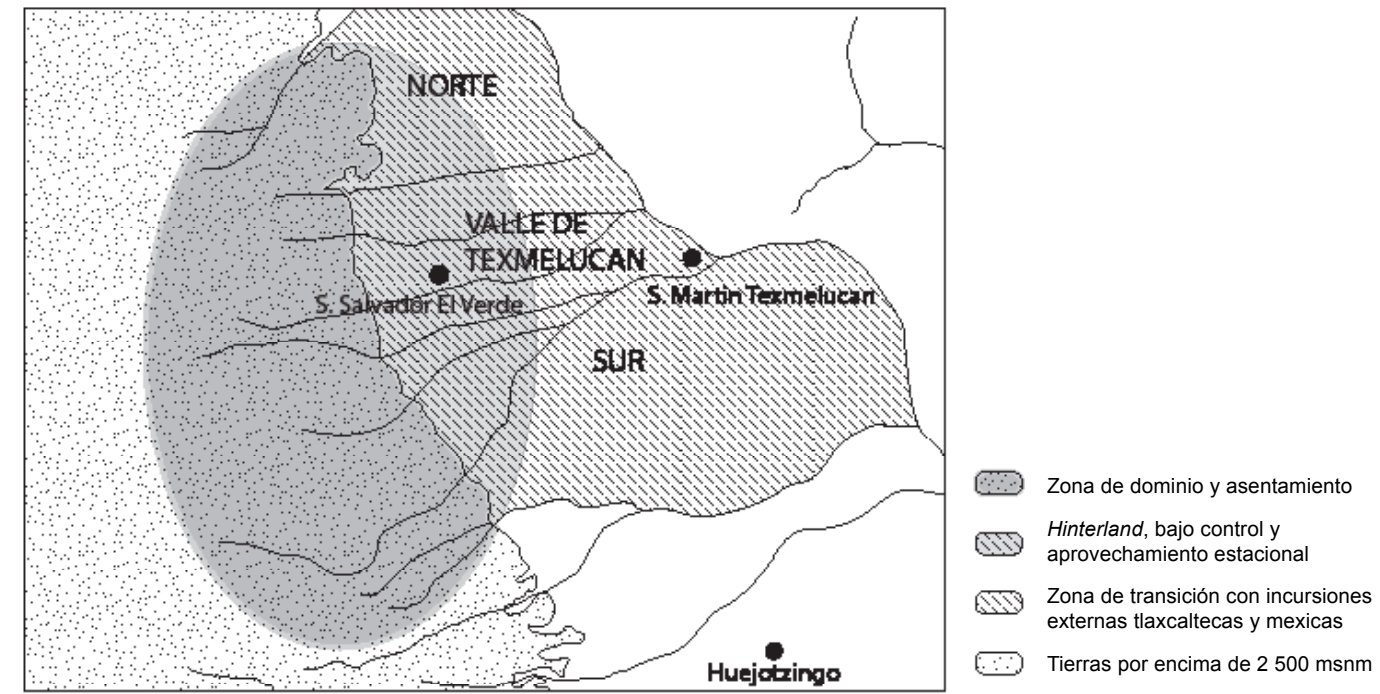

Durante la época colonial temprana la separación de los territorios fue propiciada por las actitudes de los pueblos y por los mismos principales en una suerte de distanciamiento geopolítico. De ahí que, a partir de entonces, los "espacios abiertos" a la colonización y las geoformas ${ }^{24}$ se presentaron como una puerta de entrada para los españoles que encontraron en estos territorios espacios susceptibles de ser aprovechados; se iniciaba así una construcción sociohistórica de paisajes agrícolas que provenía de una apreciación externa, que con el tiempo fue modulando y reconfigurando un paisaje sin desaparecer del todo diversos componentes de la territoria-

${ }^{23} \mathrm{~A}$ menudo se menciona que hubo intentos por parte de las autoridades españolas y de los frailes de promover la asignación o reparto de tierras a indígenas para que pudieran pagar tributo a la Corona (Brito 2011).

${ }^{24}$ Formaciones naturales que ocupan un área geográfica en el relieve terrestre.
Figura 3. Diagrama con la territorialidad y fronteras en el momento del contacto. Fuente: elaboración propia. 
lidad indígena. En la figura 3 se observa que prácticamente la totalidad de los núcleos de los asentamientos se ubican en las zonas de laderas del Iztaccíhuatl, alrededor o por encima de los $2500 \mathrm{msnm}$, lo que apoya nuestra aseveración anterior, en tanto tenemos una disposición hacia un amplio espacio transicional.

La construcción del espacio dentro de las comunidades humanas pasa por procesos de significación que superan la visión reducida de éste como una dimensión física. Esta perspectiva revela que la distribución social del espacio está asociada con la estructura de las sociedades; sus tensiones y acuerdos posibilitan describir los procesos de cambio en patrones económicos y culturales a lo largo del tiempo y contribuyen a explicar los procesos actuales de reivindicación o interpretación de derechos. Indagar en los procesos de construcción de la territorialidad de los pueblos indígenas implica remitirse a la dimensión cultural que envuelve su relación con la tierra. Desde esta perspectiva, la tierra se construye como una noción imbricada simbólicamente por significados y prácticas (tradiciones, rituales, historia), que configura el suelo y sus recursos como una unidad indivisible en la cual las comunidades construyen y afianzan su identidad. Esta relación naturaleza-cultura se contrapone a la construcción occidental de la tierra como bien mercantil de posesión individual, cuya principal orientación es la comercialización dentro de la estructura económica. Esta concepción hegemónica sustenta la separación identitaria entre tierra, recursos y comunidad y facilita el intercambio, la extracción y transformación masiva de los recursos naturales. No está de más subrayar que los procesos de reproducción de significados y prácticas de los conjuntos humanos, incluidos los grupos étnicos, no son estáticos, puros o esencialistas; por el contrario, se encuentran en permanente negociación y tensión y no deben ser separados de los contextos históricos concretos que los posibilitan.

Europa diferenciaba conceptual y físicamente el asentamiento densamente poblado y geográficamente organizado, de los asentamientos dispersos y acomodados orgánicamente sobre el territorio circundante. Al primero lo denominó ciudad o urbe (civitas o urbs) y rural o rústico (rusticitas) al segundo [...] En cambio, las diferentes etnias mesoamericanas parecen haber concebido el núcleo urbano solamente como eso, el centro de una ciudad, la cual integraba la porción que los europeos llamaron rústica o rural (Bernal y García 2006: 32).

Otra diferencia fundamental en términos de la percepción y asunción del territorio tiene que ver con el carácter sagrado implícito en la dimensión espacial del mundo mesoamericano, lo que se expresa asimismo en el componente de la identidad referida a espacios vividos, que para el caso de los europeos no existía y que se empezó a construir a partir de la colonización y de otra visión de mundo. En este sentido, la articulación de los territorios a las zonas de mon- 
taña, como es el caso del valle de Texmelucan imbricado física y culturalmente con la sierra Nevada -principalmente el Iztaccíhuatl-, requiere que observemos el particular acento que estas estructuras le confieren al entramado simbólico de los pueblos asentados en ellos.

La montaña era vista como un gran templo que cubría y proporcionaba las aguas. Las altas cimas de los volcanes y cerros de importancia se miraban como depósitos de agua, y cuando había en ellos manantiales que fluían de sus cuevas se pensaba que eran brazos de mar, cuya función era la irrigación del entorno natural donde surgía la vida. Por ello se veneraban, igual que a los ríos y los lagos que formaban parte importante del culto acuático que signó de manera hegemónica y generalizada a los pueblos prehispánicos de Mesoamérica (Hernández y Loera 2008: 23).

Con la llegada de los españoles, muchos de los elementos prehispánicos se encubrieron con aspectos del culto católico y se expresan en la actualidad en los esquemas de las mayordomías y sistemas de cargos. Diversos autores (Montero 2001; Albores y Broda 1997) han documentado en fechas recientes la continuidad del culto al agua o a Tlaloc, deidad del agua.

Alejandro Tortolero (2006), refiriéndose al agua de los indígenas, retrata muy bien estos aspectos distintivos de la cosmovisión mesoamericana, que por supuesto están presentes en la región estudiada:

Los mexica (y en general las culturas mesoamericanas) creían que la lluvia era producida por los tlatoque, deidades que habitaban los cerros y cuya personalidad se confundía con ellos; es decir, pensaban que la lluvia no era dominada por las nubes mismas o por las deidades propiamente celestes, o por el viento u otros factores, sino por los cerros, que eran los que hacían llover y dominaban a los otros elementos, la formación de nubes, los vientos que preceden a la precipitación.

Creían que los cerros eran como recipientes que se hallaban repletos de agua (entre otras cosas) y que en época de lluvias liberaban esa agua, mientras durante la sequía la retenían. Creían que el interior de la tierra era húmedo, que las cavernas comunicaban al Tlalocan, una especie de paraíso acuático donde habitaba la deidad de la lluvia y a donde iban los muertos por el rayo, por ahogamiento o por enfermedades vinculadas a las deidades del agua. Creían que los cerros dominan la precipitación fluvial forzando la formación de nubes por las corrientes ascendentes en sus laderas; que la dominan provocando que las nubes descarguen su agua justamente en las alturas, que la dominan transformando una gran masa del agua meteórica en serpeantes y violentas esponjas para hacerla brotar en forma de límpidos manantiales hacia sus faldas (Tortolero 2006: 19-20). 
Por su parte, la antropología ha mostrado cómo en estos mismos lugares sobreviven los rituales de solicitud de lluvias que año con año llevan a cabo todavía un número considerable de campesinos, que desde sus poblados se dirigen a distintos sitios sagrados ubicados en varios puntos de los volcanes y montañas (Broda et al. 2001). Hemos encontrado evidencia empírica al respecto en el valle de Texmelucan en la fiesta del tres de mayo, día de la Santa Cruz, cuando grupos de personas (familias) ascienden al Iztaccíhuatl. De manera similar, particularmente en el caso de las comunidades situadas en las laderas de la montaña, en el Alto Cotzala, por ejemplo, todavía el día de la Santa Cruz se reúnen los parientes y el encargado o los comisionados, conviviendo en una fiesta en torno a los depósitos o las fuentes de agua, incluidos los pozos -sea de agua potable o para otros usos- y los jagüeyes, sitios que adornan con una cruz hecha de flores.

En San Agustín Atzompa se refiere que antiguamente cuando se realizaba una obra de infraestructura hidráulica o un "cal y canto" para la conducción del agua, se acostumbraba ofrecer dulces a los niños de la comunidad. La gestión del agua en varias de las comunidades de la zona de laderas está supeditada hasta el día de hoy a las directrices de la comunidad y no a criterios individuales o corporativos; esto ocurre en el Alto Cotzala y también en los alrededores del Santa Elena, afluente del Cotzala, en San Andrés Hueyacatitla, en el municipio de San Salvador El Verde.

Durante la época colonial, mientras la población autóctona incorporaba los espacios agrícolas y los elementos geográficos a los núcleos de asentamiento en un continuo, los europeos consideraban estos ámbitos como predios de explotación al servicio de la urbe y de una economía de mercado. En aquel entonces la territorialidad hegemónica se sustentó sobre la propiedad sancionada por la Corona española, con base en ordenanzas y disposiciones reales que eran ejecutadas por la Real Audiencia, delimitando el territorio en corregimientos o alcaldías mayores, en las que las autoridades locales daban fe o sancionaban actuaciones sobre el territorio y sus recursos, que podían ser interpeladas por los oidores de la Real Audiencia en tanto representantes del rey.

\section{EL PROCESO DE APROPIACIÓN DEL AGUA}

Los primeros derechos para la explotación del agua del río Cotzala se remontan a la merced que se le otorgó a Leonor de Vega el 30 de agosto de $1580,{ }^{25}$ quien rápidamente la traspasó a Gonzalo Gómez de Cervantes, el que, a su vez, obtuvo la concesión de dos mercedes: una otor-

${ }^{25}$ Esta merced se cita de manera secundaria en la "Petición del capitán don Fernando de Valdés y Portugal sobre aguas del río Cotzala (3 marzo 1671)” (AgNM, Tierras, vol. 111, $1^{\text {a }}$ pte., exp. 1, ff. 325-325v). 
gada el 25 de junio de 1593 para la instalación de un herido de molino en sus propias tierras y otra tres días después, en la que se le concedían alrededor de catorce o quince caballerías de tierra y, simultáneamente, la confirmación de "tres acequias de agua de riego" para el funcionamiento del molino de San Simón y abastecimiento de la hacienda Buenavista, de la cual también era propietario. ${ }^{26}$ Así las cosas, los derechos de agua del molino pueden considerarse como los más antiguos y, por lo tanto, de primer orden en el río Cotzala.

La importancia de la merced anterior radicó no sólo en ser la primera en contener derechos de explotación sobre las aguas del río Cotzala, sino también en las características de su uso y aprovechamiento, así como por la posición geográfica del molino y hacienda de Buenavista para quienes se otorgó dicha merced. La política agraria colonial favoreció el establecimiento y desarrollo de molinos permitiendo un uso privilegiado de los recursos hídricos. Con base en ello, la ubicación del molino en la parte central del curso del río ejerció una función de control y bloqueo sobre el caudal del Cotzala superior, aunque también afectó, como se verá más adelante, los derechos de explotación sobre el río Santa Elena, tributario del Cotzala. ${ }^{27}$

La lucha por el volumen de agua restante de los ríos Cotzala y Santa Elena no se hizo esperar. A través de la solicitud de mercedes, varios españoles obtuvieron permisos y luego las respectivas concesiones para el usufructo del preciado líquido alrededor de los años de 1613 y $1614 .{ }^{28}$ Precisamente en el año de 1613 los vecinos del Cotzala inferior empezaron a solicitar el derecho de aprovechamiento del agua: en el lado derecho Lorenzo Dávila, quien fue tesorero y escribano público de la provincia de Huejotzingo, y del otro lado Juan Gómez Caballero; ambos obtuvieron primero un permiso de aprovechamiento y, posteriormente, mercedes sobre las aguas del Cotzala. ${ }^{29}$

26 "Merced de un herido de molino a Gonzalo Gómez de Cervantes (25 jun. 1593)" (AGNM, Mercedes, vol. 19, exp. 299, ff. 126-126v); "Merced de 14-15 caballerías de tierra y tres acequias de agua de riego a Gonzalo Gómez de Cervantes (28 jun. 1593)" (AGNM, Mercedes, vol. 19, exp. 301, ff. 127-127v). Existe una referencia indirecta también en "Petición del capitán don Fernando de Valdés y Portugal sobre aguas del río Cotzala (3 mar. 1671)" (AGNM, Tierras, vol. 111, 1'a . pte., exp. 1, ff. 325-325v), donde se dice que la merced se otorgó para la hacienda de Buenavista y el Molino.

${ }^{27}$ En adelante me referiré a esta concesión en particular como merced(es) central(es).

28 "Acordado a solicitud de Cristóbal López de Acosta (28 jun. 1613)" (AGNM, Mercedes, vol. 28, exp. 331, ff. 112v-113); "Acordado a Juan Gómez Caballero (13 jul. 1613)" (AGNM, Mercedes, vol. 28, exp. 357, fs. 122v123); "Acordado a Lorenzo de Ávila (21 oct. 1613)" (AGNM, Mercedes, vol. 28, exp. 471, f. 182v); "Licencia a Juan Gómez Caballero (23 dic. 1613)" (AGNM, Mercedes, vol. 28, exp. 569, f. 233).

29 "Acordado para que se vean las aguas del río Cotzala que pide Cristóbal López de Acosta (28 jun. 1613)" (AGNM, Mercedes, vol. 28, exp. 331, ff. 112v-113); "Acordado que pide Juan Gómez Caballero (13 jul. 1613)" 
Las siguientes mercedes otorgadas sobre el río Cotzala se concedieron río abajo de las tomas de agua referidas: la merced conferida a Gaspar Varela el 10 de enero de 1614, una licencia a Cristóbal López de Acosta y una merced a doña Ana de Mendoza, esposa del doctor Santiago del Riego, oidor de la Real Audiencia de la Nueva España y primer dueño de la hacienda Mendocinas, la cual se localizaba en una posición sumamente estratégica, al ser el centro medular del valle de Texmelucan, y por su extensión, en tanto era el punto de transición entre la planicie y la zona de laderas bajas, todas concedidas durante el año de $1614 .{ }^{30}$

Posteriormente, los hacendados fijaron su interés en legalizar los ojos de agua, manantiales e, incluso solicitaron mercedes sobre veneros y arroyos que no habían sido explícitamente mencionados en las anteriores, dándose tal acaparamiento que, después de 1620, era prácticamente imposible obtener una merced de agua; véase por ejemplo el desesperado intento de los mercedarios por conseguir una en $1641 .{ }^{31}$ Una situación similar ocurrió en el repartimiento de aguas de la cuenca inferior del río Nexapa, entre los valles de Atlixco e Izúcar en el año de 1622, cuando se consideró la imposibilidad de que se solicitara más agua, aun cuando se argumentara que las haciendas contaban con una superficie mayor de tierras (Camacho 1998: 165). ${ }^{32}$

(AGNM, Mercedes, vol. 28, exp. 357, ff. 122v-123): se refieren a licencias que se solicitaron para sacar agua del río Cotzala. "Licencia a Juan Gómez Caballero para sacar agua del río Cotzala (23 dic. 1613)" (AGNM, Mercedes, vol. 28, exp. 569, f. 233): se cita que hubo contradicción de los naturales de Huejotzingo, en el margen izquierdo del documento se aclara que esta licencia no pasó porque se hizo efectiva mediante merced y se asentó en el libro de mercedes por marzo de 1615. "Acordado para que se vean las aguas que pide por merced Lorenzo de Ávila, de las aguas de los arroyos Cotzala y Santa Elena y los nacimientos de las ciénegas de Tuxco (21 oct. 1613)" (AGNM, Mercedes, vol. 28, exp. 471, f. 182v); "Merced a Lorenzo de Ávila de las aguas de los ríos Cotzala y Santa Elena y nacimientos de agua de las ciénegas de San Juan Tuxco (10 ene. 1614)" (AGNM, Mercedes, vol. 28, exp. 580, ff. 240-240v; copia de la merced anterior en AGNM, Tierras, vol. 116 exp. 1, ff. 60-64v).

30 "Merced a Gaspar Varela de las aguas de los ríos Cotzala y Santa Elena (10 ene. 1614)" (AGNM, Mercedes, vol. 28, exp. 581, ff. 240v-241); "Licencia a Cristóbal López de Acosta para regar con agua del río Cotzala (2 may. 1614)" (AGNM, Mercedes, vol. 28, exp. 762, ff. 328-328v); a pesar de la contradicción de los naturales de Huejotzingo, la anterior licencia fue otorgada. "Merced a Ana de Mendoza de las aguas de los ríos Cotzala y Santa Elena (13 oct. 1614)" (AGNM, Mercedes, vol. 29, exp. 188, ff. 131v-132; traslado de la merced anterior en AGNM, Tierras, vol. 111, $1^{\text {a }}$ pte., exp. 1, ff. 342-343).

${ }_{31} 1$ "Reconocimiento de las aguas de los ríos Cotzala y Santa Elena a petición de los mercedarios (1641)" (AGNM, Mercedes, vol. 41, ff. 110v, ss.).

${ }^{32}$ Una situación diferente parece haberse presentado en el valle de Tehuacán, donde se detectó que, a partir de 1616, el otorgamiento de mercedes de tierras y aguas aumentó considerablemente (Salazar 1993: 65-66). 


\section{EL CONFLICTO POR EL AGUA}

Definida legalmente la apropiación del agua en la región de estudio, la forma que se utilizó a partir de entonces para que otros labradores, que sucesivamente se fueron instalando en sus alrededores, pudieran acceder al agua de sus ríos, consistió en acuerdos de carácter privado entre los poseedores de las mercedes y los nuevos demandantes del líquido. Tal situación provocó que durante la segunda mitad del siglo XVII los conflictos por el agua se volvieran constantes, haciendo evidente la gran competencia por este recurso entre los distintos hacendados en un proceso que incluyó también a los pueblos de indios, quienes demandaban agua para trabajar sus tierras.

La intensidad de los conflictos por el agua en Texmelucan se agudizó durante la segunda mitad del siglo XVII, particularmente en la década de 1663-1673, cuando los propietarios de la hacienda Polaxtla, junto con otros hacendados del Cotzala inferior, se quejaron y promovieron acciones contra aquellos establecidos en el alto Cotzala y en las márgenes del río Santa Elena en la zona de laderas. Lo primero que llama la atención es la situación espacial de la hacienda San Cristóbal Polaxtla, propiedad de Blas Dávila Galindo, parte actora durante el transcurso de este litigio. Esta propiedad se encuentra ubicada en pleno valle, en el último tramo del recorrido del río Cotzala, casi a punto de desembocar al río Atoyac. Por su parte, los demandados se encuentran en una posición geográfica notoriamente distinta, cuyas propiedades, situadas en las cercanías del río Santa Elena, se encuentran localizadas en la parte alta, es decir río arriba, en altitudes incluso mayores a los $2500 \mathrm{msnm}$, en un área que es irrigada por ojos de agua y veneros que descienden por las laderas de la sierra Nevada, cuya agua se suma más abajo al río Santa Elena y luego al Cotzala.

La hacienda Mendocinas, que se localizaba en una posición sumamente estratégica, tenía su presa muy cerca de San Agustín Atzompa, compartía el agua con San Juan Tetla. Por su ubicación, esta hacienda tuvo innumerables querellas con los pobladores de ambas comunidades quienes de manera permanente y constante denunciaron el desvío del agua por parte de los propietarios de Mendocinas. San Agustín Atzompa y San Juan Tetla son pueblos antiguos del valle de Texmelucan, sus habitantes han fungido como guardianes del agua y los bosques a través del tiempo; en la actualidad forman parte de un activo Cuadro de Aguas del Alto Cotzala.

De manera particular, San Agustín Atzompa, que según Úrsula Dyckerhoff (1988) es de origen prehispánico, entra en el conflicto pues estaban en pugna dos formas distintas de utilizar y percibir los recursos naturales; los fines que buscaban ambas partes -españoles y pueblos de indios- eran distantes entre sí por las concepciones de la naturaleza y la distinta manera de relacionarse con ella. El choque de los intereses que perseguían tanto los pueblos de indígenas como 
los hacendados iba entonces mucho más allá de la producción agrícola. Lo controvertido del litigio, pero sobre todo la denuncia hecha por el capitán Domingo de Chanes sobre las derivaciones sin título que había en el río Cotzala y las quejas de los naturales de San Juan Tetla respecto de los abusos cometidos en su contra, determinaron que el 5 de noviembre de 1672 los miembros de la Real Audiencia ordenaran que se hiciera vista de ojos de los ríos Cotzala y Santa Elena y que ésta fuera ejecutada por uno de los oidores de la Audiencia.

Es importante destacar que tanto el proceso de apropiación de las fuentes de agua como las disputas por el agua en el valle de Texmelucan se corresponden con la cada vez más notoria participación de este territorio en la producción agrícola. De suerte que puede observarse cómo la dinámica hidráulica del proceso agrario en la microcuenca del río Cotzala, nuestra zona de estudio, contribuyó de manera destacada a la conformación del espacio agrícola regional del valle Puebla-Tlaxcala. Si nos atenemos a la información proporcionada por las fuentes relativas a la recaudación de los diezmos durante la época colonial, tenemos que durante el siglo XVII la economía poblana tendió cada vez más a convertirse en una economía eminentemente agrícola, orientada especialmente a la producción de tres cereales: maíz, trigo y cebada (Medina 1983; Sánchez 2001). De éstos, el maíz fue el cultivo más extendido geográficamente, en tanto que el trigo y la cebada parecieron concentrarse más en algunas áreas. Para el caso particular del trigo, con anterioridad se señaló cómo desde el inicio del siglo xvir el valle de Texmelucan surge como un nuevo centro productor de este cereal. Si durante el siglo xvi el predominio de los valles de Atlixco y San Pablo como contribuyentes de la renta decimal fue aplastante, posteriormente, durante el periodo 1602-1624, la participación de Texmelucan empieza a destacar con un porcentaje relativo del orden del $15 \%$ de la producción (cuadro 2).

Cabe resaltar además que el surgimiento del valle de Texmelucan como un nuevo núcleo productor de trigo y su notable participación dentro de la producción global del obispado ocurre precisamente en este periodo, en el que se manifiesta un claro interés por la legalización de los derechos al agua. ${ }^{33} \mathrm{Si}$ tomamos en consideración que para fines del siglo xvir la colecturía de diezmos de la producción agrícola del valle de Texmelucan se concentró en el conglomerado denominado Tlaxcala, podemos inferir la notable participación de este territorio en la conformación del espacio agrícola regional (cuadro 3).

${ }^{33}$ Interés que, como se ha señalado, se dio -con algunos altibajos- prácticamente durante todo el periodo comprendido en el cuadro 2, desde 1602 hasta 1624. 


\begin{tabular}{|c|c|c|c|c|c|c|c|c|c|}
\hline \multirow{2}{*}{ Años } & \multicolumn{2}{|c|}{ Atlixco } & \multicolumn{2}{|c|}{ San Pablo } & \multicolumn{2}{|c|}{$\begin{array}{c}\text { San Salvador } \\
\text { Texmelucan }\end{array}$} & \multicolumn{2}{|c|}{ Otros } & \multirow{2}{*}{ Prod. Total } \\
\hline & Abs. & Rel. & Abs. & Rel. & Abs. & Rel. & Abs. & Rel. & \\
\hline 1602 & 5506 & 23.1 & 15146 & 63.4 & 3230 & 13.5 & & & 23882 \\
\hline 1603 & 6094 & 26.5 & 10012 & 43.5 & 3294 & 14.3 & 3602 & 15.7 & 23002 \\
\hline 1604 & 10768 & 39.2 & 12658 & 46.1 & 4050 & 14.7 & & & 27476 \\
\hline 1605 & 5556 & 20.6 & 17074 & 63.2 & 4384 & 16.2 & & & 27014 \\
\hline 1606 & 7286 & 33 & 11116 & 50.3 & 3690 & 16.7 & & & 22092 \\
\hline 1607 & 6653 & 22.2 & 20796 & 69.3 & 2580 & 8.59 & & & 30029 \\
\hline 1608 & 7230 & 30.3 & 13081 & 54.8 & 3560 & 14.9 & & & 23871 \\
\hline 1609 & 1480 & 20.5 & 4562 & 63.2 & 1176 & 16.3 & & & 7218 \\
\hline 1610 & 8738 & 44.7 & 8496 & 43.5 & 2312 & 11.8 & & & 19546 \\
\hline 1611 & 8599 & 27.3 & 17974 & 57 & 4980 & 15.8 & & & 31553 \\
\hline 1612 & 8026 & 38.1 & 10680 & 50.7 & 2354 & 11.2 & & & 21060 \\
\hline 1613 & 8659 & 41 & 9256 & 43.8 & 3204 & 15.2 & & & 21119 \\
\hline 1614 & 4495 & 46.5 & 4044 & 41.9 & 1120 & 11.6 & & & 9659 \\
\hline 1615 & 1676 & 20.7 & 3611 & 44.6 & 552 & 6.82 & 2251 & 27.8 & 8090 \\
\hline 1616 & 15471 & 48.5 & 8058 & 25.3 & 8361 & 26.2 & & & 31890 \\
\hline 1617 & 6028 & 31.7 & 11100 & 58.3 & 1898 & 9.98 & & & 19026 \\
\hline 1618 & 7528 & 45.5 & 6389 & 38.6 & 2641 & 15.9 & & & 16558 \\
\hline 1619 & 9343 & 34.1 & 10659 & 38.9 & 7400 & 27 & & & 27402 \\
\hline 1620 & 8123 & 40.3 & 8342 & 41.4 & 3700 & 18.3 & & & 20165 \\
\hline 1621 & 9811 & 38.1 & 10403 & 40.4 & 5547 & 21.5 & & & 25761 \\
\hline 1622 & 7141 & 40.1 & 7968 & 44.7 & 672 & 3.77 & 2042 & 11.5 & 17823 \\
\hline 1623 & 4282 & 23.1 & 8700 & 47 & 3023 & 16.3 & 2520 & 13.6 & 18525 \\
\hline \multirow[t]{2}{*}{1624} & 7554 & 34.8 & 7764 & 35.8 & 3516 & 16.2 & 2856 & 13.2 & 21690 \\
\hline & & & & & Prom. & 14.9 & & & \\
\hline
\end{tabular}

Cuadro 2. Obispado de Puebla. Distribución geográfica de la producción de trigo en fanegas, ${ }^{34}$ 1602-1624. Fuente: Medina 1983.

${ }^{34}$ Las medidas equivalentes de las fanegas dependían del tipo de cereal. Por ejemplo, la fanega de sembradura de maíz $=55.5$ litros de semilla de maíz $=1 / 12$ de caballería $=3.566$ hectáreas; en tanto que la fanega de sembradura de trigo $=1 / 69$ de caballería $=0.62$ hectárea (Solano 1984: 37-38; Lanz 1982: 187-191; Prem 1988: 295; Salazar 1993: 31-42). 


\begin{tabular}{|c|c|c|c|c|c|c|c|c|c|c|c|c|c|c|c|c|c|}
\hline \multirow{2}{*}{ Años } & \multicolumn{2}{|c|}{ Tlaxcala } & \multicolumn{2}{|c|}{ Puebla } & \multicolumn{2}{|c|}{ Izucar } & \multicolumn{2}{|c|}{ Tehuacán } & \multicolumn{2}{|c|}{ Chalchicomula } & \multicolumn{2}{|c|}{ San Juan } & \multicolumn{2}{|c|}{ Zacatlán } & \multicolumn{2}{|c|}{ Resto } & \multirow{2}{*}{ Total } \\
\hline & Abs. & Rel. & Abs. & Rel. & Abs. & Rel. & Abs. & Rel. & Abs. & Rel. & Abs. & Rel. & Abs. & Rel. & Abs. & Rel. & \\
\hline 1675 & 30089 & 41.7 & 4454 & 6.2 & 1726 & 2.4 & 4294 & 5.9 & 4496 & 6.2 & 9288 & 12.9 & 450 & 0.6 & 17439 & 24.1 & 72236 \\
\hline 1676 & 25731 & 39.6 & 7888 & 12.2 & 1886 & 2.9 & 4991 & 7.7 & 4459 & 6.9 & 9546 & 14.7 & 450 & 0.7 & 9955 & 15.3 & 64906 \\
\hline 1677 & 45768 & 47.8 & 11105 & 11.6 & 1457 & 1.5 & 3575 & 3.7 & 4458 & 4.7 & 11612 & 12.1 & 450 & 0.5 & 17355 & 18.1 & 95780 \\
\hline 1678 & 46536 & 45.4 & 10354 & 10.1 & 1462 & 1.4 & 4572 & 4.5 & 10973 & 10.7 & 10118 & 9.9 & 450 & 0.4 & 18139 & 17.7 & 102604 \\
\hline 1679 & 37246 & 39 & 8458 & 8.9 & 1364 & 1.4 & 5772 & 6.0 & 12518 & 13.1 & 9306 & 9.7 & 456 & 0.5 & 20385 & 21.3 & 95505 \\
\hline 1680 & 44672 & 42.9 & 9917 & 9.5 & 1111 & 1.1 & 4353 & 4.2 & 12358 & 11.9 & 10175 & 9.8 & 456 & 0.4 & 21209 & 20.3 & 104251 \\
\hline 1681 & 36564 & 38.9 & 6152 & 6.5 & 1192 & 1.3 & 4301 & 4.6 & 12323 & 13.1 & 7941 & 8.5 & 456 & 0.5 & 24996 & 26.6 & 93925 \\
\hline 1682 & 56311 & 49.2 & 9279 & 8.1 & 1057 & 0.9 & 4259 & 3.7 & 1930 & 1.7 & 12534 & 10.9 & 456 & 0.4 & 28681 & 25.0 & 114507 \\
\hline 1683 & 57365 & 50.3 & 12544 & 11.0 & 938 & 0.8 & 4512 & 4.0 & 1498 & 1.3 & 8161 & 7.2 & 456 & 0.4 & 28515 & 25.0 & 113989 \\
\hline 1684 & 59173 & 50 & 14982 & 12.7 & 1385 & 1.2 & 4000 & 3.4 & 500 & 0.4 & 11528 & 9.7 & 456 & 0.4 & 26220 & 22.2 & 118244 \\
\hline 1685 & 38666 & 36.4 & 4221 & 4.0 & 1635 & 1.5 & 4000 & 3.8 & 11311 & 10.7 & 11946 & 11.3 & 456 & 0.4 & 33932 & 32.0 & 106167 \\
\hline 1686 & 47358 & 40.3 & 6463 & 5.5 & 1203 & 1.0 & 4351 & 3.7 & 8654 & 7.4 & 13558 & 11.5 & 456 & 0.4 & 35596 & 30.3 & 117639 \\
\hline 1687 & 35831 & 30.3 & 6448 & 5.5 & 1262 & 1.1 & 4524 & 3.8 & 9934 & 8.4 & 11572 & 9.8 & 456 & 0.4 & 48178 & 40.8 & 118205 \\
\hline 1688 & 28683 & 28.4 & 4573 & 4.5 & 1278 & 1.3 & 4465 & 4.4 & 6751 & 6.7 & 11658 & 11.6 & 456 & 0.5 & 43004 & 42.6 & 100868 \\
\hline 1689 & 37119 & 35.8 & 5064 & 4.9 & 1022 & 1.0 & 4896 & 4.7 & 10361 & 10.0 & 14947 & 14.4 & 456 & 0.4 & 29768 & 28.7 & 103633 \\
\hline 1690 & 62176 & 50.2 & 4974 & 4.0 & 1705 & 1.4 & 4196 & 3.4 & 5660 & 4.6 & 8721 & 7.0 & 456 & 0.4 & 36034 & 29.1 & 123922 \\
\hline 1691 & 56502 & 46.2 & 11363 & 9.3 & 1676 & 1.4 & 1466 & 1.2 & 7182 & 5.9 & 9500 & 7.8 & 456 & 0.4 & 34264 & 28.0 & 122409 \\
\hline 1692 & 61595 & 49.3 & 13422 & 10.7 & 1342 & 1.1 & 2309 & 1.8 & 7755 & 6.2 & 6570 & 5.3 & 456 & 0.4 & 31521 & 25.2 & 124970 \\
\hline 1693 & 71203 & 51.8 & 11431 & 8.3 & 1591 & 1.2 & 3880 & 2.8 & 6462 & 4.7 & 8000 & 5.8 & 456 & 0.3 & 34311 & 25.0 & 137334 \\
\hline 1694 & 88188 & 51.8 & 23624 & 13.9 & 2400 & 1.4 & 4781 & 2.8 & 6930 & 4.1 & 10275 & 6.0 & 456 & 0.3 & 33542 & 19.7 & 170196 \\
\hline
\end{tabular}

Cuadro 3. Obispado de Puebla. Distribución geográfica del valor del diezmo líquido (en reales) 1675-1694. Fuente: Medina 1983. 


\section{ALCANCES DEL RePARTIMIENTO DE AGUAS}

Al poco tiempo del repartimiento de aguas de 1673 las disputas y conflictos se reanudaron, confirmando la tendencia agrocerealera del territorio y en concordancia con la afluencia e incremento de nuevos productores. Durante los años siguientes, el foco de disputa se trasladó de la zona de los nacimientos y cursos superiores de los ríos, hacia la planicie situada al sur del río Cotzala, la cual se extiende hasta los cerros Coxtocan y Mendocinas y por el este hasta la ciénaga, al fondo del valle. Así parece haber sucedido en 1676 cuando se presentaron nuevas quejas de los hacendados más distantes de que el agua a que tenían derecho no les estaba llegando. No obstante, fue hasta el año de 1696 cuando se llevó a cabo una nueva inspección y medición de todo el curso de los ríos, a petición del dueño de la hacienda de San Cristóbal Polaxtla, Francisco de Luna, contador del Tribunal y Real Audiencia, quien sostenía que se estaban efectuando excesos en la derivación de agua. ${ }^{35}$

Un dato interesante de esta nueva "vista de ojos" es que permite reconocer que la red básica, esto es, legal, de los usuarios de agua no se había modificado sustancialmente de la que había establecido el repartimiento de aguas del año de 1673. Se había autorizado alguna toma adicional, con base en concesiones otorgadas durante el tiempo transcurrido y en algunos acuerdos internos. Sin embargo, un hecho notorio es que en el curso inferior del Cotzala afloró un buen número de pequeños usuarios de agua, cuyo estatus legal estaba en entredicho. El saldo que arrojó esta vista de ojos fue que, en efecto, se estaba derivando mucha más agua de la permitida: primero, por parte de los que tenían un derecho legal al usufructo de las aguas de los ríos Cotzala y Santa Elena, a lo que se sumó la derivada por un gran número de usuarios que, sin un título claro o definido, se habían establecido en la zona, atraídos por el auge de la producción cerealera.

El asunto no terminó con las disposiciones de la vista de ojos anterior, por lo que el 7 de enero de 1697 se realizó una nueva inspección de las aguas de dichos ríos. Entonces se detectó (aunque no se manejan cifras) que cuatro haciendas estaban rebasando en exceso el volumen de agua que les estaba permitido. ${ }^{36}$ Aunque en este último reconocimiento no se precisan las cantidades de agua así derivadas, los resultados o consecuencias de estas prácticas a través del tiempo fueron que en algunos tramos de su curso los ríos "se secaron temporalmente", impo-

35 "Reconocimiento de las datas y tomas de agua que hay en el río Cotzala (1696)" (AGNM, Tierras, vol. 116, exp. 1, ff. 149-195v).

36 "Reconocimiento de las datas y tomas de agua que hay en el río Cotzala (1697)" (AGNM, Tierras, vol. 116, exp. 1, ff. 204-228v) 
sibilitando con ello un repartimiento equitativo del agua; por lo que entonces aparecen como justificadas las reiteradas reclamaciones e inspecciones que tuvieron lugar sobre los ríos Cotzala y Santa Elena durante la segunda mitad del siglo xvir. En consecuencia, la nueva disposición ordenó la destrucción de los jagüeyes y la prohibición de dejar pasar el agua excedente hacia los terrenos de otros productores (propietarios o poseedores). ${ }^{37}$ Es interesante hacer notar que el término "pegujalero" que refería sobre todo a estos últimos es mucho más recurrente en las inspecciones y reconocimiento de aguas de los años de 1696-1697. Como consecuencia de la coyuntura señalada surgió un nuevo mecanismo, la instauración de guardianes del agua como una forma de controlar y regular el agua en esta parte del valle de Texmelucan. ${ }^{38}$

Los litigios y disputas por el agua pusieron en tensión los intereses de los "terratenientes de abolengo", hacendados poseedores de las primeras mercedes de tierras y aguas, y la compleja red de usuarios del agua que fue incrementándose durante el siglo XVII. En torno a estos dos aspectos gira la problemática del agua en nuestro espacio de análisis, alrededor de ellos podríamos encontrar no sólo una explicación del conflicto, sino también una interpretación de lo que se ha denominado "escasez del agua". ${ }^{39}$ Sobre el conflicto, cabe preguntarse qué es lo que hay detrás de la actitud de los "hacendados de abolengo" al querellarse de otros propietarios o productores establecidos en el área; es decir, hay que analizar tanto lo aparente o evidente como lo que hay detrás.

De entrada podemos señalar que el comportamiento de dichos hacendados pudo haber provenido de una tradición de dominio y hegemonía en la zona y/o de una defensa de los derechos a los recursos ante la embestida de un mayor número de interesados en el agua. De suerte que cuando se dio un mayor despliegue de intereses sobre el agua durante la segunda mitad del siglo XVII, se suscitaron prácticas de acaparamiento de los recursos hídricos no exentas del patrocinio directo o indirecto de los usuarios, como se puede deducir de la vista de ojos efectuada en forma previa al repartimiento de 1673. Es decir, hubo un acaparamiento del agua no sólo para el usufructo propio en beneficio de las haciendas, sino también para la

${ }^{37}$ Una problemática en torno al uso de jagüeyes en una zona cercana se puede documentar en Camacho (1998: 164-205).

${ }^{38}$ En el valle de Tehuacán se dispuso de una medida similar como consecuencia de un conflicto por el agua entre los naturales de Ajalpan y los hacendados de sus inmediaciones, en la que el alcalde mayor ordenó que se notificara "a los oficiales del pueblo para que nombrasen cada semana a dos mayordomos y a dos topiles para que cuidaran las acequias (1669)” (AGNM, Tierras, vol. 901, f. 25v, en Salazar 1993: 92).

${ }^{39}$ La referencia a escasez del agua en la documentación colonial consultada para esta investigación está planteada a partir del discurso de los hacendados españoles. 
explotación de propiedades ajenas a cambio de lo cual se recibía una compensación. Si tomamos en cuenta además que el valle de Texmelucan fue lugar estratégico para el desarrollo de la agricultura comercial durante la segunda mitad del siglo xviI, entenderemos aún más cómo los dos aspectos señalados interactuaron en el proceso histórico específico de nuestra región de estudio y el porqué de la coyuntura que desató el conflicto por el agua durante la década de 1663-1673 y que se acentuó hacia fines de aquel siglo.

Otra consideración que no se puede dejar de resaltar es que esta lucha por el agua en el sur del valle de Texmelucan involucró de manera directa a los pueblos de indios. En este sentido, la emergencia de los pueblos de la región le da una nueva dimensión a la problemática, debido a que, más que una lucha por el crecimiento de la producción agrícola para satisfacer a los distintos mercados, estamos hablando de un encuentro problemático entre dos maneras distintas de percibir y manejar los recursos naturales, en especial el agua, lo cual involucra la forma e intensidad en que se explotan dichos recursos y el grado y manera en que se usan.

Es viable plantear, asimismo, que la inconformidad de los naturales haya sido un factor a considerar en la intervención de la Real Audiencia y la ejecución del repartimiento de aguas. Si bien en las disposiciones generales de las Leyes de Indias encontramos un planteamiento dirigido al aseguramiento de las propiedades de los indios y de los recursos naturales de su entorno, su aplicación o cumplimiento no siempre se dio a cabalidad, lo que se hace evidente cuando ponemos la lupa en lo local o regional. Tal parece haber acontecido en el caso de esta región.

Con ocasión de la vista de ojos del año de 1673, los naturales o sus representantes exhibieron ante el doctor Frutos Delgado -oidor de la Real Audiencia comisionado para tal efectoquejas, peticiones, testimonios o algún documento de amparo expedido con anterioridad por el virrey o la Audiencia en relación con sus derechos al agua. No obstante la reclamación e insistencia de los pueblos de indios, las disposiciones del visitador confirmaron en lo esencial que la política del repartimiento estaba dirigida a favorecer los intereses de los labradores españoles, independientemente de las diferencias que entre sí tuvieran estos últimos.

Ello no quiere decir que las cosas no hubieran cambiado. En efecto, la problemática del agua durante una década de conflicto marcó el resquebrajamiento del estado de cosas instaurado por los "hacendados de abolengo", lo que dio paso a una etapa de intensa competencia y lucha por el recurso hídrico desde varios frentes: aparecieron nuevos hacendados que se destacaron como importantes productores y actores de la región, así como pequeños productores que se instalaron para producir con destino a un mercado local y regional que se tornaba competitivo. El término "pegujalero" fue utilizado para estos últimos durante la segunda mitad del siglo XVII, en medio de un contexto en donde los pueblos de indios que luchaban por el agua lo hacían 
más por su supervivencia y consumo local o por alianzas que por intereses estrictamente comerciales, salvo algunos casos que se mencionan de manera aislada en la documentación colonial.

El repartimiento de aguas de 1673 sentó un precedente legal para los futuros repartimientos y para el ordenamiento, manejo y aprovechamiento del agua en Texmelucan a través de los siglos. Incluso en la actualidad la estructura básica del sistema de riego se mantiene, aunque con algunos cambios derivados de la reforma agraria y de la disolución del régimen hacendario. Esa estructura mantuvo y orientó los procesos organizativos para el mantenimiento, rehabilitación, monitoreo y cuidado del agua, tanto en lo que se refiere a su vigilancia como a su generación a partir del reconocimiento de la preservación de los bosques por parte de las comunidades que habitan en la actualidad en la zona de laderas; asimismo contribuyó a construir una cultura del agua a partir del manejo y explotación que fundó el nuevo orden colonial europeo sobre las prácticas y conocimientos ancestrales de la región mesoamericana y que en el presente se expresa en una gestión del agua orientada a las directrices de la comunidad, en la que se entremezclan los saberes locales, la experiencia técnica y un discurso proclive o articulado al conocimiento científico. ${ }^{40}$

Entre los conocimientos locales podemos destacar aspectos de la cosmovisión de tradición prehispánica que se expresaron tanto a través del reconocimiento de los elementos simbólicoreligiosos, como pueden ser el culto a la montaña como generadora de vida, las prácticas de los "graniceros" y "tiemperos" (especialistas que hasta la fecha sobreviven en la región) y, de manera particular, a través de las formas comunitarias de organización del trabajo, que se expresan en que el derecho al agua no sólo se otorga a partir de la contribución material o monetaria, sino que se funda en la participación del individuo y su familia con la colectividad a través de las faenas o jornadas de trabajo comunitario, en las fiestas, tradiciones y compromisos de la comunidad. En suma, sólo a partir de la participación en el trabajo comunitario se adquiere el derecho al agua.

Cabe señalar que, no obstante lo pertinente del repartimiento de aguas de 1673 para la solución del conflicto y su carácter fundamental para los subsecuentes, la denominada escasez del agua no es vista aquí como una crisis ambiental, sino como una escasez relativa consecuencia de la demanda de agua que los niveles de producción requirieron durante la segunda mitad del siglo XVII, lo que puede colegirse de la aportación de Texmelucan en la recaudación de los

${ }^{40}$ Tortolero (2006) ha señalado que el manejo del agua por parte de los indígenas durante la época prehispánica se caracterizó más por su sentido técnico y que fue durante el periodo colonial cuando se dio la transición hacia un manejo de tipo científico que partió de una consideración y racionalidad diferentes sobre los recursos y el territorio. 
diezmos en el obispado poblano. Podemos sostener que los recursos naturales (principalmente agua y suelos) favorecieron de manera particular la inserción de este territorio en el desarrollo regional del valle Poblano-Tlaxcalteca, participación que se sustentó en la dinámica y aprovechamiento de la microcuenca del río Cotzala.

Otro resultado importante del repartimiento del agua es el surgimiento de la figura de los guardianes del agua. A partir de entonces, todos los interesados, incluso los pueblos de la región, tuvieron una figura que les permitía tener mayor certidumbre y seguridad respecto al abuso de muchos de los hacendados de la región. La emergencia de los guardianes del agua en el valle de Texmelucan constituye un referente importante dentro de la historiografía agraria colonial mexicana, dado que implica un esquema de organización para la gestión y manejo del recurso desde este periodo y abona a la discusión teórica centralización/descentralización del agua planteada por Sonya Lipsett (1999). Jacinta Palerm ha destacado que, en el caso de México, desde la época colonial hasta la segunda mitad del siglo xIx:

Encontramos una situación teóricamente anómala en el sentido de que no parece haber organizaciones o instituciones que asocien a las comunidades, haciendas y ciudades que comparten infraestructura hidráulica. Los estudios existentes señalan la ausencia de instituciones para la gestión del agua.

Por ello se entiende que no había un comité o presidente electo por el conjunto de regantes, que no había personal empleado por el conjunto de regantes y que tampoco había una administración por el Estado (Palerm 2009: 11-12).

El estudio de las formas organizativas de la Nueva España y México reviste entonces un especial interés por la aparente anomalía teórica señalada por Palerm (2009). El estudio que aquí se presenta, al igual que otro caso, la llamada Sentencia Peñafiel para el río Nexapa en el estado de Puebla (1635), tienen la característica de que en el repartimiento se indica la contratación de guardias del agua. Ello implica que los usuarios deben reunirse y concertar la contratación, así como recabar lo correspondiente al pago de los guardias, lo que a su vez implica la existencia de una organización.

\section{CONCLUSIONES}

En este trabajo hemos podido observar que la influencia y la posición de dominio y poder de algunos hacendados se tradujeron en acciones dirigidas al control y bloqueo de los recursos hídricos en su conjunto. Asimismo, cómo a través del conflicto se pone en tela de juicio la vieja 
red de dominio, lo que permitió la emergencia de algunos nuevos hacendados y, a su vez, se perfiló un nuevo proceso en el que tuvieron cabida un buen número de pequeños y medianos productores quienes, sucesivamente, se fueron instalando en la zona de estudio. Al mismo tiempo, encontramos una firme respuesta por parte de la población autóctona en defensa de un recurso fundamental para su supervivencia y desarrollo.

Si bien la participación y predominio de algunos de los propietarios del área supuso cierta capacidad de concentración de los recursos, al mismo tiempo, el marcado interés en la producción cerealera durante el siglo XVII contribuyó de manera significativa a la intensificación de los conflictos por el agua. Vemos que desde el repartimiento de aguas de 1673 se perfiló una tendencia hacia el surgimiento de pequeños productores o pegujaleros que, instalados en medio o en la periferia de las grandes propiedades, paulatinamente fueron incrementando la demanda de agua.

De los litigios y disputas por el agua en el valle de Texmelucan se pueden destacar dos aspectos importantes: el primero descansa en los intereses y motivaciones de los "terratenientes de abolengo", es decir, de aquellos hacendados poseedores de las primeras mercedes de tierras y aguas y que fueron herederos de las más vastas y ricas propiedades del valle, interesados en controlar el uso y manejo de recursos hídricos del valle. El segundo aspecto atañe a la compleja red de usuarios del agua que para la segunda mitad del siglo Xvir se habían establecido en los alrededores de los ríos y manantiales del área.

El estudio de las formas organizativas de la Nueva España y México reviste un especial interés, como por ejemplo el hecho de que, desde el siglo xVII, el repartimiento indica la contratación de guardias del agua, es decir, que los usuarios deben reunirse y concertar sus intereses. Podemos concluir que este estudio, como otros, permite comenzar a contar con la suficiente información sobre la evolución, a largo plazo, de la gestión del agua en México. 


\title{
CONFORMACIÓN HISTÓRICO-TERRITORIAL Y PRODUCTIVA EN LA SEGUNDA MITAD DEL SIGLO XIX EN NATIVITAS
}

\author{
Guillermo Paleta Pérez
}

\section{INTRODUCCIÓN}

$\mathrm{E}$ n un recorrido de campo por la región, podemos observar los cascos viejos de las haciendas ubicadas en lo que hoy es el municipio de Nativitas: Santa Águeda, Los Reyes, Segura-Michac, Santa Elena, Santo Tomás Xoxtla, San Antonio Michac (hoy colonia San Antonio Teacalco) y Santa Clara Atoyac (mapa 12). Santa Águeda fue una de las haciendas más representativas de Tlaxcala dentro del proyecto nacional del México industrial del siglo XIx (Anónimo 1906). Su actividad central fue la producción de leche, contaba con criadero de ganado holandés y en sus instalaciones se erigió la primera planta pasteurizadora de América Latina; destaca, asimismo, que fue una de las primeras haciendas del país en tener servicio telefónico. Santa Águeda logró, junto con otras haciendas de Nativitas, establecer un sistema de producción agropecuaria a partir del control de los recursos naturales de la zona. Hacia finales del siglo xix la mayoría de las tierras agrícolas fértiles del suroeste de Tlaxcala estaban en manos de las haciendas: en los distritos de Hidalgo y Zaragoza había 37 haciendas y 33 ranchos (Tello et al. 2010) (mapa 11).

El acceso al agua de los ríos Atoyac y Zahuapan, además de abrir la posibilidad de un desarrollo agropecuario y crecimiento industrial desde aquel entonces, generó ríspidas relaciones entre los hacendados y las comunidades vecinas. Las haciendas locales llegaron a tener producciones importantes de ganado, leche, cereales y maíz para abastecer al mercado regional y nacional, particularmente de las ciudades de Puebla y de México. En el último tercio del siglo xIx, la región de Nativitas, conocida como ciénega de Tlaxcala y habitada históricamente por población indígena, se conformó como una zona de alta producción agropecuaria con acceso 
al sistema ferroviario, a una compleja red de negocios entre haciendas de la zona y una fuerte presencia de población española.

En este capítulo se aborda el proceso de estructuración territorial en Nativitas, Tlaxcala, desde una perspectiva de larga duración, cuyo eje articulador es el sistema de haciendas agropecuarias en la segunda mitad del siglo XIX, cuando la explotación de los recursos naturales por parte de las haciendas locales modeló su territorio. El análisis de larga data nos permite entender la reconfiguración de un territorio rural inmerso actualmente en situaciones dinámicas de integración y centralización política y económica. Desde esta perspectiva, la cultura se observa como heterogénea y conflictiva, en ella convergen múltiples maneras de relaciones sociales y formas de acercamiento a la naturaleza, lo que implica entender la diferencia cultural como desigualdades sociales y políticas. Por ello, junto con Braudel (1989), podemos decir que la cultura se convierte en socialmente constituida y socialmente constituyente de los sujetos enmarcados en procesos de corta y larga duración.

Nativitas es un municipio que se encuentra en el Altiplano central a 2200 metros sobre el nivel del mar. Se localiza al sur del estado de Tlaxcala y colinda al norte con los municipios de San Damián Texóloc y Santa Ana Nopalucan; al sur colinda con el estado de Puebla; al oriente se establecen linderos con los municipios de Tetlatlahuca, Santa Apolonia Teacalco y Zacatelco y al poniente colinda con el municipio de Tepetitla de Lardizábal (INAFED s/f). El objetivo de este capítulo es mostrar el contexto social y productivo en el que las haciendas de Nativitas, pertenecientes al antiguo distrito de Zaragoza, definieron, en buena medida, la organización del espacio geográfico de la región al controlar las mejores tierras de cultivo y el agua de riego proveniente de los ríos Atoyac y Zahuapan.

El texto está organizado en tres apartados: el primero se refiere el contexto histórico de Nativitas; en el segundo se analiza la organización territorial del distrito de Zaragoza y en el tercero se aborda la producción de las haciendas de la región y el proceso de dotaciones ejidales de Nativitas. La información que nutre este trabajo es producto de dos estancias de campo en 2010 y 2011 en Nativitas y la región de la ciénega de Tlaxcala, así como de la consulta de los Archivos Históricos Parroquial de Santa María Nativitas, de Tlaxcala en San Pablo Apetatitlán, y del Registro Agrario Nacional. 


\section{CONTEXTO HISTÓRICO DE NATIVITAS}

El territorio en el que se asienta el municipio de Nativitas tuvo una importante presencia humana en la época prehispánica, ${ }^{41}$ fue habitado por pueblos que practicaban la agricultura y que estuvieron bajo la influencia del señorío olmeca-xicalanca. ${ }^{42}$ Nativitas forma parte de la antigua ciénega de Tlaxcala, en el suroeste de Tlaxcala, que se caracterizó por la variedad de recursos naturales -especialmente agua en abundancia- y la fertilidad de sus suelos, lo que permitió altas concentraciones de población (Cesín et al.2010). Nativitas se estableció, a manera de isla, al pie de una cadena de colinas entre las cabeceras de los señoríos prehispánicos de Quiahuiztlan y Ocotelulco (Serrano 2005); destacó su cercanía a los señoríos de Huejotzingo y Cholula.

La abundancia de recursos hídricos con que cuenta la zona, las aguas de los ríos Atoyac y Zahuapan ${ }^{43}$ mantos freáticos y manantiales permitieron que se desarrollara una agricultura de irrigación y de humedad. En la época prehispánica se edificaron terrazas en las laderas de las lomas y se diseñaron técnicas para el control y aprovechamiento del agua de lluvia, además se construyeron canales, diques, camellones y chinampas (González 2008). Entre los cultivos destacados en esa época sobresalen: chile, amaranto, siete variedades de maíz, tres especies de calabaza, cuatro de frijol, aguacate y tomate (Serrano 2005).

La región de Nativitas fue evangelizada por frailes franciscanos en el siglo xvi. Hacia la segunda mitad de esa centuria se congregó como lugar central de la región (Tyrakowski 2003). $\mathrm{Al}$ respecto, el historiador Muñoz Camargo señala:

Otro pueblo que se llama Santa María Nativitas [...] es pueblo nuevamente congregado de unos indios que estaban derramados en unas ciénagas junto a esta poblazón, que, por su apartamiento, no alcanzaban a tener doctrina, porque carecían de ella por su división. Y, con acuerdo del virrey don Martín Enríquez, se fundó en este nuevo asiento otro monasterio de frailes de la orden del señor

${ }^{41}$ La antigua ciudad de Cacaxtla y Xochitécatl exhibe su relevancia como centro político, militar y religioso en la región Puebla-Tlaxcala.

42 "Los olmeca-xicalancas fueron un grupo étnico importante durante la transición del clásico terminal al posclásico temprano con importante presencia en el Altiplano Central [...] a pesar de la importancia que tuvo en cierto momento histórico, terminó disgregándose y fundiéndose con los grupos nahuas, causantes no sólo de las derrotas militares y de su expulsión de las tierras tlaxcaltecas, sino de su transición convirtiéndose en la etnia dominante en la última fase del desarrollo pre-colombino" (Guevara 1991: 132).

${ }^{43}$ A principios del siglo xx se aprovecharon las aguas del río como fuerza motriz y para dotar a las poblaciones de Tlaxcala, Chiautempan y Apetatitlán de alumbrado eléctrico (Anónimo 1906: 49). 
San Francisco. Este lugar es muy abundante de maíz y de legumbres; participa de muchas aguas y ciénagas, y de los ríos que pasan cerca de allí (descripción de Muñoz Camargo en Serrano 2005: 20).

La construcción del convento franciscano se inició en 1569 y finalizó en 1585. La iglesia de la Natividad de María se construyó alrededor de 1600, atendía a 16 iglesias de visita y a sus respectivas poblaciones: San Damián, San Bartolomé, Santa Cruz, Santa Isabel, Santa Ana, Santa Bárbara, Santa Elena, Santo Tomás, San Juan, San Rafael, Santiago, San Vicente, San Bernabé, Santa Apolonia y San Miguel (Serrano 2005: 21). Iniciaba así una compleja relación entre población española y una abundante población indígena.

En los registros de los bautizos de los feligreses del pueblo de Santa María Nativitas de la primera mitad del siglo XVII se refieren los barrios indígenas, ${ }^{44}$ asimismo, en los apuntes del libro parroquial se menciona a los barrios de San Bernabé y Santa Apolonia, los pueblos de San Miguel, San Rafael y de San Vicente. A partir de 1640 es explícita la anotación de "indio" o "india" y los lugares de origen de los feligreses; desde 1649 se asienta en los libros de la parroquia el bautizo de españoles. La parroquia también menciona el barrio de San Bernabé (enlista 11 casiques [sic]), barrio de San Juan, barrio de Jesús (1 casiques [sic]), barrio de Santa Apolonia (21 casiquez [sic]). Además, se registran viudos, viudas, solteros, doncellas y caciques. Los enlistados para 1649 son 326 habitantes.

También existe en la parroquia de Nativitas un padrón general de sus pueblos dependientes para el año de $1815 .{ }^{45}$ Del pueblo de San Rafael Tenenyecac se enlistan 70 habitantes, de Santa Inés Xochitecatitla 191, de Santiago Michaca 140, de Santo Tomas Xochitlán 53 personas, de Santa Elena 36 y de San Vicente Xiloxochitlan 55 personas. En las haciendas de Los Reyes y Santa Ana hay el registro explícito de población española: de Los Reyes 85 personas, 28 de ellos "son españoles y gentes de razón"; de la hacienda de Santa Ana 89 personas, 21 españoles. Las haciendas de la zona establecieron formas productivas extensivas e intensivas que requirieron abundante mano de obra, esta es la razón de la convivencia en la región de trabajadores con diversa adscripción étnica.

A mediados del siglo Xvi se inició la ocupación de tierras de Nativitas por parte de españoles, con el paso de los años sus propiedades se ampliaron a expensas de las tierras comunales

${ }^{44}$ AHPNT, sección: Sacramental, serie: Bautismos Indios 1632-1652, vol. 5 legajos, caja 1, legajo 1 (16411652), ff. 1-2. Los libros de la parroquia no ofrecen información de la filiación étnica de la población.

${ }^{45}$ AHPNT, sección: Disciplinar, serie: Padrones, vol. 1 legajo, caja 75, legajo 1 (1749-1933), Padrón de Indios de esta cabecera de Santa María Natívitas que para el cumplimiento de N. S. M. Iglesia es perteneciente al año de 1815. Fecha de revisión: 16 de julio de 2009. 
indígenas, la actividad ganadera acentuó este proceso; los hacendados argumentaban que el pastoreo se realizaba en terrenos baldíos de los pueblos vecinos (Giordano 2011). El cuadro 4 muestra la importante cantidad de haciendas existentes en Nativitas hacia 1765. Cabe destacar que las haciendas, como espacios productivos y de organización social complejos, poseían también uno o varios ranchos, pueblos o barrios dependientes de ellas. Fueron comunes los conflictos entre comunidades y haciendas por la tierra y el agua. Para 1689 la cabecera de Santa María Nativitas apoyó a Santa Ana Acolco y a Santa Bárbara Tamazolco en el pleito que sostenían con la hacienda de Santa Ana Atoyosalco. Según Giordano (2011) la cabecera municipal apoyó a los pueblos ante el temor de tener que albergar a sus habitantes, en caso de que perdieran los litigios con las haciendas.

El número de haciendas y el modelo de distribución en la ciénega de Tlaxcala se modificaron a inicios del siglo xx (Tyrakowski 2003: 166) a raíz del desagüe de la ciénega (mapa 17). Esta desecación y la construcción de infraestructura tenían por objetivo drenar las aguas de los ríos Atoyac y Zahuapan que inundaban tanto los pueblos como las tierras de las haciendas. Es importante recordar que en la segunda mitad del siglo XIX varias regiones de nuestro país experimentaban condiciones similares de contención y desagüe, situación que se enmarca en la política de Estado de desecación de lagos y lagunas establecida desde mediados del siglo XIX hasta mediados del xx, bajo "el argumento 'higienista' de que lagos y lagunas eran 'ciénegas', es decir, aguas estancadas" (García 2009: 220). La desecación de la ciénega de Tlaxcala inicia en 1869 y continúa después de 1900. En la tercera década del siglo xx se deseca la laguna de San Juan Molino Atoyac o El Rosario, situada en el ex distrito de Hidalgo y en Nativitas, la cual tenía en 1931 una extensión de 250 hectáreas (Tello et al. 2010). El desagüe de la ciénega significó el inicio de varios procesos de transformación del paisaje de los humedales (González 2008).

Esta política pública aplicada a nivel nacional también pretendía abrir nuevos territorios a la agricultura. Durante el gobierno de Porfirio Díaz se realizaron diferentes obras hidráulicas que pretendían desecar lagos y ciénegas para abrir al regadío tierras descubiertas y dotar de agua a industrias y ciudades (Boehm 2003). La desecación de vasos lacustres tuvo como objetivo la obtención de tierras con alto grado de fertilidad, por ello las tierras regadas por lagos y lagunas fueron concebidas como un recurso agrícola plausible (García 2009: 219), lo que implicó el principio de una política hidráulica en el país. Las constantes inundaciones contribuyeron asimismo a la reorganización geográfica regional en tanto que algunos pueblos se vieron en la necesidad de reubicarse, recuerdo que aún existe en la memoria de los habitantes de Nativitas; también fue el caso de la hacienda de Los Reyes que se inundó varias veces por el desbordamiento del río Zahuapan. Los propietarios de las haciendas desecaron extensiones de la ciénega desde la segunda 


\begin{tabular}{|c|c|c|c|}
\hline Haciendas 1712/1765 & $\begin{array}{l}\text { Primera } \\
\text { mención }\end{array}$ & Ranchos $1864 / 1893$ & $\begin{array}{l}\text { Pueblos o barrios adjuntos } \\
\text { existentes y abandonados }\end{array}$ \\
\hline San Antonio & 1712 & San Antonio Michac & Santa Cecilia Cozamalco \\
\hline \multicolumn{4}{|l|}{ Santa Bárbara } \\
\hline San José Tenexac y Buenaventura & $\begin{array}{l}1712 \\
1602\end{array}$ & & \\
\hline Nuestra Señora del Rosario & 1712 & Terrenos el Rosario & \\
\hline Santa Elena Atoyac & 1605 & Santa Elena & \\
\hline El espíritu Santo & 1712 & & \\
\hline Nuestra Señora de la Concepción & 1712 & Concepción & \\
\hline La Encarnación & 1712 & & \\
\hline Santa Ana Atoyasolco & 1712 & Santa Ana Portales & Santa Ana (Acolco) \\
\hline Santa Bárbara & 1712 & Santa Bárbara & Santa Bárbara Temazolco \\
\hline $\begin{array}{l}\text { Santa Ágata (pertenecía } \\
\text { a en } 1791 / 1794 \text { a la hacienda } \\
\text { Santa Ana Atoyasolco) }\end{array}$ & 1610 & Santa Águeda & $\begin{array}{l}\text { Santa Águeda Michtetelco } \\
\text { Santa Elena Michacatitlán }\end{array}$ \\
\hline Santo Tomás & 1620 & Santo Tomás Xoxtla & Santo Tomás Xoxtlan \\
\hline Santiago Michac La Segura & 1600 & Santiago Michac & Santiago Michac \\
\hline Santa Clara & 1712 & Santa Clara Atoyactenco & \\
\hline $\begin{array}{l}\text { San Juan Misco/Mixco y San } \\
\text { Damián }\end{array}$ & 1712 & & Mixco \\
\hline \multicolumn{4}{|l|}{ Santa Elena } \\
\hline \multirow[t]{4}{*}{$\begin{array}{l}\text { San Juan Bautista y San Miguel } \\
\text { Teopanzolco }\end{array}$} & & $\begin{array}{l}\text { San Juan Bautista } \\
\text { Terrenos Teopanzolco }\end{array}$ & \\
\hline & & Rancho San Rafael & Rafael Tenanyecac \\
\hline & & Rancho del Jagüey & \\
\hline & & Rancho Capula & \\
\hline Los Santos Reyes & 1765 & Los Santos Reyes & \\
\hline Nuestra Señora de los Dolores & 1642 & Los Dolores & \\
\hline
\end{tabular}

Cuadro 4. Haciendas y pueblos adjuntos en

Nativitas, 1765. Fuente: Serrano 2005: 27-28. 
mitad del siglo xIX para sembrar trigo y maíz. Indígenas y población mulata fueron empleados en las haciendas y en las obras de canalización del río Zahuapan (Tyrakowski 2003).

Contener las inundaciones de los ríos Zahuapan y Atoyac fue una tarea que requería de trabajo comunitario abundante y coordinado, el que no estuvo exento de diferencias entre algunas localidades vecinas. ${ }^{46}$ Muestra de estos diferendos se exhibe en una carta escrita por el señor Miguel Balión, jefe de familia de Nativitas, a la presidencia municipal en la que informaba en 1899 que existía un bordo en el río Atoyac que debía ser removido por representar un peligro potencial para el puente recién construido y para las poblaciones vecinas, por lo cual hacía la petición a pobladores de los pueblos de Xochitecatitla, San Rafael Tenanyecac y San José Atoyatenco para su colaboración en dichos trabajos de remoción. Como respuesta, estas comunidades mostraron a las autoridades locales y al señor Bailón una carta del "Gobierno Superior" en la que se les excluía de este tipo de actividades. Sin embargo, las autoridades locales obligaron a estos pobladores a trabajar en las obras de remoción porque representaban un beneficio común. La carta del señor Bailón ilustra la insistencia para que los habitantes del municipio cumplieran con obras de desazolve que evitarían inundaciones en los terrenos aledaños.

En San Vicente Xiloxochitla se construyó en 1901 una plazuela y se abrió un carril haciendo uso de trabajo comunitario. De la misma manera se realizaron obras de desazolve en el río Zahuapan. Pueblos vecinos a San Vicente manifestaron su descontento en torno al trabajo comunitario denominado "ronda". Un ejemplo es la solicitud de los vecinos del barrio de Jesús de los Tres Caminos al Ayuntamiento de Nativitas de que se asignara a un agente municipal que participaría como intermediario ante los conflictos con el barrio del centro de Nativitas. En la carta, firmada por 26 vecinos del barrio de Jesús, solicitaban se llamara la atención a quienes no cumplían con el servicio de rondas en cada uno de los barrios, se pedía que se registraran los conflictos por el incumplimiento de esas obligaciones:

porque ellos siempre han querido que sus servicios de ronda y demás municipales solo sean en su provecho, y sin embargo exigen que nosotros les impartamos nuestros servicios, lo que resulta que esto redunde en perjuicio nuestro. La falta de reciprocidad, misma que ya ha causado bastantes disgustos porque hay además la circunstancia de que los vecinos del centro están etiquetados con nosotros por las cuestiones políticas en que hemos sido contrarios... ${ }^{47}$

${ }^{46}$ AHET, sección: Justicia y Gobernación, 1901, caja 10, exp. 27, f. 4.

${ }^{47}$ AHET, sección: Justicia y Gobernación, 1905, caja 63, exp. 12, f. 2. 
Las haciendas ubicadas en lo que hoy es el municipio de Nativitas se dedicaron a la producción lechera, ganadera, de forraje y maíz, que abastecía los mercados nacionales a través del ferrocarril interoceánico el cual conectaba la región con el puerto de Veracruz y con la ciudad de México (Salas et al. 2011). Sus propietarios, en su mayoría españoles, lograron amasar importantes fortunas que invirtieron también en la industria textil de Tlaxcala y de Puebla. Fue tal la importancia de la presencia española en Nativitas que esta localidad se conocía como la "España chiquita". En 1901, Santa Águeda fue la hacienda con mayor población (cuadro 5), lo que estaba relacionado con su importante producción agropecuaria en una zona de por sí productiva.

El ferrocarril llegó al municipio de Nativitas hacia 1905. La estación del ferrocarril se encontraba en San Miguel Analco, localidad perteneciente al municipio, donde hacían parada diaria tres pares de trenes. El ferrocarril también contribuyó al desplazamiento de personas por motivos religiosos, ${ }^{48}$ lo que incrementó la afluencia al santuario de San Miguel del Milagro, el segundo más importante de la entidad (Tyrakowski 2003). De la misma manera, Nativitas articulaba vías comerciales hacia Tlaxcala, Puebla y México. Las haciendas locales más importantes tenían vías de tren particulares para trasladar sus productos a la estación de San Miguel Analco, hoy día aún pueden observarse restos de estos rieles.

\section{LA ORGANIZACIÓN TERRITORIAL DEL DISTRITO DE ZARAGOZA}

Hacia finales del siglo xix Tlaxcala estaba dividido en seis distritos políticos: Juárez o Huamantla, Cuauhtémoc, Morelos o Tlaxco, Ocampo o Calpulapan, Hidalgo o Centro y Zaragoza o Zacatelco, ${ }^{49}$ que conformaban 35 municipalidades (mapa 3). En aquellos años se tenía el

${ }^{48}$ Nativitas experimentó un dinamismo religioso porque el tren redujo considerablemente las distancias geográficas. El intercambio comercial a pequeña escala también creció de la mano con las rutas religiosas. El movimiento de población por motivos religiosos ha sido documentado para el caso de comunidades obreras textiles en la región de Cholula ( $c f r$. Paleta 2008).

${ }^{49}$ La cabecera de este distrito era el pueblo de Santa Inés Zacatelco. Los pueblos o comunidades que integraban el distrito eran: Santa María Acxotla, Santa Isabel Xiloxochtla, Santiago Tlacochcalco, Tepeyanco, San Juan Huactzinco, San Gerónimo Tzalcuapan, San Andrés Cuamilpa, San Damián Texoloc, San Vicente Xiloxochiuacan, San Miguel del Milagro, San Rafael Tenanyecac, San Miguel Xoxhitecatitla, Santiago Michac, Nativitas, Santo Tomás, Santa Isabel Tetlatlahuaca, San Lorenzo Axocomanitla, Santa Inés Zacatelco, Santa María Atzama, Santa Catarina Ayometla, San Antonio Acuamanala, San Luis Teolocholco, San Marcos 


\begin{tabular}{|c|c|c|c|}
\hline Pueblo, barrio, estación, hacienda & Hombres & Mujeres & Total \\
\hline Pueblo de Santa María Nativitas & 371 & 388 & 759 \\
\hline Santa Apolonia Teacalco & 449 & 484 & 933 \\
\hline Santo Tomás, hoy La Concordia & 161 & 166 & 327 \\
\hline San Miguel del Milagro & 237 & 221 & 458 \\
\hline San José Atoyatenco & 213 & 208 & 421 \\
\hline Santiago Michac & 326 & 322 & 648 \\
\hline San Vicente Xiloxochiuhcan & 181 & 184 & 365 \\
\hline San Rafael Tenanyecac & 206 & 217 & 423 \\
\hline San Miguel Xochitecatitlan & 288 & 299 & 587 \\
\hline Santa Elena Michacatitlan & 58 & 48 & 106 \\
\hline Barrio Capula & 169 & 158 & 327 \\
\hline Estación Analco & 6 & 4 & 10 \\
\hline Hacienda Santa Ana Portales & 41 & 35 & 76 \\
\hline Santa Águeda & 88 & 90 & 178 \\
\hline Los Reyes & 91 & 69 & 160 \\
\hline San Juan Mixco & 62 & 40 & 102 \\
\hline Santa Clara & 49 & 40 & 89 \\
\hline Santiago Michac & 47 & 39 & 84 \\
\hline San Antonio Michac & 45 & 39 & 84 \\
\hline Santa Elena Atoyac & 30 & 26 & 56 \\
\hline Santo Tomás Xoxtlan & 25 & 24 & 49 \\
\hline TOTAL & 3143 & 3101 & 6244 \\
\hline
\end{tabular}

Cuadro 5. Población de la Municipalidad de Nativitas (1901). Fuente: elaborado con base en AHET, sección: Justicia y Gobernación, 1901, caja 4, exp. 26, ff. 3-4. 
registro de dos ciudades, dos villas, 130 pueblos, una colonia, 113 haciendas y 148 ranchos. El estado tenía una extensión de 4132 kilómetros cuadrados (Anónimo 1906). Para darnos una idea general de sus condiciones podemos mencionar que el Censo General de 1900, publicado en 1902, señala que Tlaxcala tenía 172315 habitantes. Para 1901, la municipalidad de Nativitas en el distrito de Zaragoza se encontraba organizada en pueblos, haciendas, un barrio y la estación del ferrocarril, y su población ascendía a 6244 habitantes (cuadro 5).

El 17 de agosto de 1901 los pobladores del distrito de Zaragoza dieron a conocer al gobierno del estado de Tlaxcala los datos sobre los itinerarios, producciones agrícolas, pecuarias y carretas en Nativitas (cuadro 6).

\begin{tabular}{|c|c|c|c|c|c|c|c|}
\hline Itinerarios & $\begin{array}{l}\text { Ganado } \\
\text { vacuno }\end{array}$ & $\begin{array}{l}\text { Ganado } \\
\text { caballar }\end{array}$ & $\begin{array}{c}\text { Ganado } \\
\text { mular }\end{array}$ & $\begin{array}{c}\text { Ganado } \\
\text { lanar }\end{array}$ & $\begin{array}{l}\text { Ganado } \\
\text { porcino }\end{array}$ & $\begin{array}{l}\text { Carros de } \\
2 \text { ruedas }\end{array}$ & $\begin{array}{c}\text { Carros de } \\
4 \text { ruedas }\end{array}$ \\
\hline $\begin{array}{l}\text { Caminos a la cabecera de Nativitas y sus pueblos de Santa Apolonia, Xochitecatitla, } \\
\text { San Miguel del Milagro, Santiago Michac, Tenanyecac, Atoyatenco, San Vicente } \\
\text { y La Concordia, así como varias fincas inmediatas. }\end{array}$ & 1273 & 48 & 482 & 262 & 6 & 30 & 11 \\
\hline
\end{tabular}

En 1905 la Secretaría de Fomento realizó un conteo del número de haciendas y ranchos en el estado de Tlaxcala. En el cuadro 7 se señalan las características de pertenencia de la municipalidad de Nativitas y del distrito de Zaragoza. Como puede observarse, los principales cultivos de las haciendas y ranchos son el maíz y el trigo. En este mismo cuadro Ignacio Morales aparece como propietario de varias de las fincas: Santa Águeda, Dolores y Santiago Michac, situación que se explica porque estos empresarios mantenían intereses productivos diversos; Ignacio Morales también era propietario de la fábrica textil La Trinidad ubicada en Santa Cruz, Tlaxcala.

De acuerdo con la información reportada por La Antigua República (Anónimo 1906: 43) acerca del "Establo y criadero de Santa Águeda", poseía uno de los establos más modernos en México, ocupaba una extensión de 31 hectáreas dentro de la hacienda y estaba organizado en cuatro departamentos: sementales: 20 toros padres y 68 toretes; ordeña: 390 vacas y 400 crías; vaciada: 390 vacas y 264 terneras; veterinaria: 14 vacas próximas y 4 en la sala de partos. En suma, el ganado ascendía a 1550 cabezas, lo que nos da una idea de la importancia en la producción del establo de Santa Águeda.

Contlatzinco, Santo Toribio Xicotzinco, San Francisco Papalotla, San Cosme Mazatecochco, San Miguel Tenancingo, San Pablo del Monte (Anónimo 1906: 69).

Cuadro 6. Caminos, ganado e inventario vehicular en Nativitas (1901). Fuente: Elaborado con base en AHET, sección Justicia y Gobernación, 1901. Caja número 10, exp. 45, fs. 1 . 


\begin{tabular}{|c|c|c|c|c|c|c|}
\hline Nombre del dueño & Nombre de la finca & $\begin{array}{c}\text { Extensión } \\
\text { (ha) }\end{array}$ & Áreas & Centiáreas & Valor fiscal finca & Productos \\
\hline Ignacio Morales Benítez & Sta. Águeda & & & & 50000 & Maíz y trigo \\
\hline Ignacio Morales Benítez & Dolores & & & & 35000 & Maíz y trigo \\
\hline Bernardo y Alfredo Caso & Michac & & & & 40000 & $"$ \\
\hline Bernardo y Alfredo Caso & Sta. Bárbara & & & & 40000 & $"$ \\
\hline Bernardo y Alfredo Caso & Sto. Tomás & 526 & 79 & 00 & 60000 & $"$ \\
\hline Bernardo y Alfredo Caso & Sta. Clara & 575 & 95 & 67 & 80000 & $"$ \\
\hline Bernardo y Alfredo Caso & Sta. Ana Portales & 476 & 53 & 87 & 70000 & $"$ \\
\hline Ignacio Morales Benítez & Santiago Michac & 513 & 18 & 24 & 62000 & $"$ \\
\hline Blas Reguero y Caso & Los Reyes & 531 & 81 & 71 & 82000 & $"$ \\
\hline Ricardo Carvajal & Hda. Mixco & 867 & 01 & 20 & 54500 & $"$ \\
\hline Román Cervantes & Hda. Buenavista & & & & 8222 & $"$ \\
\hline Baldomero Rejón & Hda. Santa Elena & 558 & 05 & 07 & 85000 & $"$ \\
\hline Félix Pérez & S. Bartolo & 1227 & 26 & 53 & 20000 & $"$ \\
\hline Félix Pérez & S. Jacinto & & & & 36000 & $"$ \\
\hline Juan Pérez & S. Miguel Xoxtla & & & & 20000 & $"$ \\
\hline Mariano Medel & Rcho. San José & 310 & 84 & 72 & 927 & $"$ \\
\hline Mariano Medel & Rcho. Concepción & & & & 720 & $"$ \\
\hline Francisco Cotarelo & Rcho. Buenavista & 37 & 59 & 86 & 6000 & $"$ \\
\hline José M. Calvario & Rancho & & & & 1000 & $"$ \\
\hline Secundino Hernández & Rcho. Buenavista & 59 & 43 & 00 & 12000 & $"$ \\
\hline Ezequiel Madrid & Rcho. Los Rojas & & & & 2585 & $"$ \\
\hline
\end{tabular}

Cuadro 7. Haciendas y ranchos en Nativitas, distrito de Zaragoza (1905). ${ }^{50}$ Fuente: elaborado con base en AHET, sección: Justicia y Gobernación, 1905, caja 61, exp. 3, f. 16.

${ }^{50}$ Las haciendas registradas en 1905 en el distrito eran 19: Rosario, Mixco, Santa Elena, Buenavista, San José, Los Reyes (o Los Santos Reyes), San Antonio Michac, Santa Clara, Portales, Santa Águeda, Dolores, La Torrecilla, Fábrica El Valor, Palula, San Diego Buenavista, San Pedro Tecotzinco, Xaltelulco, Abaroa, Acopilco (AHET, sección: Justicia y Gobernación, 1905, caja 61, exp. 3, f. 16). 


\section{DOTACIONES EJIDALES Y REPARTO DE LA HACIENDA SANTA ÁGUEDA}

En el contexto de la Reforma Agraria se negaron peticiones de dotación ejidal a centros de población de reciente creación, tal fue el caso de la hacienda Santa Águeda, en cuyo casco vivían los antiguos peones acasillados. Entre los años de 1915 y 1930 Santa Águeda y Dolores en conjunto tenían una superficie de 574.18 hectáreas. En 1920 las instancias agrarias resolvieron dotar 101 hectáreas de Santa Águeda a favor del pueblo de Santo Toribio Xicohtzingo, Tlaxcala, bajo el argumento de que los vecinos de Santo Toribio no cubrían sus necesidades básicas con las tierras que poseían, razón por la que "se ven precisados a trabajar como obreros en las fábricas cercanas y emplearse como peones en las haciendas inmediatas". ${ }^{11}$ En 1923 se dotó de 476 hectáreas de tierra de la hacienda de Santa Águeda y su anexo Dolores a Santa Inés Zacatelco. ${ }^{52}$

En 1925 el propietario de lo que quedaba de la hacienda era Manuel Flores Conde, español con residencia en Puebla (González 2008). En 1934 el señor Manuel Conde y su hermano Luis Conde eran propietarios de forma mancomunada de Santa Águeda que para entonces tenía 100 hectáreas de riego. Manuel Conde también era propietario de la finca de San Antonio Tamariz, en Tepeaca, Puebla, con una extensión de 200 hectáreas de temporal, y dueño de la hacienda de La Trinidad en Libres, Puebla, de 1528 hectáreas. ${ }^{53}$ En 1938 se dota a Santa Cruz Aquiahuac, Tlaxcala, de 50 hectáreas de tierras de riego de la hacienda de Santa Águeda. ${ }^{54}$

En 1905, la Secretaría de Fomento, Colonización e Industria de la República Mexicana confirmó al señor Ignacio Morales Benítez los derechos al uso de aguas para riego de terrenos de la hacienda Santiago Michac, jurisdicción del distrito de Zacatelco, Tlaxcala, y consideró que el señor "Blas Reguero y Caso solicita al gobierno del estado se le confirmen los derechos al uso de las aguas del río Zahuapan en la Hacienda de su propiedad llamada 'Los Santos Reyes' y su rancho anexo de 'San Joaquín' cuyas aguas aprovecha para el riego de sus terrenos laboríos". ${ }^{55}$ El Gobierno del Estado otorgó la resolución a dicha petición, expedida en marzo de 1905, en la que se menciona que tanto el señor Reguero como sus antecesores en posesión de las fincas tratadas habían venido ocupando dichas aguas desde treinta años atrás, que el río Zahuapan no

${ }^{51}$ RAN-T, Dotación, carpeta básica Santa Inés Zacatelco 23/238, caja XVIII-bis, f. 2.

${ }^{52}$ RAN-T, Dotación, Historial agrario, Municipio Zacatelco, Serie documental 2, 278-1/93, exp. 3, f. 8.

${ }^{53}$ RAN-T, Dotación, carpeta básica Santa Inés Zacatelco 23/238, caja XVIII-bis, f. 2.

${ }^{54}$ Carpeta básica municipal. Nuevo centro de población agrícola. Santa Cruz Aquiahuac municipio de Tetlatlauca, Tlaxcala. RAN-T, Dotación, caja XVIII-bis, f. 2. Diario Oficial, noviembre de 1938.

${ }^{55}$ AHET, sección: Justicia y Gobernación, 1905, caja 59, exp. 2, f. 3. 
estaba comprendido en la ley general de 5 de junio de 1888 y que no era jurisdicción federal. Se le autorizaba seguir utilizando las aguas sin que se construyan presas firmes o de mampostería. Sólo se le permitían presas provisionales de acuerdo con lo dispuesto en la ley estatal de 29 de diciembre de 1885 y el reglamento del 24 de abril de $1886 .{ }^{56}$

Argumentar el uso de los recursos (agua y tierra) desde tiempos inmemoriales y contar con el apoyo de argucias legales que entorpecían el proceso de dotaciones de agua y tierra fue común entre los hacendados de aquella época, hecho que marcó el futuro contencioso de esta pródiga región por el acceso de las comunidades a los recursos naturales con lo que se hizo frente a los hacendados locales en las reconfiguraciones territoriales y productivas ejidales.

\section{CONCLUSIONES}

El caso de la conformación territorial de Nativitas ilustra el devenir de una región privilegiada por el acceso a recursos naturales abundantes, basada en la explotación intensiva de haciendas pecuarias en una zona con densidad poblacional indígena. La configuración social del paisaje y del territorio de la región denominada "ciénega de Tlaxcala" ha sido moldeada por la entonces "moderna" producción ganadera, lechera y maicera. Nativitas fungió como centro rector de prácticamente toda la región debido a la importancia de su producción, que abastecía a entidades del centro del país, particularmente las ciudades de Puebla y de México.

El establecimiento de haciendas, propiedad de españoles, generó relaciones contenciosas con la población indígena debido a las disputas por el control de tierras de cultivo. Las haciendas de Nativitas no requirieron de grandes extensiones de tierra para producir porque eran muy fértiles, pero necesitaban extensiones significativas para apacentar el ganado. El aprovechamiento de los ríos Atoyac y Zahuapan generó frecuentes conflictos entre las haciendas y las comunidades indígenas circundantes. Los esfuerzos continuos por controlar los desbordamientos de los ríos y el inicio del proceso de desecación de la ciénega de Tlaxcala fueron nodales para la transformación del entorno regional. Analizar la región de Nativitas desde una perspectiva de larga data nos permite comprender que la reconfiguración del paisaje, del entorno natural y territorial de la zona fue resultado, indudablemente, del proceso de cambio social y económico de la región, debido a la intensiva actividad ganadera, lechera y agrícola en una zona con población indígena.

${ }^{56}$ AHET, sección: Justicia y Gobernación, 1905, caja 63, exp. 66, f. 1. 


\title{
EL REPARTO AGRARIO EN NATIVITAS, RESULTADO DE LUCHAS SOCIALES EN LAS PRIMERAS DÉCADAS DEL SIGLO XX
}

\author{
Óscar Gerardo Hernández Lara
}

\section{INTRODUCCIÓN}

$\mathrm{P}$ ensar sobre la manera en que se forma y se vive un sitio lleva a indagar y buscar razones y procesos, al encadenamiento de acontecimientos, así como a recordar nombres y personajes, pues son éstos quienes contribuyeron para que ciertos hechos se llevaran a cabo en ese sitio, con una historia particular, enraizada y significante de la cotidianidad.

La historia detrás de cada individuo y habitante en relación con su medio "se nos presentan bajo la forma de una serie de acontecimientos: de actos dramáticos y breves. Una batalla, un encuentro de hombres de Estado, un importante discurso, una carta fundamental, son instantáneas en la historia" (Braudel 1986: 27); sin embargo, los resultados de esos eventos no son fugaces ni temporales, podrán ser súbitos y precipitados, ser acto de combates y gestas, pero permanecen en el sentido y forma de vida de los que habitan el lugar, para sus descendientes y para aquellos que han partido.

El próposito de este trabajo es analizar el reparto agrario como el evento relevante que da forma y actualidad al municipio de Nativitas, sin dejar de lado a algunos personajes involucrados en el mismo. La historia del municipio de Nativitas, Tlaxcala, cuenta con este acontecimiento, con este tipo de arraigo e historia que secunda y respalda a quienes tienen esa herencia. A unos años del primer centenario del reparto en los pueblos que conforman el municipio, la intención es entender la realidad actual con base en ese hecho viejo, pero vigente. La elección de la temporalidad que contempla este trabajo se basa en los ejemplos que se tomaron para la realización del mismo, pues son pueblos representativos del reparto agrario en el municipio. 
Se trata de un municipio con historia agraria importante, pues, como informa Isabel González (1969), en 1712 el partido de Nativitas contaba con 22 haciendas, 15 ranchos y 2 casas de campo que sumaban en total 15157 hectáreas en manos de 34 propietarios. Algunos cascos aún siguen en pie aunque no dedicados a su antiguo funcionamiento y las tierras se encuentran repartidas entre la población ejidataria y pequeños propietarios.

Este trabajo tiene como objetivo describir la situación y el proceso que dio origen al fraccionamiento de las tierras y con ello al sistema ejidal, poniendo especial atención al caso de la hacienda Segura Michac como propiedad afectada en el periodo de 1917 a 1926, y de esta manera dar cuenta de los cambios productivos y sociales ocurridos a principios del siglo xx en el municipio como resultado del reparto agrario.

Este capítulo comienza con la descripción del contexto regional del municipio, algunas características geográficas que explican el gran número de haciendas y la productividad que alcanzaron, además de un panorama social de la época con base en bibliografía que aborda la región y el municipio en las primeras décadas del siglo xx. Después se describe el reparto agrario, con base en información extraída del Registro Agrario Nacional Delegación Tlaxcala (RAN-T), con el fin de analizar el proceso que, a partir de esos resultados, siguió el municipio a principios del siglo xx con el caso de la hacienda Segura Michac. Por último, se presentan resultados y comentarios finales.

\section{EL SUR DE TLAXCALA, REGIÓN ENRAIZADA Y TRASCENDENTAL. CONDICIONES SOCIOECONÓMICAS Y TERRITORIALES, 1926}

A principios del siglo $\mathrm{xx}$, el estado de Tlaxcala contaba con una división político-administrativa basada en distritos, los cuales "están formados por la agrupación de varios municipios que presentan unidad geográfica y semejanza en sus características climáticas, agrícolas y económicas" (DGE 1930: 7). Dicha división fue utilizada para la realización del censo agrícola y ganadero y fue originalmente formada y adoptada por la Secretaría de Agricultura y Fomento para fines estadísticos. Una imagen de esta división se observa en el mapa de 1848 (mapa 1) y en el de 1881 (mapa 11).

El valle de Nativitas, en el distrito de Zaragoza, es conocido por ser una zona fértil, de buenas siembras y productiva, pues como lo informa Tyrakowski (2003: 166) citando a Ciudad Real (1976: 94), "ya en 1585 [...] este aquél pueblo [de Nativitas se ubica] en un valle muy grande y fértil de maíz, donde también hay algunas estancias de ganado mayor y menor, y se coge algún trigo". 
Tal como lo describe y analiza Galicia (2010: 1), en el periodo colonial, y desde una visión geohistórica, ${ }^{57}$ la subcuenca Puebla-Tlaxcala contaba con una gran diversidad físico-geográfica, pues "su configuración espacial-territorial se caracterizaba por una amplia gama de paisajes naturales y usos de suelo, asociados con una distribución diferenciada del agua". En efecto, en los municipios del distrito de Zaragoza (entre ellos Nativitas), desde finales del siglo XIX, y se puede afirmar que hasta la actualidad, "además de consumir agua de manantial de manera generalizada, sus habitantes utilizaban ríos y pozos someros como fuentes de abastecimiento. Las zonas inundables y pantanosas se ubicaban principalmente en el distrito de Zaragoza [...] dentro de dicha zona destacaban los humedales de Nativitas" (Galicia 2010: 9-10). Esta razón histórica y ambiental, el alto nivel de fertilidad e irrigación, llevó a españoles residentes en Puebla y la ciudad de México a localizar haciendas en dicha subcuenca, conocida en esos tiempos como un valle, como lo refirió Tyrakowski.

El periodo de las haciendas es relevante en la descripción que aquí se hace del municipio, pues es explicativo y razón del reparto agrario. Afirma Ramírez (1990: 17-50) que éstas tuvieron su apogeo durante el porfiriato, pues se apoyaban en el poder y la cercana relación del gobernador de la entidad con el presidente Díaz, quienes poseían haciendas y grandes extensiones en el estado. ${ }^{58}$

En esta etapa surgieron actores sociales fortalecidos por el poder político que se materializaba en el control económico y territorial, pues éstos dominaban las relaciones sociales con base en la posesión de grandes extensiones de tierra, de la producción y de bienes comerciables. La población económicamente activa se dedicaba en su gran mayoría al campo, como peones de las haciendas o jornaleros, mientras que una pequeña parte se ocupaba en las actividades de los sectores secundario y terciario.

${ }^{57}$ En su análisis, Galicia (2010: 1) señala que "el proceso de apropiación del medio natural, condicionado por la presencia o ausencia de agua superficial y subterránea, también ha conllevado a formas particulares de uso, integración o desintegración del territorio natural y construido. Esto es, la distribución diferenciada del agua en la subcuenca en general, además de definir una gama de paisajes naturales, ha restringido la ubicación de la población y condicionado sus actividades económicas y relaciones sociales" (cursivas mías). Tal como afirma Braudel, la geohistoria es justamente la historia que el medio le impone a los hombres a través de sus constantes [...] pero la geohistoria es también la historia del hombre enfrentando su espacio, luchando contra él a lo largo de su dura vida [...] es el estudio de un doble vínculo, de la naturaleza con el hombre y del hombre con la naturaleza, el estudio de una acción y una reacción (Braudel 2002: 78).

${ }^{58}$ Se trata de Próspero Cahuantzi, quien gobernó la entidad casi a la par del periodo del presidente Porfirio Díaz, quien tenía una adhesión y complacencia muy marcada con los hacendados, empresarios textiles, pequeños comerciantes y artesanos. 
El cuadro 8 contiene información de González (1969) y se puede observar el tamaño, cantidad de aperos, insumos y valor de algunas haciendas en 1712; y en el cuadro 9 se muestra una comparación en cuanto a la extensión y dotación a distintos pueblos a principios del siglo xx. Una vez realizado el reparto agrario, se observa que el tamaño promedio no variaba de manera significativa, lo que demuestra que entre las haciendas no existía una hegemonía muy marcada, ni comercial ni territorialmente. Se observa también el destino y superficie de las tierras afectadas a favor de los pueblos que solicitaron el reparto, así como las fechas y nombre de los propietarios.

\begin{tabular}{|c|c|c|c|c|}
\hline Propietarios & Nombre de haciendas & $\begin{array}{l}\text { Extensión, propiedades, } \\
\text { calidad de la tierra }\end{array}$ & Valor & Aperos \\
\hline $\begin{array}{l}\text { Isabel Bravo de Laguna, } \\
\text { Vda. de Nicolás de Bañuelos } \\
\text { Cabeza de Vaca }\end{array}$ & Santa Elena & 12 caballerías, 516 ha & $\$ 36000.00$ & 180 bueyes, 80 yeguas y caballos, rejas y trojes \\
\hline Juan Álvarez Barrientos & Santa Bárbara & $\begin{array}{l}16 \text { caballerías laborías } \\
\text { y pastos, } 688 \text { ha }\end{array}$ & $\$ 33000.00$ & $\begin{array}{l}185 \text { bueyes mansos de arado, } 20 \text { vacas y becerros, } \\
70 \text { potros, } 16 \text { caballos }\end{array}$ \\
\hline Gerónimo Villa Septién & Santa Águeda & $\begin{array}{l}9 \text { caballerías de riego, } \\
3 \text { caballerías de pastos, } 516 \text { ha }\end{array}$ & $\$ 30000.00$ & $\begin{array}{l}180 \text { bueyes de tiro aperados, } 8 \text { vacas de vientre, } \\
12 \text { becerros, } 50 \text { cabezas de ganado de cerda }\end{array}$ \\
\hline María de Villegas Carranco & Santiago Michaque & $\begin{array}{l}8 \text { caballerías laborías } \\
\text { y } 2 \text { de ciénaga, } 430 \text { ha }\end{array}$ & $\$ 24000.00$ & 100 bueyes de arado, 30 caballos de trilla \\
\hline
\end{tabular}

Como puede observarse, el promedio de extensión de las haciendas era cercano a las 500 hectáreas, tamaño por el cual en algunos lugares podrían ser consideradas como ranchos, pero su funcionamiento, el control de la fuerza de trabajo, la cantidad de aperos y propiedades, así como su articulación con mercados regionales, revelan que se trata de haciendas económicaCuadro 8. Haciendas en el partido de Nativitas, Tlaxcala, 1712. Fuente: elaborado con base en González (1969). mente fuertes.

El cuadro 9 presenta un inventario de la repartición de las tierras y la forma en que afectó a las haciendas. Presenta también a los últimos propietarios, aquellos quienes no pudieron retener su propiedad, aunque algunos utilizaban una estrategia que se observó en diversos documentos en el RAN-T, que consistía en repartir el terreno entre los hijos y con ello declarar pequeñas propiedades, que por su tamaño eran inafectables y así evitar el reparto de tierras. Sin embargo, ello no ocurrió en Nativitas. 


\begin{tabular}{|c|c|c|c|c|c|c|c|}
\hline \multirow{2}{*}{$\begin{array}{c}\text { Hacienda } \\
\text { (superficie original) }\end{array}$} & \multirow{2}{*}{\multicolumn{4}{|c|}{ Pueblos favorecidos (extensión y fecha de resolución presidencial / ejecución) }} & \multicolumn{2}{|c|}{ Totales } & \multirow{2}{*}{ Propietario(s) } \\
\hline & & & & & Afectaciones & $\begin{array}{l}\text { Conserva } \\
\text { hacienda }\end{array}$ & \\
\hline $\begin{array}{l}\text { San Antonio } \\
\text { Michac (288) }\end{array}$ & $\begin{array}{l}\text { Santo Tomás la Concordia } \\
40 \text { ha de riego } \\
15 / 11 / 1917 \\
02 / 01 / 1918\end{array}$ & $\begin{array}{l}\text { San Juan Huactzingo } \\
108.8 \text { ha de riego } \\
13 / 10 / 1937 \\
13 / 11 / 1937\end{array}$ & \multicolumn{2}{|c|}{$\begin{array}{l}\text { Santo Tomás la Concordia } \\
\text { (ampliación) } 40 \text { ha de riego } \\
23 / 12 / 1936 \\
17 / 12 / 1937\end{array}$} & $188 \mathrm{ha}$ & 100 ha de riego & $\begin{array}{l}\text { Familia Caso } \\
\text { y Velazco }\end{array}$ \\
\hline $\begin{array}{l}\text { Santa Elena } \\
(520.95)\end{array}$ & $\begin{array}{l}\text { San Miguel } \\
\text { Xochitecatitla } 100 \text { ha } \\
\text { 18/09/1919 } \\
18 / 12 / 1919\end{array}$ & $\begin{array}{l}\text { Santiago Michac } \\
237.9 \text { ha } \\
26 / 08 / 1920 \\
15 / 10 / 1920\end{array}$ & $\begin{array}{l}\text { San Bernabé } \\
\text { Capulac } 58 \text { ha } \\
07 / 08 / 1924 \\
19 / 09 / 1919\end{array}$ & $\begin{array}{l}\text { San Miguel } \\
\text { Xochitecatitla } \\
\text { (ampliación) } \\
36.2 \text { ha } \\
28 / 07 / 1927 \\
17 / 08 / 1927\end{array}$ & 432.1 ha & $\begin{array}{l}88.85 \text { ha } \\
\text { de riego }\end{array}$ & $\begin{array}{l}\text { Guadalupe } \\
\text { Vázquez }\end{array}$ \\
\hline $\begin{array}{l}\text { Santa Clara } \\
\text { Atoyatenco } \\
(512.9)\end{array}$ & \multicolumn{2}{|c|}{$\begin{array}{l}\text { San Miguel Analco } 112 \text { ha } \\
26 / 06 / 1924 \\
27 / 08 / 1924\end{array}$} & \multicolumn{2}{|c|}{$\begin{array}{l}\text { San Antonio Mihuacán (Puebla) } \\
300 \text { ha }\end{array}$} & $412 \mathrm{ha}$ & $\begin{array}{l}100.9 \text { ha } \\
\text { Temporal, } \\
\text { agostadero }\end{array}$ & $\begin{array}{l}\text { Familia Díaz } \\
\text { Rubín y Velazco }\end{array}$ \\
\hline $\begin{array}{l}\text { Santo Tomás } \\
\text { Xoxtla (Puebla) }\end{array}$ & $\begin{array}{l}\text { Santa Inés } \\
\text { Zacatelco } 339.21 \text { ha }\end{array}$ & $\begin{array}{l}\text { Santa Isabel } \\
\text { Tetletleuhca } 33.6 \text { ha }\end{array}$ & $\begin{array}{l}\text { Santo Tomás } \\
\text { la Concordia } \\
172.68 \text { ha }\end{array}$ & $\begin{array}{l}\text { Jesús Tepactepec } \\
166.1 \text { ha }\end{array}$ & $162.78 \mathrm{ha}$ & & \\
\hline $\begin{array}{l}\text { Santa Ana } \\
\text { Portales }\end{array}$ & $\begin{array}{l}\text { Santa Isabel Tetlatlauhca } \\
42 \mathrm{ha}\end{array}$ & $\begin{array}{l}\text { Santa Cruz } \\
\text { Aquiahuac } 72 \text { ha }\end{array}$ & \multicolumn{2}{|c|}{ San Bartolomé Tenango 213 ha } & & & \\
\hline $\begin{array}{l}\text { Santa Águeda } \\
\text { (676) }\end{array}$ & \multicolumn{2}{|c|}{$\begin{array}{l}\text { Santo Toribio Xicotzingo } 104 \text { ha } \\
23 / 04 / 1924\end{array}$} & \multicolumn{2}{|c|}{ Santa Inés Zacatelco 476 ha } & 580 ha & 96 ha & $\begin{array}{l}\text { Ignacio Morales } \\
\text { Benítez }\end{array}$ \\
\hline
\end{tabular}

Cuadro 9. Ejemplos de pueblos favorecidos de afectaciones a haciendas en el valle de Nativitas, 1917-1937 (hectáreas). Fuente: elaborado con base en el Registro Agrario Nacional (RAN). ${ }^{59}$

${ }^{59}$ RAN-T, caja 1, expediente 00207, clave 23, Ejido Santo Tomás la Concordia, legajo 01/25 con fecha 18 de agosto de 2006, asunto: dotación de tierras, foja: 00445-00447, 22 de septiembre de 1941; RAN-T, caja 2, expediente 00207, clave 25, Ejido Santo Tomás la Concordia, legajo 03/25 con fecha 18 de agosto de 2006, asunto: ampliación negada, foja: 00010, 23 de octubre de 1930; RAN-T, caja 2, expediente 00207, clave 25, Ejido Santo Tomás la Concordia, legajo 04/25 con fecha 18 de agosto de 2006, asunto: ampliación de ejidos, foja: 00218, 29 
Comparar ambos cuadros permite observar la importancia que tuvieron las luchas locales en favor de la repartición de tierras, pues como se infiere y muestra en el mapa 2, la región del valle de Nativitas contaba con un número importante de haciendas, las cuales disponían de extensiones para la explotación agrícola y pecuaria, en promedio, como ya se indicó, de 500 hectáreas por hacienda. Esa importancia sigue vigente, pues un segmento de los habitantes permanece ligado a los resultados de su lucha revolucionaria: la tierra.

Un elemento que contribuyó a la transformación del paisaje y a la dinámica social y económica fue el ferrocarril. Su aparición implicó una dinámica socioterritorial y económica mayor a nivel regional, así como la articulación a nivel nacional, además del impulso a las actividades industriales. Buve (1979: 535) afirma que las haciendas poseían vías privadas que se conectaban con el Ferrocarril Interoceánico y el Mexicano, ${ }^{60}$ éstos tenían conexión con Puebla y San Martín Texmelucan, y las estaciones más próximas a las haciendas de Nativitas eran Analco, a seis kilómetros, y Panzacola, a diez.

De acuerdo con los proyectos de explotación agrícola/ejidal de Santo Tomás la Concordia, Jesús y los barrios San Juan Tepactepec y Santa María Nativitas (elaborados en 1923 y 1924 por el ingeniero agrónomo de la dirección de aprovechamiento de ejidos, Luis Santibáñez), mantenían relación comercial por medio de un "camino carretero en buenas condiciones y por medio de otro con San Martín Texmelucan del estado de Puebla, cuyo mercado es el más propicio para la venta de los productos, pues dista de él unos 12 kilómetros", ${ }^{61}$ además del Ferrocarril Interoceánico.

El mismo ingeniero señalaba en sus informes y diagnósticos que la población prefería comerciar sus productos en San Martín y no en la capital de la entidad, por "su mayor importancia comercial interior, como porque en esa población se encuentra instalada la estación del F.C. Interoceánico, que une la ciudad de Puebla con la capital de la República; siendo la esta-

de noviembre de 1937; RAN-T, caja 2, expediente 134, clave 23/134, Ejido Santa María Natívitas, legajo 05/18 con fecha 5 de julio de 2005, asunto: dotación de tierras, foja: 00045-00049, 15 de diciembre de 1921.

${ }^{60}$ Busto (1880: 390) informa que el 14 de septiembre de 1880 se firmó un "contrato con el gobierno de Tlaxcala para construir un ferrocarril y telégrafo, de San Martín (Texmelucan, Puebla) al punto donde sea más conveniente ligarlo con el ferrocarril de Hidalgo, haciendo un ramal a Tlaxcala; debiendo concluirlo dentro de 5 años”. Este ferrocarril "tiene una vía principal entre México y el puerto de Vera Cruz y dos líneas secundarias que se ponen en relación a la principal con las ciudades de Puebla y Jalapa” (Busto 1880: 446). Esta línea férrea tenía en ese tiempo una extensión de $423.75 \mathrm{~km}$.

${ }^{61}$ RAN-T, caja 2, expediente 134, clave 23/134, Ejido Santa María Natívitas, legajo 05/18 con fecha 5 de julio de 2005, asunto: dotación de tierras, fojas 00109-00111, 31 de mayo de 1923. 
ción ubicada en el puente referido en la que se embarcan buenas cantidades de los productos agrícolas de la región". ${ }^{62}$

Los cultivos desarrollados en la región, según información del RAN-T y de los diagnósticos del ingeniero citado son: maíz, trigo, haba y frijol. El jornal promedio diario varía, pues en 1914 era de $\$ 0.50$ y en 1924 era de $\$ 0.75 .{ }^{63}$

Según los censos realizados en 1926 de los pueblos Santo Tomás la Concordia (166 jefes de familia y 490 habitantes en 1917), ${ }^{64}$ Jesús Tepactepec (313 habitantes en 1926) ${ }^{65}$ y Santa María Nativitas cabecera municipal (72 jefes de familia ${ }^{66}$ y 319 habitantes en $1920 ;{ }^{67} 103$ jefes de familia en 1926) ${ }^{68}$ extraídos del RAN-T, la totalidad de los habitantes de los dos primeros eran agricultores (campesinos), algunos sin solar o tierra, mientras que el censo de la cabecera municipal registra que además de agricultores y/o jornaleros, algunos habitantes se desempeñaban como comerciantes, carpinteros, herreros, mecánicos, albañiles, músicos o como peluqueros. ${ }^{69}$ Eran tiempos en que la población se dedicaba a la agricultura, al menos en los dos primeros pueblos; sin embargo, en la cabecera municipal ya era evidente la pluriactividad económica. Sin importar el tamaño de la localidad, los oficios y actividades diferentes a la agricultura se desa-

${ }^{62}$ RAN-T, caja 1, expediente 00207, clave 23, Ejido Santo Tomás la Concordia, legajo 01/25 con fecha 18 de agosto de 2006, asunto: dotación de tierras, fojas 00341-00348, 30 de junio de 1924.

${ }^{63}$ RAN-T, caja 1, expediente 00207, clave 23, Ejido Santo Tomás la Concordia, legajo 01/25 con fecha 18 de agosto de 2006, asunto: dotación de tierras, fojas 00341-00348, 30 de junio de 1924; RAN-T, caja 1, expediente 00207, clave 23, Ejido Santo Tomás la Concordia, legajo 01/25 con fecha 18 de agosto de 2006, asunto: dotación de tierras, fojas 00012-00013, 27 de agosto de 1914.

${ }^{64}$ RAN-T, caja 1, expediente 00207, clave 23, Ejido Santo Tomás la Concordia, legajo 01/25 con fecha 18 de agosto de 2006, asunto: dotación de tierras, fojas 00012-00013, 27 de agosto de 1914; RAN-T, caja 2, expediente 00207, clave 25, Ejido Santo Tomás la Concordia, legajo 03/25 con fecha 18 de agosto de 2006, asunto: ampliación negada, fojas 00002-00003, 1917.

${ }^{65}$ RAN-T, caja 4, expediente 0098, clave 248.5, Ejido Santa María Nativitas, legajo 16/16 con fecha 20 de abril de 2004, asunto: cambio de autoridades ejidales, fojas 00023-00032, 29 de octubre de 1926.

${ }^{66}$ RAN-T, caja 1, expediente 00207, clave 23, Ejido Santo Tomás la Concordia, legajo 01/25 con fecha 18 de agosto de 2006, asunto: dotación de tierras, fojas 00012-00013, 27 de agosto de 1914.

${ }^{67}$ RAN-T, caja 2, expediente 134, clave 23/134, Ejido Santa María Nativitas, legajo 05/18 con fecha 5 de julio de 2005, asunto: dotación de tierras, fojas 00045-00049, 15 de diciembre de 1921.

${ }^{68}$ RAN-T, caja 1, expediente 00134, clave 271.71, Ejido Santa María Nativitas, legajo 04/18 con fecha 5 de julio de 2005, asunto: privación de derechos ejidales y nuevas adquisiciones, fojas 00009-00017, 1926.

${ }^{69}$ RAN-T, caja 1, expediente 00134, clave 271.71, Ejido Santa María Nativitas, legajo 04/18 con fecha 5 de julio de 2005, asunto: privación de derechos ejidales y nuevas adquisiciones, fojas 00009-00017, 1926. 
rrollaban en Nativitas. Como se observa, eran pueblos muy pequeños, que han mantenido un acercamiento y cohesión social importante entre ellos y dentro de los mismos.

Evidentemente el reparto agrario, como instrumento de justicia social y ampliación de posibilidades y oportunidades para la mayoría, era inminente y necesario. Las condiciones físicas estaban dadas, pues los datos y diagnósticos del ingeniero mencionado planteaban que se trataba de pueblos con ventajas agronómicas importantes. Sin embargo, las tierras no pertenecían a quienes la trabajaban, para ello fue necesario un proceso de reforma agraria, personajes locales y la materialización del reparto que se efectuaría de forma diferenciada en los pueblos que constituyen el municipio. En este trabajo se analizan los beneficiados por la afectación a la hacienda Segura Michac.

\section{ANTECEDENTES Y CONTEXTO DEL PROCESO DE REPARTO AGRARIO}

Con base en información de González (1969), Fabila et al. (1955: 43-64) y Ramírez (1990: 26) es posible reconstruir la serie relativa al número de haciendas y ranchos en Tlaxcala entre los años 1712 y 1930. El objetivo de concentrar esta información en el cuadro 10 es dar evidencia del alto número de inmuebles con los que contaba la entidad a lo largo del periodo mencionado, así como la paulatina disminución de las grandes propiedades.

\begin{tabular}{rcc}
\hline Año & Haciendas & Ranchos \\
\hline 1712 & 108 & 58 \\
\hline 1757 & 145 & 69 \\
\hline 1824 & 153 & 134 \\
\hline 1876 & 123 & 116 \\
\hline 1900 & 113 & 148 \\
\hline 1910 & 117 & 110 \\
\hline 1923 & 88 & 74 \\
\hline 1930 & 66 & 55 \\
\hline
\end{tabular}

Cuadro 10. Número de haciendas y ranchos en Tlaxcala, 1712-1930. Fuente: elaborado con base en González (1969), Ramírez (1990) y Fabila et al. (1955). Nota: en referencia a las cifras de este cuadro, González (1969) aclara que dentro de las 108 haciendas de 1712, 8 estaban arrendadas y 13 con uno o dos ranchos anexos a otras propiedades. Y señala que se considera como rancho las propiedades privadas con extensión de entre 501 y 1000 hectáreas y como hacienda a las que cuentan con más de 1000 hectáreas.
El mapa 11 muestra la localización de las haciendas por distritos en Tlaxcala en finales del siglo XIX (1881). Es importante resaltar, con base en el cuadro 10 y el mapa, la densidad de ranchos y haciendas en la entidad y que, evidentemente, ocupaban grandes extensiones, lo que 
permitió repartir la mayor parte del territorio y las tierras productivas que pasaron a ser ejidos. Con ello la población encontró un nuevo arraigo a la tierra, elemento que aún es significativo.

En el mapa referido se observa la densidad de haciendas en el norte y en el sur de la entidad en el territorio que hoy constituye el municipio de Nativitas, concentración de propiedades que pone en evidencia que existían buenas condiciones edafológicas e hídricas para el desarrollo de la agricultura, ventajas que aún se conservan y se aprovechan, además de dar una idea del grado de consolidación y control del sistema de haciendas en la región.

Durante finales del siglo xix y las dos primeras décadas del xx, en Tlaxcala, en especial el sur y occidente de la entidad y en parte de Puebla, tuvieron lugar movimientos revolucionarios regionales-locales con un buen número de actores sociales. La tesis que Buve sostiene es que "uno de los resultados más importantes de los estudios regionales de la Revolución Mexicana [...] es el reconocimiento general de las considerables diferencias en las condiciones revolucionarias al nivel local" (Buve 1989: 181), pues "el complejo proceso de cambio político-social violento es ahora más bien visto como la convergencia de una infinidad de movimientos sociales de la más variada índole" (Leal y Menegus, en Buve 1986: 119).

El análisis de estos movimientos sociales locales propuesto por Buve (1986: 120) para esta región de Tlaxcala es particular en cuanto a algunas variables (cuadro 11):

- La composición social de la sociedad regional, su estructura de clases y las relaciones entre grupos sociales y étnicos.

- La tenencia de la tierra.

- El grado de urbanización y desarrollo económico industrial capitalista.

El autor considera la importancia del papel que desempeñaron instituciones como el Estado y la Iglesia y los intereses extranjeros. Afirma que estas variables resultaron en el desarrollo de movimientos revolucionarios muy diferentes, porque se observa el origen social de sus líderes, seguidores, masas, sus metas y horizontes, sus estrategias de movilización y control, sus recursos y problemas de manutención. Aspectos, todos ellos, con especificidades y diferencias de acuerdo con cada región y localidad.

Esta breve síntesis permite relacionar dos temas fundamentales: 1) la situación social y económica de la región centro-sur de Tlaxcala en 1910, antecedente de 2) las razones que llevaron a la movilización regional basada en el apoyo de rancheros, maestros rurales, profesionistas y estudiantes, pero más aún, sustentada en campesinos, obreros y líderes locales.

El primer tema se relaciona con lo declarado por Buve (1979) respecto a la tenencia de la tierra, que era poca en cuanto a extensión, para realizar únicamente actividades agrícolas. Por 


\begin{tabular}{|c|c|}
\hline Variable & Situación en la región \\
\hline $\begin{array}{l}\text { Diversidad en el origen social } \\
\text { de los participantes en movimientos } \\
\text { revolucionarios }\end{array}$ & $\begin{array}{l}\text { Conexión entre trabajo industrial, artesanal y agrícola parcelaria: } \\
\text { base para una fuerte movilización revolucionaria (Buve 1986: } \\
\text { 120-121 citando a Knight 1980: 20-21; Buve 1975). El movimiento } \\
\text { revolucionario era prácticamente un "consenso socialmente aceptado", } \\
\text { a pesar del origen y clases diversas de los actores. }\end{array}$ \\
\hline $\begin{array}{l}\text { Relaciones diferenciadas entre jefes, } \\
\text { seguidores y masas populares }\end{array}$ & $\begin{array}{l}\text { Pautas tradicionales de control y movilización de un campesinado } \\
\text { residente en comunidades de tipo indígena-colonial con tierras } \\
\text { comunales, aunque mestizados, reforzadas por relaciones de parentesco } \\
\text { y matrimonio. }\end{array}$ \\
\hline $\begin{array}{l}\text { Comportamientos tradicionales } \\
\text { y modernos }\end{array}$ & $\begin{array}{l}\text { Combinación entre nuevos recursos políticos (armas, votos, reparto } \\
\text { de tierras) y cacicazgos locales. El deterioro progresivo de tierras y } \\
\text { la presión demográfica sobre las mismas trajo un malestar de tipo } \\
\text { tradicional agrario y pueblerino (Buve 1986: 124). }\end{array}$ \\
\hline Tenencia de la tierra & $\begin{array}{l}\text { Según Buve (1979: 536) los pueblos de la región disponían de una } \\
\text { extensión mínima de tierra, en promedio de entre } 0.1 \text { y } 1.5 \text { hectáreas } \\
\text { o bien nada. Además, en } 1910 \text { los campesinos de la zona centro-sur } \\
\text { de Tlaxcala tenían más de } 60000 \text { ha de tierra, pero fraccionada en } \\
\text { minúsculas parcelas que se explotaban en forma individual y una } \\
\text { pequeña superficie de terrenos de uso común, sin uso agrícola (Fabila } \\
\text { en Buve 1986: 124). }\end{array}$ \\
\hline $\begin{array}{l}\text { Grado de urbanización } \\
\text { y desarrollo económico }\end{array}$ & $\begin{array}{l}\text { El grado de urbanización era nulo en estos contextos, sin embargo, } \\
\text { en cuanto a la cantidad/densidad de población, Buve (1986: 123) } \\
\text { afirma que era alta en la parte central-sur de la entidad, así como la } \\
\text { introducción de infraestructura urbana. En este sentido ocurrían } \\
\text { dos situaciones: la población basaba su economía en la agricultura } \\
\text { parcelaria, artesanías, trabajo en las haciendas cercanas, comercio } \\
\text { ambulante y otros servicios, y "las comunidades estaban entrelazadas } \\
\text { por relaciones de intercambio, reforzadas por parentesco real } \\
\text { o ceremonial" (Buve 1986: 124); y los parceleros-trabajadores } \\
\text { incorporaron el trabajo fabril al conjunto de sus actividades } \\
\text { económicas, como consecuencia de la introducción del ferrocarril, } \\
\text { la cercanía a los mercados urbanos y la política modernizadora del } \\
\text { gobernador Cahuantzi (Nutini en Buve 1986: 124). }\end{array}$ \\
\hline
\end{tabular}

\footnotetext{
Cuadro 11. Variables y condiciones en la región sur de Tlaxcala en la etapa revolucionaria de 1910.
} 
ello, varios autores han insistido en la condición y cualidad de la población como pluriactivos con origen de ingreso familiar múltiple, pues si bien la actividad y conocimiento principales han estado ligados al trabajo de la tierra, también se encuentran entre los censos comerciantes, artesanos, obreros, peluqueros, músicos, etcétera, ${ }^{70}$ como ya se señaló. La escasa extensión de tierra y el control que ejercían sobre ella los hacendados, sumado al conocimiento de los habitantes del trabajo agrícola, era una situación que indicaba necesidades que se fueron generalizando: la movilización revolucionaria que conduciría a la población a apropiarse de la tierra, y así iniciar una situación social y comunitaria diferente.

Respecto a la pluriactividad laboral como necesidad y estrategia, fue favorecida por la actividad fabril promovida a finales del siglo xIx y principios del xx. Como afirma Buve (1989: 195):

se fundó en la zona centro-sur de Tlaxcala una docena de fábricas de textiles entre Apizaco y Panzacola, aprovechando las aguas de los ríos Atoyac y Zahuapan, la comunicación por ferrocarril hacia Puebla y México, y la disponibilidad de mano de obra residente en los muchos pueblos cercanos. Esta población ya tenía una larga experiencia en actividades económicas fuera de la agricultura (artesanías, comercio ambulante, arriería). La industria textil podía [...] aprovecharse hábilmente de la ingente necesidad de buscar ingresos adicionales.

Sin embargo, la pluriactividad era una estrategia que no satisfacía los gustos, las preferencias o necesidades de la población. El movimiento revolucionario no sólo buscaba la repartición de la tierra como elemento significativo de la vida cotidiana, también buscaba libertades y bienestar social, y en cierta forma terminar con el sistema de haciendas para dedicarse a las labores agrícolas, un encuentro entre la población, su conocimiento y la tierra.

El segundo aspecto, el de las razones que llevaron a la movilización regional, es resultado del primero, pues aborda la organización y unión de campesinos en favor de líderes locales,

${ }^{70}$ Fabila et al. afirman que los habitantes de la entidad desempeñaban al mismo tiempo las actividades propiamente rurales (agricultura y ganadería) con otras de carácter urbano (comercio y servicios). Las razones son la subocupación y el bajo ingreso en las labores agrícolas. Además, demuestra que si bien ha habido movimientos de población hacia localidades mayores y relativamente urbanizadas, ésta continúa ocupándose en actividades de carácter agrícola. En 1950, 70.3 \% de la población de Tlaxcala se ocupaba en la agricultura (rama de actividad que incluye ganadería, silvicultura, pesca y caza), $12.2 \%$ en las industrias de transformación y $9.9 \%$ en comercio y servicios. Datos que, según el análisis del autor, se presentan como contrarios a la tendencia nacional (Fabila et al. 1955: 34-36). Existen trabajos que demuestran que la pluriactividad, la movilidad laboral y espacial de los habitantes de Tlaxcala es una cualidad histórica y actual, en específico de la región sur; ver por ejemplo: Restrepo y Sánchez 1972; Rendón 1996; Buve 2010; Hernández 2011; Salas y Rivermar 2011. 
como lo menciona Rendón (1996: 101): "muchos de los dirigentes del naciente Movimiento Revolucionario de Tlaxcala [MRT], como Máximo Rojas y Anastasio Meneses, eran parceleros, obreros textiles y vendedores ambulantes. Domingo 'El Manco' Arenas y su hermano, Cirilo, pastoreaban un rebaño familiar y, al igual que Antonio y Octavio Hidalgo, trabajaban en una fábrica", a quienes se suma también Juan Cuamatzi. ${ }^{71}$ Se trataba de pobladores que resentían la situación antes planteada y que estaban en busca de un movimiento agrarista, por ello, estos personajes se presentaron como líderes locales-regionales, actores en la lucha social.

Buve (2010) afirma que Domingo Arenas Pérez (1888-1917) es considerado por los tlaxcaltecas como el gran héroe revolucionario y destacado agrarista. Era originario de Zacatelco, campesino y obrero textil en Atlixco, pastoreaba el rebaño familiar y, de vez en cuando vendía tortillas, era miembro activo del PAT (Partido Antireeleccionista de Tlaxcala), ${ }^{72}$ participó informando a los peones de sus derechos, y de las colonias agrícolas que se establecieron en 1912. Se incorporó tanto al movimiento constitucionalista como al zapatista, a través de los cuales realizó repartición de "grandes porciones de tierra y establecieron [él y algunos jefes arenistas, como Felipe González y Pedro Susano] colonias agrícolas para peones en varias haciendas" (Buve 2010: 117). Fue asesinado a finales de 1917 y sucedido como líder y jefe militar por su hermano Cirilo, quien después de efectuar saqueos a haciendas, fábricas y ferrocarriles como respuesta a la persecución del gobernador Luis M. Hernández, fue detenido y fusilado en 1920.

Como se mencionó, el MRT estaba conformado en su columna vertebral por campesinosobreros y pequeños rancheros que vivían dispersos en los pueblos (entre los que se encontraban líderes natos, como Juan Cuamatzi, Marcos Hernández Xolocotzi, Trinidad y Máximo Rojas, Domingo Arenas y Severino Pulido), maestros rurales (Porfirio del Castillo, Andrés Angulo, Anastasio Maldonado, Leopoldo Sánchez, Juan Vázquez), escritores y periodistas (Modesto González Galindo), profesionistas y estudiantes e intelectuales (José Rumbia), algunos de ellos asesores de quien sería gobernador de origen obrero-campesino, Antonio Hidalgo Sandoval (de diciembre de 1911 a enero de 1913).

Las demandas y solicitudes que este movimiento perseguía (1912-1913), a grandes rasgos, eran la creación de colonias agrícolas en las haciendas, mejores condiciones laborales, la salida de gendarmería rural, la derogación de las contribuciones prediales en las propiedades minifundistas, la devolución de tierras y aguas enajenadas ilícitamente y el castigo de los culpables de represión y asesinato (Buve 1986: 125).

${ }^{71}$ Para una revisión más amplia de la vida y obra de Juan Cuamatzi, ver Reyes (1961) y Cuéllar (1935); para el caso de Domingo Arenas, ver Cuéllar (1961) y Lira (1932).

${ }^{72}$ Para más información relacionada al Partido Antireeleccionista de Tlaxcala, ver Ramírez (1988) y Buve (1986). 
La Liga de Agricultores, creada por las élites tlaxcaltecas (hacendados y agricultores fuertes de cereales), buscaba derrocar al gobierno estatal de Hidalgo Sandoval por medio de "un sistema uniforme de rayas para mano de obra rural y de eliminar en gran parte la competencia entre los propietarios" (Leal en Buve 1986: 125). Lograron debilitar la organización del MRT, pero emergieron con más fuerza líderes como los hermanos Rojas y Domingo Arenas, quien en ese momento contaba con menor rango dentro del movimiento y más tarde causaría la escisión permanente del mismo al llevarse a "la gran mayoría de oficiales y tropa en su declaración a favor de Zapata” (Buve 1986: 126). Arenas llevó a cabo una dotación militar en 1916 afectando las haciendas de Segura Michac y Santa Elena en Nativitas, y en una reunión en Santiago Michac, señaló:

uno de los principios por lo que ha venido luchando [el ejército convencionista], es el de dar tierra al campesino, que por muchos años ha sufrido los rigores de la necesidad debido a las ambiciones y opresión de los ricos y hacendados, y que tratando de llevar a efecto tal aspiración, con esta fecha pone en posesión a este pueblo, de una parte de la hacienda de Segura, y otra de la hacienda de Santa Elena, a fin de que pueda satisfacer sus necesidades; con lo que quedan satisfechos todos los presentes, a quienes se les indica la necesidad de que deben nombrar una comisión para que ella sea la que se encargue de hacer todas las gestiones necesarias sobre el particular ante las autoridades que emanen de la revolución. ${ }^{73}$

Muchos movimientos llevados a cabo por caudillos tenían bases y origen familiar, pues como menciona Buve (1975: 134): "la mayoría de ellos empezaron en una base familiar y en su propio pueblo: Aranas Bonilla, Cuamatzi, Hernández, Morales, Rojas, Serrano, Villegas y otros caudillos adjudicaron a sus hermanos y familiares como oficiales, sus esposas y hermanas participaron en sus movimientos y sus soldados fueron reclutados de su mismo pueblo". Esto plantea que las labores productivas anteriores (agricultura y pastoreo) se llevaban a cabo de forma familiar y que la decisión del levantamiento en armas dependió de la totalidad de la familia.

Para el caso de Tlaxcala, Buve (1975: 149) formula la hipótesis de que fueron aquellos campesinos relativamente "más acomodados" quienes iniciaron y presentaron mayor liderazgo local, además de que éstos poseían una habilidad que se caracterizaba por "un grado considerable de movilidad, tanto geográfico como ocupacional, incluso hacia el mundo urbano [...] un buen número de ellos [de campesinos líderes] no eran ni completamente campesinos o no

${ }^{73}$ RAN-T, caja 1, expediente 194, clave 23/194, Ejido: Santiago Michac, legajo 01/44 con fecha 19 de junio de 2006, asunto: dotación de tierras, foja 00012, 2 de octubre de 1916. 
pertenecían ya a este grupo". De esa forma podemos inferir que se trataba de campesinos o propietarios de tierras que contaban con la posibilidad de insertarse en mercados diferentes al agrícola, sin depender de esa actividad completamente, por ejemplo, el comercio de zapatos, ropa y trastes en otros municipios o dependientes de fábricas.

Debido a lo anterior, la producción en general fue decreciendo como consecuencia del estado de guerra (Buve 1975: 138), pues eran familias completas las que se unían al movimiento revolucionario, abandonando temporalmente sus labores agrícolas. Entre los resultados positivos del reparto agrario, además de cumplir y subsanar las demandas de los habitantes, condujo a un estado pacífico, a restituir un nuevo orden social basado en el ejido y reiniciar así la dinámica económica rural.

Una vez llevado a cabo el reparto agrario, Nativitas tomó otra cara, pues los hacendados y terratenientes perdieron protagonismo. El reparto se llevó a cabo entre 1917 y 1937; el avance del reparto permitió la consolidación de la relación entre los habitantes y su territorio. Así, se dio paso a una nueva forma de organización socioterritorial y política en los pueblos del municipio, centrada en el ejido.

\section{El CASO DE LA HACIENDA SEGURA MICHAC DE NATIVITAS, TLAXCALA}

Para los fines de este trabajo, se toma como ejemplo representativo del reparto agrario el caso de la hacienda Segura Michac en 1919. La elección se debe a su contribución territorial en el reparto, pues se afectó un total de 496 hectáreas que se distribuyeron en favor de cinco pueblos. Además, según información obtenida del RAN-T se afirma que era la única colindante con Santa María Nativitas, ${ }^{74}$ cabecera municipal, por ello es que se repartieron 275 hectáreas entre 103 jefes de familia habitantes de esa localidad. Los detalles de esa aportación se presentan en el cuadro 12.

Ubicada en el municipio de Nativitas, distrito de Zaragoza, tenía un valor de $\$ 130000.00^{75} \mathrm{y}$ en 1922 de $\$ 250000.00 .{ }^{76}$ El propietario era Don Miguel Díaz Barriga hasta el 25 de marzo de

${ }^{74}$ Expediente 134, clave 23/134, legajo 05/18, asunto: dotación de tierras, foja 00122-00124, 16 de noviembre de 1923.

${ }^{75}$ Valor calculado para el pago de contribuciones por el ingeniero Enrique González, jefe de la oficina Sección de Catastro, RAN-T, expediente 0098, clave 23/98, legajo 06/16, asunto: relativo a la solicitud de dotación de ejidos promovida por los vecinos del pueblo de Jesús y barrio de San Juan Tepactepec, pertenecientes al municipio de Nativitas, distrito de Zaragoza, estado de Tlaxcala, foja 00041, 3 de marzo de 1919.

${ }^{76}$ Valor asignado por el recaudador de impuestos del distrito de Zaragoza, RAN-T, expediente 0098, clave $23 / 98$, legajo $06 / 16$, asunto: relativo a la solicitud de dotación de ejidos promovida por los vecinos del pueblo 


\begin{tabular}{|c|c|c|c|c|c|c|}
\hline $\begin{array}{c}\text { Pueblo } \\
\text { (año dotación definitiva) }\end{array}$ & $\begin{array}{l}\text { Fecha posesión } \\
\quad \text { definitiva }\end{array}$ & $\begin{array}{l}\text { Jefes de familia } \\
\qquad(a \tilde{n} o)\end{array}$ & $\begin{array}{l}\text { Hacienda Segura } \\
\text { Michac (total } \\
\text { afectación en ha) }\end{array}$ & 1ra clase / tipo & 2da clase / tipo & 3ra clase / tipo \\
\hline $\begin{array}{l}\text { Santa María Nativitas, cabecera municipal } \\
(25 \text { octubre } 1923)\end{array}$ & 25 marzo 1924 & 103 (1926) & 275 & $\begin{array}{l}191-84-00 \text { ha } \\
\text { de riego }\end{array}$ & $\begin{array}{l}\text { 46-18-00 ha } \\
\text { de temporal }\end{array}$ & $\begin{array}{l}\text { 36-98-00 ha } \\
\text { de cerril }\end{array}$ \\
\hline $\begin{array}{l}\text { Santiago Michac } \\
(26 \text { agosto } 1920)\end{array}$ & 15 octubre 1920 & $283(1920)$ & 108 & $\begin{array}{l}\text { 108-70-00 ha } \\
\text { de riego }\end{array}$ & & \\
\hline Guadalupe Victoria & \multicolumn{6}{|c|}{$\begin{array}{l}\text { Superficie segregada de Santiago Michac por solicitud de campesinos que formaron } \\
\text { posteriormente el poblado de Guadalupe Victoria. 30-00-00 ha de riego }\end{array}$} \\
\hline $\begin{array}{l}\text { Santo Tomás la Concordia } \\
\text { (15 noviembre } 1917)\end{array}$ & 2 enero 1918 & $166(1924)$ & 67 & $\begin{array}{l}67-22-43 \text { ha } \\
\text { de riego }\end{array}$ & & \\
\hline $\begin{array}{l}\text { Jesús y San Juan Tepactepec } \\
\text { (15 noviembre 1917) }\end{array}$ & 4 enero 1918 & $102(1918)$ & 46 & $10 \mathrm{ha}, 7300 \mathrm{~m}^{2}$ & $33 \mathrm{ha}, 7074 \mathrm{~m}^{2}$ & $1 \mathrm{ha}, 8000 \mathrm{~m}^{2}$ \\
\hline Totales & & 644 & 496 & 377.74 & 80 & 38 \\
\hline
\end{tabular}

Cuadro 12. Padrón y afectaciones a la hacienda

Segura Michac, su aportación territorial y económica. Fuente: elaborado con base en

información del RAN-T, expediente 0098, clave $23 / 98$, legajo $06 / 16$, asunto: relativo a la solicitud de dotación de ejidos promovida por los vecinos del pueblo de Jesús y barrio de San Juan Tepactepec, pertenecientes al municipio de Nativitas, distrito de Zaragoza, estado de Tlaxcala, fojas 0008-0012, 24 de septiembre de 1917; RAN-T, expediente 134, 23/134, legajo 05/18, asunto: dotación de tierras, fojas 0010900111, 31 de mayo de 1923.
- 1924, fecha en la que se da la última posesión definitiva de 275 hectáreas de tierra a 103 jefes de familia ejidatarios en el pueblo de Santa María Nativitas, cabecera municipal. Esta hacienda fue la única que favoreció a la cabecera municipal por ser la única colindante con ésta y por su importancia comercial.

Además de Santa María Nativitas, también se dotó de tierras a los pueblos de Santo Tomás La Concordia, Jesús Tepactepec y Santiago Michac, y por ampliación tomada de este último, en diferentes años, un total de 496 hectáreas de las 513 de la hacienda.

En el cuadro se puede observar la diferencia temporal del reparto en los pueblos, lo que habla de un proceso gradual. Ello dependía de la organización y solicitud de los pueblos, así como de la aprobación y dotación presidencial definitiva. También resalta la extensión según clase/tipo de tierra, donde 377.74 ha $(73 \%)$ del total era de primera calidad.

Es interesante conocer la última etapa de esta hacienda que da origen a la conformación de los ejidos mencionados, a través del testimonio del último administrador, el señor Alberto

de Jesús y barrio de San Juan Tepactepec, pertenecientes al municipio de Nativitas, distrito de Zaragoza, estado de Tlaxcala, foja 00078, 11 de noviembre de 1922. 
Espinoza, ${ }^{77}$ lo que ha permitido confeccionar el siguiente mapa en el que pueden observarse las relaciones de mercado de la hacienda, los pueblos en los cuales era distribuida su producción (maíz, forraje) o animales, así como también el origen de los compradores (figura 4). En él se muestra que en la última etapa productiva, la hacienda Segura Michac mantenía relaciones económicas con un amplio territorio: San Martín Texmelucan, Nativitas, Santa Apolonia, Santa Isabel, Santa Cruz, San Bartolo Tenango, San Damián Texoloc, Michac, Santa Ana Mimilulco, San Rafael, Tepetitla, Xoxtla, San Antonio Mihuacán, San Francisco Ocotlán, Cuautlalzingo, Cuautenango, Coronango. Afirma el señor Espinoza que la hacienda era conocida a nivel regional por el comercio de su ganado: "de una o dos vacas se llevaban", ${ }^{78}$ distribuía su producción en pueblos y ciudades mayores, como Atlixco y Puebla, además del interior del municipio de Nativitas y pueblos pequeños, como los acreditados en el área de mercado señalada.

Don Miguel Díaz Barriga, quien vivía en Puebla, intentó retener su propiedad ante el inminente reparto y afectación de sus tierras. Por ejemplo, en un documento fechado el 11 de agosto de 1919, se afirma que el dueño, con "el fin de eludir el decreto del 6 de enero de 1915 [...] está intentando vender los terrenos colindantes de su hacienda [...] a vecinos extraños al pueblo de Santiago Michac". ${ }^{79}$ Nuevamente intentó recuperar parte de lo que fuera su propiedad en 1926, a través del presidente de la Comisión Nacional Agraria, para delimitar la zona de protección correspondiente a la hacienda de Santiago Michac, dado que, se argumentaba, se había repartido toda la propiedad sin haber dejado la menor cantidad de terreno, alegando que los campesinos estaban conformes con este trato..$^{80}$

Después de afectada la hacienda, y a falta de quien fuera dueño y herederas, la hermana de éste, Esther Díaz Barriga, presentó una querella con fecha 20 de octubre de 1947 en la cual informaba al delegado del Departamento Agrario que las afectaciones fueron indebidas, pues todavía en vida, sus hermanas y ella se repartieron las tierras en 1918 como sigue: 48-95-38, 15-40-54 y 36-64-95 ha, respectivamente; además, hace referencia a una resolución presidencial del 15 de agosto de 1945, donde "se consideró justo su cargo y declaró que habían sido

${ }^{77}$ Alberto Espinoza, habitante de Santiago Michac. Entrevista realizada en febrero de 2011 en Santiago Michac, Nativitas, Tlaxcala.

${ }^{78}$ Alberto Espinoza, entrevista realizada en febrero de 2011 en Santiago Michac, Nativitas, Tlaxcala.

${ }^{79}$ RAN-T, caja 1, expediente 194, clave 23/194, Ejido Santiago Michac, legajo 01/44 con fecha 19 de junio de 2006, asunto: dotación de tierras, foja 00025, 11 de agosto de 1919.

${ }^{80}$ RAN-T, caja 1, expediente 194, clave 23/194, Ejido Santiago Michac, legajo 01/44 con fecha 19 de junio de 2006, asunto: dotación de tierras, foja 00335, 3 de julio de 1926. 


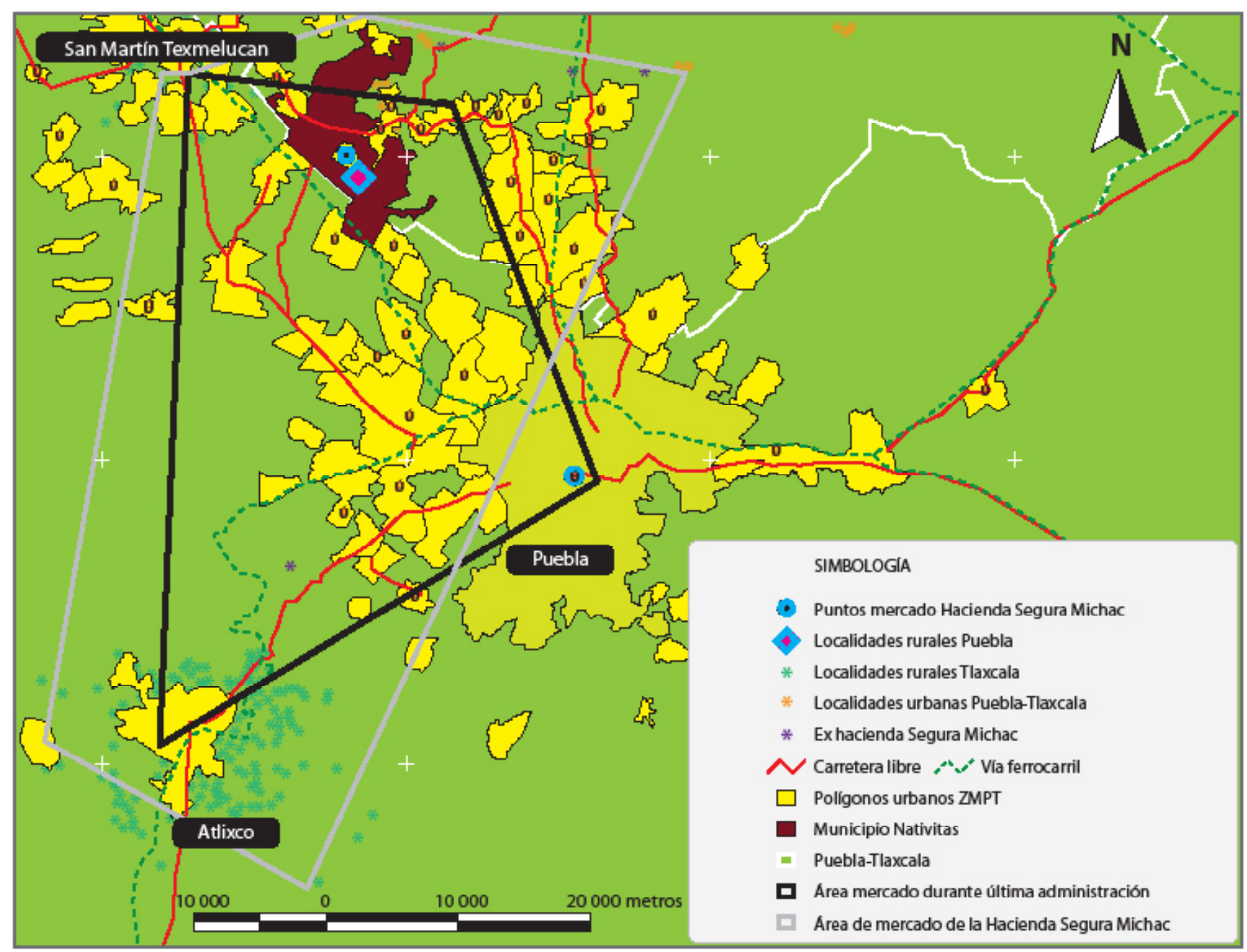

Figura 4. Nativitas en la zona metropolitana Puebla-Tlaxcala (ZMPT 2005) y área de mercado de la hacienda Segura Michac durante la última administración (1960). Fuente: elaborado con base en entrevista con el Sr. Alberto Espinoza e INEGI, 2005. 
indebidamente afectadas" ${ }^{\prime 11}$ y que por lo tanto no eran extensiones afectables. Así, solicita se le devuelvan 100 hectáreas de riego. Respecto a lo anterior, en otro oficio, fechado 29 de noviembre de 1947, el delegado referido solicita a la misma persona "que presente o informe a qué expediente se refiere la Resolución Presidencial dictada el 15 de agosto de 1945 que menciona usted en su escrito, por no tener en esta oficina ningunos antecedentes relacionados con las afectaciones indebidas a la finca de que se trata" ${ }^{82}$

Evidentemente los herederos de la hacienda Segura Michac no pudieron comprobar la tenencia ni presentar los documentos que hubieran declarado injusta e indebida la resolución a favor de los habitantes.

\section{RESULTADOS DEL REPARTO: ASPECTOS Y LECCIONES MEMORABLES}

El proceso de reparto agrario y sus consecuencias, en el municipio de Nativitas, se pueden agrupar en:

1. Una cuestión fundamental para la pacificación de la región, que se caracterizaba por ser problemática y de armas tomar, ${ }^{83}$ además de una mayor dedicación al trabajo de la tierra por parte de los habitantes.

2. Un evento que ha transformado una realidad agraria dependiente y de explotación de la mayoría en una realidad agraria basada en activos y aspectos comunes y de igualdad, dirigida hacia la consolidación de pautas culturales de cohesión social y de libertad de decisión laboral y movilidad. Los abusos por parte de los hacendados son parte de la historia de la región.

3. Un nuevo régimen, a nivel local, donde el campesino adquiere formas de participación política, social y económica: el ejido como la arena de negociación con el Estado.

${ }^{81}$ RAN-T, caja 3, expediente 0194, clave 271.71, Ejido Santiago Michac, legajo 09/44 con fecha 20 de junio de 2006, asunto: privación de derechos ejidales y nuevas adjudicaciones, foja 00278, 20 de octubre de 1947.

${ }^{82}$ RAN-T, caja 3, expediente 0194, clave 271.71, Ejido Santiago Michac, legajo 09/44 con fecha 20 de junio de 2006, asunto: privación de derechos ejidales y nuevas adjudicaciones, foja 00288, 29 de noviembre de 1947.

${ }^{83}$ Como lo expresan oficios revisados del RAN-T, caja 1, expediente 124, clave 23/194, Ejido Santiago Michac, legajo 01/44 con fecha 19 de junio de 2006, asunto: dotación de tierras, foja 00010, 14 de septiembre de 1918, y foja 00056, 18 de noviembre de 1920, donde se habla de levantamientos y/o amenazas de armas tomar por parte de los habitantes de Santiago Michac si la comisión agraria no les resuelve sus asuntos. 
4. Un novedoso orden de organización y producción agrícola, que conlleva a formas particulares de relaciones sociales y económicas en un ámbito relacionado con éstas: el rural.

5. Una ruptura en cuanto al entendimiento conceptual y teórico de dicho ámbito, pues inicia décadas de asimilación y casi sinonimia entre actividades, relaciones y pertenencia a la tierra y entre los habitantes, con el ámbito en el que ello se desarrolla: lo rural. Antes de ese evento, era difícil entender el ámbito rural bajo la definición que predominó durante el siglo pasado, pues las libertades de la población no eran las mismas antes del reparto, el binomio tierra-campesinos no encontraba punto de encuentro equitativo y posible, pues no había propiedad sobre ésta, control sobre la producción, la maquinaria, herramienta o aperos. Las relaciones sociales eran dictadas por las necesidades de las haciendas.

6. Una acentuada discusión académica acerca de la dicotomía campo-ciudad. Al contar con tierra, los campesinos limitarán su búsqueda de oportunidades laborales y habitacionales -al menos inmediatamente después del reparto- como lo solían hacer. Esto permite pensar en variables y parámetros tradicionales de la ruralidad, dejando atrás pautas cotidianas en las cuales la pluriactividad era una constante.

7. Un refuerzo del sentimiento de pertenencia de la población, así como de la cohesión social de las comunidades, pues obtuvieron poder para decidir sobre su territorio al ser parte del mismo. El reparto agrario trajo más libertades a los habitantes para tener decisión sobre su territorio, el cual habían habitado y trabajado bajo una relación ingrata pues en medio de ésta se encontraba todo un sistema que la controlaba: el de las haciendas y sus señores.

8. Una nueva configuración de los núcleos de población, lo que trajo consigo el arraigo de los habitantes y sus familias y demoró, por un tiempo, la emigración hacia Puebla, el Distrito Federal y algunas otras entidades, movimiento demográfico característico en el centro de México durante las décadas del 60 y 70 del siglo xx (mapas 6-9).

\section{COMENTARIOS FINALES}

Sumado a los resultados arriba expuestos, que se pueden resumir como los inicios de una condición importante de arraigo y de una historia diferente en los niveles social y económico para la población del municipio, es preciso acentuar el caso en particular.

Se debe de tomar en cuenta, una vez más, la condición regional con la que cumple el valle de Nativitas en general y el municipio en particular, la cual ha beneficiado histórica y paulatinamente a la población en cuanto a mercados de demanda (de fuerza de trabajo y de producción) para adquirir herramientas, insumos o para enviar a sus hijos o familiares a servicios de salud, 
educación o empleo, pues se encuentra en una región que ha experimentado los efectos del proceso de urbanización, por hallarse relativamente cerca de lugares centrales con "funciones económicas típicas". ${ }^{84}$

El municipio se encuentra en medio de una dinámica importante que recorre desde el Golfo de México hasta la capital nacional, que no es nueva y donde convergen en influencia regional ciudades como Puebla, San Martín Texmelucan y Tlaxcala; desde un enfoque económicoespacial, éstas y otras ciudades pequeñas cumplen con su función principal inherente como ciudades. Afirma Richardson (1973) que esta función es un centro de suministro de servicios y distribución de bienes a la región en que se encuentra, además de ser también lugar de gran consumo y demanda de producción y fuerza laboral proveniente de su hinterland ${ }^{85} \mathrm{u}$ otros lugares de niveles menores a la región en la que se encuentra.

En esta región se han dado procesos estructurales fuera del alcance de los pobladores y de movimientos locales, los cuales no es posible modificar, prohibir o menguar, como el sistema de haciendas. En este caso, se trata del proceso de industrialización que crea condiciones para la modificación del paisaje, pues éste se ve transformado, así como de las expectativas y modos de vida, dirigidos a las ciudades, metrópolis o en algunos casos registrados hacia otros países; del arraigo a la tierra, a la familia, a la comunidad, pues se inicia la migración (nacional e internacional), el abandono de la actividad agrícola como eje de las economías familiares y por lo tanto, municipal; de las actividades laborales tradicionales en mayor magnitud, es decir, el tránsito del sector primario al secundario y/o terciario; a ello, se suma el proceso de envejecimiento que va ligado a otros, como el migratorio. Después de observar qué sucede con la po-

${ }^{84}$ Para Walter Christaller (en Richardson 1973), autor que desarrolló la teoría de los lugares centrales, las ciudades con ciertos aspectos especializados, llamados "funciones económicas típicas" -que pueden ser distribución de las rutas de transporte, la fuerza de trabajo, concentración de actividades industriales, financieras, comerciales, culturales, políticas y administrativas, así como las necesidades de vivienda, transporte y empleo-, son núcleos regionales que a su vez, en su funcionamiento e influencia (donde una restricción es la fricción de la distancia), integran otros lugares, dando así origen a jerarquías y a un hinterland conformado por la movilización de personas, vehículos y bienes. Desde una perspectiva regional, y dado que ha aumentado la cobertura de la infraestructura (vial especialmente) en la región, la población de Nativitas, ocupantes de este histórico territorio y forjadores de su historia, justifica la importancia de ese crecimiento urbano-regional.

${ }^{85} \mathrm{Nels}$ Anderson (1975) describe el hinterland como el (los) territorio(s) objetivo de las "ciudades modernas misioneras", es decir, de las orientadas al comercio y a la industria. Los hinterland son territorios con vastos terrenos que sirven a la ciudad central de varias maneras, por ejemplo, producción agrícola, población en edad laboral, terrenos como reservas para la urbanización. 
blación en su aspecto demográfico y socioeconómico, también vale la pregunta: ¿qué sucederá con estas tierras, con su historia de luchas agrarias, productiva y de importancia regional?

El binomio tierra-población por el que se luchó a principios de siglo xx y se expuso en este trabajo, no parece conservarse como una posibilidad económica para las generaciones presentes y futuras. Es posible afirmar, con base en observaciones y opiniones obtenidas de forma directa de habitantes de algunos pueblos de Nativitas, que el interés por el trabajo de la tierra se mantuvo vigente durante dos generaciones. Después vinieron otros desafíos para los campesinos, sus líderes y sus luchas sociales.

Es claro que en el imaginario colectivo de la población la lucha por el reparto agrario ya no se entiende como una forma de pacificación de la región, pero sí como razón de las relaciones sociales, de la estructura rural-urbana y de las condiciones históricas bajo las cuales se ha desarrollado el municipio. A esto hay que sumar el respeto con el que se trata y entiende a los ejidatarios, además de ser, en su mayoría, personas de la tercera edad, reconocidos como trabajadores, honestos, personas importantes en los núcleos familiares y en la comunidad. Reconocimiento que no es coherente con las políticas agrarias actuales, como se verá en otros capítulos de este libro.

Por otra parte, las necesidades de la población han aumentado y con ellas los intereses y expectativas de la población adulta y joven; de esa manera, el arraigo e interdependencia con la tierra que produjo el reparto ha disminuido.

Es innegable la herencia que el reparto agrario dejó al municipio, no sólo a las personas de aquellos tiempos, sino a los actuales habitantes, pues constituye una razón de ser para quienes cimentaron ese territorio y para quienes valoran esa historia única, de la cual Nativitas fue pilar importante en la región.

Los nombres, fechas, actos, padrones y cartas archivados en expedientes y legajos pueden ser tan sólo registros de injusticias y/o peticiones, controversias o padrones; sin embargo, van más allá de eso. Significan la perdurabilidad de una historia innegable complicada, pero vigente que debe ser conocida por los actuales y futuros habitantes de Nativitas.

Del análisis anterior se desprende una pregunta: ¿qué evento podría ser tan poderoso en el medio rural como el reparto agrario, que trajo consigo novedades y puntos de partida en las esferas de lo político, lo social, lo agrario, lo económico? En Nativitas, como en otros territorios con historia agraria parecida, la vida rural fue una antes del reparto y otra muy distinta después de éste.

Por último, ante los escenarios que se pueden plantear a partir del presente análisis resultante del reparto agrario, será interesante observar las estrategias y respuestas que la población logre desarrollar en el futuro. 


\title{
EL EJIDO EN NATIVITAS: PASADO, PRESENTE Y FUTURO
}

\author{
Hernán Salas Quintanal \\ Rubén Luna Castillo
}

\section{INTRODUCCIÓN}

\section{$\mathrm{D}$}

spués de la Revolución mexicana, la reforma agraria desempeñó un papel central para fortalecer el aparato gubernamental, y junto con la reconstrucción de la economía rural, buscaba hacer justicia social a los pobladores del campo. La forma que adquirió fue el reparto agrario, política del Estado que entregaba las tierras de manera gratuita en forma de ejidos, cuya extensión incluía tierras de labor, residencial y servicios y, a veces, áreas comunes. ${ }^{86}$ Bajo la premisa de que la tierra pertenece a la nación, ${ }^{87}$ el gobierno entregaba la tierra para su uso, pero no en propiedad, a los ejidatarios quienes solamente podían heredarla, en ningún caso venderla ni rentarla. Obviamente este proceso estuvo cargado de conflictos entre hacendados y agraristas. ${ }^{88}$

Desde el inicio del reparto agrario y la creación de los ejidos colectivos en el municipio de Nativitas, proceso que llevó varias décadas después de haber comenzado la revolución de 1910, el ejido ha conducido la vida productiva, la distribución y el acceso a los recursos naturales

${ }^{86}$ Además de la propiedad ejidal, la tierra se repartió bajo los formatos de propiedad privada y mínimamente comunal, tipos de propiedad que no serán incluidos de manera central en este análisis sobre el ejido.

${ }^{87}$ Esta premisa corresponde al artículo 27 de la Constitución de 1917 que establecía la propiedad de la nación sobre el suelo y el subsuelo.

${ }^{88}$ El movimiento agrario o agrarismo se caracteriza por una movilización de masas en la cual los campesinos participaban organizadamente, procurando una distribución justa de la tierra. En México marca el inicio de la Revolución mexicana cuando los campesinos enfrentaron a los latifundistas y hacendados. 
-agua y tierra-, la organización social, territorial y política del municipio. De acuerdo con el INEGI (2007), hoy en día, de las 4234 hectáreas sembradas, 3920.59 (92.58 \% de la superficie cultivable) son ocupadas por doce ejidos y por pequeñas propiedades ${ }^{89}$ Los ejidos conforman, además, patrones residenciales y pueblos, algunos de los cuales no sólo preceden la conformación de aquellos, sino que sobre ellos se conformó la actual distribución ejidal que ocupa 2583 ha (mapa 15).

A partir de indagar el origen de los ejidos del municipio, este trabajo se plantea como objetivo dar cuenta del proceso de consolidación del ejido, de la orientación productiva, de las formas de utilización del trabajo y de las perspectivas que los habitantes tienen respecto al futuro del ejido. La información que sustenta lo aquí presentado fue recabada en entrevistas a ejidatarios y algunos comisarios ejidales, realizadas durante 2010 y 2011; asimismo, se llevó a cabo el trabajo de campo en los ejidos, comunidades y pueblos, con el fin de ubicar antecedentes, recuerdos, historias, anécdotas de la conformación de los distintos ejidos. Los ejidatarios entrevistados son, en algunos casos, hijos o nietos de los ejidatarios originales; aunque la información puede carecer de precisión histórica, expresa la historia de una parte de la población. Por ejemplo, todos recuerdan el nombre de la hacienda y de los dueños a la cual pertenecían las tierras, y algunos se acuerdan del año en que se expropiaron, cuando se hicieron las solicitudes de ampliación del ejido para extender la planta de ejidatarios, construir la escuela o áreas residenciales. Algunos, incluso, recuerdan cuando trabajaron en las últimas haciendas, antes del reparto agrario.

Este trabajo se divide en tres apartados: en el primero se trata el origen y la historia del ejido, para lo cual nos remontamos, brevemente, a la época de las haciendas, asimismo de cómo se conformaron los ejidos y de las principales actividades productivas de aquellos años; en el segundo apartado se describe el proceso de desarrollo y consolidación del ejido en el municipio, analizamos el acceso de la población a la tierra y a los mercados laborales industriales y sus actividades agropecuarias. Finalmente, en el tercer apartado se describe la orientación productiva actual y las perspectivas que los ejidatarios tienen respecto al futuro del ejido y las actividades agropecuarias.

${ }^{89}$ En la entidad existen 4130 unidades productivas, de las cuales 1336.70 son de pequeña propiedad y 2583.45 ejidal. La unidad de producción se refiere al conjunto formado por los terrenos, con o sin actividad agropecuaria o forestal en el área rural o con actividad agropecuaria en el área urbana, siempre y cuando se trabajen bajo una misma administración y se haga uso de los mismos recursos, maquinaria, instrumentos de labranza y mano de obra (INEGI 2007). 


\section{ORIGEN E HISTORIA DE LOS EJIDOS DE NATIVITAS}

Hablar de la historia y del proceso de conformación de los ejidos en el actual municipio de Nativitas nos obliga a hacer un breve recuento de la historia de las haciendas en la región. Esto nos permitirá ver con cierta claridad los elementos comunitarios, económicos y territoriales que siguen teniendo vigencia en la vida social y económica de los pueblos y ejidos que conforman el municipio.

Hasta 1920 las haciendas más importantes, debido a su extensión y al número de personas que empleaban, fueron: Santa Águeda, La Segura, San Juan Molina, Santa Elena, San Antonio, Santo Domingo, San Joaquín y Santa Clara Atoyatenco (Buve 1989; González 1969; Ramírez 1990). En aquel entonces, los poblados en donde residía la mayor parte de la población del municipio eran Santa María Nativitas, cabecera de municipio, San Miguel del Milagro, Jesús Tepactepec, San Miguel Xochitecatitla y San Miguel Analco (mapa 5).

Durante muchos años las haciendas coexistieron con los pueblos donde se agrupaba la población "libre", es decir, que no vivía dentro del territorio de la hacienda, pero que formaba parte del sistema hacendario a través de contratos de fuerza de trabajo. Las haciendas constituían una estructura social cerrada en la que los trabajadores y sus familias laboraban y residían, conformando un sistema económico-productivo en el cual el hacendado era propietario de las tierras, recursos naturales, medios de trabajo y, mediante el sistema de "acasillamiento", tenía el dominio absoluto sobre la mano de obra..$^{90}$ Además, a través de este sistema que imponía un modo de vida, se ejercía un control cultural de la población que, más allá de las fuertes medidas autoritarias impuestas por la administración de la hacienda y el hacendado sobre los trabajadores que habitaban los pueblos aledaños, mantenía a los peones acasillados sujetos a una relación paternalista con base en la dominación ideológica. La carencia de escuelas y la difusión de la fe católica fueron parte de los mecanismos de dominación que apenas comenzaron a desmoronarse con la Revolución mexicana cuando, además de cambiar las condiciones materiales de vida de las poblaciones a la luz del reparto de tierras y del otorgamiento de derechos de agua, se abrieron las posibilidades de la participación política y el acceso a la educación.

El proceso de conformación de los actuales ejidos se inicia en el periodo revolucionario y posrevolucionario -entre 1915 y 1925- sobre la base de la distribución territorial de la pobla-

${ }^{90} \mathrm{La}$ estructura laboral típica de una hacienda consideraba peones acasillados o encasillados -a diferencia de los peones eventuales que permanecían en la hacienda solamente mientras duraba su contrato de trabajoa aquellos trabajadores que habitaban con su familia una casa construida dentro de los límites de la hacienda y contaban con un terreno en el que producían para la autosubsistencia -cuyas dimensiones eran establecidas por el dueño de la hacienda- y que recibían un jornal o salario por cultivar las tierra del hacendado. 
ción en los pueblos y haciendas. Sin embargo, la conformación definitiva de los ejidos es más tardía, en algunos casos data de la década de los sesenta del siglo xx, cuando todavía se dieron dotaciones para la ampliación de ejidos. En casi todos los casos, la conformación de los ejidos generó conflictos; algunos recuerdan confrontaciones con hacendados, invasión de tierras, cesión de terrenos municipales, problemas que fueron parte del contexto revolucionario que en aquel entonces agitaba al país.

La expropiación de una parte de las tierras de la hacienda La Segura -de la cual actualmente sólo queda el casco- dio origen a la conformación del ejido de Santa María Nativitas en el año 1926, con 275 ha repartidas entre 103 ejidatarios. ${ }^{91}$ Con las tierras de la hacienda de San Juan Molina se formó el ejido de San Miguel del Milagro-San Juan Molina; según el actual comisario ejidal, el señor Mauro Morales Hernández, ${ }^{92}$ "estas tierras eran del hacendado, de la hacienda de San Juan Molina, ellos eran dueños de todo esto. En tiempos de la Revolución se les quitó las tierras a todos ellos y se repartió a todos los campesinos". Parte de los terrenos de las haciendas de Santa Elena, Santo Domingo y San Joaquín conformaron el ejido de San Miguel Xochitecatitla, su repartición tuvo lugar entre 1938 y 1940. Posteriormente, entre 1945 y 1950 se realizó una ampliación de alrededor de 75 hectáreas de tierras de temporal. También de la hacienda Santa Elena queda únicamente el casco.

Un ejemplo más de la coexistencia entre pueblos y haciendas es el caso de Santiago Michac. El ejido del mismo nombre se conformó en 1920, con 108 ha de la hacienda La Segura Michac y 237 de la hacienda Santa Elena, agrupaba a 283 ejidatarios y sus respectivas familias. ${ }^{93}$ La población con la que se formó este ejido provenía de la hacienda y del mismo pueblo; sin embargo, según el comisario ejidal, ${ }^{94}$ el pueblo se fundó de manera independiente a la hacienda y antes de la dotación ejidal. De la hacienda La Segura Michac, el señor Alberto Espinoza comenta: ${ }^{95}$

${ }^{91}$ RAN, expediente 134, legajo 05/18., asunto: dotación de tierra, poblado Santa María Nativitas, fojas 00109-00111, 31 de mayo de 1923.

${ }^{92}$ Mauro Morales Hernández nació en 1940 en Nativitas, es comisario ejidal de San Miguel del Milagro. Entrevista realizada en noviembre de 2010 en San Miguel del Milagro, Nativitas, Tlaxcala.

${ }^{93}$ RAN, expediente 194, legajo 01/44, asunto: dotación de tierra, poblado Santiago Michac, foja 037, 08 de enero de 1920; fojas 077-078, 02 de junio de 1921.

${ }^{94}$ Raúl Tenchil Flores nació en 1954 en Santiago Michac, es comisario ejidal de Santiago Michac. Entrevista realizada el 25 de noviembre en Santiago Michac, Nativitas, Tlaxcala.

${ }^{95}$ Alberto Espinoza nació en 1920 en el rancho de Segura, exadministrador de la hacienda de Segura. Entrevista realizada en enero de 2011 en Santiago Michac, Nativitas, Tlaxcala. 
Antes llegaba hasta Nativitas y Jesús Tepactepec, colindaba con la hacienda de San Antonio Michac. Sus dueños eran los Caso, un tal Bernardo Caso, porque más antes todas las haciendas tenían sus dueños. Posteriormente, cuando hicieron el reparto de las tierras, primero agarraron los ejidatarios de Michac toda esta parte, luego los de Nativitas agarraron a los tres años de que tomó el ejido Michac.

[Los del ejido] de Santo Tomás la Concordia ya le habían quitado [tierras] a la hacienda, por eso don Emilio [Emilio Maurer, último propietario de la hacienda San Antonio] ya sólo tenía 100 hectáreas. Por ahí de los años sesenta, los ejidatarios de Santa Apolonia le quitaron esas tierras, [entonces] Natalia Temiza [quien encabezó las demandas de tierra de Santa Apolonia] llevó gente y le quitaron las 100 hectáreas.

Los ejidos de Santo Tomás la Concordia y Santa Apolonia Teacalco tuvieron diferente origen. El primero se formó con la población que se reubicó debido a las inundaciones en sus tierras y el segundo por luchas agrarias locales, respectivamente. En la actualidad, Santa Apolonia constituye un municipio desde 1995 y Santo Tomás es uno de los pueblos y ejido del municipio de Nativitas.

Es importante señalar que la existencia de algunos pueblos es anterior a la conformación de los ejidos como tales, algunos concentraron a la población y servicios para la propia organización social y laboral de las haciendas. El caso de la cabecera municipal, Santa María Nativitas, que seguramente es el pueblo más antiguo del municipio, es particularmente significativo. De acuerdo con la información presentada por Tyrakowski (2003: 161), Nativitas se fundó en los años cuarenta del siglo Xvi cuando se puso en marcha la política de congregación de las poblaciones indígenas que propició la formación de los pueblos de indios en la depresión fluvial del sur de Tlaxcala, perteneciente al señorío de Ocotelulco. Muñoz Camargo (en Tyrakowski 2003: 160) es más preciso en la fecha de fundación de este asentamiento: en 1580 el pueblo con el que se conocía como Santa María Nativitas, Pueblo Nuevo o Tierra Nueva (de acuerdo con el vocablo náhuatl Yancuitlalpan) congregaba indios en ciénagas muy abundantes de maíz y legumbres, ahí -señala- también se asentó un monasterio de frailes franciscanos.

La organización misma de Santa María da muestras de un pueblo estructurado en torno al convento franciscano, del cual aún se conserva parte del edificio, el trazo de la plaza principal y las primeras calles, residencias de administradores tempranos del poder local, hacendario y eclesiástico, quienes luego construyeron el templo dedicado al nacimiento de la Virgen María, hoy la parroquia que constituye el centro de la cabecera municipal. Los demás pueblos se fueron conformando en torno a iglesias católicas consagradas a San Miguel, San José, San Rafael, Santiago Apóstol, Padre Jesús y la Virgen de Guadalupe. 
Otros ejemplos notables son los pueblos que se constituyen muy tempranamente en torno a eventos religiosos, como la aparición del Arcángel San Miguel a principios del siglo xviI, lugar donde se construyen el santuario y el pueblo de San Miguel del Milagro; o las tradiciones alrededor de Jesús de los Tres Caminos, guía y patrono de los arrieros, en Jesús Tepactepec. San Miguel Analco es el caso de un pueblo que crece en las inmediaciones de la hacienda Santa Clara y, en 1873, en torno a la estación del ferrocarril, que formaba parte de una red que unía las haciendas de la región con la ciudad de México y el puerto de Veracruz a través del Ferrocarril Interoceánico. ${ }^{96}$

Como hemos señalado en esta breve descripción del origen de los ejidos del municipio, la conformación de la relación territorial es clara, pero no así la de los pueblos con las haciendas. Esta relación no sólo se limitó a lo territorial, implicó lo económico y lo social, en tanto que, como señalamos con anterioridad, se estima que buena parte de la población de estos pueblos trabajaba en las haciendas y una parte también fue beneficiada con el reparto de tierras convirtiéndose en ejidatarios. De esta manera, al desplomarse el sistema de haciendas con la reforma agraria, la población se fue asentando en los pueblos, los que adquirieron el carácter de residenciales que mantienen hasta la actualidad (mapas 11 y 12 ).

La producción de las haciendas del estado de Tlaxcala tenía una distribución muy específica: las del norte se distinguían por su tradición pulquera, aunque algunas se dedicaban a la ganadería; las del centro estaban volcadas a actividades más industriales, como la confección de textiles y las del sur, región en la que se ubica el municipio de estudio, combinaban la ganadería con la producción de granos, específicamente trigo y maíz (Ramírez 1990).

En términos económico-productivos, la última etapa de las haciendas del sur del estado se caracterizó por la producción de granos, maíz y trigo y actividades pecuarias, como la cría de ganado bovino y producción lechera y sus derivados. Al respecto, un folleto de difusión de la época señala que en la hacienda Santa Águeda se instaló una pasteurizadora de leche en los primeros años del siglo xx (Anónimo 1906). Las haciendas ganaderas abastecían los mercados local y regional, haciendo uso de la conveniente cercanía con la estación del Ferrocarril Interoceánico en Analco. Para asegurar que sus productos pudieran llegar a mercados mayores, como los de las ciudades de Tlaxcala, Puebla y México, los mismos hacendados tendieron vías para conectar sus haciendas con el ramal principal.

Durante aquellos años, las haciendas constituían el principal mercado laboral. Reclutaban trabajadores de acuerdo con las demandas anuales que exigían las labores agrícolas y ganaderas,

${ }^{96}$ Trautmann (1981) establece con claridad los cambios territoriales y poblacionales del paisaje cultural de Tlaxcala en la época colonial. 
por lo que estas tareas no eran desconocidas para quienes, en años posteriores, se convertirían en ejidatarios, de manera que transmitieron las habilidades para combinar el trabajo agrícola con el asalariado a las generaciones venideras, lo que se refleja en la actualidad en los ejidos y unidades familiares de producción. En el pueblo de Santiago Michac, Raúl Tenchil comenta: ${ }^{97}$

Yo iba a trabajar ahí, a la ex hacienda Santa Elena [cuyo dueño era Isidro Candia, quien fue gobernador del estado de 1937 a 1940]. Tenía unos diez años, íbamos porque había muchas vacas, a la ordeña, a la pisca de maíz, a meter forraje para las vacas, etcétera. Pero esta hacienda no era la única. En la ex hacienda de San Antonio también trabajábamos, no estaba lejos, nos íbamos caminando. Emilio Maurer y los Maurer [...] vivieron de la hacienda de San Antonio. Casi todos los del pueblo trabajaban ahí, había mucho trabajo, tenían muchísimas vacas. Llegaba una camioneta especial a cargar la leche. Mi papá todo el tiempo tuvo vacas, ahora las tiene mi hermano, pero todo el tiempo hubo vacas.

Como se puede observar en el testimonio anterior, la relación entre las haciendas y los pueblos no se acabó con la conformación de los ejidos. Después de la expropiación, los dueños de las haciendas conservaron el casco, una parte de sus tierras, las instalaciones productivas y las maquinarias, lo que permitió que continuaran ofreciendo empleo, aunque sobre reglas distintas a las de la etapa anterior. Ahora se trataba de una relación de trabajo mediada, fundamentalmente, por el salario, lo que vino a transformar radicalmente las dinámicas laborales en la región y, tiempo después, en los sesenta, los herederos de los hacendados siguieron empleando población de los pueblos aledaños.

En esta nueva relación entre los pueblos y las ex haciendas, las familias de los ejidatarios comenzaron a combinar la producción dentro de sus unidades con el trabajo asalariado como jornaleros agrícolas, en especial en las ex haciendas que en esta etapa se constituyeron en unidades productivas de corte capitalista. De manera paralela comenzó la diversificación de los ingresos familiares, a través de la participación en actividades asalariadas en diversos mercados laborales. Estas experiencias permitían a poblaciones, en posteriores etapas de industrialización del país, diseñar estrategias para insertarse en otros mercados laborales, industriales y de servicio, dentro y fuera del municipio y de la región.

${ }^{97}$ Entrevista realizada en noviembre de 2010 en Santiago Michac, Nativitas, Tlaxcala. 


\section{DESARROLLO DEL EJIDO EN NATIVITAS: EL BINOMIO AGRICULTURA-TRABAJO ASALARIADO}

Como hemos señalado líneas arriba, uno de los efectos más visibles de la Revolución mexicana en esta región fue la expropiación de las propiedades de las haciendas. El reparto de tierras incluía la cesión de derechos sobre el agua de riego a las poblaciones que residían y trabajaban en el interior de las haciendas y a familias campesinas que habitaban los pueblos. Esta reforma agraria articuló una forma de organización económica y social bajo el sistema ejidal que estableció unidades de producción familiares que cultivaban maíz, así como la liberación de la mano de obra rural. Ambos aspectos fueron fundamentales para la posterior etapa de industrialización; por un lado, la producción de alimentos para las clases proletarias urbanas y, por otro, la posibilidad de costear parte de los gastos de reproducción de mano de obra familiar que, de esta manera, se podía integrar a la industria devengando bajos salarios. Paulatinamente, las unidades domésticas familiares campesinas comenzaron a transformarse en unidades de producción, de consumo y de refugio de fuerza de trabajo que se incorporaba a los mercados laborales únicamente cuando era requerida.

De acuerdo con el modelo nacional de industrialización y ante la necesidad de hacer más productivas las tierras bajo el esquema de los ejidos, después de mediados del siglo $\mathrm{xx}$, tanto el gobierno federal como el estatal comenzaron a crear las condiciones para el establecimiento de un corredor industrial en el valle Puebla-Tlaxcala, aprovechando diversas ventajas: fuerza de trabajo disponible y de bajo costo, infraestructura vial y de comunicaciones que facilitaban el acceso a los mercados urbanos y recursos naturales en abundancia (tierra y agua). Todo esto hace que la región se caracterice por una particular articulación entre las actividades agropecuarias y las industriales (Pérez y Valdivieso 1990; Terrazas 2005; Salas y Rivermar 2011).

Tal como se describe en el séptimo capítulo de este libro, en la década de los sesenta del siglo xx se instaló en los vecinos municipios poblanos de Xoxtla la siderúrgica Hojalata y Lámina S. A. (HYLSA), en San Martín Texmelucan la Petroquímica Industrial Texmelucan y en Cuauhtlancingo la planta de vehículos Volkswagen (mapas 13 y 14). Casi al mismo tiempo se construyó la autopista México-Puebla que conecta el Distrito Federal con las ciudades de Puebla, Tlaxcala y el puerto de Veracruz (Flores 1993: 143-145). Ante este proceso de reconversión económica en que la región pasó a formar parte del modelo nacional de sustitución de importaciones que buscaba impulsar la industrialización del país dejando de lado la agricultura, los pobladores de Nativitas no dejaron de ser ejidatarios ni campesinos, su producción agrícola de subsistencia les permitió convertirse en importantes proveedores de fuerza de trabajo y de 
alimentos que demandaba la creciente clase trabajadora urbana-industrial. Hasta fines de los años setenta este desarrollo industrial permitió que la región se convirtiera en un importante polo de atracción para poblaciones del interior de Puebla, de Tlaxcala y de otras entidades del país que, provenientes de regiones rurales, acudían en busca de trabajo, muchas de las cuales ya formaban parte de un proceso migratorio interno hacia la ciudad capital (véase el capítulo de Rivermar en este mismo volumen).

En este contexto de fuertes transformaciones socioeconómicas en la región y a la par de la introducción de la industria, el sistema ejidal siguió desarrollando el papel de proveedor de mano de obra y de alimentos como base de la economía campesina. En la década de los sesenta, la migración a los principales centros urbanos y el trabajo asalariado en la industria fueron tomando posición como alternativas laborales y de vida. Iniciaba un periodo de migraciones contemporáneas caracterizado por el traslado de población campesina joven, principalmente a las ciudades de Tlaxcala, Puebla y México, impulsadas por varios factores.

En esos años también comenzaba la presión por la tierra. El aumento en el número de familias y el crecimiento del número de hijos de los ejidatarios incrementaron la demanda por la tierra y la poca disponibilidad de ésta obligó, hasta donde fue posible, a la fragmentación de las parcelas, quedando una buena parte de los descendientes sin herencia. Al mismo tiempo, la atracción que las grandes urbes ejercían en la población -fuera por la oferta laboral, por el acceso a servicios, como una alternativa de mejoramiento del nivel de vida y una oportunidad para ahorrar dinero y comprar tierra en sus lugares de origen, la migración estacional o permanente, laboral o por motivos educativos- se fue convirtiendo en un fenómeno generalizado en la dinámica de la población del municipio.

Interesa recalcar que, al inicio, la migración se alternó con las actividades agropecuarias en la comunidad y en el ejido. No fueron pocas las personas de los distintos ejidos del municipio que optaron por la migración temporal a las urbes como alternativa o respuesta a la dificultad para acceder o heredar tierras, desde aquellas que acudían diariamente a las industrias del vecino corredor industrial poblano-tlaxcalteca y de San Martín Texmelucan, hasta los que se instalaban en la ciudad de México, pasando por los que regresaban cada fin de semana a la comunidad, después de trabajar en el comercio informal, en el servicio doméstico, en los servicios comerciales, industrias y en la construcción. Tal como hemos registrado en el trabajo de campo en los poblados señalados, los ingresos obtenidos y, en algunos casos, el ahorro logrado, les permitió a algunos la compra y adquisición de derechos parcelarios, de ganado, de maquinaria agrícola menor, también se invirtió en la construcción de corrales para el ganado, entre otras necesidades. 
En este sentido, las múltiples formas que adquirió el acceso a los mercados laborales permitieron fortalecer la infraestructura productiva agropecuaria, abonando el imaginario tanto de los ejidatarios como de sus hijos en el sentido de vigorizar la parcela ejidal como medio de vida. En otros casos, el ingreso monetario fue utilizado en el mantenimiento cotidiano de quienes permanecieron en los ejidos: la manutención de hijos o padres, los requerimientos escolares, las urgencias de salud y los compromisos en las fiestas u otras obligaciones comunitarias. Al respecto, Mauro Morales, de San Miguel del Milagro, recuerda: ${ }^{98}$

Yo trabajé en [la ciudad de] México treinta años como doblador de láminas en una máquina de 450 toneladas de presión. En un taller mexicano hacíamos placa y lámina. Siempre estaba yo acá, iba y venía a diario, a veces me quedaba yo allá, uno que otro día. [Estuve] en Vallejo treinta años. Me fui de 19-20 años y estuve treinta, me aburrí y me dieron mi dinero en el 86 y me vine para acá [...] Trabajé una temporada en Puebla, pero no me gustó y me fui a México. No trabajé en HYLSA [...] Las tierras las compré con lo que gané allá, antes de ir no tenía tierras. Ya tenía hijos, pero estaban chicos, de ahí salió para las tierras y para mantenerlos, para la escuela [...] todos terminaron la secundaria, porque sólo había eso [...] Yo soy ejidatario desde el 70, ya son 40 años. Compré un ejido que me dejó uno de mis compadres, tengo cinco parcelas, me ofrecen pero ya no he comprado más, me ofrecen porque sabe[n] que uno lo paga, pero ya no. Yo soy dueño más o menos de unas 10 hectáreas, unos cachitos de riego, otros de temporal, otros de cerro y así. Todas compradas, porque yo no soy ejidatario desde un principio, no heredé.

Como vemos, los recursos provenientes del trabajo asalariado posibilitaron el acceso de un sector de la población a la tierra y, con ello, el sustento de las familias por medio de las actividades agropecuarias. Las familias campesinas que invirtieron en la producción agropecuaria y agregaron fuerza de trabajo a las unidades de producción familiar pudieron combinar actividades agropecuarias con industriales, de autosubsistencia con asalariadas, todo ello en un contexto de fuerte interacción del ámbito urbano con el rural. Es importante destacar el sentido agrarista de aquellos años, donde los recursos extra agrícolas se invertían en ampliar las superficies de cultivo de las parcelas ejidales, a pesar de que, en aquellos años no estaba legalmente permitida la compra-venta de tierras porque la ejidal solamente se podía heredar. ${ }^{99}$

${ }^{98}$ Entrevista realizada en noviembre de 2010 en San Miguel del Milagro, Nativitas, Tlaxcala.

${ }^{99}$ Las modificaciones al artículo 27 constitucional, después de 1991, acabaron con esta prohibición, lo que abrió, pero no necesariamente aceleró, un mercado de tierras ejidales. 
Por el contrario, hoy hemos observado que los recursos provenientes de labores fuera de la unidad económica se invierten en un pequeño negocio.

La instalación de un corredor industrial en los años sesenta, dedicado a la actividad automotriz e industrias asociadas como la fabricación de textiles y vestiduras, hojalatería, láminas, pinturas, propició el aumento de la demanda de mano de obra especializada y no especializada, de proveedores, de servicios, de alimentos, al mismo tiempo que se acentuaba la contaminación de tierras y ríos (sobre la contaminación del río Atoyac, ver el capítulo de Salas y Velasco en este libro).

Tanto el trabajo en las industrias aledañas como la migración fueron una alternativa para las unidades de producción familiar ante la paulatina pérdida de sustentabilidad de las actividades agropecuarias. Algunos miembros de la familia continuaron trabajando las tierras y criando animales, otros combinaron el trabajo en la parcela con el trabajo en la industria, otros más cambiaron las actividades agropecuarias por las industriales, otros se establecieron definitivamente en las ciudades.

El caso de la familia de don Eladio Méndez ilustra la combinación del trabajo asalariado con el trabajo en la parcela: ${ }^{100}$

Nunca he trabajado en la industria, yo trabajé de chofer en carretera, ya tengo como cinco años que no trabajo en la carretera. Pero muchas personas sí han trabajo en las fábricas, inclusive mis hijos trabajan en las fábricas. A mí no me gustó. Ellos [sus hijos] nada más en sus tiempos libres trabajan en el campo, pero no tienen vacas porque no les da tiempo de atenderlas. Un hijo estudió en el Colegio Militar de México, cumplió la milicia y se salió, conoció [a] un militar que trabajaba en San Martín, él lo llamó para que trabajara en la planta de Santa Julia, donde hacen cerámica, loseta. El otro trabaja de albañil.

La alternancia de actividades agropecuarias en el ejido y las asalariadas ha representado a lo largo de las últimas décadas una alternativa para la población de Nativitas. Además de satisfacer una parte de las necesidades de la familia, el ejido provee mano de obra y ha continuado abasteciendo alimentos al mercado regional. Los centros de población, los pueblos que conforman el municipio, fueron consolidándose como núcleos urbanos que demandan servicios y productos manufacturados. A la luz de la transformación de la composición del ingreso familiar, que trajo aparejado el aumento de los ingresos monetarios, se generó una diversificación de la oferta de

${ }^{100}$ Eladio Méndez es comisario ejidal de San María Nativitas, cabecera municipal. Entrevista realizada en octubre de 2010 en Santa María Nativitas, Tlaxcala. 
servicios, con lo que se dio un importante crecimiento del sector terciario. La pluriactividad ${ }^{101}$ surge entonces no sólo como una alternativa a la contracción de las actividades agropecuarias, sino como una demanda de la propia población, demanda que se modificó a la luz de los procesos de urbanización de las zonas rurales vividos en el país y, de manera concreta, en el municipio de estudio, en las últimas décadas.

Don Raúl Tenchil ${ }^{102}$ relata sus experiencias laborales donde se puede observar la combinación de diversas actividades a lo largo de su vida y en el interior de la economía familiar, cuando comenzó a buscar la complementación de ingresos, más allá de las actividades agropecuarias, pero sin abandonarlas completamente.

Después [de trabajar en las haciendas de San Antonio y Michac] estudié primaria y secundaria, a los 18 años me fui a trabajar a la fábrica. Estudié en Santa Apolonia Teacalco la secundaria, porque entonces no había aquí [en Michac]. Me ayudó mucho porque esa fábrica lo que pedía era que tuviera certificado de secundaria. A los 23 años entré a HYLSA, tardé 15 años. HYLSA llegó como en 1965-67. Estaba yo chiquito cuando llegó la fábrica, mi papá trabajó allá, mucha gente de aquí trabajó allá. Trabajábamos las 24 horas [...] Mi esposa y yo teníamos animales. En ese entonces no tenía mi terreno. Tenía terrenos empeñados y de ahí sacaba la alfalfa y les daba de comer a las vacas. Mi esposa les echaba de comer y a la ordeña. Nos ayudamos entre los dos, por eso tenemos el terreno éste, yo no tenía nada, por eso mi esposa y yo le damos el valor a esa tierra porque nos costó. Puro trabajo, hasta ahora en la actualidad [...] Trabajé [en HYLSA] como hasta el 94, dejé la fábrica por el riesgo. En aquel tiempo era muy rústico, pura gente es la que hacía el trabajo. En ese tiempo mucha gente se accidentó y falleció. Yo me salí por ese riesgo. Decidí mejor irme, hubo oportunidad de la liquidación, me liquidaron, me incorporé cien por ciento a mis vacas. No trabajé en otra actividad. Mi esposa estaba prácticamente al frente de los animales mientras yo estaba en la fábrica. De las vacas salió para la casa, para el terreno, para la educación de los hijos, útiles, pasaje [...] afortunadamente ese esfuerzo valió la pena: saqué a mi familia adelante, saqué mi casita, tengo una hectárea de terreno, que con esa sobrevivo.

Es hacia finales del siglo xx, en el contexto de la globalización, que comienza a visualizarse la profundidad de la crisis de producción de las economías campesinas y por lo tanto el significativo aumento de los ingresos rurales no agropecuarios. Como dos imágenes de una misma moneda, estos hechos pusieron de relevancia la complejidad de las sociedades rurales al inte-

${ }^{101}$ Respecto al análisis de la pluriactividad en los pueblos rurales y ejidos, ver Arias 2009.

${ }^{102}$ Entrevista realizada en noviembre de 2010 en Santiago Michac, Nativitas, Tlaxcala. 
grarse a mercados laborales industriales, de servicios y comerciales, de sectores secundario y terciario (Carton de Grammont y Martínez 2009).

\section{SITUACIÓN ACTUAL DEL EJIDO}

A lo largo del siglo xx, el paso del sistema de haciendas a ejidos significó fuertes alteraciones en la orientación productiva de la región y del municipio. La fragmentación de las propiedades, la parcelación, las modificaciones en el acceso y propiedad y la generación de conocimientos sobre técnicas de cultivo y uso de tecnologías, como las que representaron la revolución verde, y las políticas de apertura paulatina al comercio internacional, dejaron en el pasado los sistemas extensivos de trabajo de la tierra.

Lo anterior se vería reflejado en la estructura de cultivos del municipio. Por ejemplo el trigo, cultivo central en la economía hacendaria, fue perdiendo superficie cultivada hasta después de los años cincuenta del siglo $\mathrm{xx}$, que fue cuando comenzó a incrementarse la superficie cultivada de maíz, que para el censo agropecuario de 1950 era de 2275 ha y para el año 1960 de 3590 , magnitud que con algunas variaciones se mantiene hasta nuestros días. Otro ejemplo de los cambios productivos fue la introducción y ampliación del cultivo de alfalfa desde 1970 que corresponde a la época en que adquiere importancia la actividad ganadera y la crianza de animales domésticos en la economía campesina. Fue en las décadas de los cincuenta y sesenta del siglo xx cuando el país ingresó al comercio mundial de productos agrícolas y con ello decayó completamente el comercio interno, de manera que las economías campesinas cerraron filas en torno a la producción de productos básicos y de subsistencia, como frijoles y maíz. En muchas economías ejidales, como veremos en el caso del municipio estudiado, estos cultivos se acompañaron de algunos comerciales que son secundarios en el uso de extensión de tierra, como hortalizas, chiles y amaranto, pero centrales para ingresar al mercado.

A partir de los datos censales disponibles es evidente la importancia del cultivo de maíz en las parcelas ejidales. Desde la segunda mitad del siglo pasado hasta el presente, el maíz ha sido central, es el cultivo que ocupa la mayor parte de hectáreas destinadas a su producción, tanto en el estado de Tlaxcala, donde continúa creciendo la superficie cultivada, como en el municipio de Nativitas, como puede observarse en las figuras 5 y 6 y los cuadros 13 y 14 .

A diferencia del espacio municipal, en el estado de Tlaxcala el trigo vuelve a adquirir importancia a partir de la década del 90 del siglo xx, desplazando incluso a la cebada. Destaca en este año la aparición del cultivo de alfalfa que en cantidad de superficie puede parecer insignificante, pero adquiere relevancia por su valor como forraje. Esto indica una inclinación cada vez 
más específica en el estado hacia la ganadería, quedando la agricultura en un papel económico secundario y/o como complemento de la actividad pecuaria.

Actualmente, de acuerdo con el último censo agropecuario (INEGI 2007), del total de la extensión territorial del municipio de Nativitas, $77 \%$ está destinado a la agricultura, $14 \%$ a zona urbana, $8 \%$ a pastizal y $1 \%$ de bosque. Al igual que el comportamiento estatal, a nivel municipal el maíz forrajero ha sido el principal cultivo, excepto en el año de 1991, cuando el cultivo de cebada se elevó de tal manera que coincide con la caída del precio del maíz y con el incremento de actividades pecuarias, ya que buena parte de la producción de cebada tiene como finalidad la fabricación de alimentos para ganado.

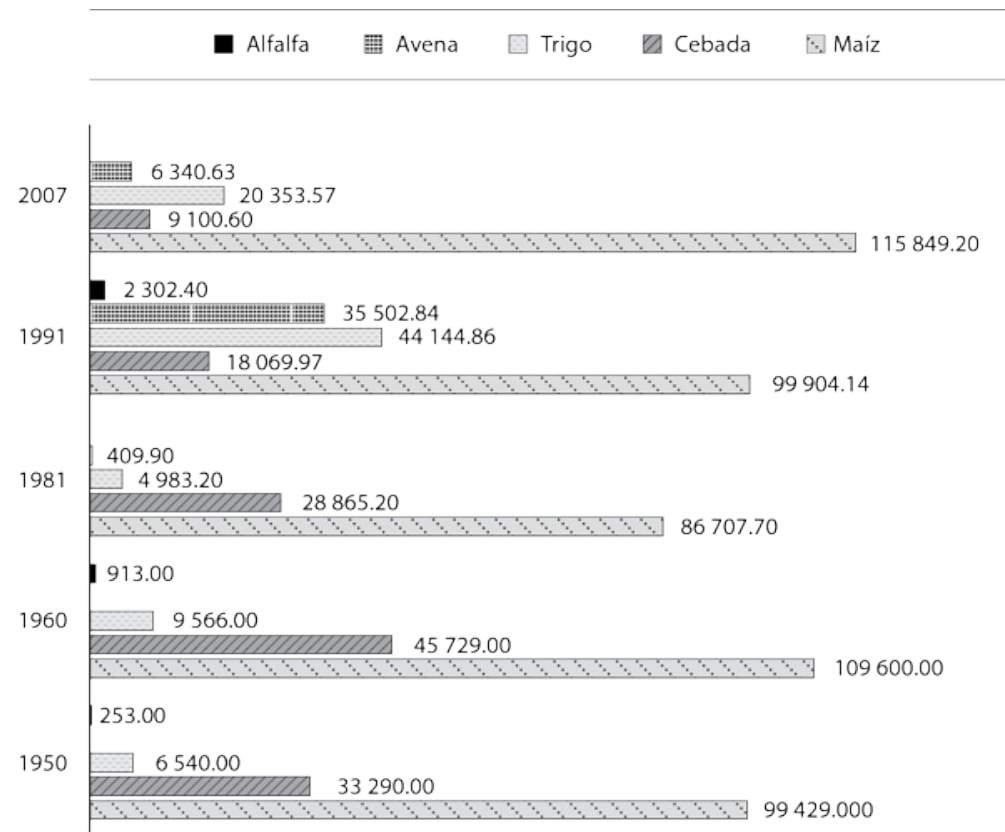

De acuerdo con la superficie sembrada (INEGI 2009), en la actualidad el cultivo de maíz continúa siendo central en los terrenos ejidales, pero es notable la importancia de la alfalfa verde y forrajera. Si consideramos los cultivos destinados a forrajes, alfalfa y maíz de grano, tenemos que casi $70 \%$ de la superficie cultivada está asociada a la producción de alimentos para ganado. En el cuadro 13 destaca, además, que la totalidad de la tierra está cultivada.
Figura 5. Superficie sembrada y cultivo por año censal en el estado de Tlaxcala (hectáreas). Fuente: DGE 1956, 1965; INEGI 1981a, 1991a, 2007. 
Figura 6. Superficie sembrada y cultivo por año censal en el municipio de Nativitas (hectáreas).

Fuente: DGE 1956, 1965; INEGI 1991a, 2007.

\section{- Alfalfa 叛 Avena $\square$ Trigo Cebada $\square$ Má́z}

2007

991

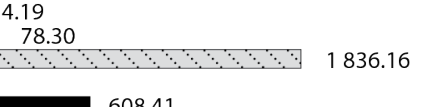

4.50

608.41

IIIII 3400.00

89.00

1960

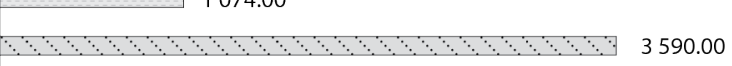

62.00

1950

$\because \because \because \because \because \because \because \because \bigcirc \quad 2375.00$

\begin{tabular}{lcc}
\hline \multicolumn{1}{c}{ Cultivo } & Superficie (ha) & Porcentaje \\
\hline Maíz grano & 2939 & 69 \\
\hline Frijol & 279 & 6 \\
\hline Alfalfa verde & 214 & 5 \\
\hline Avena forrajera & 193 & 4 \\
\hline Tomate verde & 43 & 1 \\
\hline Otros cultivos & 567 & 13 \\
\hline Total & 4234 & 100 \\
\hline
\end{tabular}

La mayoría de las familias ejidatarias del municipio de Nativitas se dedica a la ganadería, principalmente a la producción de leche. Por ello, buena parte de la actividad agrícola está enfocada a la producción de forraje y, en menor medida, de maíz, frijol y jitomate, destinados al autoconsumo y al mercado regional. Cabe mencionar que en el municipio se cosecha el maíz criollo, la milpa, además genera una variedad importante de alimentos para los seres humanos -elotes, cuitlacoche, calabazas, flor de calabaza y, en algunas ocasiones, frijoles y chiles- y el maíz se utiliza para alimentar aves, borregos, cerdos y vacas, de acuerdo con la tradicional forma de combinar los forrajes. Las unidades de producción familiar tienen en promedio hatos 
de seis a diez vacas lecheras, muchos apenas tienen una o dos, en la modalidad de traspatio en pequeños corrales que operan con mano de obra familiar.

Respecto a la crianza de animales y en específico de vacas, la principal actividad comercial de las familias es la venta de leche, por encima de la de ganado. Eladio Méndez, nativiteño dedicado a la producción de leche, comenta al respecto: ${ }^{103}$

Desde que yo recuerdo siempre hemos tenido vacas, [antes] se alternaban con las legumbres, ahora siembran cada año tomate, en febrero, marzo, pero se corre el riesgo de que se queme por el agua contaminada [...] Aquí más que nada sembramos maíz, frijol ya no porque se echa a perder, y alfalfa para el ganado. La mayoría de los ejidatarios producen alfalfa pero en poca extensión, por lo que la mayoría se dedica al ganado, vacas y borregos.

Las vacas se ordeñan dos veces al día: en la mañana y en tarde-noche; la leche es recolectada todas las mañanas por empresas procesadoras de lácteos. El promedio de producción de leche por vaca es aproximadamente de seis a diez litros diarios, cantidad que puede variar dependiendo de la calidad del ganado, del alimento y de su cuidado. El precio del litro actualmente se paga entre 4.50 y 5.00 pesos. El comercio de ganado se da en dos modalidades: compra-venta de vaquillas al destete entre productores regionales y venta de vacas de desecho a carniceros locales. El precio de pie de cría oscila entre 18 y 20 pesos por kilo y el de las vacas de desecho entre 500 y 800 pesos, dependiendo el estado del animal y los acuerdos en el momento de la compra-venta.

El ejido de Santiago Michac ilustra la actividad ganadera en pequeña escala, definida por las características de las tierras. Según el comisariado ejidal de esta localidad, don Raúl Tenchil: ${ }^{104}$

hay tierras de temporal y de irrigación. Como un $60 \%$ de riego por $40 \%$ de temporal. El agua de riego es de los pozos, no es de río, no está contaminada [...] casi todos [los ejidatarios de Nativitas] sacan leche, como un $70 \%$. [Ellos] también tienen sus tierras y siembran puro forraje y zacate, avena, evo, alfalfa [...], todo lo que es el forraje para las vacas. [...] Producen otras cosas, y de eso, lo que se logre vender se va y lo que no, se va para las vacas. El resto se dedica a la construcción, son profesionistas. Algunos otros siembran acelga, perejil, cilantro, col, rábano, como un $5 \%$.

${ }^{103}$ Entrevista realizada en octubre de 2010 en Santa María Nativitas, Tlaxcala.

${ }^{104}$ Entrevista realizada en noviembre de 2010 en Santiago Michac, Nativitas, Tlaxcala. 
No cabe duda de que la fluidez diaria de ingresos monetarios por la venta de leche y la posibilidad de vender un ejemplar en casos de una emergencia son importantes incentivos para que un buen número de familias destinen sus esfuerzos a la ganadería bovina. Hemos registrado casos en los que la venta de una vaca ha permitido financiar la migración de algún miembro de la familia, una celebración familiar, como boda, quince años, bautizo, clausura escolar, etcétera. Las familias crían, además, otros animales -aves, puercos, borregos, chivos- que tienen un papel central en el ciclo ceremonial y festivo de la comunidad, además del mercado. En el cuadro 14 se puede observar el total de ganado y recursos pecuarios en el municipio en los años de 1997, 2002 y 2009.

Cuadro 14. Ganado y recursos pecuarios en el municipio. Fuentes: a) INEGI 2003; b) INEGI 2010a.

\begin{tabular}{lccc}
\hline \multicolumn{1}{c}{ Ganado } & $1997(a)$ & $2002(a)$ & $2009(b)$ \\
\hline Bovino & 3129 & 4226 & 4626 \\
\hline Porcino & 1394 & 4632 & 4713 \\
\hline Ovino & $\mathrm{s} / \mathrm{i}$ & $\mathrm{s} / \mathrm{i}$ & 3347 \\
\hline Caprino & 18 & $\mathrm{~s} / \mathrm{i}$ & 180 \\
\hline Aves & 3408 & 12979 & 18242 \\
\hline Colmenas & 285 & 435 & 68 \\
\hline
\end{tabular}

Es indudable la importancia que estas cifras revelan sobre la ganadería de traspatio en el municipio, y hay que llamar la atención sobre el proceso de complementación entre la agricultura y la ganadería como estrategia productiva de las familias ejidales, que opera de manera diferenciada en cada pueblo del municipio. La creciente demanda de algunos alimentos en el mercado regional y nacional incentivó la diversificación de actividades agrícolas en la región. Aunado a la feracidad de la tierra, el acceso al agua de riego ha definido la reorientación de la producción de algunos ejidos del municipio hacia el mercado de hortalizas y cereales. Es el caso de los ejidos de San Miguel Xochitecatitla y San Miguel del Milagro, que cuentan con tierras de riego, en su mayoría parceladas y, en menor medida, para uso común, lo que les ha permitido posicionarse como los principales productores de hortalizas en la región.

Según el comisario ejidal, una de las particularidades de San Miguel Xochitecatitla es que no hay tierras de uso común y la mayoría son de riego, lo que le da un potencial productivo importante a la localidad. Ahí se han dedicado a la agricultura protegida, bajo el formato de invernaderos. La producción intensiva de algunas hortalizas, principalmente jitomate, ha permitido la diversificación de las técnicas de producción, lo que ha redundado, en ocasiones, en el incremento de la misma. A lo anterior se suma que este ejido logró tener un local en la central 
de abasto de la ciudad de México, por lo que el proceso de comercialización no depende de intermediarios para colocar sus productos; son los mismos productores quienes trasladan y venden su cosecha.

Otro ejemplo de la complementación de actividades pecuarias con la producción de hortalizas y cereales destinada al mercado regional y nacional ocurre en el ejido de San Miguel del Milagro. Don Mauro Morales narra la orientación productiva de una unidad de producción familiar característica del ejido: ${ }^{105}$

Sólo me dedico al campo. Siembro maíz, frijol, amaranto, que es el que deja más dinero, vale más. El maíz es para las vacas, [producimos] forraje porque tenemos animales. En los últimos años sembramos mitad de maíz y mitad de amaranto. La mayoría de ejidatarios tienen animales, muy pocos, unas dos o tres vacas. Todos trabajan sus parcelas para forraje o los engordan y después los venden, porque el maíz es barato. Aquí también sembramos para la venta, mandamos maíz, tomate, carne, no sabemos para dónde, Puebla o México. Este ejido puede ser [definido] como ganadero, porque criamos animales y la siembra es para los animales.

Cabe mencionar la importancia que tiene la producción de cereales, particularmente el amaranto, en el ciclo 2001-02 la región ocupó 177 ha en la producción de este producto (INEGI 2003), al que se le agrega valor al procesarlo en los 16 talleres semifamiliares de San Miguel del Milagro, por lo que hay una producción diferenciada. A decir de don Mauro "[el] amaranto aquí se hace y se lleva para la ciudad de México, otros hacen el dulce. Sí siembro el amaranto, no hago [el dulce], se lo vendo al que está haciéndolo [...] y con eso me ayudo de dinero. La gente que hace el dulce no trabaja el campo, sólo se dedica a procesarlo".

\section{REFLEXIÓN FINAL: PERSPECTIVAS DEL EJIDO}

En este trabajo hemos podido observar la importancia del ejido en tanto formato de tenencia de la tierra como en la organización productiva, como complemento y, en algunos casos, refugio de la fuerza de trabajo familiar que se emplea fuera del ejido. Desde que se hicieron las dotaciones ejidales, el ejido ha desempeñado un papel fundamental en la reproducción de prácticas socioculturales de la población. Las perspectivas que algunos ejidatarios tienen respecto al papel del ejido en un futuro inmediato son diversas. Por un lado, existe una visión que valora y

${ }^{105}$ Entrevista realizada en noviembre de 2010 en San Miguel del Milagro, Nativitas, Tlaxcala. 
aprecia las tierras con fines productivos, asignando al ejido un futuro viable como abastecedor de alimentos y base de la satisfacción de diversas necesidades familiares. Don Raúl Tenchil expresa esta perspectiva en los siguientes términos: ${ }^{106}$

El ejido para mí es algo grande. Desde el principio sabía que tarde que temprano sobreviviría de ahí. He tenido la idea de que no todo el tiempo estaría en la fábrica, todo el tiempo tuve mis animales. Por nada ahorita doy mi terreno. Hasta ahorita no lo he heredado, sólo tengo a mi esposa como sucesora. Es algo grande, algo que me costó muchos años de trabajo. Por nada lo doy, primero porque me gusta la tierra, de ahí tengo, de ahí como, de ahí le tomo yo el valor a todo, de ahí he sacado a mi familia adelante. No me voy a deshacer de ella mientras viva. Es la única forma de vida que tenemos mi esposa y yo ahorita.

Sin embargo, no todos comparten esta idea respecto al papel y al futuro del ejido como posesión de tierras pero, sobre todo, como medio de vida de las familias. Al respecto, don Mauro Morales comenta: ${ }^{107}$

yo digo que los terrenos van a llegar a manos de los ricos otra vez, porque ya los jóvenes no quieren trabajar. Aquellos que pelearon para que nosotros tuviéramos y nosotros vamos a entregar otra vez, porque ya no se mantiene uno del campo. Una o dos parcelitas, $\iota^{a}$ poco vas a darle estudio a tus hijos con lo que salga de ahí? Por eso lo que hacen unos es vender y les compran una plaza a sus hijos y ya, porque del campo ya no van a vivir.

Estos contrastantes testimonios representan la visión que buena parte de los campesinos del municipio tienen del ejido. Las perspectivas que tienen los ejidatarios pueden resumirse en los siguientes puntos fundamentales:

a) El valor económico y social que tiene el ejido.

b) El ejido como alternativa económica.

c) El ejido como forma de vida.

d) La idea de que los jóvenes no saben trabajar la tierra y tampoco están interesados en ser agricultores.

e) El temor de que vuelva a haber un proceso de concentración de tierras.

${ }^{106}$ Entrevista realizada en noviembre de 2010 en Santiago Michac, Nativitas, Tlaxcala.

${ }^{107}$ Entrevista realizada en noviembre de 2010 en San Miguel del Milagro, Nativitas, Tlaxcala. 
A partir de estas perspectivas sobre el ejido, podemos concluir que:

1. El ejido se valora económica y socialmente, por lo que se le considera un bien inalienable, valoración que deriva de las dificultades que sus antecesores tuvieron para llegar a obtener tierras. Asimismo, el valor social que se le asigna al ejido tiene su sustento en concebir la agricultura como una forma de vida.

2. Al igual que en otros aspectos, existen versiones encontradas respecto al valor económico del ejido: para algunos ejidatarios el ideal sería que sus hijos continuaran trabajando las tierras del ejido, mientras que otros quisieran que sus descendientes fueran profesionistas o, en el peor de los casos, trabajadores asalariados, pero no campesinos.

3. Se valora su carácter productivo. Aunque, como hemos visto, la pluriactividad es fundamental dentro de la economía familiar, se sigue reconociendo que el ejido satisface de manera complementaria ciertas necesidades básicas de las familias.

4. Una idea generalizada entre los ejidatarios entrevistados es que los jóvenes no están interesados en las actividades agrícolas o ganaderas, porque desean obtener dinero rápido y fácil, por lo que no ven en el campo una alternativa económica ni laboral. Los mayores explican esta situación por el hecho de que a los jóvenes no les ha costado tener tierras, por eso no las valoran. Esto les genera gran incertidumbre, pues no saben quién se hará cargo del cuidado y reproducción de las tierras ejidales.

5. Un último aspecto, que permite ver el carácter ideológico-político que subyace en la mentalidad de los ejidatarios y tiene su base en las luchas que sus padres y/o abuelos libraron contra los hacendados, las cuales derivaron en el reparto agrario, es la preocupación sobre la posible concentración de tierras en pocas manos. Los ejidatarios ven con preocupación que la posesión o el usufructo de las tierras a través del trabajo en mediería, renta o venta, se diluya si las tierras se vuelven a concentrar en pocas manos y, con ello, se pierda su carácter social y comunitario.

Podemos concluir con una reflexión, un cuestionamiento discutible. El ejido, que ha sido una forma de organización social, productiva y de representación política por casi cien años, se encuentra en un claro deterioro en su papel fundamental que fue el de sostener la economía familiar de la sociedad rural y su tendencia a desaparecer genera incertidumbre, en la medida que no se vislumbra un sistema de representaciones que pueda reemplazarlo. 


\title{
REPENSANDO EL PASADO AGRÍCOLA PARA ENTENDER EL PRESENTE RURAL
}

\author{
Paola Velasco Santos
}

\footnotetext{
$\mathrm{C}$
} omo ya es sabido, las políticas neoliberales, la contrarreforma agraria, el tratado de libre comercio y la reestructuración económica tuvieron efectos negativos en el campo mexicano, sobre todo en los pequeños productores. Desde la década de 1970 el número de personas dedicadas a las labores agrícolas está en franco decrecimiento y, por el contrario, aquellos dedicados a los sectores terciario y secundario engrosan las estadísticas laborales.

En 1994, en su libro La historia del siglo XX, el historiador Eric Hobsbawm sostuvo que: "El cambio social más drástico y de mayor alcance en la segunda mitad de este siglo [el xx], y el que nos separa para siempre del mundo del pasado, es la muerte del campesinado" (Hobsbawm 1998: 292). Ciertamente, a nivel global, la imagen tradicional del campesino se ha vuelto un poco difusa, particularmente debido a una crisis sistémica en el campo; la agricultura de pequeña escala como única vía para el sostenimiento de una familia resulta improbable. El ingreso de los hogares en los llamados espacios rurales proviene de una diversidad de fuentes que combinan la elaboración de artesanías, el trabajo asalariado, los servicios, el comercio, la migración, la recepción de remesas, los programas asistencialistas y la agricultura a pequeña escala.

Contra todo pronóstico, el país aún cuenta con pequeños productores que continúan trabajando sus tierras ejidales o de propiedad privada, con producción para el autoconsumo, la alimentación de animales de traspatio o para un mercado local o regional, articulando ésta con actividades múltiples en el seno familiar y en un mismo individuo. Hace un siglo, la cuestión agraria surgió como una herramienta analítica para comprender la forma en la que la agricultura a pequeña escala se acoplaba al sistema capitalista y cómo ciertos factores que la caracterizaban, como la tenencia de la tierra, la organización laboral (familiar) y la reproducción social, se transformaban para dar paso a la acumulación de capital. 
Sin el afán de regresar a la discusión sobre el futuro del campesinado, la continuidad de estos productores y la forma en la que se han enfrentado a la globalización neoliberal merece especial atención y nos obliga a preguntarnos no sólo cómo las sociedades rurales se han transformado, sino cómo y por qué los pequeños productores siguen cultivando en el contexto de un sistema capitalista cada vez más libre y flexible. A partir del caso del municipio de Nativitas, Tlaxcala, el presente trabajo busca entender la dinámica socioeconómica que ha permitido a los ejidatarios y pequeños productores reconfigurar el trabajo agrícola frente a sus otras actividades y enfrentar condiciones adversas, como el estado de deterioro ambiental en el que se encuentra su principal fuente de riego y la negligencia del Estado y de las clases hegemónicas en materia agrícola y de bienestar social.

En un primer vistazo el análisis parecería centrarse en las posibles respuestas, resistencias y acomodos de los nativiteños ante las políticas neoliberales más recientes; sin embargo, este corte temporal nos ofrecería explicaciones parciales o inmediatas que aíslan los procesos de larga duración que han dado forma a la situación actual. Por ende, el trabajo opta por ofrecer un panorama histórico más profundo, el cual nos permite redimensionar el neoliberalismo y colocarlo en la historia local y global como la prolongación de un conjunto de relaciones, discursos y prácticas capitalistas.

Ciertamente las prácticas y políticas neoliberales han generado mayor desigualdad, mayor explotación y mayor rapacidad de las clases hegemónicas. La "violencia global forense del neoliberalismo", como le llama Neil Smith (2009: 407), ha sacrificado ya miles de vidas a través de la violencia de Estado, de la guerra, del desempleo o de la hambruna, por mencionar sólo algunos. No obstante, es necesario tomar en cuenta que esta oleada es una extensión del sistema capitalista; sus efectos, por tanto, no deben aislarse de este devenir histórico, el cual se ha configurado de manera diferenciada en cada nación, región y lugar. En este sentido, para poder entender la situación actual de los ejidatarios de Nativitas es importante tener una dimensión histórica, en tanto que no es posible explicar el presente sin comprender el pasado (Roseberry 1991).

La propuesta del último trabajo del antropólogo William Roseberry de localizar histórica, espacial y estructuralmente al capitalismo nos puede ayudar en esta tarea, en tanto que busca una conceptualización etnográfica para delinear constelaciones locales apropiadas para el análisis de momentos particulares y configuraciones estructurales de un capitalismo histórico. Su propuesta radica en contextualizar las situaciones locales, rastreando redes y definiendo lo local y lo global como relaciones, más que como esencias de espacios diferenciados. El objetivo, pues, es convertir los poderes y fuerzas externas en internas, lo que se consigue a través de "colocar lo local en una relación específica con procesos de acumulación específicos" (Roseberry 2002: 65). De tal suerte, el análisis etnográfico que internaliza lo global dentro de lo local 
nos da luz sobre "la formación de estructuras específicas de acumulación en el tiempo y en el espacio" (Roseberry 2002: 77).

Bajo esta lente, el texto sugiere que la precarización de la agricultura, la diversificación ocupacional, la migración y el fin de la agricultura como eje de la vida comunitaria no son producto unívoco de la neoliberalización, sino la continuación de procesos de adaptación, negociación y resistencia que las sociedades rurales en México han ido tejiendo para enfrentar las políticas socioeconómicas que les son adversas desde mediados del siglo pasado. Estas acciones, sin embargo, están inmersas en una estructura hegemónica que si bien no las determina, las constriñe. Traigo a colación la propuesta de Ricardo Macip y los autores del libro Sujetos neoliberales en México (2009) de utilizar el concepto de sujeto, en vez de actor o agente social, en tanto que el segundo concepto supone una arena de acción libre y autónoma del Estado. Si el neoliberalismo es parte del aparato estatal mismo y éste produce ciertos sujetos, entonces, éstos actúan (ya sea a través de resistencias, negociaciones, adaptaciones) bajo circunstancias que no son completamente elegidas por ellos mismos. De forma que las transformaciones en Nativitas responden a varios momentos de cambio estructural nacional dictados por las necesidades del capital mundial y nacional, entre los que destacan la llamada revolución verde y la apertura comercial neoliberal. Los reacomodos y reconfiguraciones adoptadas por los pequeños agricultores al responder a los efectos indirectos de la revolución verde se constituyeron como los cimientos más fuertes para la persistencia de una agricultura complementaria y mínima, pero que continúa dándole vida a los ejidos del municipio.

La información empírica en la que se basa parte de este trabajo se recopiló durante diversas temporadas de campo entre junio de 2008 y diciembre de 2010. El presente capítulo consta de cuatro apartados. El primero es una sucinta exposición de antecedentes sobre el municipio. El segundo se refiere al pasado agrícola de Nativitas y el contexto nacional (global) de las décadas de 1940-1970 cuando las políticas en torno a dicho sector tomaron un rumbo que priorizó los intereses del gran capital, siendo negligente con los pequeños productores, la autosuficiencia alimentaria y el medio ambiente. El tercer apartado describe la continuación de estas políticas y la postura del Estado y gobierno mexicano, que no se han desvanecido, sino que continúan siendo el garante de los intereses de las grandes empresas, pero a un ritmo más salvaje y depredador. Históricamente estos dos momentos han sido catalogados como la "revolución verde" y el "capitalismo neoliberal", y no son los únicos procesos globales-nacionales que se han expresado localmente, sin embargo, en términos analíticos son dos momentos definitorios, además de la fuerte industrialización de la región entre 1960 y 1990, en las dinámicas económicas, sociales y territoriales de Nativitas. 
Finalmente, el último apartado sitúa a Nativitas en el presente, como resultado de la dinámica histórica presentada en las primeras tres secciones. Se analiza la forma en la que la agricultura y la ganadería de traspatio están insertas en las formas de subsistencia de los habitantes de este municipio y el papel de la contaminación de sus principales ríos. El objetivo principal de este capítulo es dar cuenta de la forma en que los nativiteños han entretejido complejas estrategias socioeconómicas que no son resultado de una decisión libre y racionalizada individualmente, sino que son formas de negociar, resistir y adaptarse al contexto ambiental, social y político en el que están insertos y en donde las relaciones desiguales de poder son evidentes.

\section{ANTECEDENTES BREVES DEL MUNICIPIO}

El municipio de Nativitas está ubicado en el suroeste de Tlaxcala. Sus tierras agrícolas se pueden apreciar en una porción del recorrido por la autopista de la ciudad de México a Puebla. Detrás de los verdes campos de cultivo, sobresalen en el paisaje dos montes que sirven de base para los sitios arqueológicos de Cacaxtla y Xochitécatl. Además de colindar con la autopista México-Puebla, Nativitas es también paso obligado del camino que va desde San Martín Texmelucan, Puebla, un importante centro de comercio regional (que alberga presumiblemente el tianguis más grande de América Latina), hasta la ciudad de Tlaxcala. Este camino cruza Nativitas de oeste a este, a su paso se puede observar una buena parte de las construcciones del municipio: locales de tiendas de regalos, papelerías, cafés internet, tiendas de abarrotes, panaderías, estéticas, talleres de bicicleta, estudios de fotografía, una primaria, una secundaria, el anuncio de un colegio de bachilleres, el palacio municipal y un banco en pleno centro de la cabecera. Al menos ocho de las trece comunidades que forman este municipio colindan con esta carretera de doble sentido, y el conjunto de casas parece atraído a esta vía principal. Sin embargo, "tierra adentro" se extienden los campos de cultivo, interrumpidos solamente por las comunidades restantes (algunas con mayor concentración de población que otras), por algunas colonias y por las múltiples iglesias y capillas que alimentan la fe y las estructuras de poder comunitario.

Éste es uno de los municipios más antiguos del estado de Tlaxcala; su historia data del siglo Xvi. A pesar de que la región estaba densamente poblada por grupos originarios, ${ }^{108}$ Nativitas

${ }^{108}$ Tradicionalmente se había considerado que hasta su última ocupación antes de la llegada de los españoles los antiguos pobladores de este territorio eran olmecas-xicalancas; sin embargo, recientemente los arqueólogos Mari Carmen Serra y Carlos Lazcano (2011) plantearon que el grupo étnico que reocupó el complejo habitacional y cívico-religioso de Xochitécatl-Cacaxtla-Nativitas durante el Epiclásico era de filiación otomí. 
fue fundada con población española y asociada a la construcción de un convento franciscano. Tiene una extensión de 61 kilómetros cuadrados, y según el más reciente censo de 2010 cuenta con una población de 23621 personas (12 291 mujeres y 11330 hombres) (figura 7). Hoy en día, tiene en funcionamiento todos sus ejidos, doce en total ${ }^{109}$ (mapa 15), que ocupan una superficie de 3324 hectáreas (poco más de la mitad de la extensión municipal). Las tierras del municipio de Nativitas están bañadas por los dos ríos principales del estado: el Zahuapan y el Atoyac (mapa 5); el Atoyac corre al poniente del municipio y el Zahuapan está ubicado al oriente. Aunque no juntan sus aguas en tierras nativiteñas, los ríos forman un triangulo invertido en cuya superficie se ubican sus trece comunidades y tres colonias (mapa 6).

Nativitas se ubica en la región más fértil del estado de Tlaxcala y su historia ha estado marcada por una rica tradición agrícola desde tiempos anteriores a la Colonia. La historia regional decimonónica denominaba esta zona (suroeste de Tlaxcala) como "antigua ciénaga de Tlaxcala" (González 2008: 15). Lo que actualmente es visto como un valle agrícola de tierras fértiles era anteriormente una zona de humedales, lagunas y lagos, desecados paulatinamente desde finales del siglo xix hasta la década de 1960. La incorporación de actividades ganaderas y agrícolas extensivas durante el periodo colonial, intensificadas durante el porfiriato, promovieron la desecación de estos cuerpos de agua y la extensión de la frontera agrícola, lo cual transformó por completo el paisaje nativiteño y modificó la dinámica socioambiental profundamente.

De la mano de la transformación del paisaje para expandir la frontera agrícola, la industria aprovechó la abundancia de agua y mano de obra en la región para florecer. Históricamente la industria en Tlaxcala surge en la época colonial en las riberas de los ríos Atoyac y Zahuapan, no obstante, su verdadero desarrollo y auge fue hasta el siglo XIX, en articulación con el surgimiento y evolución de la industria en el vecino estado de Puebla (González 1991: 14-15). Aunque con ciertos altibajos, la industria en el valle permaneció, hasta que en 1950 se creó el corredor industrial Puebla-Tlaxcala donde además de las fábricas de textiles, se instalaron industrias automotrices, de maquinaria, de alimentos, de bebidas alcohólicas y hasta de productos químicos. Esta zona consolidó su vocación y su importancia a nivel regional (PueblaTlaxcala) algunos años después, ocasionando, como veremos más adelante, no sólo cambios a

${ }^{109}$ Sólo hay doce ejidos para trece comunidades debido a que los pobladores de San Francisco Tenexyecac eran anteriormente parte de la comunidad de San Vicente Xiloxochitla, y alrededor del 2002 decidieron constituirse como una comunidad independiente. Debido a su reciente creación los ejidatarios de este poblado pertenecen al ejido de Xiloxochitla. 
nivel laboral, sino ambiental. No obstante, previo a esta industrialización, las haciendas y los campos dorados de trigo dominaron el territorio nativiteño.

Población total Nativitas, $1990-2010$

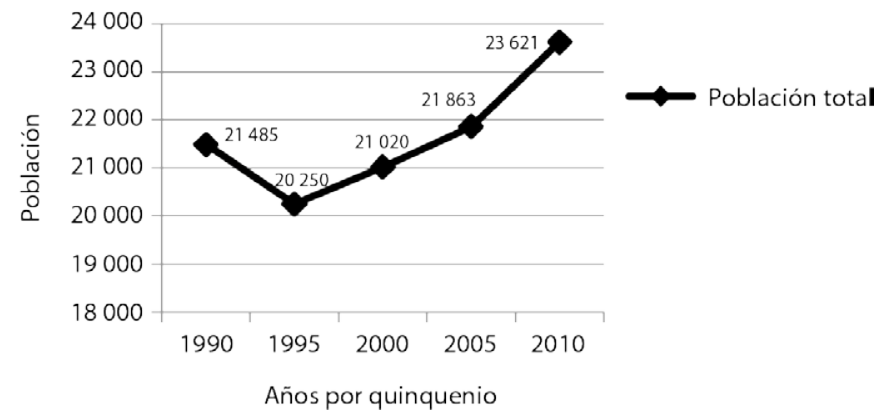

Figura 7. Población total de Nativitas de 1990-2010. ${ }^{110}$ Fuente: elaborado con base en INEGI (1991b, 1995, 2001, 2005, 2010b).

\section{LA RECONVERSIÓN PRODUCTIVA Y LOS EFECTOS INDIRECTOS DE LA "REVOLUCIÓN VERDE"}

Antes, fijese usted, sembrábamos mucho trigo, hubo, bueno, todos los pueblos de por acá sembrábamos trigo, salían toneladas de trigo, había máquinas que venían a trillar el trigo. Hacíamos cuatro meses trillando el trigo.

Y eran cuatro máquinas; una que venía de Matamoros, la otra de Gustavo Brito y l'otra de Ruperto y otra de don Manuel Vásquez. Todas esas máquinas, trillábamos el trigo; en cada casa ponían sus montones de trigo, cada casa ya luego nosotros con las máquinas trillábamos este montón de trigo, luego al otro, la otra, así... (don Julián, ejidatario de Nativitas, 2009). ${ }^{111}$

En la década de 1940 el gobierno mexicano buscaba ponerse al día con el proyecto capitalista mundial, quería ser parte de esa "promesa de la modernidad". Con la salida del presidente Lázaro Cárdenas y con Ávila Camacho al frente de la República, las políticas económicas oficiales cambiaron el rumbo del país, enfocándose en el crecimiento industrial y en la tecnologización y "modernización" del sector agropecuario (Hewitt 1988: 22-23). En términos de reparto de

${ }^{110}$ El decrecimiento de la población observado en el año de 1995 se debe a que, como resultado de las nuevas leyes municipales, la antes comunidad de Santa Apolonia Teacalco se independizó de Nativitas y formó un nuevo municipio.

${ }^{111}$ Entrevista realizada en junio de 2009 en Santa María Nativitas, Tlaxcala. 
tierras, el discurso oficial pregonaba que la reforma agraria había casi terminado, que el latifundismo había sido desmantelado y que las metas agrarias habían sido cumplidas.

A través de instituciones de investigación nacionales apoyadas y promovidas por fundaciones estadounidenses, como la Rockefeller, se impulsaron proyectos científicos-prácticos cuyo objetivo era incorporar nuevas tecnologías al agro mexicano, sobre todo a productos como el maíz y el trigo, para incrementar la producción en el sector privado (Hewitt 1988: 32). Este proceso fue etiquetado como la "revolución verde". El trigo fue el caso más "exitoso". Los trabajos de hibridación, introducción de fertilizantes, herbicidas y pesticidas, hicieron de este cultivo una operación muy tecnificada y mecanizada, que sólo pudo ser incorporada en los estados del noroeste del país, con el impulso y subvención estatal. Con los paquetes tecnológicos y el apoyo gubernamental en marcha, para 1950 la producción del trigo creció exponencialmente, consolidando la hegemonía productiva de los estados del norte, desplazando el poder de la agricultura tradicional del centro y el Bajío hacia esa región.

Además de los ya conocidos problemas ecológicos que provocó la presunta modernización del agro, un efecto importante de estas políticas fue que las zonas de temporal del centro del país, así como las pequeñas parcelas agrícolas, fueron relegadas. Se creó una marcada diferenciación económica entre los pequeños y los grandes productores. El paquete tecnológico de la producción de trigo implicaba grandes inversiones de capital y recursos, por lo que los productores minifundistas no eran capaces de adoptar estas medidas (Marroni 1995: 2).

Aunque en pocos años, entre 1950 y 1960, México pasó a ser uno de los países con más alto rendimiento de trigo en el mundo; estos logros duraron poco tiempo ya que para 1970 los costos de la explotación de los sistemas de riego y la tecnología comenzaron a volverse insostenibles y la producción comenzó estancarse (Marroni 1995: 4). Sin embargo, muchos de los trabajadores agrícolas que no podían competir en la carrera tecnológica fueron atraídos o expulsados para buscar trabajo en las ciudades industrializadas del país, mientras que otros se enrolaron en el programa bracero. El éxodo de la mano de obra del campo a las ciudades o al extranjero trajo problemas de desabasto de productos básicos del campo, así como un alza considerable de los precios de los alimentos. En este punto, es preciso hacer énfasis en que los problemas agrícolas de esta época (desabasto) tenían más que ver con un cambio en las prioridades de la política económica gubernamental que con una deficiencia en la capacidad productiva de la pequeña producción o del ejido (Hewitt 1988: 25-26).

En el caso de Tlaxcala, la tradición triguera fue profunda. La temprana colonización española y la cercanía al mayor mercado de harina de trigo (Puebla de los Ángeles), así como el establecimiento de haciendas trigueras de gran valor y múltiples molinos, marcaron una trayectoria productiva histórica que fue afectada fuertemente por las dinámicas desatadas por 
la revolución verde, sobre todo en regiones como el valle de Nativitas con alta producción de trigo. Entre 1925 y 1928, por ejemplo, se ha documentado que la región del suroeste tlaxcalteca era el principal productor de haba, frijol y trigo, acaparando $74.8,60.3$ y $42.6 \%$, respectivamente, de la producción estatal. De los 17 municipios considerados dentro de la región del suroeste, Nativitas era el primer productor con 730 toneladas de trigo, seguido de Lardizábal que producía 264 (González 2008: 202-203). En contraste, para el periodo de 1940 a 1950, Gilberto Fabila et al. documentan que hubo una evidente disminución en la producción de trigo de riego tanto en las propiedades privadas como ejidales en Tlaxcala. Su investigación arrojó que la superficie de cultivo de trigo en tierras ejidales disminuyó de 10952 hectáreas a 1152 en ese periodo, mientras que en la propiedad privada disminuyeron, además del trigo (de 1705 a 478 hectáreas), otros cultivos, como el arvejón, frijol solo y el haba, pero aumentó en $40 \%$ la producción de alfalfa, cebada, chile verde y maíz solo (Fabila et al. 1955: 78-79).

Localizadas entre los dos ríos más importantes, las planicies aluviales que conforman $\mathrm{Na}$ tivitas dieron cabida a haciendas trigueras que, aunque no eran las más extensas del estado, sí figuraban entre las de mayor valor y producción (Ramírez 1990). Aunque gran parte de las haciendas trigueras ya habían sido desmanteladas para estos años, muchos ejidatarios y diversos remanentes de las haciendas mantenían el cultivo del trigo. Para 1971, por ejemplo, los restos de la hacienda San Antonio Michac, propiedad de Emilio Maurer Bretón, era la única finca catalogada como cerealera en Nativitas (Ramírez 1990: 280).

La imposibilidad de adquirir los paquetes tecnológicos para aumentar la productividad del cultivo, las fuertes plagas y la desintegración de los mercados de trigo regionales provocaron estragos en su comercialización en toda la región del suroeste de Tlaxcala. Su falta de competitividad, en los términos modernos, los orilló a buscar productos alternativos o fuentes de ingreso diferentes. El cultivo de alfalfa y otros forrajes fue una de esas alternativas, que en parte fue alentada por ciertos programas de gobierno. Anteriormente, la producción de alfalfa era prácticamente inexistente, hasta que alrededor de 1940 el gobierno federal impulsó programas de ganado lechero que fueron ganando terreno y que facilitaron la conversión agrícola: si el trigo ya no era rentable y el ganado (que parecía un buen negocio) necesitaba alimento, qué mejor que cultivarlo en la propia parcela. Todo el valle de Nativitas se enganchó con la tendencia hacía el ganado lechero y de traspatio, y a partir de la cuarta década del siglo xx en algunas comunidades cercanas se organizaron cooperativas lecheras y queserías, como en Santa Cruz Aquiahuac, lo que posteriormente incentivó la instalación de agroindustrias como Liconsa. ${ }^{12}$

${ }^{112}$ Liconsa se estableció en el municipio de Tetlatlahuca en 1980. Durante años compró leche a los productores de las comunidades de éste y otros municipios del valle de Nativitas, pero, a partir de 1998 dejó de 
La demanda de productos lácteos estimuló aún más el cambio de ganado criollo trashumante por ganado lechero de traspatio, y al mismo tiempo el cultivo de forrajes. Desde entonces, la ganadería de traspatio y el cultivo de forrajes caminaron de la mano.

De esta forma, entre 1940 y 1960 hubo un fuerte cambio en el paisaje agrícola de Nativitas. La información recopilada durante diversas temporadas de campo entre 2008 y 2010 arrojó datos similares; gran parte de los ejidatarios y exejidatarios de edad avanzada coincidieron en que para estas décadas los "campos dorados" comenzaron a desaparecer. Luna coincide en este sentido: "El trigo, después de ser uno de los cultivos más importantes en la zona, comenzó a decaer en la década de 1960, debido a la alta incidencia de enfermedades, pero sobre todo porque era incosteable, no había competencia alguna con la producción altamente tecnologizada y mecanizada de estados del norte del país como el bajío y el noroeste" (Luna 1993: 100, 142).

Según datos recopilados por el proyecto PRIDA de la SARH-UAT y el CIISDER-MAR durante el periodo entre 1940 y 1949, el productor de trigo con mayor superficie cosechada de Tlaxcala era el municipio de Huamantla con 1415 hectáreas, mientras que Nativitas estaba en el segundo lugar con 1248.70. Los demás municipios quedaban lejos de estas extensiones. Aunque la mayor producción se concentraba en Huamantla, se puede apreciar alguna incidencia de la producción en la región del valle donde se encuentra Nativitas. Dentro de los primeros diez productores más importantes en la década de 1940, tres son del suroeste, una región de haciendas con tradición triguera de alto valor. De ocupar el segundo sitio con mayor superficie de cultivo de trigo, en poco menos de 40 años Nativitas no reportaba ni una sola hectárea dedicada a este cereal.

El cuadro 15 se elaboró con base en los datos recopilados por los censos agrícolas, ganaderos y ejidales desde 1950 hasta 2007. En él se puede apreciar igualmente cómo el cultivo de trigo en Nativitas fue decreciendo hasta llegar a cero hectáreas cosechadas, mientras que la alfalfa ${ }^{113}$ experimentó el proceso contrario (cuadro 16). En ambos grupos de datos se puede observar la tendencia a la baja de la producción de trigo en Nativitas.

Los ejidatarios y trabajadores agrícolas con mayor edad recuerdan que toda la región del valle de Nativitas se dedicaba al cultivo del trigo. Don Joaquín, ${ }^{114}$ un ejidatario de Nativitas de

hacerlo y ahora se dedica a la rehidratación de leche en polvo y a la maquila de pasteurización y envasado de leche. Sin embargo, muchas de estas comunidades, como Santa Cruz Aquiahuac, prefieren no vender a estas grandes empresas tanto por los precios y las demandas industriales de producto como porque ellos mismos comercializan derivados de la leche, como quesos y cremas (Cesín et al. 2007: 67).

${ }^{113}$ Tomo el ejemplo de la alfalfa por ser el más representativo, sin embargo, cultivos como la avena forrajera, el maíz forrajero, el ebo y otros productos para alimentación de animales también experimentaron un aumento.

${ }^{114}$ Entrevista realizada en noviembre de 2010 en Santa María Nativitas, Tlaxcala. 
81 años, comentaba que antes todos producían trigo, era el cultivo más importante. Cuando él y su esposa eran chicos, sus padres y todos los demás agricultores cultivaban trigo para vender. Este grano no era muy utilizado en las casas, por lo que se quedaba con muy poco para autoconsumo. De vez en cuando se hacían tortillas de trigo, pero en general toda la cosecha se vendía a coyotes o intermediarios que venían a comprar directamente a los campos o a las casas donde trillaban el trigo. Don Gregorio, ${ }^{115}$ otro ejidatario de 74 años, recuerda que todos los campos estaban llenos de trigo, pero hace más de 50 años, dice, ya no se podía vender bien, por lo que dejó de ser rentable y lo dejaron de sembrar. La falta de competitividad de la producción de granos comerciales como el trigo por parte de agricultores y ejidatarios del centro del país, sobre todo del valle de Puebla-Tlaxcala, provocó una ruptura en los mercados regionales y las redes de molinos establecidas desde siglos atrás, lo que trajo un problema para comercializar el producto y una reducción en los precios (González 2008: 205).

\begin{tabular}{lcc|ccc}
\hline \multicolumn{1}{c}{ Municipios } & $1940-1949$ & $1950-1959$ & $1960-1969$ & $1970-1979$ & $1980-1989$ \\
\hline Huamantla & 1415.00 & 1173.42 & 1295.55 & 217.14 & 452.62 \\
\hline Nativitas & $\mathbf{1 2 4 8 . 0 0}$ & $\mathbf{1 1 6 1 . 4 2}$ & $\mathbf{7 8 8 . 7 5}$ & $\mathbf{1 8 . 0 0}$ & nd \\
\hline Calpulalpan & 773.50 & 799.00 & 136.50 & 163.00 & 1021.83 \\
\hline Altzayanca & 699.00 & 1798.00 & 845.00 & 142.00 & 637.42 \\
\hline Xalostoc & 697.22 & 201.42 & 218.75 & 110.00 & 67.33 \\
\hline Tetlatlahuca & 610.00 & 181.25 & 103.75 & nd & 8.00 \\
\hline Terrenate & 539.62 & 1145.00 & 660.00 & 125.25 & 696.14 \\
\hline Zacatelco & 534.28 & 41.75 & 42.40 & 2.00 & 4.00 \\
\hline Tlaxco & 496.62 & 395.00 & 316.00 & 170.66 & 6469.87 \\
\hline Trinidad Sánchez Santos & 418.33 & 241.66 & 74.37 & 99.00 & 108.85 \\
\hline
\end{tabular}

La producción de ganado lechero de traspatio en combinación con la producción de cultivos forrajeros, como la alfalfa, ebo, grano de maíz y avena, se concentró en las localidades situadas en el centro sur y suroeste de Tlaxcala: Tetlatlahuca, Aquiahuac, Zacualpan y Nativi-

${ }^{115}$ Entrevista realizada en noviembre de 2010 en San María Nativitas, Tlaxcala.
Cuadro 15. Promedio por década de la superficie cosechada (ha) de trigo 1940-1988. Fuente: elaborado con base en Marroni (1995: 10). 
tas (Luna 1993: 145). Este proceso se dio de forma generalizada, aunque algunas comunidades del municipio de Nativitas, como San Miguel Xochitecatitla o San José Atoyatenco (en menor medida), lograron desde entonces establecer una exitosa conversión agrícola hacia las hortalizas. Hoy en día Xochitectatitla, por ejemplo, tiene un nicho comercial bien establecido en las centrales de abasto de las ciudades de México y Puebla.

\begin{tabular}{lrrrrr}
\hline & \multicolumn{1}{c}{1950} & 1960 & 1970 & 1991 & 2007 \\
\hline Nativitas & & & & & \\
\hline Alfalfa Verde & 62 & 89 & 282.4 & 608.4 & 214 \\
\hline Trigo & 645 & 1074 & 14.9 & 0.5 & 0 \\
\hline Maíz & 2275 & 3590 & 3277.4 & 2020.05 & 2939 \\
\hline Tlaxcala & 253 & 913 & 1654.6 & 2302.3 & 3547 \\
\hline Alfalfa verde & 7513 & 9566 & 1932.9 & 42050.8 & 45225 \\
\hline Trigo & 90142 & 109600 & 73656.4 & 93286.92 & 115831 \\
\hline Maíz & & & & & \\
\hline
\end{tabular}

Entonces, a partir de mediados del siglo pasado y ante la limitación de las tierras ejidales a un número condicionado de dueños, la agricultura de pequeña escala se destinó a generar insumos para la ganadería de traspatio, complementar los ingresos provenientes de otras actividades, complementar en ocasiones los insumos de la casa para algunos alimentos y dar continuidad a las actividades de los ejidatarios. La ventaja relativa es que la producción es segura: si no se consume en casa se puede vender, ya que alguien siempre necesitará de alimento para sus animales. Sobre las ventajas de producir alfalfa, don Antonio, ${ }^{116}$ un agricultor, me comentaba: “¿Para qué vamos a sembrar hortalizas? Si cultivamos la hortaliza no habría espacio para cultivar la comida para los animales y comprarla saldría muy caro. Mejor ocupar las tierras en cultivos para los animales". Mientras que don Refugio, ${ }^{117}$ un ejidatario de 74 años, me dijo: "Además, otra ventaja de sembrar pura pastura es que no se gasta en alimento balanceado, se puede ahorrar un tanto. Algunas veces también saco bultos de maíz para forraje".

${ }^{116}$ Entrevista realizada en marzo de 2009 en Jesús Tepactepec, Nativitas, Tlaxcala.

${ }^{117}$ Entrevista realizada en diciembre de 2010 en Jesús Tepactepec, Nativitas, Tlaxcala. 
La conversión productiva se enfocó en el trigo, mientras que la producción de maíz se ha mantenido más o menos constante en Nativitas. Entre las opciones productivas como la alfalfa, también figuraron cultivos comerciales como el tomate verde y el amaranto, sin embargo éstos son complementarios a aquellos e implican una inversión mayor.

Es importante señalar que la conversión productiva y los cambios en las dinámicas socioeconómicas no fueron resultado único de la revolución verde; hubo diversos factores que movilizaron a los sujetos en búsqueda de alternativas de subsistencia. En primer lugar, la población creció de forma tal que las tierras de cultivo ya no eran suficientes; los ejidos habían sido pensados para satisfacer a un número determinado de familias, y las ampliaciones eran prácticamente imposibles, no había más terrenos que dotar en la región. En segundo lugar, Estados Unidos comenzó a demandar más jornaleros mexicanos para trabajar el campo. El programa bracero llamó la atención de muchos tlaxcaltecas, un estado de tradición migrante desde épocas coloniales, y Nativitas no fue la excepción. La misma ausencia de la fuerza de trabajo masculina dificultó la continuación de sistemas de agricultura intensiva, incidiendo en la expansión del monocultivo del maíz y/o de la producción de forrajes en relación con el ganado de traspatio (González 2008: 202). Finalmente, la ciudad de México ejerció una gran atracción como un centro de oportunidades sobre la fuerza de trabajo masculina de Nativitas. Una buena parte de la generación de jóvenes del periodo entre 1940-1960 trabajó en la ciudad de México. Algunos de ellos se quedaron en la ciudad, mientras que otros migraron de forma pendular y hoy en día, en edad avanzada, siguen trabajando su parcela ejidal.

La conversión agrícola de trigo hacia el cultivo de alfalfa, maíz y otros forrajes, o bien hacia la producción de hortalizas, se configuró como complemento de otras actividades económicas. Las familias e individuos combinaban actividades diversas que dependían, entre otros factores, de los recursos familiares (número de parcelas, de hectáreas, de familiares, de varones, etc.). La migración laboral pendular a las ciudades de México y Puebla, la incorporación al programa bracero, el trabajo en fábricas de la región, el comercio, la contratación como choferes (autobuses comerciales o de carga), eran las más frecuentes.

Las reformas estructurales y el regreso con venganza de los principios económicos de Adam Smith y los liberales defensores de la propiedad privada, la supuesta libre competencia, el consumo enajenante y la búsqueda del interés (acumulación) personal sobre todas las cosas, han envilecido aún más al capitalismo y han deteriorado las condiciones de vida de más personas. Con todo, la globalización neoliberal se manifiesta y entreteje de diversas formas. A continuación discutiré el llamado neoliberalismo en general, para luego ver su forma local. 


\section{NEOLIBERALISMO Y REFORMAS ESTRUCTURALES}

Las contradicciones internas del sistema capitalista han generado en varias ocasiones momentos de crisis y altibajos en el proceso de acumulación; sin embargo, los grupos hegemónicos han logrado superar cada una de ellas. En 1970 el crecimiento económico mundial parecía haberse estancado: en estos años las tasas de interés se volvieron negativas y las ganancias comenzaron a bajar. Para sobrevivir, el sistema capitalista necesitaba reavivar el proceso de acumulación, lo cual implicaba la apertura de nuevos espacios y bienes.

A través del desmantelamiento de los estados de bienestar y de las políticas desarrollistas comenzó la era de la globalización neoliberal, o como Araghi (2009) le llama, la era de la globalización poscolonial neoliberal. Ideada en diversos salones de la escuela de Chicago por economistas como Milton Friedman, esta doctrina prometía una salida a esta nueva crisis. El neoliberalismo ofrecía una forma de transferir los bienes o redistribuir la riqueza y el ingreso del grueso de la población hacia las clases altas, o bien de los países vulnerables hacia los más ricos. El proceso de apertura de nuevos mercados para la acumulación, el acceso a materiales nuevos y menos costosos, así como la "liberación" de más mano de obra barata es lo que Harvey (2005) llama "acumulación por despojo", que no es otra cosa que la llamada por Marx "acumulación primitiva", pero que posibilita la continuación del proceso de acumulación sobre productos que anteriormente no estaban sujetos a la comercialización. La privatización de recursos naturales, de la cultura y la identidad; la supresión de los derechos de los bienes comunales y otras formas alternativas de producción y consumo, así como el uso del sistema crediticio como una forma de acumulación primitiva, han extendido las fronteras del capital. El agotamiento de recursos ambientales comunes, como la tierra, el agua y el aire, así como la proliferación de medios ambientes degradados han sido resultado en gran parte de la mercancianización de la naturaleza en todas sus formas y, por ende, de la manera en la que la naturaleza es construida por el discurso neoliberal (Harvey 2005: 148).

Es preciso anotar que el neoliberalismo no se puede identificar como un todo coherente y homogéneo, ya que ha tomado diferentes formas y grados dependiendo del entramado de fuerzas políticas, tradiciones históricas y arreglos institucionales en cada lugar (Harvey 2006: 148). De manera que esta red de prácticas e ideologías que se llama neoliberalismo no es un producto terminado ni coherente, sino un complejo cúmulo de procesos (en constante contestación) que están conformados por una multiplicidad de políticas, prácticas y discursos que emergen de una diversidad de contextos políticos, históricos y socioeconómicos, y de negociaciones entre diferentes clases en escalas geográficas diversas (Perrault y Martín 2005: 194; McCarthy y Prudham 2004: 276). 
Esta contingencia, sin embargo, no nos impide encontrar líneas o directrices comunes que nos permitan identificar el fenómeno neoliberal en torno a, por ejemplo, la dinámica agrícola y agroindustrial. A través de políticas de: desregulación de los mercados de tierras, remoción de los controles para la importación y subsidios para alimentos, instauración de regímenes de exportación agrícola y exposición de millones de pequeños productores agrícolas en el sur a una competencia desleal ante corporaciones transnacionales subsidiadas, así como de productores agrícolas capitalizados en el norte del hemisferio (Araghi 2009: 112), han creado una fuerte dependencia alimentaria en países como México, transformando profundamente las dinámicas agrícolas en los países del sur global.

En México no hizo falta imponer una dictadura para implantar estas políticas; el remedio recetado por el Banco Mundial para resolver la fuerte crisis económica de 1982 fue hacer ajustes estructurales. El énfasis en la exportación de productos agrícolas de gran valor, asociada con las devaluaciones y la eliminación de aranceles para las importaciones a través de la puesta en marcha del Tratado de Libre Comercio de América del Norte (TLCAN) en 1994, relegó al olvido la producción agrícola para el mercado local, creó una fuerte dependencia alimentaria y deterioró aún más las condiciones de vida de la población rural y campesina. Además, generó el aumento en las importaciones de alimentos más rápido que las exportaciones, poniendo en estado de crisis el sector alimentario local (Akram-Lodhi y Kay 2010: 277).

Una de las modificaciones más fuertes a la política agrícola nacional cristalizó entre 1991 y 1992 con las reformas al artículo 27 constitucional. La llamada "contra-reforma agraria" terminó formalmente con el reparto de tierras y creó mecanismos jurídicos para modificar el estatus de las tierras ejidales e incorporarlas al mercado de tierras. Se buscaba sustituir el carácter inalienable, imprescriptible, inembargable e intransmisible de los ejidos por una propiedad de tierra más flexible, en donde cupiera la posibilidad de venderla, heredarla, rentarla o formar una empresa, a través de ofrecer certidumbre legal a sus usufructuarios con la expedición de títulos individuales y privados a través del Programa de Certificación de Derechos Ejidales y Titulación de Solares (Procede).

En suma, uno de los principales objetivos de este proyecto neoliberal era preparar al campo mexicano para enfrentar nuevos procesos de acumulación capitalista, por medio de la consolidación del agronegocio como primer motor de la economía rural (Sanderson 1990: 223). Esta meta coincidía con la incorporación de México al TLCAN y la apertura comercial de la agricultura. La otrora política corporativista que ligaba al Estado y a los campesinos, y que ofrecía concesiones y garantías a cambio de apoyo político-electoral, fue sustituida por una relación sujeta a las fuerzas del mercado, una relación que, para muchos investigadores, simplemente cambió un modo de dominación por otro (Gómez 1998: 17). 
Los cambios a la ley agraria generaron una fuerte oposición. Se temía que la privatización de las parcelas ejidales permitiría la concentración de tierras, avizorando un proceso de latifundización (Calva 1993: 42). En efecto, la nueva ley contemplaba y promovía la participación en las otrora intocables tierras ejidales, de sociedades mercantiles (extranjeras o nacionales), personas ajenas al ejido, bancos, instituciones crediticias o cualquier interesado con los recursos suficientes. No obstante, la "seducción" de vender, como sugiere Gómez (1998), no surtió efecto de forma generalizada; en buena parte del país las tierras de propiedad social se consolidaron como un patrimonio familiar invaluable que gracias a los certificados parcelarios podría ser heredado a las siguientes generaciones. Las políticas neoliberales en este caso no surtieron el efecto esperado; a casi 20 años de la contrarreforma se ha constatado que miles de hectáreas siguen siendo de propiedad social. En el caso de Tlaxcala, para 1999 se reportaba un mercado de tierras bajo; en total este estado contaba con 234 ejidos (227 certificados por Procede), con una superficie de 190000 hectáreas (160 000 certificadas) en posesión de 39500 ejidatarios. Hasta 1998 sólo $3.5 \%$ de los ejidatarios con certificados parcelarios vendieron una o todas sus parcelas y solamente $2.5 \%$ de la superficie parcelada certificada había cambiado de dueños entre los años de 1992 y 1998 (Bouquet 1999: 74-76).

La situación de las poblaciones rurales en el mundo dentro del marco de la globalización neoliberal actual cobra relevancia, no porque debamos estar preocupados por su desaparición, sino porque la evidencia empírica nos ha mostrado que tanto a nivel colectivo como individual tienen una gran capacidad de negociación, contestación y adaptación social, económica, política y cultural, y que en múltiples momentos han sabido sortear las adversidades, evidenciando su capacidad de resistencia, aunque esto signifique vivir en una situación endémica de precariedad. Los resultados, por supuesto, no son homogéneos ni responden a una dinámica de causa y efecto rígida; por el contrario, la conjunción de estos procesos ha generado una multiplicidad de escenarios en el medio rural, no obstante, en su mayoría se caracterizan por la exclusión social y el desplazamiento de la agricultura como elemento característico de lo "rural".

En el caso mexicano, los procesos de transformación rural desatados por la globalización neoliberal, combinados con el contexto nacional han configurado complejas redes económicas, sociales, políticas y ambientales que han expuesto a los sujetos sociales con menor poder económico a una serie limitada de decisiones en torno a sus estrategias socioeconómicas y al manejo de sus recursos naturales. Sin embargo, la condición complementaria y marginal de la actividad agrícola, así como su configuración actual en Nativitas, no es una respuesta directa a la puesta en práctica de las políticas neoliberales en México; su situación es la continuación de un proceso de adaptación, reacomodo y resistencia que se puede rastrear hasta la década de 1940 y que después, con la incentivación de las industrias en la región Puebla-Tlaxcala, se volvió a ajustar. El fin de la 
agricultura como eje estructurador de la vida social y económica de los nativiteños, así como la pluri- y multiactividad como estrategias socioeconómicas, preceden los fuertes cambios en las leyes agrarias, el fin de los subsidios gubernamentales y la suma de las políticas neoliberales nacionales; sin embargo, han servido como plataforma estratégica para enfrentar los nuevos embates capitalistas, encarnados en el manto neoliberal, los cuales no pueden ni deben ser soslayados.

Es importante hacer énfasis en esto: la fase neoliberal del capitalismo global no ha sido inocua. La creciente flexibilización, descentralización y rapacidad de las industrias transnacionales y nacionales han generado condiciones de trabajo más precarias, más inestables y más duras. La negligencia del Estado ante la sociedad que dice representar en general ha empoderado aún más a las élites empresariales y éstas, además de abusar de la mano de obra local, se han vuelto más depredadoras del medio ambiente. La subrogación y subcontratación de fases de la producción de muchos bienes industrializados han atomizado sus responsabilidades hacia los trabajadores y hacia la naturaleza, degradando las condiciones socioambientales de la región del valle de Puebla-Tlaxcala, lo que ha precarizado aún más las condiciones de vida y laborales de sus habitantes.

\section{EL TRABAJO AGRÍCOLA COMO COMPLEMENTO MÍNIMO DE SUBSISTENCIA EN NATIVITAS}

Echando mano de diferentes recursos (económicos, sociales, políticos y familiares), los habitantes de Nativitas han desplegado un sinnúmero de combinaciones laborales y estrategias socioeconómicas que evidencian la forma en la que los sujetos rurales negocian, adaptan, construyen y reconstruyen sus formas de vida. La pluri- y multiactividad no es algo que trajo la neoliberalización, pero sí la intensificó. El fin de la agricultura como eje fundamental de la vida socioeconómica de los pobladores del municipio cuya tendencia comienza alrededor de 1940, así como la fuerte contaminación de la fuente principal de riego de las tierras ejidales iniciada alrededor de 1960 y recrudecida en la última década del siglo xx, no se ha traducido en el abandono del campo, sino en su reconfiguración.

Las transformaciones rurales en esta localidad tlaxcalteca son procesos que han estado mediados por relaciones desiguales de poder históricamente específicas. Pese a que en Nativitas existe una creciente tendencia, sobre todo de las nuevas generaciones, a incorporarse a actividades fuera del campo, las tierras de propiedad social no han desaparecido, al contrario, siguen siendo utilizadas para la producción agrícola, así como muchas tierras de propiedad privada. 
Por adelantar un dato, en el 2009 la Sagarpa calculó que se sembraron 4232 hectáreas en todo el municipio, cuando, según datos del Registro Agrario Nacional, en el 2008 se registró una superficie de poco más de 2700 hectáreas ejidales parceladas. Sin embargo, el contexto en el que la agricultura se inserta y el papel que tiene dentro de las dinámicas socioeconómicas y culturales de la población es obviamente diferente al de hace 30 o 50 años.

Aunque el porcentaje de población económicamente activa en el sector agrícola ha disminuido paulatinamente (ver capítulo de Salas y González de este libro), el número de personas ocupado en el sector en términos absolutos se ha mantenido con una leve baja: en 1980 era de 3 174, en el 2000 de 2373 y en 2010 de 2491 (INEGI 1980, 2001, 2010b). El número de ejidatarios ha sido constante; aunque es cierto que una gran mayoría de los ejidatarios rebasan los 50 años, también lo es que algunos jóvenes (hijos o familiares) han tomado su lugar y continuado con el trabajo agrícola, lo que se verá más adelante con la creación de "posesionarios". Durante el trabajo de campo, muchos ejidatarios mayores confesaron que nunca han deseado para sus hijos la vida en el campo, más bien, su meta era "darle escuela" a la mayor parte de sus vástagos para que "salieran adelante".

El trabajo agrícola está tan devaluado para la juventud, en el sentido monetario y simbólico, que pocos jóvenes se dedican por convicción a las labores agropecuarias, aunque sea como complemento al sustento familiar. Lo cierto es que, debido a que ya no hay tierras disponibles, aunque hubieran querido, no todos podrían haber seguido con las labores en la parcela ejidal. La propiedad privada dedicada a las labores del campo ha ido decreciendo pero, como se puede apreciar en el cuadro 17, el número de hectáreas de labor ejidal se ha mantenido prácticamente igual. La vocación agropecuaria del municipio, aunque no es central, sigue teniendo una presencia fuerte, lo cual se puede constatar en la cantidad de tierras de cultivo, el trajín constante de carretas o camiones con alfalfa, la presencia de tiendas o bodegas donde se surten de fertilizantes, semillas y alimentos para animales de corral, así como talleres de reparación de segadoras y otras herramientas, entre otras cosas.

La mayor parte de la agricultura que se practica en el municipio es en tierras ejidales, como se puede observar en el mapa correspondiente (mapa 15) y en el cuadro 17. El número de ejidatarios ha permanecido en números constantes, y después de 1992 aumentó en $10 \%$. En el 2001, los ejidos del municipio de Nativitas estaban en manos de poco más de 2100 ejidatarios (INEGi 2001), ${ }^{118}$ mientras que en el 2008, el Registro Agrario Nacional contabilizó 2138 ejidatarios y 255 posesionarios, en total 2393 personas, número que presumiblemente refleja

${ }^{118}$ El número de 2127 ejidatarios es una cifra aproximada, porque en el censo ejidal del 2001 se contabilizaron para el municipio de Nativitas 15 propiedades sociales, adjudicándole dos ejidos que no le correspon- 
el de familias, que cultivan las parcelas ejidales, lo que representa poco más de $10 \%$ de sus habitantes. Este aumento es resultado del Procede, en tanto que la certificación hizo posible la compra-venta y/o cesión de parcelas ejidales a personas ajenas (mas no necesariamente externas) al núcleo original de ejidatarios (hijos, parientes, vecinos del pueblo generalmente), pero aprobados por la asamblea de ejidatarios. ${ }^{119}$

\begin{tabular}{ccc}
\hline Años & Superficie de labor total (ejidos y propiedad privada) $(\mathrm{ha})$ & Superficie de labor ejidos $(\mathrm{ha})$ \\
\hline 1950 & 5487.0 & 2625 \\
\hline 1970 & 4260.7 & 2517.9 \\
\hline 1991 & 3509.2 & 2857.05 \\
\hline 2007 & 3920.6 & 2583.45 \\
\hline
\end{tabular}

La mayor parte de las tierras ejidales siguen siendo utilizadas para el cultivo, y es posible sugerir que la incorporación de posesionarios se debió al interés en continuar las labores agrícolas y, en menor medida, para construir casas-habitación. El cuadro 18 da cuenta de que menos de $5 \%$ de los ejidos del municipio están ocupados por asentamientos humanos, además de que, con excepción de unas cuantas hectáreas de un ejido, los demás no han tomado la figura de dominio pleno contemplada en la reforma al artículo 27 que permite la privatización y generalmente significa su incorporación al uso de suelo urbano de las parcelas ejidales, al concederles un título de propiedad.

den: Santa Cruz Aquiahuac y San Juan Huactzingo. Para ajustar el número de ejidatarios que verdaderamente pertenecen a Nativitas, se restó del total el número de ejidatarios que corresponden a ambos ejidos.

${ }^{119}$ Este hecho abre la posibilidad de diversas hipótesis en cuanto al mercado de tierras y sus resultados, que merecerían un estudio profundo aparte. Por un lado, sería interesante indagar las edades y parentesco de los posesionarios con respecto a los dueños originales del certificado parcelario, para ver ante qué proceso o combinación de procesos estamos: herencia, venta de parcelas por urgencias económicas, acaparamiento de una o varias familias, etc. Por otro lado, aunque la Nueva Ley Agraria no permite la subdivisión de una parcela, es preciso acotar que en muchas ocasiones las hectáreas de un ejidatario pueden estar divididas en dos o tres parcelas no contiguas: una de riego, otra de temporal $y / u$ otra de cerro. El ejidatario recibe un certificado parcelario por cada uno de estos polígonos, pudiendo establecer negocios por separado para cada uno de ellos. Esto sin mencionar las transacciones no formalizadas o fuera del conocimiento del Registro Agrario Nacional, en las que se rentan, venden, arrendan o prestan porciones de las parcelas. Hasta entonces, se podrá hablar de un proceso de minifundización o no, y sus alcances.

\section{Cuadro 17. Superficie de labor ejidal y de} propiedad privada en Nativitas, 1950-2007. Fuente: elaborado con base en DGE $(1956,1970)$; INEGI (1991a, 2007). 


\begin{tabular}{|c|c|c|c|c|c|}
\hline Ejido & $\begin{array}{l}\text { Superficie delimitada } \\
(h a)^{*}\end{array}$ & $\begin{array}{c}\text { Superficie parcelada } \\
\text { (ha) }\end{array}$ & $\begin{array}{l}\text { Superficie de uso } \\
\text { común (ha) }\end{array}$ & Dominio pleno & $\begin{array}{l}\text { Asentamientos } \\
\text { humanos (ha) }\end{array}$ \\
\hline Jesús Tepactepec & 213.35 & 195.96 & 0 & 0 & 17.39 \\
\hline G. Victoria & 56.15 & 48.2 & 0 & 7.95 & 0 \\
\hline $\mathrm{NCPE}^{120}$ & 81.61 & 78.46 & 0.22 & 0 & 2.92 \\
\hline Capulac & 59.9 & 51.9 & 0 & 0 & 8 \\
\hline Atoyatenco & 152.43 & 145.92 & 6.51 & 0 & 0 \\
\hline Analco & 113 & 97.81 & 0 & 0 & 16.01 \\
\hline Del Milagro & 340.62 & 316.34 & 24.28 & 0 & 0 \\
\hline Xochitecatitla & 205.05 & 205.05 & 0 & 0 & 0 \\
\hline Tenanyecac & 341.69 & 319.41 & 0 & 0 & 22.28 \\
\hline Xiloxochitla & 232.65 & 210.51 & 0.98 & 0 & 21.16 \\
\hline Santa María Nativitas & 275.6 & 263.91 & 3.85 & 0 & 7.84 \\
\hline Santiago Michac & 348.82 & 342.32 & 0.07 & 0 & 6.43 \\
\hline Concordia & 523.25 & 489.79 & 0 & 0 & 33.46 \\
\hline Total & 2944.12 & 2765.58 & 35.91 & 7.95 & 135.49 \\
\hline
\end{tabular}

Cuadro 18. Datos sobre ejidos de Nativitas. Fuente: elaborado con base en datos del Registro Agrario Nacional (2008).

${ }^{*}$ La superficie delimitada se refiere al total del ejido: la suma de la superficie parcelada, de uso

común y de asentamientos humanos.
- Las tierras de cultivo del municipio dan cabida a diversos productos, los cuales varían dependiendo de si las tierras son regadas con agua de pozo o río o si son de temporal. En general, los dos primeros tipos de tierra se caracterizan por el cultivo de maíz, alfalfa y otros forrajes, amaranto, tomate, chiles, habas, el destino de estos productos es el autoconsumo, para alimento de animales de traspatio o en ocasiones el comercio local. Aunque una buena parte de las hortalizas se riega con agua de pozo, de vez en cuando también echan mano de las aguas del río y otras corrientes que vienen contaminadas por desechos tanto industriales como urbanos.

Según los datos más recientes, durante el ciclo de cultivo del 2009 en Nativitas se sembraron 4234 hectáreas con diversos productos, entre los que destacan los tradicionales maíz y frijol,

${ }^{120}$ Este Nuevo Centro de Población Ejidal pertenece a Santa Apolonia Teacalco y se constituyó en la década de los años 70 en lo que era parte del casco de la exhacienda de San Antonio. A pesar de que Santa Apolonia Teacalco se independizó de Nativitas en 1995, en todos los censos y padrones agrarios tanto del INEGI como del Registro Agrario Nacional aparece como parte de este municipio. Para darle continuidad a los datos estadísticos, decidí dejarlo como parte de Nativitas. 
los forrajes y las hortalizas. El que ocupó más superficie fue el maíz de grano, con 2939 hectáreas, seguido por el frijol con 279; en tercer y cuarto sitios se encontraron la alfalfa verde con 214 hectáreas y la avena de forraje con 193, mientras que alrededor de 55 hectáreas se ocuparon para la siembra de maíz de forraje. En total, Nativitas cuenta con 2888 unidades de explotación de animales; en el 2007 un total de 478 hectáreas se destinaron a cultivar productos para la ganadería. En este mismo año se contabilizaron 311 toneladas de carne en canal de bovino y 3700 litros de leche de bovino (INEGI 2007), y en el 2009 hubo una producción ganadera de 647 toneladas de ganado bovino en pie (SAGARPA 2009).

\begin{tabular}{lrcc}
\hline \multicolumn{1}{c}{ Ejido } & Ejidatarios & Posesionarios & Avecindados \\
\hline Jesús Tepactepec & 120 & 5 & 92 \\
\hline G. Victoria & 59 & 11 & 0 \\
\hline NCPE & 109 & 1 & 10 \\
\hline Capulac & 51 & 8 & 26 \\
\hline Atoyatenco & 110 & 12 & 0 \\
\hline Analco & 64 & 14 & 39 \\
\hline Del Milagro & 222 & 18 & 0 \\
\hline Xochitecatitla & 203 & 19 & 0 \\
\hline Tenanyecac & 214 & 68 & 170 \\
\hline Xiloxochitla & 86 & 38 & 64 \\
\hline Nativitas & 138 & 10 & 52 \\
\hline Santiago Michac & 387 & 34 & 133 \\
\hline Concordia & 375 & 17 & 590 \\
\hline Total & 2138 & 255 & 4 \\
\hline
\end{tabular}

Como ya vimos, la conversión agrícola llevada a cabo entre 1940 y 1960 resultó ser útil para resistir los problemas traídos por la apertura comercial neoliberal posterior. Hoy más que nunca, la economía ejidataria se ha apoyado en la crianza de animales de traspatio. La mayoría de las familias actualmente cuenta con borregos, vacas lecheras, cerdos, aves u otros animales menores en el traspatio de las casas. Estos animales, alimentados con productos de las tierras de cultivo y con otros insumos, funcionan como un tipo de alcancía. Su mantenimiento requiere de tiempo, esfuerzo y algo de dinero (si se compra alimento especial para complementar el maíz
Cuadro 19. Información sobre ejidatarios y personas que ocupan los ejidos en Nativitas. Fuente: elaborado con base en datos del Registro Agrario Nacional (2008). 
forrajero, la alfalfa y la avena del campo). Cuando están listos o hay una emergencia que necesite de dinero en efectivo, se pueden vender sus productos (huevos o leche) o los animales mismos.

Más de la mitad de los doce ejidos de Nativitas cuenta con tierras irrigables con acceso al río Atoyac, los demás cuentan con aguas del Zahuapan, el Totolac y otras corrientes de menor importancia, como el Ajejela y el Xopanac. Pese a la fuerte presencia de químicos tóxicos, basura y residuos diversos en las aguas de ambos ríos, los ejidos siguen siendo cultivados y regados (en su mayoría) con estas aguas. Paradójicamente, su condición no ha desmejorado significativamente la producción de estos cultivos ni ha impedido su venta o consumo local.

La instalación de grandes corredores industriales en los municipios poblanos vecinos y que se han extendido a la región suroeste de Tlaxcala en los últimos años, aunada a la crisis endémica de la pequeña agricultura en México, contribuyó igualmente a la reconfiguración del papel del campo en Nativitas. La expansión de la industria en el valle de Tlaxcala-Puebla se ha dado a costa de las tierras más fértiles de los ejidos del lado poblano y de la contaminación y acaparamiento de las corrientes de agua y la sobreexplotación de la mano de obra tanto en Puebla como en el sur de Tlaxcala, provocando fuertes cambios en los patrones productivos, culturales y familiares. A partir de la instalación de la armadora de Volkswagen, a mediados de 1960, y de HyLSA (Hojalata y Lámina, S. A), estos corredores industriales albergaron cada vez más empresas, muchas de ellas fuente importante de desechos contaminantes y tóxicos. El ejemplo más emblemático es la petroquímica Independencia de PEMEx instalada en 1970 (mapas 13 y 14).

A partir de la firma del Tratado de Libre Comercio comenzaron a proliferar modalidades de producción cada vez más flexibles, basadas en la fragmentación de la producción para abaratar los costos al máximo. Aunque las maquilas se instalaron en la frontera norte de México desde 1960, la apertura comercial facilitó e incentivó la dispersión de este tipo de establecimientos en todo el país. La tradición textil del valle poblano-tlaxcalteca, la abundancia de agua subterránea para producir y superficial (ríos y zanjas) para desechar, y de mano de obra barata y necesitada atrajo compañías maquiladoras de ropa, particularmente de mezclilla. Algunas personas han visto en estos talleres de confección o lavanderías una forma de sobrevivencia, por lo que en las últimas décadas han crecido este tipo de establecimientos, los cuales maquilan para empresas que, a su vez, maquilan (o son intermediarias) para marcas reconocidas en Estados Unidos y México. Nativitas escapó a esta inercia; empero, es de vital importancia señalar el punto debido a que las lavanderías caseras o de mayor escala están apostadas río arriba, y sin ninguna regulación vierten desechos tóxicos (nocivos tanto para las corrientes superficiales como para los mismos trabajadores) a los drenajes comunitarios que se van directamente 
al río Atoyac. ${ }^{121}$ Esta maquila flexible deslinda a los contratantes de las responsabilidades sobre las condiciones laborales y de salud de los trabajadores, así como del manejo de los desechos.

Las lavanderías de mezclilla, así como las industrias de los corredores fabriles en toda la región del valle de Puebla-Tlaxcala, vierten sus desechos tóxicos en los ríos Zahuapan y Atoyac, provocando que la cuenca formada por ambos sea considerada una de las más contaminadas del país, y el río Atoyac específicamente, es señalado como uno de los diez con mayor índice de contaminación de la República. ${ }^{122}$

Las estrategias y respuestas a la contaminación han sido diversas. ${ }^{123}$ Algunos con mayores recursos económicos y con cultivos comerciales con nichos de mercado establecido, han perforado pozos para el riego; otros han comenzado a depender más del temporal y a limitar los productos que se pueden cultivar. Algo interesante ha sido encontrar que hay ejidos que tienen pozo, pero admiten que el zacomite (un pasto silvestre que crece en los campos de cultivo libremente) crece más alto, más bonito y le gusta más a los animales cuando las tierras están regadas con agua de los ríos; sin mencionar que es menos costoso regar por gravedad que pagar la electricidad para bombear el agua de pozo.

Un elemento clave del análisis histórico de la permanencia de la producción agrícola de pequeña escala ha estado relacionado con las barreras sociales, culturales y/o económicas locales que han inhibido o retardado la introducción de ciertas relaciones (económicas, sociales, políticas) hegemónicas capitalistas, o bien, las han refuncionalizado y adaptado. Pocas veces

${ }^{121}$ Si bien es cierto que la afectación más obvia y evidente es para el río y para los usuarios de los químicos para teñir y deslavar, la salud de los pobladores que viven cercanos (de 1 a $5 \mathrm{~km}$ ) al río también se ve afectada por la evaporación de partículas tóxicas.

${ }^{122}$ Sobre la degradación socioambiental y las instalaciones industriales en la región, y en el municipio, ver capítulo de Salas y Velasco en este libro.

${ }^{123}$ Existen algunas asociaciones o sociedades civiles que están luchando por revertir el estado de contaminación de los ríos y sobre todo buscando justicia para las personas que tienen enfermedades que pueden estar relacionadas con la exposición a los contaminantes o tóxicos emanados desde el río y de los vertederos industriales. Las asociaciones que más destacan son Atoyac Zahuapan y Calidad de Vida S. C. y Por un Atoyac Limpio, encabezadas mayoritariamente por habitantes de comunidades poblanas y algunas tlaxcaltecas, como Villa Alta, que están más cercanas a los centros industriales. Aunque efectivamente tienen miembros de comunidades de Nativitas, como Santiago Michac, éstos son un grupo poco representativo y prácticamente invisible entre el grueso de los nativiteños. El comité de Santiago Michac está constituido por siete personas, de las cuales dos están más activas. Sus actividades van desde ir a reuniones, como la de los Afectados Ambientales, hasta buscar gente con enfermedades como leucemia, púrpura trombocitopénica y otros tipos de cáncer que pueden estar relacionadas con la contaminación. 
se ha considerado que estos obstáculos también pueden provenir de la naturaleza o de los procesos biofísicos. El capitalismo, a pesar de los grandes avances tecnológicos y científicos, no ha logrado cooptar en su totalidad (y en algunos casos ni siquiera parcialmente) muchos procesos naturales relacionados con la agricultura, como el tiempo de crecimiento de las plantas, las inclemencias climáticas, la resistencia total y definitiva de las plantas a las plagas, el control del agua superficial y subterránea, etc. (Mann y Dickinson 1978; Kloppenburg 2004). Ciertamente, aunque se han esquivado muchos obstáculos, la naturaleza en ocasiones parece no responder a los requerimientos del capital. Estas limitaciones, pocas veces consideradas, han desempeñado también un papel importante en la persistencia (aunque reconfigurada) de los pequeños agricultores en el mundo.

En el caso de Nativitas, la acción de la naturaleza es un tanto complicada y contradictoria, ya que los esfuerzos de acumulación personificados en las grandes y pequeñas industrias, las maquilas y las lavanderías de mezclilla han convertido el río en un caño receptor de sustancias químicas y tóxicas, degradándolo al grado de que ya no ha tenido la capacidad de renovarse. Empero, con todos los problemas de salud que eso implica, sus aguas siguen sirviendo para dar vida a los sembradíos de alfalfa, avena, ebo, tomate, amaranto y otros cultivos, como el maíz, que en ocasiones necesitan agua durante los meses de estiaje (noviembre a mayo).

Frente a una agricultura desvalorada y mínima, y ante un medio ambiente degradado y que pone en riesgo su salud, estos sujetos han "decidido" seguir cultivando sus tierras y cada año poner las presas en los ríos para regar. De esta manera, las estrategias socioeconómicas de gran parte de los ejidatarios y pequeños agricultores de Nativitas consisten, hoy en día, en la diversificación de sus actividades y complementadas con la labor del campo. Para lograrlo deben ignorar o poner bajo el tapete la contaminación de las aguas del río Atoyac. No obstante, esta capacidad de adaptación o resistencia no los hace actores libres, sino sujetos en un entramado sociopolítico en donde tienen que valorar y escoger el menor de los males.

Se podría decir entonces que la actividad agrícola, independientemente de los elementos culturales y simbólicos atados a ella, ha persistido en Nativitas a lo largo de los años, debido a que los ejidatarios y pequeños agricultores han reconfigurado, adaptado e innovado estrategias socioeconómicas para enfrentar no una, sino varias etapas de reestructuración económica nacional. La revolución verde, las políticas de industrialización y urbanización y la apertura comercial neoliberal son sólo algunos de esos cambios estructurales que han afectado directa o indirectamente el devenir agropecuario en el país. En este sentido, analizar lo global en lo local nos permite ver esas formas particulares del desarrollo capitalista y las configuraciones desiguales que se han construido. Ciertamente la agricultura ha permanecido, pero en condiciones francamente precarias y sin desempeñar el papel que debería ocupar en la seguridad 
alimentaria del país. Hoy sirve para alimentar a animales de traspatio y como un soporte ínfimo de subsistencia. La histórica vocación agrícola de Nativitas y la región en la que está enclavada ha sorteado hasta ahora todos los obstáculos, lo interesante será ver de qué forma estas estrategias se siguen reconfigurando ante la expansión urbana de las metrópolis cercanas y la presión sobre la tierra, ante el inminente relevo de la propiedad ejidal de las generaciones jóvenes y la continua contaminación de sus fuentes superficiales y subterráneas.

\section{IDEAS FINALES}

La dinámica agrícola del municipio de Nativitas comenzó a modificarse desde la cuarta década del siglo xx. Durante estos años se conjuntaron varios hechos: la llamada revolución verde fue adoptada como política agrícola en el país, lo que en términos simples provocó que la producción de trigo comercial, sumamente importante en Nativitas, no pudiera competir con una producción altamente tecnologizada en el norte de México. Por otro lado, el programa bracero en Estados Unidos solicitaba mano de obra mexicana ante la ausencia de una fuerza de trabajo masculina propia; y finalmente, la población rural en el centro del país había aumentado de forma tal que las parcelas de propiedad social y privada ya no eran suficientes (si es que alguna vez lo fueron) para satisfacer las necesidades de las nuevas generaciones.

Esto provocó una movilización de personas en búsqueda de nuevas opciones y estrategias de sobreviviencia, de forma que se conjuntó la migración laboral pendular a la ciudad de México, la incorporación al programa bracero y una conversión agrícola del trigo hacia productos forrajeros que giraron en torno a una ganadería doméstica o de pequeña escala, o bien, en los casos más exitosos, hacia la producción de hortalizas. Esta compleja trama socioeconómica que coloca a lo global en lo local es crucial en el entendimiento de la configuración del papel de la agricultura y las estrategias socioeconómicas de Nativitas que hoy en día han sido útiles y eficaces ante los persistentes embates capitalistas personificados en las relaciones neoliberales más recientes.

La permanencia de la producción ejidal en función de la ganadería de traspatio como complemento a la multiplicidad de actividades remuneradas que tienen los habitantes de Nativitas les ha permitido complementar estrategias familiares de sobrevivencia diversificada y múltiple. En este entramado complejo, dos asuntos han llamado mi atención y me gustaría lanzar al aire para su futuro análisis. Uno tiene que ver con el evidente envejecimiento de los ejidatarios, el otro se centra en los problemas socioambientales de la región.

En su mayoría, los hijos de los ejidatarios no están dispuestos a continuar con el trabajo agrícola de las tierras de sus padres, ya sea porque se dedican a otras actividades o porque defi- 
nitivamente consideran que el campo no es una vía para satisfacer sus necesidades económicas y sociales. Sin embargo, hasta ahora ha habido un relevo en los ejidos que ha permitido su labor continua. Por otra parte, los ahora viejos tuvieron también la oportunidad de irse, como muchos de sus familiares y conocidos, de braceros a Estados Unidos, a la ciudad de México o de obreros a las fábricas de la región; de toda esa generación unos decidieron (por necesidad o convicción) seguir cultivando la parcela y cerrar filas en torno al ejido. Más allá del arraigo a la tierra, ante las magras posibilidades de sustento digno que el sistema económico deja para los más pobres, tal vez la producción de forrajes y la ganadería de traspatio seguirá siendo una opción, un seguro mínimo de subsistencia, sobre todo para la población que envejece; el tiempo dirá.

Por otro lado, las industrias químicas, petroquímicas, automotrices y de alimentos apostadas en los corredores industriales de los municipios poblanos de San Martín Texmelucan y Huejotzingo, y en el municipio tlaxcalteca de Ixtacuixtla, así como los pequeños talleres de lavado y teñido de mezclilla ubicados en diversas localidades río arriba desde hace más de 30 años han estado vertiendo sus desechos químicos y tóxicos al río, en su mayoría sin tratamiento alguno. Esta combinación de sustancias ha eliminado la vida animal y vegetal acuática del río Atoyac, sin embargo, las parcelas ejidales siguen siendo regadas con esta agua. La producción para el comercio local o autoconsumo de forrajes, maíz, amaranto y tomates verdes que muchas veces son regados con agua de río contaminada no ha decrecido. Cabe preguntarse si en algún momento, además del gradual deterioro en la salud de los habitantes de esta zona, los productos del campo resentirán la contaminación y la producción será imposible.

Ambos cuestionamientos parecen fatalistas. Sería ocioso volver a una discusión sobre la desaparición de los productores agrícolas de pequeña escala, sobre todo después del argumento central del artículo sobre la capacidad de adaptación y resistencia de estos sujetos dentro del devenir histórico del capitalismo en lo local y lo global. Lo saco a colación porque son dos elementos que deberán ser tomados en cuenta en los futuros análisis sobre las estrategias socioeconómicas de esta región.

Es sumamente relevante, en el contexto de la globalización neoliberal actual, la permanencia agrícola en lugares como Nativitas, debido a que la resistencia, negociación, adaptación e innovación de los nativiteños sugiere que el capitalismo no impone leyes o caminos rígidos para transformar la agricultura o a sus productores (Akram-Lodhi y Kay 2009: 11) y que los periodos de campesinización o descampesinización no son parte de un proceso unilineal o etapas históricas mutuamente exclusivas. Desafortunadamente, la única tendencia real es que estas configuraciones siguen estando inmersas en contextos de pobreza, marginación y exclusión. 


\title{
LOS EFECTOS SOCIOAMBIENTALES DE LA CONTAMINACIÓN DEL RÍO ATOYAC EN NATIVITAS
}

\author{
Hernán Salas Quintanal \\ Paola Velasco Santos
}

\section{INTRODUCCIÓN}

A partir de sus propios recursos económicos, sociales y políticos, las familias de Nativitas han desplegado una amplia variedad de actividades laborales y estrategias socioeconómicas que ponen en evidencia la forma en que los actores rurales adaptan, construyen y reconstruyen sus formas de vida. Una buena parte de éstas se derivan de una profunda transformación del entramado económico global y nacional, y del socionatural local que será objeto de esta reflexión. El caso que más llama la atención en Nativitas es el de los pequeños productores, quienes han "decidido" continuar -aunque de manera reconfigurada- con una producción agrícola mínima y complementaria, por lo que sus estrategias de sobrevivencia tienen su sustento en la diversificación de actividades que se combinan con labores agropecuarias. La permanencia de estas últimas ha implicado ignorar -aunque no desconocer- el estado de contaminación del río Atoyac -considerado uno de los ríos más contaminados del país (GEo México 2004: 83)-, principal fuente de riego y que atraviesa una parte importante del territorio municipal, centro de nuestra investigación (mapa 5).

En este trabajo partimos del supuesto de que el estado neoliberal prioriza el desarrollo económico de una minoría al bienestar de una mayoría, considerado éste en términos de la salud, el medio ambiente, los modos de vida alternos, el patrimonio agrícola, entre otros. En su libro Normal Accidents, Charles Perrow (1999), a partir del análisis de sistemas tecnológicos diversos, como las plantas nucleares, las petroquímicas, la aviación, las presas, las minas, la exploración del espacio y hasta los estudios genéticos, sostiene que los accidentes derivados de estos sistemas tecnológicos son eventos esperados, normales y anticipados. Su argumento es 
que cuando un sistema social, económico y tecnológico se organiza de tal forma que su único fin es la ganancia económica, los accidentes son algo normal y la seguridad humana y ambiental es algo secundario frente a las ganancias. Es más barato controlar los daños que prevenirlos organizando el sistema político, económico y tecnológico en torno al bien social. De acuerdo con esta interpretación, podemos decir que la condición del río Atoyac es una consecuencia "normal" de la priorización de la industria en la región, el deterioro de la salud y de la calidad de vida de sus habitantes es una externalidad esperada, es decir, es parte de los efectos "no esperados" de la modernidad. ${ }^{124}$

La concepción de desarrollo que respalda el supuesto del productivismo industrial a cambio de la sobreexplotación de los recursos naturales y humanos, como es el caso del corredor industrial del valle Puebla-Tlaxcala en la región de estudio, ha sido formulada por Arturo Escobar (1998) al señalar que desde la Segunda Guerra Mundial éste ha sido inventado desde la posición de una propuesta histórica que consiste en la transformación total de las culturas, naturalezas y las formaciones sociales de América Latina, de acuerdo con los dictados de la ideología del llamado Primer Mundo. Desde su origen, el propósito del desarrollo era ambicioso porque pretendía crear las condiciones necesarias para reproducir en todo el mundo los rasgos característicos de las sociedades avanzadas, un alto nivel de industrialización y urbanización, tecnificación de la agricultura, rápido crecimiento de la producción material y niveles de vida, adopción de la educación y valores culturales modernos. La tríada que estaba llamada a ejecutar esta revolución masiva era el capital, la ciencia y la tecnología. Esta perspectiva, además de etnocéntrica, suponía una linealidad universal en los ritmos occidentales, sin tomar en cuenta los tiempos y espacios que posee cada cultura y pueblo.

Como veremos en este trabajo, la normatividad ambiental es parte de la construcción del sistema mundial-local, de manera que se constituye como un elemento jurídico central que permite la continuación del ciclo de acumulación capitalista. En este sentido, su objetivo no es frenar el deterioro ambiental, sino establecer límites -obviamente arbitrarios, que no afecten las ganancias económicas- para contaminar. En México, la descarga de aguas residuales sigue una Norma Oficial ${ }^{125}$ que establece el "límite máximo permitido" de una descarga de agua residual, mientras que otra Norma ${ }^{126}$ ordena los límites máximos permitidos de sustancias contaminantes en una descarga de agua residual a un sistema de drenaje municipal o urbano;

\footnotetext{
${ }^{124}$ Para profundizar sobre las consecuencias no esperadas de la modernidad, ver la compilación de Beriain

${ }^{125}$ La Norma Oficial Mexicana NOM-001-ECOL-1996.

${ }^{126}$ La NOM-002-ECOL-1996.
} (1996). 
y finalmente una Norma ${ }^{127}$ que dispone los límites de evaluación de la calidad del agua para consumo humano (Navarro y Morales 2004: 18-19).

En primer lugar, las normas contemplan los límites permisibles de sustancias individuales, pero no toman en cuenta cuáles serían los resultados de la combinación de sustancias. Individualmente una sustancia puede no ser riesgosa, pero si se junta con otra puede resultar tóxica y perjudicial para la flora y fauna expuesta (incluyendo al ser humano). Segundo, compuestos orgánicos volátiles -como el cloroformo y el cloruro, ambos hallados en el Atoyac- no son reconocidos en estas normas, a pesar de ser considerados residuos peligrosos (por su toxicidad) en otras normas mexicanas. Es decir, los parámetros para la descarga de aguas residuales sólo contemplan residuos físicos y algunos metales, por lo que la contaminación biológica y química no es registrada. En tercer lugar, las normas oficiales no consideran el impacto total de la contaminación en una corriente resultado de la acumulación de descargas residuales durante un largo tiempo y por parte de un cada vez mayor número de fuentes (Atoyac Zahuapan y Calidad de Vida y Centro "Fray Julián Garcés" 2009: 10 y 35).

A partir de un análisis descriptivo del ambiente socionatural del municipio, este trabajo tiene por objetivo demostrar cómo los cambios ambientales, fundamentalmente expresados en la contaminación del río Atoyac, principal fuente de agua para las labores agropecuarias, industriales y domésticas del municipio de Nativitas, han afectado sistemas productivos históricos en una región definida por su vocación agrícola. A tal efecto, el capítulo inicia con una descripción física e histórica del río Atoyac y el valle de Tlaxcala, haciendo énfasis en la historia del uso del río, los asentamientos en sus riberas y la infraestructura para su aprovechamiento. Enseguida, damos cuenta del proceso de deterioro ambiental del Atoyac y de los pueblos que han utilizado sus aguas desde la época prehispánica hasta la actualidad, cuando tiene especial importancia la actividad industrial y el crecimiento urbano en la contaminación de la región. Finalmente, analizamos las consecuencias que la contaminación ha tenido en la calidad de vida de las poblaciones.

\section{EL RÍO ATOYAC, RELACIÓN SOCIEDAD-NATURALEZA}

El territorio tlaxcalteca se ubica dentro de tres regiones hidrológicas (RH). Alrededor de $75 \%$ del estado (centro y sur) pertenece a la RH Balsas (núm. 18). Sólo $18 \%$ corresponde a la cuenca del río Moctezuma, ubicada al noroeste de la entidad, que es parte de la RH Pánuco (núm.

${ }^{127}$ La NOM-127-SSAI-1994. 
26) y el resto se localiza en la cuenca del río Tecolutla que corresponde a la Tuxpan-Nautla (RH 27), que cubre el noreste del estado (INEGI s/fa). En cuanto a la precipitación, $81 \%$ de la recibida en la RH del Balsas se evapo-transpira, $15 \%$ escurre por los ríos y arroyos que la forman y sólo $4 \%$ se filtra al subsuelo para recargar los mantos acuíferos (Conagua 2009: 30).

La región Balsas contiene un total de quince cuencas hidrológicas que están interconectadas entre sí y drenan sus aguas hacia el océano Pacífico a través del río Balsas. Estas cuencas están distribuidas en tres subregiones: Bajo, Medio y Alto Balsas, esta última se extiende por 334 municipios de seis estados (127 de Puebla y 56 de Tlaxcala), abarcando $79 \%$ del total de la región. De los $4505 \mathrm{~km}^{2}$ que tiene de superficie Tlaxcala, 3505 son ocupados por la región del Alto Balsas. Asimismo, esta región contiene siete cuencas, entre las que destaca la del Alto Atoyac, por la cual escurren el Atoyac, el Mixteco, el Nexapa, el Tlapaneco y otros ríos más (Conagua 2009: 2-5, 33) que conforman el valle de Texmelucan, lo que lo conecta con la vertiente del Pacífico. Por cada río importante de la región se extiende una microcuenca, la del Atoyac-Zahuapan ocupa una buena parte del territorio tlaxcalteca y aguas abajo es tributario del Balsas, uno de los principales ríos mexicanos. En otro orden de cosas, en general, el valle de Puebla-Tlaxcala ha estado más ligado al Golfo de México, incluso ha sido nodal en la interrelación entre la región Golfo y el México central.

La cuenca del río Atoyac nace cerca del límite de los estados de México y Puebla, en la vertiente oriental de la sierra Nevada. Durante la primera etapa de su recorrido recibe la afluencia de un buen número de ríos -entre los que destacan el Cotzala y el Santa Elena-, arroyos, veneros y ojos de agua que bajan por ambas márgenes, aunque la mayoría lo hace por la sierra y por las estribaciones del volcán Iztaccíhuatl. No está de más señalar que la zona occidental de la cuenca del Alto Atoyac, particularmente el área de la sierra Nevada y sus alrededores, es la más escabrosa, está conformada por una gran cantidad de hondonadas y gargantas. Las barrancas tienen pendientes prolongadas que, en tramos relativamente cortos, bajan con rapidez hacia el valle, lo cual no imposibilita que los veneros o ríos puedan ser desviados para el beneficio de los terrenos adyacentes, inclusive desde las faldas superiores de la sierra. Esta red hídrica que baña buena parte del valle de Texmelucan se ha formado gracias a una precipitación promedio anual de unos $850-900 \mathrm{~mm}$, lo que ha favorecido la acumulación de mantos acuíferos que desempeñan hasta hoy un papel importante en el desarrollo de las actividades agrícolas, domésticas e industriales de la zona (Mazabel 2007).

El río Atoyac se alimenta del escurrimiento de los deshielos del volcán Iztaccíhuatl, dando lugar a la formación del amplio valle altiplánico poblano-tlaxcalteca, que comienza en la cuenca alta del valle de Texmelucan, después del cual se introduce al sureste tlaxcalteca (precisamente por el municipio de Nativitas) para servir, en un pequeño tramo, como línea divisoria 
con el estado de Puebla. En el extremo sur de Tlaxcala el río Atoyac se une con el Zahuapan y prosigue su curso hacia Puebla a través del sistema Balsas para, finalmente, desembocar en el océano Pacífico (Morales 1999: 27). El gran valle poblano tlaxcalteca se encuentra resguardado por los volcanes Iztaccíhuatl, Popocatepétl y Malinche, que conforman el eje neovolcánico, y en su amplia extensión une el océano Pacífico con el Golfo de México. Los volcanes y otras elevaciones constituyen una orografía que posee gran importancia paisajística y cultural y son fundamentales para los recursos hídricos de la región.

\section{ANTECEDENTES DEL APROVECHAMIENTO Y DETERIORO AMBIENTAL DEL RÍO ATOYAC}

En la época prehispánica, las aguas del Atoyac conformaban lagunas y ciénegas que eran aprovechadas por los habitantes de Xochitécatl y Cacaxtla -hoy municipio de Nativitas- por su gran variedad de especies florales y faunísticas. Según el registro arqueológico, algunas de estas especies eran aves: pato, grulla, gallareta, guajolote; vertebrados: zorrillo, ratón, tlacuache, conejo, liebre, ardilla, perro, lobo, venado, pecarí; especies acuáticas: peces, ranas, diferentes tipos de tortugas. En cuanto a la flora y material botánico, casi toda para alimentación, uso medicinal y confección de artesanías, se ubican uauhquilitl (quelites y amaranto), nopal, peonia, hierba del cáncer, gramíneas para forraje, gramíneas como maíz, elote (cuitlacoche), leguminosas y tomate (Serra y Lazcano 2011: 171-180).

El aprovechamiento de las aguas del río Atoyac se intensifica con el establecimiento de las poblaciones hispanas a finales del siglo xvi. Durante la Colonia, la utilización de sus aguas permitió la constitución de grandes haciendas, que basaron su desarrollo en la agricultura extensiva, la ganadería y la agroindustria textilera. Desde entonces comienza el deterioro del Atoyac y los conflictos por el vital líquido.

De acuerdo con Silvio Zavala (citado por Chevalier 1975), la hacienda surgió de la encomienda de manera indirecta; quizás sus antecedentes más inmediatos en el centro y sur del país fueron los ingenios azucareros semiautónomos desde el siglo XVI y las grandes estancias ganaderas del México septentrional. La lucha por el poder entre metrópoli y colonia, que en determinados momentos favoreció a los establecidos en México, consolidando la hegemonía hispánica, alteró de manera significativa las culturas indígenas ligadas a la tierra. Al respecto, Martínez (1994) propone una definición del concepto de "despojo", subdividiéndolo en tres categorías: la expoliación, que es la usurpación mediante el uso de la violencia o de la fuerza; 
la usurpación sublimada, la que se realizó de manera sutil, a través de la donación o del matrimonio, y la usurpación formal, la más importante, que se realizó con base en las disposiciones y los mecanismos legales del sistema colonial.

Además de las formas de propiedad y explotación de la tierra y el agua, otra problemática, respecto de la ocupación hispana, fue la progresiva deforestación del valle como consecuencia de la extensión de las áreas de pastoreo. En una región orientada a la producción triguera, donde la falta de pastos y forrajes era evidente, otro factor que seguramente incrementó la presión sobre las tierras de pastura fue el hecho de que las poblaciones indias incorporaron el ganado menor a su economía. De manera que se puede apreciar, en los inicios de la explotación del Atoyac, no sólo una lucha entre indios y españoles, sino también otra entre pastores y labradores.

Desde el siglo xvi el río Atoyac ha sido utilizado para cumplir con diferentes funciones productivas. Primero sirvió para los obrajes textiles en Puebla y, posteriormente, en Tlaxcala. Después, en el siglo XIX, sus aguas se utilizaron para las primeras fábricas textiles impulsadas por fuerza hidráulica y desde mediados del siglo xx su fuerza motriz dejó de ser útil y pasó a ser un simple receptor de desechos y residuos que rebasan el límite que el río es capaz de degradar o purificar.

Aprovechando la fuerza motriz que podía ofrecer el río Atoyac, a principios del siglo XVII se instalaron en sus inmediaciones obrajes textiles; para 1604 ya existían 13 (González 2006: 20), lo que constituyó un incipiente proceso de industrialización que, además de impactar en el ámbito económico, modificó sobremanera las relaciones con la tierra y el agua.

Aunque históricamente la industria en Tlaxcala surgió en la época colonial, su desarrollo y auge se dio hasta el siglo xIx, incentivado por el gobierno central y en articulación con el surgimiento y evolución de la industria en la vecina ciudad de Puebla. La imposición de aranceles elevados para la importación de productos y de exenciones fiscales a las fábricas impulsó el desarrollo industrial en el país; en el valle Puebla-Tlaxcala se propició la instalación de un corredor fabril en el que se instalaron empresas textiles (González 1991: 14-17).

La primera fábrica textil fundada en el valle, La Constancia Mexicana, propiedad de Esteban de Antuñano, fue además la primera fábrica mecanizada del país, se instaló en 1835 en las márgenes del río Atoyac en territorio poblano. En las riberas de los ríos Zahuapan y Atoyac, en la parte suroeste de Tlaxcala, se construyó en 1842 la fábrica de hilados El Valor, con lo cual se inició la ola industrializadora en el valle y el acaparamiento de agua del río. Estas fábricas se situaban en lugares estratégicos donde podían controlar dos tipos de recursos: agua y mano de obra; ya que además de situarse en las riberas del río se establecían en las inmediaciones de pue- 
blos, cuyos habitantes fungían como una reserva de fuerza de trabajo (González 1991: 18, 23). ${ }^{128}$ Esta zona industrial se vio beneficiada con la construcción de la primera línea interurbana del ferrocarril entre Puebla y Apizaco en 1871, que conectaba la ciudad de México con Veracruz y permitió expandir el área de abastecimiento de materia prima para las fábricas de hilado en Puebla, impulsando el crecimiento de la industria textil tlaxcalteca (Robichaux 2006: 3).

La contaminación del río Atoyac comienza en los ríos Cotzala y Santa Elena, tributarios del Atoyac. La historia productiva del Atoyac se desdibuja cuando hoy vemos el deterioro de los ríos, aprovechado hasta hoy como generador de energía eléctrica para la fábrica textil El Pilar, localizada en la ribera del río Santa Elena, donde puede observarse, desde la altura del pueblo de San Andrés Hueyacatitla en las laderas de la sierra Nevada, apenas iniciando su descenso, una notoria contaminación tanto en sus aguas como en sus alrededores. La contaminación del Cotzala se observa al llegar al municipio de San Martín Texmelucan, cuando desemboca en el río Atoyac y lo convierte en canal de aguas negras y basurero.

Río abajo, en la zona de influencia de San Martín Texmelucan, la contaminación más intensa del Atoyac comienza en la década de los años 70 del siglo xx, con los vertederos urbanos e industriales, primero a partir de la urbanización creciente de la ciudad de Texmelucan y después con la instalación de otras industrias pesadas en las comunidades periféricas de San Martín, a partir del desarrollo del corredor industrial Puebla-Texmelucan. El complejo petroquímico Independencia (PEMEX), ubicado en la comunidad de Santa María Moyotzingo, es un ejemplo paradigmático de una empresa contaminante. "[E] ste complejo inicia operaciones en 1969, con la producción de dodecilbenceno y alquilarilo pesado; posteriormente produce acrilonitrino [dejó de producirlo en el año 2000], ácido cianhídrico, propileno acetonitrilo y metanol" (Navarro y Morales 2004: 16).

Hoy en día, la cuenca del Atoyac, junto con la del río Apatlaco en el valle de Cuernavaca, es la que concentra mayor número de industrias en la región del Balsas (Morales 2010: 241-242). Sin embargo, el río no sólo se utiliza como drenaje por las industrias, también ahí terminan las aguas negras generadas por la población de la región. Tanto en las industrias como en los drenajes municipales se han instalado algunas plantas de tratamiento; no obstante, éstas son

${ }^{128}$ Entre 1842 y 1894 se fundaron nueve fábricas textiles más en la cuenca del Atoyac-Zahuapan; entre ellas, en 1877 Luis García Teruel construyó la fábrica de hilados y tejidos San Manuel Morcom en el pueblo de San Miguel Contla; en 1880 se instaló La Trinidad en Santa Cruz Tlaxcala; y en 1885 La Josefina y La Tlaxcalteca en Santo Toribio Xicohtzingo, todas en las orillas del río Zahuapan (González 1991: 23-24). 
escasas y sólo algunas están en pleno funcionamiento. ${ }^{129}$ Paralelamente, el agua del río sirvió como fuente de riego de los campos de cultivo, función que continúa hoy en día a pesar de los altos niveles de contaminación. ${ }^{130}$ Actualmente el río es un lecho sin vida; las especies animales y vegetales acuáticas han desaparecido, en sus inmediaciones se respira un olor fétido y en las de las fábricas y talleres el color del agua puede ir del azul índigo a rojo y amarillo.

La microcuenca del Atoyac-Zahuapan es la región que cuenta con mayor disponibilidad de agua en el estado. A través del uso de 92 manantiales, más de 700 pozos, presas de almacenamiento y los ríos Atoyac y Zahuapan, cuyos principales usos consuntivos son las labores agrícolas, el agua urbana y la industria, los usuarios de esta región acaparan alrededor de $68 \%$ del total del agua concesionada en el estado, que se eleva a poco más de 294 millones de metros cúbicos (Hernández 2011: 237-238).

La aglomeración industrial de la zona se intensificó en 1990, provocando una agudización en el deterioro ambiental de la región. La mayor concentración de industrias se localiza en las riberas del río Atoyac. En Puebla, las industrias cuyos desechos tóxicos afectan directamente a Nativitas son las ubicadas en los municipios de San Martín Texmelucan y Huejotzingo; mientras que en Tlaxcala, el corredor de Ixtacuixtla es el que genera la mayor parte de los residuos industriales. ${ }^{131}$ Las industrias se agrupan en los espacios descritos a continuación (mapas 13 y 14).

${ }^{129}$ En el caso de Tlaxcala, un total de 825 localidades de 48 municipios descargan de manera oficial sus aguas residuales tanto en el río Atoyac como en el Zahuapan. Aproximadamente estas descargas son de 1453 lps, de los cuales sólo 426 ingresan a 26 sistemas de tratamiento. De estos 26, sólo 18 sistemas de tratamiento se encuentran operando, 16 lo hacen "de forma deficiente" y sólo dos de forma regular (SEMARNAT 2007: 3).

${ }^{130}$ En el sentido más común, se entiende por “contaminación” la introducción de sustancias en un medio al cual no pertenecen, lo que puede causar efectos (generalmente adversos) para la salud o el medio ambiente.

${ }^{131}$ En el ámbito nacional, el sector industrial descarga al año aproximadamente $6.5 \mathrm{~km}^{3}$ de aguas residuales sin tratamiento en cuerpos de agua, lo que representa 6 millones de toneladas de carga orgánica. Estas descargas de aguas residuales provocan la contaminación del agua, una evidente disminución de su calidad, la destrucción o daño a ecosistemas acuáticos y el ecocidio de flora y fauna. Según datos de la Conagua, sólo $10 \%$ de las aguas superficiales tienen una buena calidad, en tanto $65 \%$ es de calidad media y el $25 \%$ restante tiene una calidad mala (Conagua 2005). Por orden de importancia, las industrias que más contaminan son la acuacultura, la azucarera, la petrolera, de servicios, la química y farmacéutica, la de celulosa y papel, la agropecuaria, de alimentos y bebidas, de cerveza y la minera (GEo México 2004: 79). En el corredor industrial Puebla-Tlaxcala se localizan varias industrias de las ramas mencionadas. 
a) El área industrial de San Martín Texmelucan acapara la mayor parte de las empresas de la región. Los principales giros encontrados en este municipio poblano son la producción textil, la rama petroquímica, la automotriz, la metalmecánica, las bebidas y las industrias químicas. La textil, que ocupa $24 \%$ de la producción, es el principal generador de aguas residuales (Saldaña y Gómez 2006: 2). En 1981 el gobierno de Puebla puso en marcha el Corredor Industrial Quetzalcóatl; tanto en el municipio de San Martín como en el de Huejotzingo, el gobierno compró terrenos para luego venderlos a empresarios; hoy en día son parques promovidos por el estado, pero de propiedad privada (SDIP s/f; CIEP s/f).

En Texmelucan se compraron 35 hectáreas en la comunidad de Moyotzingo para montar el parque industrial Área 1. El principal giro de las industrias albergadas aquí es de alimentos, químico, textil, confección, metalmecánica y construcción (SDIP s/f; CIEP s/f). En otras localidades del municipio se encuentran diversas empresas cuyos giros van desde los textiles y alimentos hasta las fábricas de químicos aromáticos, frenos, ladrillos y una metalúrgica. Algunas de las más destacadas industrias son: Oxiquímica, San Luis Rassini, ${ }^{132}$ Servicios Metalúrgicos del Sur, Dupont Pinturas y Papelera Kimberly Clark (mapa 13).

b) En Huejotzingo se hicieron cuatro parques industriales que pertenecen igualmente al corredor industrial Quetzalcóatl. El parque industrial San Miguel es el más importante por su tamaño y por las industrias que en él se establecieron. Con una extensión de 81.6 hectáreas (compradas por el gobierno y ahora propiedad privada), se ubica al este del poblado de Santa Ana Xalmimilulco sobre la carretera federal México-Puebla, y sus giros principales son alimentos, transporte, químicos, servicios y textiles. Las empresas más destacadas son las textileras (mezclilleras) Skytex, Globaltex y Aunde, la refresquera Big Cola, una fábrica de material de curación Kendall y varias empresas de las ramas del plástico, metalmecánica y farmacéutica. Los otros tres parques son El Carmen, con una extensión de 32.56 hectáreas; el Área 4 anexo con 21.64 hectáreas y Ciudad Textil con 70 hectáreas destinadas a las empresas de construcción, metalmecánica, textiles y confección (SDIP s/f; CIEP s/f).

${ }^{132}$ Esta industria pertenece a la rama automotriz y se dedica a fabricar muelles y frenos para diversas empresas, como General Motors y Volkswagen, esta última ubicada a pocos kilómetros de San Martín en la carretera a Puebla. Según su página oficial, cuenta con diversas plantas de producción en Brasil y México, además de otras sedes en diferentes partes del mundo; sin embargo, según nos informó un empleado indemnizado, a finales de 2009 cerró sus instalaciones en San Martín como consecuencia de la crisis económica. 
En suma, las industrias asentadas en los municipios poblanos colindantes con Nativitas en su mayoría son catalogadas como pesadas o mixtas y con uso intensivo de agua y se extienden por más de 240.95 hectáreas $\left(2.4 \mathrm{~km}^{2}\right)$. Paradójicamente, esta gran extensión industrial no hace a esta región ciento por ciento obrera. La zona, tanto en Puebla como en Tlaxcala, sigue teniendo una vocación agrícola que ha sido fuertemente afectada porque los ríos y arroyos (fuente de riego), canales y zanjas están contaminados con desechos de estas industrias.

c) En el corredor Ixtacuixtla, ubicado en la carretera federal San Martín Texmelucan-Tlaxcala, ya en territorio tlaxcalteca, se encuentran dos corredores industriales importantes, el primero es precisamente el corredor Ixtacuixtla, ubicado en la localidad de Villalta, municipio de Tepetitla de Lardizábal, y se extiende hasta el municipio de Ixtacuixtla; las ramas principales de estos corredores son la industria textil y de prendas de vestir, bebidas, petroquímica, agroindustria, automotriz, alimentos y minerales no mecánicos. Entre los poblados Villa Mariano Matamoros y Villa Alta, además, se encuentran una planta de adhesivos, una empacadora de champiñones y otra de maquila de partes eléctricas de la Volkswagen, cuya planta automotriz se encuentra muy próxima, en la carretera México-Puebla, en el municipio de Cuauhtlancingo, Puebla.

El segundo corredor es Panzacola-Zacatelco, el cual recorre de norte a sur los municipios de Zacatelco, Xicohtzinco, Papalotla y Tenancingo, al sur del estado; genera descargas de las industrias textil, petroquímica, agroindustria, automotriz, alimentos y minerales al río Atoyac; ubicado al sur de Nativitas, por lo que afecta al río aguas más abajo (mapa 14).

Además de estas industrias de gran escala, se suma el desarrollo de la maquila dispersa en los domicilios de varias comunidades, empresas medianas y pequeños talleres familiares que operan para la gran industria textil de la mezclilla. El municipio de Tepetitla de Lardizabal, ubicado en medio de los corredores industriales de San Martín Texmelucan y los de Tlaxcala, cuenta, según el directorio oficial del gobierno del estado, con sólo dos industrias, una dedicada a la fabricación de telas para tapicería automotriz y de decoración y otra que produce embutidos y carnes de cordero. Los conteos oficiales no toman en cuenta todos los pequeños talleres domésticos que se dedican a actividades que van desde la decoloración, deslavado o teñido de la mezclilla hasta la costura de prendas y que en esta localidad son abundantes. Este tipo de maquila o lavanderías, como se les denomina localmente, se ubican también en comunidades como San Rafael Tenanyecac, Villa Alta, San Mateo Ayecac y Santa Ana Xalmimilulco.

De acuerdo con datos oficiales, los principales focos rojos en materia ambiental en el estado de Tlaxcala son las más de 17 lavanderías de mezclilla cuyas descargas al río no están normadas. Además de extraer agua a través de pozos subterráneos, estos pequeños talleres descargan agua con sustancias tóxicas utilizadas para lavar la mezclilla al drenaje municipal, el cual va directa- 
mente al río Atoyac sin ningún tipo de tratamiento, de acuerdo con información de la propia SEMARNAT (2007: 12), y que pudimos observar de primera mano en recorridos por la región.

Las mezclillas están teñidas con diferentes sustancias sintéticas. Los tintes de mayor uso están catalogados como desechos peligrosos, ya que en condiciones aeróbicas su degradación es muy difícil, y en condiciones anaeróbicas la sustancia se convierte en un amino tóxico. El mercado actual de la mezclilla ofrece productos que dan la apariencia de estar usados o viejos, para obtener esta apariencia las prendas se sujetan a un proceso de deslave. Los procedimientos más comunes son deslavarlos con piedras pómez, aplicar cloros o un tipo de encima de celulosa (Solís et al. 2008: 6). En el Atoyac se han encontrado este tipo de sustancias, así como la evidencia contundente de tintes de colores; estas sustancias recorren el municipio de Nativitas, afectando directamente a pobladores y ejidatarios de Santiago Michac y las parcelas de ejidatarios de las comunidades de San Miguel Xochitecatitla, Santo Tomás la Concordia y la cabecera municipal, principalmente.

A este deterioro ambiental provocado por la industrialización se suma que, a partir de la década de 1940, se comenzaron a modernizar y transformar las actividades agrícolas al introducir cultivos de hortalizas para abastecer mercados de las ciudades de México, Puebla y Tlaxcala, así como el cultivo de alfalfa y otros forrajes para el consumo del creciente número de animales de traspatio, todo a través del acceso al agua del río Atoyac. En la década de los 60 se construyeron nuevos canales y con la revolución verde se modernizaron procesos que incluyen el uso de maquinarias y un paquete tecnológico con base en el uso de agroquímicos, fertilizantes, plaguicidas y productos foliares, que también han ocasionado problemas de contaminación de suelos y aguas subterráneas. Existen dos distritos de riego en toda la cuenca: el Atoyac-Zahuapan (ubicado al norte de nuestra zona de estudio) y el Atlixco-Valsequillo; ambos utilizan fuertes cantidades de agua, al tiempo que están contribuyendo a la contaminación del ambiente. Estudios recientes han encontrado en el río Atoyac rastros de productos químicos como el tamaron, el 2,4-D, el cuproquat y el gramoxone, identificados como nocivos para la salud (Morales 2010: 243).

Un elemento que se ha utilizado para explicar el proceso de contaminación y deterioro del río ha sido el aumento demográfico, resultado tanto del crecimiento natural de la población originaria como de la llegada de nuevos pobladores ante la oferta de trabajo de las industrias asentadas en la región. Si nos atenemos a las cifras (cuadro 20), pese al dinamismo económico que adquirió la región, el crecimiento demográfico ha sido el normal, por lo que podemos afirmar que, tal como lo señala un habitante del municipio de Nativitas: "es cierto que aventamos la basura al río, pero eso la gente no lo hacía cuando el río estaba limpio, además no hay recolección de basuras y el drenaje doméstico se ha vertido a canales que pasan por frente de 
nuestras casas y que llegan al río" (entrevista a ejidatario de Jesús Tepactepec, Nativitas, julio de 2009). Esto nos permite afirmar que el crecimiento natural de la población no es una causa directa del deterioro del medio, sin embargo, este aumento ha generado una urbanización caótica, problema que se agudiza por un mal manejo de aguas residuales y drenaje municipales, recolección de basuras, etcétera.

\begin{tabular}{|c|c|c|c|c|}
\hline Municipio & $\begin{array}{c}\text { Población total } \\
1980\end{array}$ & $\begin{array}{l}\text { Población total } \\
2005\end{array}$ & $\begin{array}{l}\text { Población total } \\
2010\end{array}$ & $\begin{array}{c}\text { Porcentaje } \\
\text { de crecimiento } \\
1980-2010\end{array}$ \\
\hline San Martín Texmelucan, Pue. & 79504 & 130316 & 141112 & $77.49 \%$ \\
\hline Huejotzingo, Pue. & 31997 & 59822 & 63457 & $98.32 \%$ \\
\hline Tepetitla de Lardizabal, Tlax. & 8614 & 16368 & 18725 & $117.38 \%$ \\
\hline Nativitas, Tlax. & 16912 & 21863 & 23621 & $39.67 \%$ \\
\hline Total de la región & 137027 & 228369 & 246915 & $80.19 \%$ \\
\hline
\end{tabular}

En su estudio sobre la contaminación del Atoyac, Navarro, Flores y Valladares (2004: 29) indican que:

en el Río Atoyac se identifican 3 emisores de aguas residuales industriales provenientes del complejo petroquímico y del Corredor Industrial Quetzalcóatl. El corredor de Ixtacuixtla descarga al drenaje municipal de esta población. Las empresas pequeñas de la maquila de la mezclilla descargan sin tratamiento, a los drenajes municipales de las comunidades donde se ubican o, a través de descargas clandestinas, directas al río. No todas las empresas ubicadas en los corredores industriales dan tratamiento a sus aguas residuales [o lo hacen eventualmente, de manera que] los colectores llevan múltiples descargas. La operación y mantenimiento de los colectores o drenajes industriales es en general muy deficiente [en toda la región, por lo cual...] ocurren derrames de estos conductos que han contaminado terrenos agrícolas y canales de riego.

Al respecto, podemos señalar que existe una planta de tratamiento de agua residual que recibe las descargas de la comunidad de Ixtacuixtla y su efluente es una descarga directa al Atoyac; asimismo San Martín Texmelucan tiene una planta de tratamiento cuyo efluente también descarga en el río. En las comunidades restantes, el drenaje municipal descarga directamente al Atoyac o, lo que es más frecuente, a los diferentes canales de riego abiertos que surcan la
Cuadro 20. Población municipal de la región afectada por la contaminación del río Atoyac. Fuente: INEGI (1980, 1982a, 1982b, 2005, 2010b). 
región. Esta agua de desecho, a su vez, se emplea para el riego agrícola, lo que genera otras consecuencias que limitan el riego, la agricultura, la productividad y el tipo de cultivos.

Otro ejemplo de estas irregularidades ocurrió en abril de 2009 cuando la empresa Oxiquímica, dedicada a la fabricación de químicos aromáticos, esencias y aceites para el hogar, tuvo una fuga de más de mil kilos de acrilato de estilio que intoxicó a alrededor de 40 personas de la junta auxiliar de San Baltazar Temaxcalac, en San Martín Texmelucan, donde está ubicada la empresa. Esta fuga provocó la evacuación de más de mil familias de los pueblos aledaños y afectó a otras juntas auxiliares tanto de Puebla (Santa María Moyotzingo y San Martín Texmelucan) como de Tlaxcala (Popocatla, Villa Alta, Tepetitla de Lardizábal, San Mateo Ayecac y Nativitas). Según información periodística, el accidente fue el detonante para que pobladores de Temaxcalac bloquearan la carretera que va de San Martín Texmelucan a Moyotzingo durante varias horas exigiendo el cierre de esta empresa que manejaba sustancias muy tóxicas que eran vertidas tanto en los terrenos como al drenaje, contaminando agua y tierra. A la empresa se le aplicó una multa por no contar con un programa de contingencia en caso de fugas y permanece cerrada hasta hoy en día (Gálvez 2009).

Los drenajes urbanos y rurales también participan en la contaminación del río. Desechos domésticos y agrícolas van a parar al río sin tratamiento y, al final, los ejidatarios las utilizan pues, en su mayoria, no cuentan con pozos para riego o simplemente no los usan por los altos costos. En el municipio de Nativitas las aguas de drenaje provenientes de San Miguel Xochitecatitla, San Bernabé Capula, Guadalupe Victoria, Santo Tomás Concordia, la cabecera municipal de Nativitas y Jesús Tepactepec, confluyen en un solo drenaje que pasa de forma subterránea por tierras residenciales y ejidales de Jesús Tepactepec y que desemboca en una pequeña planta de rebombeo, ubicada en el ejido de esta última comunidad, que dirige el agua residual por un drenaje que corre paralelo al camino que va a San Miguel Xoxtla, Puebla y que desemboca en el río Atoyac.

El estudio de Navarro et al. (2004) también obtuvo muestras de agua en las tomas domiciliarias de doce comunidades para analizar la presencia de compuestos orgánicos volátiles (voc). Se detectaron cuatro compuestos -cloroformo, bromoformo, bromodiclorometano y clorodibromometano- en las muestras de cinco comunidades. En la toma de Santa Ana Xalmimilulco se encontraron concentraciones para los cuatro compuestos; en Santa María Moyotzingo, Santiago Michac, Tepetitla y en San Mateo Ayecac, se ubicaron los otros elementos excepto bromoformo; en San Francisco Tepeyecac y en San Rafael Tenanyecac sólo se detectaron los dos compuestos bromoclorados (Navarro et al. 2004: 46). La capacidad de depuración y descomposición de los desechos y residuos vertidos a lo largo del río Atoyac y de sus corrientes adyacentes ha sido totalmente rebasada. Legalmente existen ciertas normas y disposiciones que, 
más que evitar la contaminación de las aguas superficiales, buscan el control de daños. Como ya señalamos, este comportamiento corresponde a una concepción hegemónica de desarrollo con una visión economicista que prioriza la productividad por sobre el uso adecuado de los recursos naturales y por sobre el bienestar de la mayoría, organizado de tal manera que el único fin es la ganancia económica; la seguridad tanto humana como ambiental es secundaria. La situación actual del Atoyac es una consecuencia "normal" de decisiones tomadas en el pasado respecto al impulso a un programa industrializador en detrimento del pasado agrícola, en el cual el deterioro de la salud y calidad de vida de los habitantes es una externalidad esperada.

En el estudio sobre la contaminación del Atoyac llevado a cabo por el Centro "Fray Julián Garcés" Derechos Humanos y Desarrollo Local A. C., se detectaron compuestos en las descargas de agua residual al río que ponen en evidencia la confluencia de agua no tratada, tanto de descargas municipales como industriales. Además, según Morales (2004: 80):

los parques industriales aportan múltiples descargas de agua residual de origen y características contaminantes diversas, que no se encuentra[n] contemplada[s] por la norma vigente, que se combinan con los compuestos y sustancias provenientes de aguas residuales domésticas que hacen más complejo el problema de degradación ambiental.

Navarro et al. (2004: 35) tomaron muestras en varias de las descargas del río: en el primer emisor de PEMEx, río Xochiac afluente del Atoyac, en una industria de pisos y cerámicos localizada en Nativitas, en Santiago Michac, en la zanja Real Carrizal, en Tepetitla, en el drenaje de San Mateo Ayecac, en la laguna de oxidación, en el segundo emisor de PEMEx y en el corredor industrial. Todas ellas excedían los contenidos permisibles de contaminantes por la Norma Oficial Mexicana (NOM) establecida por SEMARNAT y la Secretaría de Salud y se sobrepasaban los límites máximos permisibles de grasas y aceites, sólidos suspendidos totales (ssT), sólidos sedimentables y demanda bioquímica de oxígeno (DBо).

Los contaminantes encontrados en los puntos de muestreo por Navarro et al. (2004: 35-37) fueron: grasas y aceites que rebasan el límite máximo permitido entre 10 y $200 \%$; un exceso de grasas y aceites disminuye la capacidad de vida acuática, ya que son causantes de la poca disolución de oxígeno en el agua, siendo éste indispensable en el proceso biológico de purificación natural de las aguas residuales. Respecto a sst, los resultados obtenidos muestran que el nivel alcanzado de éstos rebasa el límite máximo permitido entre 9 y $90 \%$, lo que provoca la disminución de la eficiencia del proceso natural de purificación del agua, llegando a contribuir 
en el fenómeno de la eutrofización. ${ }^{133}$ En cuanto a sólidos sedimentables, los niveles alcanzados rebasan hasta $100 \%$ en promedio el límite máximo permitido; afectan los cuerpos de agua al incrementar la cantidad de desechos sedimentables, aunque no sean propiamente lodos. La $\mathrm{DBO}^{134}$ en los puntos de muestreo presenta niveles entre 11 y $118 \%$ superiores al límite máximo permitido. En el estudio citado, los indicadores para metales pesados se cumplen; se encontró la presencia de cobre y zinc.

La dilución no desempeña un papel importante en la disminución de los efectos contaminantes en estos cuerpos de agua. En todos los sitios muestreados se observó la presencia de cloroformo y cloruro de metileno y una carga contaminante media de cloruros; se observó el cambio del color del agua en diferentes tramos en color azul, otros rojos y color "aguas negras". Otro aspecto observado es el organoléptico, característico de aguas negras y malos olores irritantes (Navarro et al. 2004: 41). Específicamente, las descargas de maquilas de la mezclilla en San Martín Texmelucan, en la zona conurbada de Puebla-Tlaxcala, en Tehuacán y en Tepetitla de Lardizábal, vierten residuos de cloroformo, cloruro de metileno, tolueno y aminas. La primer sustancia es cancerígena y es conocida por afectar órganos vitales de roedores de laboratorio; la segunda sustancia, se presume puede ser cancerígeno y es capaz de dañar el sistema nervioso central, causar mareos y nauseas; el tolueno es un componente del petróleo y no es cancerígeno, pero también es tóxico para el sistema nervioso central, puede causar depresión y en altas concentraciones puede dañar los riñones (Atoyac Zahuapan y Calidad de Vida y Centro "Fray Julián Garcés" 2009: 34).

Los desechos que contienen las aguas del río Atoyac han traído como consecuencia la contaminación de las aguas subterráneas. Los picos identificados sugieren la necesidad de una investigación analítica de los agroquímicos que se emplean en la región, para establecer si hay un factor potencial de riesgo a la exposición a este tipo de compuestos en el consumo de agua potable, toda vez que los suelos presentan permeabilidades medias y el nivel freático se

${ }^{133}$ Es un proceso natural en ecosistemas acuáticos, caracterizado por un aumento en la concentración de nutrientes como nitratos y fosfatos, lo que provoca cambios en la composición de la comunidad de seres vivos que habitan en ese mismo espacio. Uno de ellos es principalmente el crecimiento excesivo de algas, las cuales al descomponerse ocupan gran parte del oxígeno disponible, provocando la muerte de otros organismos. El proceso ocurre de forma natural; sin embargo, las actividades humanas, como los vertidos agrícolas, urbanos e industriales, elevan tanto los niveles de ciertos elementos que los ríos son incapaces de descomponerlos (Art 1993: 196).

${ }^{134}$ La prueba Dво es de gran valor en el análisis de afluentes de agua residuales para comprobar la contaminación con materia orgánica que disminuye el oxígeno necesario para la vida acuática normal. 
encuentra a menos de $10 \mathrm{~m}$ de profundidad, de acuerdo con la CNA (2002), citada en el estudio de Navarro et al. (2004: 43). A pesar de la ausencia de este análisis, persiste el riesgo en el consumo de agua de pozos.

\section{DETERIORO DE LA CALIDAD DE VIDA EN LAS POBLACIONES DE NATIVITAS ${ }^{135}$}

El municipio de Nativitas se localiza inmediatamente aguas abajo del río y colinda con San Martín Texmelucan en el breve paso del Atoyac por territorio tlaxcalteca. La contaminación descrita ha tenido efectos en toda la región, no solamente en los poblados que se ubican en las riberas del río. Una de las principales consecuencias de toda contaminación es en la salud de la población.

Como efecto de la contaminación en la salud humana, el riesgo solamente ha sido estimado. No existen correlaciones ni se puede realizar experimentaciones para obtener una mayor precisión sobre la relación de los contaminantes con ciertas enfermedades que atacan al ser humano. La estimación se realiza con base en la exposición por inhalación crónica a compuestos tóxicos volátiles, como el cloruro de metileno y el cloroformo, detectados a lo largo del río Atoyac.

La población que habita a unos metros de los canales abiertos que recorren las comunidades de San Lucas Atoyatenco, San Mateo Ayecac y Tepetitla, principalmente, en el centro de la zona de estudio, son la población más vulnerable a este riesgo potencial de exposición. Otro grupo es el de los trabajadores del campo que emplean esa agua en el riego por inundación de sus terrenos de cultivo. Es importante señalar que la frecuencia de exposición está asociada a la periodicidad, volumen y concentración en las descargas de agua residual (Navarro et al. 2004: 52).

Otro factor de riesgo que se suma a los anteriores se produce por irregularidades en las condiciones de operación y mantenimiento de los drenajes industriales, lo que, como mencionamos, se manifiesta en derrames o desbordamientos porque en algunos tramos operan como conductos abiertos. Estos accidentes han ocasionado la contaminación de suelo agrícola y deshabilitado los terrenos para el cultivo por un lapso indeterminado, así como contaminado varios de los canales de riego, con repercusiones en terrenos alejados de los parques industriales (Navarro

${ }^{135}$ En este apartado se hace referencia a la información entregada por pobladores de los pueblos de Jesús Tepactepec, San Miguel Xochitecatitla, Santiago Michac y la cabera municipal de Nativitas, recogida en varios trabajos de campo durante los años 2009 y 2010. 
et al. 2004: 52). Estas irregularidades tienen un efecto adicional, la extensión de los contaminantes hacia los terrenos de cultivos y las consecuentes limitaciones al riego, producción y desarrollo de la agricultura.

Las enfermedades asociadas con la exposición a los contaminantes se pueden agrupar en efectos críticos (toxicidad hígado, quistes en hígado, lesiones hepáticas y renales) y carcinomas (hepático, intestino grueso, tubo renal):

Por lo tanto, la presencia recurrente de compuestos clorados en el río, en las descargas industriales y en la toma domiciliaria de algunas comunidades, advierte de riesgos a través del consumo humano cotidiano de trihalometanos, con indicios de exposición por inhalación; del consumo de agua potable con plaguicidas no identificados, aun cuando su peligrosidad sea menor a los normados, es un escenario de salud pública no deseable; la exposición por inhalación ambiental, donde se comprueba la presencia de olores desagradables y señales de malestares por el olor penetrante; y la exposición laboral, industrial y agrícola, por el uso insuficiente o ausente de equipo de protección (Navarro et al. 2004: 53, 57).

La doctora Alicia Lara, de una comunidad de Nativitas, continúa hasta hoy rastreando casos de enfermedades relacionadas con la contaminación del río, en una entrevista comentaba: "el registro de anemia, leucemia, asma, sangrado nasal, dolores agudos de cabeza, irritación de ojos y garganta, malestares gastrointestinales, alergias de la piel y otros padecimientos" que ella misma ha tenido que tratar. En un estudio realizado con su grupo, concluyeron que

se puede establecer que de los 45 casos registrados, 34 pertenecen a la relación existente entre anemia, púrpura trombocitopénica y leucemia, concentrados en cuatro comunidades, tres de ellas paralelas al río Atoyac (Tepetitla, Villa Alta y Ayecac) a través de la carretera San Martín Texmelucan Tlaxcala vía Nativitas y San Baltasar Temaxcalac ubicada a dos km al sur de San Mateo Ayecac y en donde se encuentra el Corredor Industrial Quetzalcóatl (Lara et al. 2004: 70). ${ }^{136}$

${ }^{136}$ Según la evaluación epidemiológica hecha por la UNAM y la UAM en once comunidades de la región en la orilla del río Atoyac, las sustancias como el cloroformo, bromoformo, bromodiclorometano y dibroclorometano, son reconocidas como agentes potencialmente cancerígenos. En total se encontraron alrededor de 60 casos de personas enfermas o muertas de trombocitopenia (etapa previa a la leucemia), leucemia y otros tipos de cáncer entre los años de 1996 y 2003; valores que superan la incidencia a nivel nacional (Navarro et al. 2004: 1). La Dra. Regina Montero y un grupo de investigadores de la UNAM encontraron cloroformo, cloruro de metileno, índigo y tolueno en el Atoyac y en el río Xochiac, que mezclados con otros desechos vertidos en el 
Para el 2010, el número de casos registrados aumentó a 48, y la enfermedad con mayores registros fue la leucemia linfoblástica (18 casos), seguida de la anemia hemolítica (13). Más de la mitad de las personas enfermas son menores de 20 años (Morales 2010: 264-265).

Los ejidatarios y habitantes de la región han notado que desde hace más de diez años ya no hay vida en el río. Sin tener conocimiento exacto de qué sustancias o tóxicos se encuentran presentes en el agua, así como sus posibles efectos, para ellos es evidente que la contaminación ha terminado al menos con la vida acuática de plantas y animales y hace imposible el consumo humano. Con respecto a la propia salud de los que viven muy cercanos a la ribera del río o los ejidatarios que tienen contacto directo con el agua, las historias son diversas.

A pesar de la falta de datos y del tiempo generacional ${ }^{137}$ para medir los efectos en la salud de la población, hay estudios concluyentes. Efectivamente existe un daño genotóxico en los individuos estudiados de la región, lo que indica que existe una acción de los agentes tóxicos en sus células. El daño mayor fue encontrado en aquellos individuos que trabajan o residen en las zonas cercanas a las industrias, a las lavanderías y/o los puntos de descarga; ellos son los que presentan mayores daños genéticos, independientemente de su ocupación (Montero et al. 2006: 341). Villalobos-Pietrini y otros investigadores (1994) estudiaron igualmente los efectos genotóxicos de las aguas de los ríos tlaxcaltecas y llegaron a la misma conclusión: las descargas de las industrias de la mezclilla (que es la fuente de mayor contaminación) en los ríos (tanto del Atoyac como del Zahuapan) están generando daños en los cromosomas de plantas, animales y seres humanos. Daños cuyos efectos podrían observarse en generaciones venideras.

Hoy en día los pobladores y autoridades políticas y agrarias del municipio y los ejidatarios que aún trabajan la tierra y mantienen los sistemas de riego en los trece pueblos que conforman el municipio, tienen pleno conocimiento de la contaminación del río. En general se percibe que el río está contaminado, dicen que huele muy mal, que dependiendo de la época

río, como grasas y aceites, entre otros, representan un nivel de toxicidad importante. Además del contacto directo con los contaminantes, la principal preocupación de los investigadores era que su presencia en el río se evaporaba en el aire, exponiendo a todos sus habitantes a la inhalación crónica de sustancias tóxicas, ya que pueden quedarse más de cien días en el aire y provocar mutaciones genéticas; todos estos químicos y el índigo son cancerígenos (Montero et al. 2006: 336).

${ }^{137}$ De acuerdo con el estudio de Valencia-Quintana et al. (2011: 81), las sustancias contaminantes que contiene el Atoyac y el Zahuapan tienen efectos nocivos para la salud humana; sin embargo, el problema es que no generan efectos detectables de forma inmediata, sino que se hacen presentes tiempo después a través de una exposición crónica a ellos, y puede ser que después de una periodo largo de latencia se manifiesten clínicamente. Debido a que la exposición a dosis menores no genera efectos agudos, los daños se pueden manifestar a nivel genético. 
cambia de color debido a los tintes provenientes de las lavanderías de mezclilla, que ya no hay los peces y animales que hace 30 años aún se podían encontrar, como carpas, ranas, acociles, serpientes de agua y otros peces pequeños del río y animales ribereños, como las gallaretas y las garzas -que ahora está prohibido cazar-, y variedades de plantas, como los quelites, fundamentales en la dieta de los tlaxcaltecas.

En las comunidades existen contados pozos, cuyas aguas se utilizan para regar alfalfa y tomate cuando el temporal no es suficiente, el maíz se riega con agua del río. La producción de maíz es fundamentalmente utilizada como forraje, por eso se prefiere el maíz criollo que permite un mayor follaje de las hojas y ramas de la planta, aunque también el maíz se utiliza para el consumo humano. Las aguas del río alimentan también los cultivos de tomate, cuya producción compran intermediarios que luego llevan a las centrales de abastos de México y Puebla. La contaminación del agua ha inhibido la producción de otros granos, como trigo y avena, productos alimentarios $y$ hortalizas que en el pasado constituyeron una fuente importante de ingresos por su acceso a los mercados; hoy en día si estos productos no se riegan con agua de pozos son rechazados en el mercado.

En las tierras de cultivo crecen hierbas y verduras, como las verdolagas, los quiltoniles y los berros, hoy prácticamente extintos, que eran parte de la dieta de las familias y con los cuales se hacían muchos platillos considerados tradicionales. Hace 20 años, recuerdan las jefas de familia, cuando la carne no era parte principal de la ingesta, los quintoniles y las verdolagas eran un excelente proveedor de proteínas y minerales. Algunos atribuyen su esporádico consumo a la contaminación de las aguas del río con las que se riegan los campos, mientras que otros lo imputan a los cambios en la dieta. Lo cierto es que jóvenes y niños ya no están familiarizados con estas plantas, no las reconocen en su entorno, por lo que no las conciben como parte de su alimentación.

Las familias en Nativitas se han volcado a la crianza de animales; es común ver en los traspatios borregos, vacas lecheras, cerdos, aves y otros animales menores, de manera que los productos agrícolas tienen en la ganadería su principal destino, tanto para la venta de forrajes como para la alimentación de los propios hatos familiares. ${ }^{138}$ Aunque no existen estudios especializados ni se ha percibido ningún efecto directo en la salud de los animales que ingieren los productos regados con aguas del río, éstos cargan con toxinas que después son consumidas por las familias en los productos que derivan de sus animales, como carne de cerdo, vaca, po-

${ }^{138}$ Evidentemente la transformación en la economía campesina y en la agricultura deriva de muchos otros factores que tienen relación con los cambios estructurales, la globalización de los mercados de productos y de trabajo y con las migraciones, tal como lo hemos comentado en trabajos previos (cfr. Salas y Rivermar 2011). 
llo y borrego, así como la leche, quesos y huevos. Esto puede ser causa de riesgos en la salud humana, de manera que ante la incertidumbre y falta de información, hemos observado que la población más joven percibe que consumirlos no es bueno para ellos y para su salud, informados de los riesgos que ello trae y de los que han observado entre la población. Los mayores, cuya cercanía con las aguas del río ha sido permanente y en una larga temporalidad, perciben los riesgos de otra forma; no consideran que los alimentos obtenidos con el riego o los provenientes de animales alimentados con forrajes regados con agua de río sean peligrosos, por el contrario, consideran más temibles los alimentos "modernos", como las papas fritas, los refrescos, la comida enlatada y en general los alimentos procesados.

Otra problemática se deriva de que los ejidatarios y agricultores en general que utilizan el agua en sus sistemas de riego se ven expuestos a su contaminación tóxica. No sólo es cuando la riegan, sino que debido a que las presas son operadas de manera manual, tienen que meterse al río con todos los riesgos que implica el contacto de su cuerpo con el agua. Además, al regar sus campos quedan expuestos a la inhalación de los diferentes compuestos del agua. Ellos saben que esto es incorrecto, conocen los síntomas, como el dolor de cabeza agudo, la irritación de ojos y piel, las posibles consecuencias cancerígenas y otras amenazas para su salud, pero no tienen otra alternativa.

Las personas mayores de 30 o 40 años recuerdan que el lecho del río, así como las acequias, canales, azolcos (término con el que se refiere la gente del lugar a los canales que corren junto al río) y el totolac (en lengua náhuatl "agua de los pájaros" = tótol, pájaros, y atl, agua) eran lugares donde jóvenes y niños podían nadar y las familias pasar el día de descanso. Es común escuchar los relatos acerca de la importancia que tenía pasar el Sábado de Gloria en el río, cuando gente de otros pueblos venía en busca de las aguas cristalinas de los ríos y canales. Hoy en día nadie se acerca al río, porque además de que saben que sus aguas están contaminadas, emiten fétidos olores, especialmente en época de secas que es cuando los contaminantes vienen más concentrados.

La respuesta de los gobiernos para resolver el deterioro ambiental y los problemas de salud ha sido escasa y ha girado en torno a intereses ajenos a los de los habitantes de la región. En el 2006, en el marco del Iv Foro Mundial del Agua, los gobiernos de Puebla y Tlaxcala firmaron dos convenios que planteaban la realización de estudios especializados en la cuenca AtoyacZahuapan como parte del "Proyecto de rescate ecológico de los ríos Zahuapan, Atoyac, Alseseca y la presa Manuel Ávila Camacho (Valsequillo)". Desafortunadamente, lejos de buscar una solución al problema en la cuenca, el gobierno del estado de Puebla pretende llevar a cabo el "Proyecto Puerto Aura" que consiste en convertir la presa Valsequillo en una zona turística, con malecón, parques temáticos, zonas habitacionales, hoteles y otros servicios (Morales 2010: 
254). Al utilizar como excusa la contingencia ambiental de la presa el proyecto busca maquillar el verdadero interés de las autoridades y élites: generar un jugoso negocio de especulación inmobiliaria que ya ha comenzado a generar problemas con ejidatarios de la región (La Jornada 2009). Aunque el proyecto no se ha llevado a cabo porque aún siguen explorando la posibilidad de sanear la presa, la actuación del gobierno en alianza con una élite local es otra evidencia de que los problemas socioambientales están relacionados directamente con la priorización de la acumulación y el control de daños; es decir, no son procesos neutrales, sino que están intersectados por relaciones de poder.

\section{REFLEXIONES FINALES}

El río Atoyac ha sido central para las sociedades que durante un periodo amplio de tiempo se han establecido en el valle de Tlaxcala. Desde épocas prehispánicas permitió nutrir de agua, recursos naturales, flora y fauna a las poblaciones. Con el paso del tiempo permitió la formación de haciendas agrícolas, ganaderas y textiles, que derivaron en industrias que ejercieron una significativa atracción de mano de obra regional y nacional. Durante todo el siglo xx fue la principal fuente de agua para el desarrollo de la agricultura posterior a las haciendas, tanto en terrenos ejidales como en parcelas de pequeños propietarios.

El río y sus canales, zanjas, arroyos y lagunas conformaron un paisaje cultural activo, en el sentido de que es parte de la vida económica, social, productiva y ritual de las poblaciones, y cuando los campesinos tuvieron que dejar sus parcelas y ocuparse en las industrias de la región, el río continuó siendo un fiel acompañante. Es importante preguntarse en qué momento este elemento vital y central en la vida de la población dejó de serlo y pasó a ser el vertedero de desechos industriales y urbanos, domésticos y comerciales. Amén de buscar la explicación de esta situación, aquí presentamos las consecuencias que tuvo esta transformación y su deterioro.

Además de las consecuencias económicas que hemos comentado, la situación ambiental adversa en la que esta región se encuentra implica también un problema de derechos humanos fundamentales. Como ha sido señalado por Navarro y Morales (2004: 23-24), existe una clara asociación entre un ambiente contaminado y la aparición de enfermedades atípicas en la población, de manera que, en estas condiciones, no se puede garantizar ni proteger el derecho a la salud; además, la contaminación del agua no permite su reutilización para el riego; tampoco se puede garantizar el derecho a la alimentación, ya que los alimentos que producen los pequeños campesinos y ejidatarios deberían estar libres de sustancias nocivas. 
Podemos concluir que la forma que han adquirido los desarrollos agrícola-industrial y urbano-rural es contradictoria en el uso que se ha dado a los cuerpos de agua. Por un lado, se espera que alimenten la producción agropecuaria, donde se ha creado históricamente un conocimiento, instalaciones, servicios y condiciones para su desarrollo, considerando la calidad de las tierras, las características agroclimáticas y la disposición de la población; pero, por otro lado, este mismo modelo de desarrollo ha priorizado la creación de una infraestructura para la descarga de los desechos líquidos industriales y domésticos, la cual posibilita que los cuerpos de agua sean utilizados como vertederos de residuos y basuras.

En esta tensión se encuentran los pobladores, quienes ven afectada su situación de salud así como el soporte de sus actividades económicas y su modo de vida: la producción agrícola que podría garantizar la autosubsistencia alimentaria y la reproducción de las condiciones de vida de la población de las comunidades. Visto estructuralmente, parece sencillo pensar en una reconversión productiva de la región y de la población, desde las actividades agrícolas y ganaderas hacia las industriales, comerciales y urbanas; sin embargo, en este trabajo hemos querido destacar la complejidad que este proceso ha significado para los habitantes de las comunidades rurales. No solamente se ha desarticulado un sistema productivo, sino que se ha desplazado un modo de vida que otorgaba a sus habitantes un medio de subsistencia que les permitía reproducir su vida social y cultural, sin que haya sido reemplazado por otro; lo que tenemos es un sistema productivo anclado en lo industrial que no termina de consolidarse como una oferta sólida de reconversión económica regional.

El caso estudiado plantea para las generaciones futuras el dilema entre producir y proteger el medio ambiente; entre conservar los modos de vida (la cultura) regionales o desarrollar un modelo que se funda en una visión productivista, pragmática y consumista. Es indudable que los problemas de contaminación no se pueden disociar del proyecto económico-político local y global, además de que no es posible verlos como procesos neutrales. Los procesos ambientales no empatan con la lógica del mercado, cuya finalidad es la acumulación del capital y la maximización de la tasa de ganancia individual. Eso quiere decir que no existe una solución sencilla y única al problema del medio ambiente en un contexto neoliberal y frente a una cultura enajenada con el consumo como la actual (Vallejos 2005: 200). El mercado hoy en día está reproduciendo condiciones de inequidad y concentración de recursos que generan problemas ambientales localizados y riesgos en territorios donde habitan los menos favorecidos económicamente. No obstante, a la larga, como sugiere Ulrich Beck (2006), algunos de estos riesgos alcanzarán a todo el mundo sin excepción. Cabe preguntarnos entonces hasta cuándo y dónde las políticas y discursos neoliberales hegemónicos podrán utilizar la crisis ambiental a su favor. 
Nos interesa destacar que ante los cambios estructurales existen respuestas de la sociedad. Las comunidades más afectadas se han organizado para combatir el deterioro ambiental. Un ejemplo de ello fue la demanda ante el Tribunal Latinoamericano del Agua que reconoció, en 2006, la afectación a la población, la imposibilidad de continuar utilizando el río en las actuales condiciones y recomendó que se estableciera un compromiso entre las empresas, las autoridades ambientales y las organizaciones civiles para diseñar y poner en marcha un plan de rehabilitación de la cuenca del río Atoyac, lo cual incluye la construcción de plantas tratadoras de agua. ${ }^{139}$ Otro ejemplo es la asociación con el grupo nacional de "Afectados Ambientales" que representan más de 100 localidades en doce estados de la República que se han unido para compartir experiencias y unir esfuerzos para presionar a los gobiernos locales y buscar soluciones a los problemas sociales, ambientales y de salud. ${ }^{140}$

Lo cierto es que el río trae, cada año, generosas cantidades de agua que provienen de las faldas volcánicas. Mientras esto ocurra, la posibilidad de recuperar la cuenca del Atoyac es factible, por eso las comunidades continúan organizadas, utilizando sus recursos sociales y su repertorio cultural, su memoria en torno a los beneficios de los cuerpos de agua. Los ríos Atoyac y Zahuapan siguen vigentes en el imaginario de los ejidatarios como la principal fuente de agua, de vida y de sociabilidad.

${ }^{139}$ Esta información proviene del acta de veredicto del Tribunal Latinoamericano del Agua. Disponible en: <http://www.boell-latinoamerica.org/download_es/Veredicto_Rio_Atoyac.pdf $>$ [consulta: 18 de marzo de 2010].

${ }^{140}$ Para mayor información, consultar el informe presentado por representantes de comunidades poblanas y tlaxcaltecas, como Villa Alta, Tepetitla, San Mateo Ayecac, San Rafael Tenanyecac y Santiago Michac, en la Asamblea de Afectados Ambientales del 2009, disponible en <http://afectadosambientales.blogspot. com/2009/05/danos-la-salud-por-contaminacion-del.html>. 


\title{
ESTRATEGIAS SOCIOLABORALES Y ECONÓMICAS DE LOS EJIDATARIOS DE NATIVITAS
}

\author{
Hernán Salas Quintanal \\ Ínigo González de la Fuente
}

\section{INTRODUCCIÓN}

\section{$\mathrm{D}$} urante el último siglo, el territorio del municipio de Nativitas, al sur del estado de Tlaxcala, ha experimentado una serie de transformaciones que han terminado afectando de manera extraordinaria a sus habitantes y las prácticas agrícolas de éstos. Hacia finales de la década de los 90, los procesos asociados con la globalización, y en concreto, con la reestructuración de la economía, han tenido el efecto de la llamada desagrarización, es decir, una disminución paulatina y sostenida de la superficie cultivada, especialmente en la pequeña propiedad y en las tierras ejidales, transformando y, en algunos casos, desarticulando formas históricas de organización de la producción y del trabajo rural, que en el plano familiar del medio rural se refleja en una reducción del aporte de las actividades agrícolas a la generación de ingresos (Escalante et al. 2007; Carton de Grammont 2009).

En este trabajo se reconocen al menos tres momentos en las transformaciones sociales del municipio que corresponden a estrategias laborales y económicas, las cuales permiten entender la desagrarización, sus efectos en la sociedad rural y que ésta no viene asociada necesariamente a un proceso de desruralización, como se piensa (Salas y Rivermar 2011). Estas etapas corresponden: a) al establecimiento de un sistema agrícola basado en la hacienda (1900-1920); b) al reparto agrario, el desarrollo de una agricultura ejidal y la industrialización del país y de la región (1920-1990); y c) la globalización y los cambios estructurales hacia finales del siglo xx (1990-2010), los cuales no superan la etapa ejidal, sino que la transforman de tal manera que la agricultura pierde centralidad y se convierte en uno más de los múltiples ingresos familiares. 
Junto con la afectación de la vida laboral y comunitaria de miles de personas, la desarticulación productiva ha traído consigo cambios en los estilos de vida que se centraban en una ruralidad articulada a través de las actividades agropecuarias de unidades campesinas, ${ }^{141}$ siendo ahora una ruralidad que ha diversificado las actividades, especialmente asalariadas, que son las que ordenan y dan sentido a la vida y reproducción de las familias y comunidades. En este trabajo comentaremos cómo se ha acentuado la pluriactividad tradicional campesina dando lugar a una mayor diversificación de las fuentes de las que provienen los ingresos, de manera que los salarios tienen cada vez más peso en las economías familiares, lo que trae aparejado una notable inserción de las poblaciones rurales en mercados laborales, tanto nacionales como internacionales.

La economía y sociedad rurales se han transformado en toda América Latina en décadas recientes como consecuencia de la dependencia de las relaciones capitalistas, de la incorporación de la agricultura y la producción de alimentos a los mercados de la economía mundial $\mathrm{y}$ a formas de modernización que han beneficiado a grupos de agroindustriales, empresarios agrícolas capitalistas y a algunas unidades campesinas familiares. La mayoría de los campesinos y trabajadores rurales se emplean en condiciones contractuales temporales, precarias y flexibles (Kay 2007: 134). Este trabajo tiene como objetivo conocer las transformaciones de las instituciones que han regulado la vida socioeconómica y sus efectos en el modo de vida rural de la población del municipio de Nativitas.

Este municipio se ubica en una región con una amplia tradición agrícola que permitió la organización de la vida social y económica, la conformación de un estilo de vida rural centrado en prácticas agrícolas ancestrales y una organización comunitaria, política y religiosa que, con diferentes matices, ha perdurado hasta la actualidad. Estas evidencias nos llevan a proponer que las transformaciones rurales no han convertido estas regiones en espacios totalmente urbanos. La ruralidad, como la hemos conocido tradicionalmente -con una economía campesina que regía la producción y el trabajo de las poblaciones y organizaba la vida familiar y cultural de las comunidades- se ha alterado; la tendencia actual es que los miembros de las familias se empleen en diferentes ámbitos y sectores, de manera que es necesario preguntarnos qué queda de aquella ruralidad y cómo se define en este contexto lo rural. A partir del análisis de la región estudiada, se busca en este trabajo dar algunas respuestas a estas interrogantes.

${ }^{141}$ Es importante señalar que en algunas de las definiciones más rigurosas de "campesino", como las que dieron Wolf (1955) o Redfield (1960), se excluye explícita o implícitamente toda actividad no agrícola. En la actualidad, Bryceson (2007: 2) delimita cuatro criterios fundamentales para una definición de campesinos: farm, family, class y community. 


\section{TRANSFORMACIONES RURALES Y DIVERSIFICACIÓN DEL INGRESO}

Desde su fundación, el municipio de Nativitas, ubicado en la región sur del estado -valle Puebla-Tlaxcala- se ha caracterizado por su vocación agrícola. Durante la época colonial y tras la consolidación del sistema de haciendas, sus pobladores supieron aprovechar los recursos naturales para la producción agrícola. Sus tierras cultivables resultaron de la desecación de áreas lacustres alimentadas por agua proveniente de dos de los más importantes ríos de la región, que en la actualidad conforman el distrito de riego Zahuapan-Atoyac. Estas condiciones, sumadas al clima templado que caracteriza al altiplano mexicano, permitieron una significativa fertilidad y productividad; la abundancia de recursos naturales vinculó la agricultura y crianza de animales con la recolección de frutos y vegetales, la caza y la pesca.

La época del reparto agrario, desde la primera dotación del año 1918 de los ejidos Jesús Tepactepec y Santo Tomás La Concordia, y después Santiago Michac en 1920, transcurrió entre grandes esfuerzos por intensificar la producción agrícola, aprovechando la cercanía de mercados de abasto crecientes, como los de la ciudad de Puebla y del Distrito Federal, que hasta la actualidad son fundamentales para los agricultores de la región. En la misma proporción que fue cayendo la rentabilidad de los productos agrícolas, las familias comenzaron a fortalecer sus estrategias ganaderas, incrementando y manteniendo aves, borregos, puercos y, en algunos casos, vacas lecheras y de engorda. De esta manera, al cultivo del maíz siguió el de otros productos más comerciales y atractivos para el mercado regional y nacional, como forrajes -especialmente alfalfa, avena, cebada y maíz forraje (utilizado para alimentar a los animales domésticos)-, amaranto -que se procesa y empaca en San Miguel del Milagro, uno de los pueblos de la entidad, y en Xochitecatitla, otro ejido del municipio- y hortalizas ${ }^{142}$-que es el cultivo más comercial y que requiere para el riego la disponibilidad de agua subterránea.

Como efecto del reparto agrario y la conformación del sistema ejidal para controlar la tierra y el agua, se establecieron unidades de producción familiar, asegurando con ello la continuidad de la actividad agrícola sobre la base del cultivo del maíz y de actividades ganaderas secundarias. El problema agrario no se resolvió después del reparto como consecuencia del reducido tamaño de las parcelas, la escasez de créditos, el apoyo financiero y las transferencias

${ }^{142}$ En el caso de las hortalizas y las hierbas de olor, que tienen gran importancia para el mercado por su valor comercial, hay que señalar que son cultivos que se han visto afectados por la contaminación del río Atoyac, principal fuente de aguas "rodadas". Cuando las condiciones económicas lo permiten, algunos agricultores recurren al uso de aguas subterráneas. El mayor costo de estas aguas eleva los gastos de producción (Salas y Velasco 2010). 
de tecnologías, la sobreexplotación de suelos y aguas, lo que llevó a constantes movilizaciones campesinas que ponían énfasis en la creación de nuevas fuentes de ingresos y la apertura de mercados de trabajo. Asimismo, la creación de los ejidos y el declive de la hacienda liberó la mano de obra rural y abrió mercados de trabajo en asentamientos rurales, lo que será fundamental para la siguiente etapa marcada por los intentos de industrialización.

En efecto, a mediados del siglo $\mathrm{xx}$ se abrieron las condiciones para establecer un corredor industrial en la región. Desde 1950, el gobierno tlaxcalteca se había propuesto un programa de reubicación industrial como respuesta al deterioro de la industria pulquera y la crisis de la industria textil regional, dos iconos de la economía de la entidad. Era evidente que el territorio no podía continuar con la economía agraria tradicional y que debía aprovechar su ubicación geográfica, sus vías de comunicación y transporte para la instalación de un corredor industrial. A estos factores se suma la construcción de la autopista México-Puebla en los años 60 y la carretera Tlaxcala-Puebla a principios de los 70. Un factor indiscutible para el desarrollo industrial de la región sería la disponibilidad y abundancia de mano de obra proveniente de las ajadas economías campesinas de municipios vecinos.

La planeación industrial en territorios colindantes de Nativitas se hace efectiva a partir de la instalación, en el año 1969, del área industrial Texmelucan con el complejo petroquímico "Independencia" de PEMEX, al que se agregan progresivamente la rama automotriz, metalmecánica, refresquera y química de plásticos. Después vino el corredor Quetzalcóatl en la localidad de San Baltazar Temexcalac - parte del municipio de San Martín Texmelucan, Puebla- en el que se instalaron industrias de las ramas textil, de alimentos, metalúrgica, de químicos aromáticos, de recubrimientos y lozas cerámicas y ladrillos. Más tarde se asentó en este corredor el Parque Industrial Huejotzingo, localizado sobre la carretera federal México-Puebla, dedicado a las ramas del plástico, metalmecánica, textil, refresquera y farmacéutica.

En las inmediaciones de la carretera federal San Martín Texmelucan-Tlaxcala se ubica el corredor Ixtacuixtla, el cual se extiende desde la localidad de Villa Alta, municipio de Tepetitla de Lardizábal (colindante con el de Nativitas) hasta el municipio de Ixtacuixtla. Las principales ramas en este corredor son: textil (prendas de vestir), bebidas, petroquímica, agroindustria, automotriz, alimentos y minerales no mecánicos. Entre los poblados Villa Mariano Matamoros y Villa Alta se encuentran una planta de adhesivos, una de champiñones y otra de maquila de partes eléctricas de la Volkswagen, industria automotriz que se ubica sobre la carretera México-Puebla, en el municipio de Cuauhtlancingo, Puebla (cercano a Nativitas). El segundo corredor tlaxcalteca se sitúa en Panzacola-Zacatelco y recorre de norte a sur los municipios de Zacatelco, Xicohtzinco, Papalotla de Xicohtencátl y Tenancingo, al sur del estado (para la 
descripción detallada de los corredores industriales, ver capítulo de Salas y Velasco en este libro; mapas 13 y 14).

Para el año 1989, el área metropolitana de la ciudad de Puebla -dentro de la cual se ubican algunos municipios del sur del estado de Tlaxcala- contaba con dos de las diez industrias más grandes del país, de acuerdo con su volumen de venta: la planta armadora de vehículos Volkswagen y la siderúrgica Hojalatas y Laminas, S. A. (HYLSA) (Flores 1993: 66), ubicadas en los circunvecinos municipios poblanos de Cuautlancingo y Xoxtla, donde se han empleado un buen número de vecinos de Nativitas.

Esta relación de las instalaciones industriales locales evidencia cómo se fue abriendo el mercado laboral siguiendo un modelo de desarrollo que desplaza la centralidad de las actividades primarias y privilegia la industria y los servicios, en especial el comercio. Además de utilizar la mano de obra rural, las ramas industriales mencionadas han ocupado progresivamente los recursos naturales, entre los que destaca el agua de los ríos Atoyac y Zahuapan, antaño vitales para la agricultura, y han ido generando descargas industriales contaminantes directas al río Atoyac, ${ }^{143}$ lo que afecta las aguas que históricamente dieron origen y permitieron el desarrollo de la región, en especial de Nativitas. En la actualidad, el agua de los ríos continúa regando los campos, disminuyendo la fertilidad de los suelos.

El deterioro ambiental se agudizó hacia los años 90 con la consolidación y crecimiento de los corredores industriales y el desarrollo de la industria de exportación, que trajo aparejado el crecimiento de la maquila domiciliaria en varias comunidades y de pequeñas y medianas empresas que laboran para la industria textil de la mezclilla. En los recorridos de campo hemos podido observar cómo estos pequeños talleres utilizan el drenaje doméstico para verter sus desechos químicos los cuales, junto con los residuos domésticos y urbanos, van a dar al lecho del Atoyac (Salas y Velasco 2010; ver capítulo de Salas y Velasco en este libro).

Estos hechos marcan la reconversión económica de la región, inmersa en un modelo nacional que buscaba impulsar la industrialización sobre la base de una economía agropecuaria que permitiera estabilizar los salarios industriales y atraer, al mismo tiempo, inversionistas. Es la etapa en la que el gobierno toma el control del mercado interno de alimentos e impulsa la producción de agroexportación debido a la existencia de un mercado internacional atractivo y al interés por atraer divisas para financiar la industrialización. Sin perder su calidad de pro-

${ }^{143}$ En este corredor industrial de Puebla-Tlaxcala están prácticamente todas las industrias consideradas como las más contaminantes, como son la petrolera, de servicios, la química y farmacéutica, la de celulosa y papel, la agropecuaria, de alimentos y bebidas, de cerveza y la minera, de acuerdo con estudios de GEO México (2004). 
ductores agropecuarios, los ejidatarios y campesinos de Nativitas se convirtieron en importantes proveedores de fuerza de trabajo barata y fácilmente disponible ubicada en asentamientos rurales vecinos a las industrias. ${ }^{144}$ Esta situación, además de satisfacer la demanda de empleo de la región, la convirtió en lugar de atracción de poblaciones del propio estado de Tlaxcala y de los vecinos Puebla y Veracruz.

A partir de 1990, como resultado de los ajustes estructurales en el ámbito mundial y nacional, la región experimentó serias transformaciones. La industria automotriz comenzó un proceso de flexibilización industrial que significó desmontar el proceso productivo y trasladarlo a pequeñas y medianas fábricas satélites que se extienden por un nuevo corredor industrial que va desde San Martín Texmelucan hacia las ciudades de Puebla y Tlaxcala. De esta manera, ante la fragmentación del proceso productivo, se crearon pequeñas industrias y talleres a domicilio que se encargaron de fabricar autopartes, como vestiduras, correas, mangueras, hojalata, etcétera. Esta forma de la organización de la producción ha permitido contratar trabajadores por tiempo parcial, menos especializados, o mediante esquemas flexibles y establecer maquiladoras de autopartes. ${ }^{145}$

Uno de los más importantes efectos de estas transformaciones ha sido la consolidación de estrategias de formación del ingreso familiar mucho más dúctiles, con mayor énfasis en la diversificación laboral de los hogares rurales con el fin de satisfacer sus necesidades básicas, en donde el trabajo asalariado se ha convertido en una de las actividades fundamentales, pero no en la única fuente de ingresos. Así, es común encontrarse con familias que tienen, cuando menos, a uno de sus miembros laborando en las industrias que hemos señalado líneas arriba, que cuentan con un muy pequeño comercio y que continúan cultivando para el autoconsumo y criando animales de traspatio.

En el estado de Tlaxcala, el proceso de desagrarización ha seguido una ruta diferente a la de otras regiones de la República. Aquí todavía se puede apreciar que la actividad agrícola sigue

${ }^{144}$ Desde fines del siglo xix, la industria textil localizada en zonas rurales aprovechaba los recursos naturales y humanos disponibles, lo que marcó el inicio del vínculo entre fuerza de trabajo agrícola e industrial (véase Paleta 2008). Esta relación fue favorecida por la presencia de numerosos pueblos de campesinos indígenas que conformaban una enorme reserva de mano de obra temporal y barata. En la medida en que estas poblaciones conservaron sus tierras y unidades de producción, lo que les permitía producir una parte importante de sus alimentos, cargaron sobre sus espaldas la reproducción de la fuerza de trabajo que demandaba la industria en crecimiento (Buve 1975).

${ }^{145}$ Las maquiladoras son pequeñas factorías que requieren una infraestructura industrial básica y que poseen ventajas arancelarias para importar materias primas cuando se trata de generar productos que serán comercializados en el interior del país. 
siendo importante para la población, lo que puede apreciarse en la vida laboral de la población municipal (cuadros 21 y 22), la cual dedica $30.8 \%$ a la agricultura frente a un exiguo $15.6 \%$ en todo el estado de Tlaxcala. Sin embargo, en lo que refiere a las condiciones de vida de la población rural, los resultados son similares a los de otras regiones, con niveles de marginación y emigración cada vez mayores.

\begin{tabular}{ccccc}
\hline Año & Sector primario & Sector secundario & Sector terciario & $\begin{array}{c}\text { Desocupado/ } \\
\text { no especificado }\end{array}$ \\
\hline 1980 (a) & 37.8 & 19.0 & 42.6 & 0.54 \\
\hline 1990 (b) & 28.7 & 33.7 & 35.6 & 1.8 \\
\hline 2000 (c) & 18.3 & 37.6 & 41.9 & 2.0 \\
\hline 2010 (d) & 15.6 & 32.6 & 51.7 & 0.1 \\
\hline
\end{tabular}

Con el fin de poner en evidencia las actividades laborales del municipio, hemos analizado el comportamiento de la población económicamente activa (PEA), que mide la población de 12 años y más con ocupación en el momento del Censo, de acuerdo con su inserción laboral en los sectores primario, secundario y terciario. ${ }^{146}$ De acuerdo con lo anterior, entre 1980 y 2010 el empleo en el sector agrícola del estado de Tlaxcala cayó de 37.8 a $15.6 \%$ y en el terciario creció de 42.6 a $51.7 \%$, mientras que en el sector secundario se elevó de 19 a $32.6 \%$. Este importante aumento en el porcentaje de mano de obra ocupada en el sector secundario -específicamente en las industrias de la transformación, química y de la construcción- se explica, en parte, por el desarrollo del corredor industrial ubicado en la autopista que atraviesa el valle PueblaTlaxcala, al sur de la entidad tlaxcalteca, precisamente en la región de estudio.

Se puede apreciar en el cuadro 22 la importancia del empleo en el sector agrícola del municipio: fue más de 50 \% hasta 1990; incluso en 1980 era de $60.9 \%$, decreciendo sin embargo a

${ }^{146} \mathrm{El}$ sector primario incluye todas las actividades que aprovechan los recursos naturales tal como se obtienen de la naturaleza, ya sea para alimento o para generar materias primas, como agricultura, explotación forestal, ganadería, minería, pesca; el sector secundario se caracteriza por el uso de maquinaria y procesos cada vez más automatizados para transformar las materias primas que se obtienen del sector primario, incluye fábricas, talleres y laboratorios de todos los tipos de industrias y, de acuerdo con lo que producen, se divide en: construcción, electricidad, gas y agua e industria manufacturera; el sector terciario recibe los productos elaborados en el secundario para su venta o para promover su aprovechamiento, como es el caso de los servicios, de manera que incluye las comunicaciones y los transportes (INEGI 2001). 
30.8 \% para el año 2010. Paralelo a esta disminución del empleo agrícola, observamos un sustancial aumento del empleo en el sector secundario de $9.2 \%$ en 1980 a $25.5 \%$ en el año 2010 . Es evidente que el establecimiento del corredor industrial señalado líneas arriba genera, por un lado, que las actividades agropecuarias pierdan centralidad y, por otro, que se diversifiquen las fuentes del ingreso de las familias. A la ya significativa ocupación en el sector terciario se suma de manera importante el empleo en industrias manufactureras y maquiladoras que paulatinamente se han ido estableciendo en el entorno regional.

\begin{tabular}{ccccccccc}
\hline Año & Total & \multicolumn{2}{c}{ Sector primario } & \multicolumn{2}{c}{ Sector secundario } & Sector terciario & $\begin{array}{c}\text { Desocupado/ } \\
\text { no especificado }\end{array}$ \\
\hline 1980 (a) & 5180 & 3174 & 60.9 & 480 & 9.2 & 1526 & 29.2 & 0.5 \\
\hline 1990 (b) & 5412 & 2962 & 52.2 & 985 & 18.0 & 1465 & 27.0 & 2.5 \\
\hline 2000 (c) & 6614 & 2373 & 35.3 & 1923 & 28.6 & 2318 & 34.4 & 1.5 \\
\hline 2010 (d) & 8061 & 2491 & 30.8 & 2058 & 25.5 & 3512 & 43.5 & 0.2 \\
\hline
\end{tabular}

Asumiendo la importancia de las actividades agropecuarias que estas cifras reflejan, se puede advertir, a partir del análisis de los datos que refieren la PEA, la paulatina centralidad que han adquirido en la última década las actividades terciarias -dentro de las que destaca el comercio- en detrimento de las primarias. Así, para el año 2010, la PEA en el municipio era de 8061 individuos, de los cuales $30.8 \%$ se dedicaba a actividades primarias, cifra que contrasta con el $15.6 \%$ a nivel estatal. Sin duda, Nativitas es uno de los municipios más rurales de la entidad: $25.5 \%$ de su población se dedica a actividades secundarias y $43.5 \%$ a terciarias (INEGI 2010b). Esta información nos permite constatar que los pobladores de este municipio combinan las actividades agropecuarias con trabajo asalariado, el empleo informal y el comercio. El trabajo asalariado se lleva a cabo en el sector industrial, en las maquiladoras y en servicios, tanto en la región y otras entidades del país como en el extranjero.

\section{EL PAPEL DE LA AGRICULTURA EN LAS ESTRATEGIAS DE FORMACIÓN DEL INGRESO}

De manera paralela al proceso acelerado de industrialización, que luego devino en desmantelamiento industrial, y el auge del sector comercial y de servicios, se ha dado un debilitamien-
Cuadro 22. Evolución de la PEA (total y porcentaje) en el municipio de Nativitas (19802010). Fuente: (a) INEGI 1981b, (b) INEGI 1991b; (c) INEGI 2001; (d) INEGI 2010b. 
to de las actividades agropecuarias, lo que no ha implicado necesariamente su abandono. La cuestión es analizar el papel que siguen cumpliendo estas actividades en la reproducción de los grupos domésticos. Como hemos visto, desde el punto de vista laboral la región enfrenta el desplazamiento de las actividades agropecuarias, la oferta de empleos industriales precarios e inestables, la terciarización y flexibilización del empleo, desequilibrios sociales, deterioro de los recursos naturales -tierra y agua-, intensificación de la migración ${ }^{147}$ y alteración de la organización cultural, religiosa y política que ha dado sentido a la vida comunitaria y que ha sido un referente fundamental de las identidades colectivas en el medio rural.

Este proceso, llamado "desagrarización de la ruralidad mexicana" (Escalante et al. 2007), permite observar el tránsito de las actividades agropecuarias hacia la pluralidad de actividades, el cual está marcado por diversos procesos: la dinámica del mercado de tierras -que se destinan a múltiples usos más allá del agropecuario-, los cambios en el mundo del trabajo -a partir de los cuales la fuerza laboral rural se inserta en mercados urbanos nacionales e internacionales-, el reemplazo de los jefes de familia, ejidatarios y comuneros por nuevas generaciones y la presencia de mujeres como detentadoras de derechos ejidales, el ingreso de mujeres y jóvenes al mundo laboral y el significativo aumento de los ingresos provenientes de actividades extra agropecuarias, entre los que destacan las remesas. La tendencia al multiempleo define hoy en día la "multifuncionalidad de la agricultura" (Bonnal et al. 2004) o "pluriactividad campesina". ${ }^{148}$ Estos conceptos hacen referencia a la compleja relación entre actividad productiva y asalariada, que hoy en día está caracterizada por la trasmutación de productor independiente a asalariado. Además, esta relación refleja un proceso -cuyo origen está en la etapa industrial- en el cual los pobladores rurales, quienes mantienen su tierra y economía campesina para producir parte de sus alimentos, poseen exigencias laborales y salariales diferentes a las de pobladores urbanos (Robichaux 1995: 228, cit. en Magazine y Robichaux 2010).

En este sentido, podemos decir que, aunque las actividades agropecuarias ya no son complemento del desarrollo industrial, continúan siendo un abrigo para las poblaciones rurales que se mueven en diferentes mercados laborales, proporcionándoles una base material constituida por un hogar, es decir, un lugar de residencia y de consumo. Es ahí donde se lleva a cabo la producción de alimentos que posibilita la reproducción material y biológica de la fuerza de trabajo.

${ }^{147}$ A diferencia de lo que ocurrió en el pasado, cuando la región de estudio fue un destino privilegiado para migrantes originarios de los estados aledaños, hoy en día se puede caracterizar como una región de expulsión de población en edad productiva.

${ }^{148}$ La pluriactividad en el campo tiene expresiones diversas en América Latina (Carton de Grammont y Martínez 2009). 
La crianza de animales tiene un fin que va más allá del meramente comercial. La ganadería en pequeña escala se ha convertido en un recurso ante situaciones de emergencia, enfermedades o fallecimiento de algún miembro de la familia, pero además es un "recurso ceremonial" que permite a las familias solventar las diferentes fases del ciclo festivo y ritual, tanto familiar como comunitario. En este sentido, González (2011b: 99-100) ha señalado que el sistema de $\operatorname{cargos}^{149}$ en esta región es una estructura que fomenta y mantiene interacciones de parentesco, amistad y compadrazgo, las cuales aseguran "la consolidación de redes de ayuda mutua" entre los miembros de la comunidad y entre éstos y los de comunidades aledañas. ${ }^{150}$

En contraste con lo que ocurría en 1950, cuando en el municipio existían 1726 unidades de producción que cultivaban 5487 ha, lo que da un tamaño promedio de las parcelas de 3.1 ha (DGE 1950), el último Censo Agropecuario (INEGi 2007) reporta que en el municipio existen 4130 unidades de producción que cultivan un total de 3920.59 ha (un promedio de 0.9 ha por unidad). Estamos, de manera indiscutible, frente a una fuerte pulverización de la tierra y una producción agrícola muy escasa.

En el cuadro 23 se puede observar la importancia de la actividad agrícola en los últimos años. Destaca la superficie de los cultivos destinados al forraje de los animales, como alfalfa verde, avena forrajera, maíz forraje, ebo y avena ebo. En el ciclo 1996-97, esta superficie sumó 341 ha, en el ciclo 2001-02, 850 ha y en 2008407 ha (en este último año sólo se sembró alfalfa y avena). Igualmente, en términos del volumen de la producción, el cultivo de forrajes presenta incrementos considerables entre los ciclos 1996-97 y 2001-02: en el caso de la alfalfa fue de 14980 a 16710 toneladas, la avena forraje de 850 a 6536 y el maíz forraje pasó de 2070 a 3538 toneladas (INEGI 2003). Estas cifras se complementan con los pastos cultivados, como la cebada y el ebo, y dan cuenta de la importancia que ha adquirido el cultivo de forrajes, consolidando el binomio agricultura-ganadería y la importancia que tiene para la población tanto la cría de animales

${ }^{149}$ El sistema de cargos es una forma de organización compuesta por dos estructuras jerárquicas paralelas, la política y la religiosa. Posee rasgos prehispánicos, que durante la época colonial se combinaron con elementos hispanos. Sus características básicas se establecen con base en un número de oficios/cargos claramente definidos con un orden jerárquico, los cuales se van intercambiando entre los miembros de la comunidad, incorporando en su elección a todos o casi todos ellos. Los cargos no son remunerados, forman parte del servicio comunitario que es compensado en formas particulares de prestigio y de respeto.

${ }^{150}$ En trabajo de campo en las comunidades rurales de Nativitas se ha comprobado que los productos de la ganadería de traspatio y la agricultura de subsistencia se utilizan tanto en fiestas familiares (bautizos, comuniones, cumpleaños, aniversarios, celebración de quince años, graduaciones, etc.) como comunitarias (patronales, día de la cruz, posadas, carnaval, etc.), que se realizan con aportaciones de padrinos (con ayuda de familiares) y de la comunidad, mediante cooperaciones en dinero, en trabajo y en especie. 
como el mercado local para esos cultivos. El cultivo de amaranto y tomate verde ha adquirido importancia por la facilidad reciente de acceso a los mercados.

Por su importancia, consideramos que el cultivo del maíz y frijol merece un estudio pormenorizado. A partir de los datos reportados en el cuadro 23, planteamos que se trata de cultivos de subsistencia y autoconsumo. Sirva el cuadro 24 para apreciar la importancia histórica del maíz como un cultivo básico.

\begin{tabular}{lccc}
\hline \multicolumn{1}{c}{ Cultivo } & Ciclo $1996-97(a)$ & Ciclo 2001-02 (a) & 2008 (b) \\
\hline Alfalfa verde (perenne) & 216 & 188 & 214 \\
\hline Avena forrajera & 29 & 408 & 193 \\
\hline Frijol & 251 & 397 & 279 \\
\hline Maíz grano & 3227 & 2496 & 2939 \\
\hline Tomate verde & 40 & 89 & 35 \\
\hline Amaranto & 165 & 177 & -- \\
\hline Otros cultivos & 151 & 630 & 560 \\
\hline Total & 4387 & 4385 & 4220 \\
\hline
\end{tabular}

Cuadro 23. Superficie sembrada (hectáreas)

Nativitas, ciclo 1996-97, 2001-02 y año 2008. Fuente: (a) INEGI 2003; (b) INEGI 2008.

La tendencia a que el cultivo de maíz ocupe cerca de dos tercios de la superficie sembrada reafirma un aspecto fundamental en las economías agrícolas campesinas: la importancia de este producto tanto para la alimentación de las familias como para la crianza de animales de traspatio. La observación en las comunidades de estudio permite registrar el aprovechamiento que se hace de los elotes para consumo humano, alimento para aves y como forraje de ovinos, bovinos y porcinos. Por tanto, podemos reiterar la creciente importancia que la asociación agriculturaganadería ha adquirido entre los pequeños campesinos como una más de las estrategias de diversificación de sus actividades productivas: en una mayoría de casos, la actividad ganadera se ubica en el espacio doméstico (manejo y cuidado de animales de traspatio), mientras las actividades agrícolas siguen estando articuladas en torno al uso de las parcelas ejidales.

En el proceso de investigación hemos observado que la actividad más significativa de la economía doméstica está representada por la crianza de animales. Incluso familias que no tie-

${ }^{151}$ En la información del año 2008 se agruparon varios cultivos, pero en años anteriores se puede apreciar en detalle la diversidad de especies sembradas que incluye: cebada, trigo, haba verde, cilantro, maíz, frijol, espinaca, maíz forraje, ebo, acelga, cebolla, avena ebo, col, lechuga, ajo y haba seca. 


\begin{tabular}{|c|c|c|c|c|}
\hline Año & $\begin{array}{l}\text { Superficie total cultivada } \\
\text { (hectáreas) }\end{array}$ & $\begin{array}{c}\text { Superficie cultivada de maíz } \\
\text { (hectáreas) }\end{array}$ & $\begin{array}{l}\text { Porcentaje de superficie } \\
\text { cultivada con maíz }\end{array}$ & $\begin{array}{l}\text { Volumen producido } \\
\text { (toneladas) }\end{array}$ \\
\hline 1960 (a) & 5101 & 3590 & 70.3 & 2940 \\
\hline 1991 (b) & 3509 & 2160 & 61.5 & 3377 \\
\hline $1996 / 97$ (c) & 4387 & 3227 & 73.5 & 5382 \\
\hline $2001 / 02(c)$ & 4385 & 2496 & 56.9 & 4481 \\
\hline 2008 (d) & 4219 & 2939 & 69.6 & 6289 \\
\hline
\end{tabular}

nen acceso a ningún terreno crían animales de traspatio y compran su alimento en el mercado local y regional. De acuerdo con los datos sobre ganadería entregados en el capítulo de Salas y Luna en este libro, es evidente la importancia que ha ido adquiriendo la ganadería de traspatio.

Resulta evidente la importancia del ganado en el aumento progresivo de los inventarios. En primer lugar, destaca la crianza de cerdos que entre 1997 y 2007 aumentó de 1394 a 4713 cabezas (INEGI 2003, 2010a), los cuales se producen para la venta o para comidas ceremoniales en algunas de las múltiples fases del ciclo festivo familiar o comunitario. ${ }^{152}$ Aunque en esas ocasiones también se consumen aves, especialmente guajolotes y pollos en la preparación del mole, se utilizan más en las fiestas familiares y se destinan al intercambio, su cría tuvo un incremento notable entre 1997, cuando eran 3408 (INEGI 2003), y 2007, cuando se contabilizaron 18242 (INEGI 2010a). La crianza de borregos es una actividad muy importante, hoy se registran 3374 cabezas (INEGI 2010a) cuyo destino suele ser la preparación de barbacoa, que también tiene un fin ceremonial o comercial. Finalmente, el ganado bovino, de cual se registraron 4626 cabezas (INEGI 2010a), se destina al mercado, la mayoría del hato tiene un doble propósito: la leche se vende a un comerciante que recorre los poblados y la carne se envía al rastro; sólo algunas familias tienen ganado especializado de engorda.

${ }^{152}$ Hemos detectado entre 18 y 20 fiestas comunitarias anuales de importancia en cada una de las 15 localidades que conforman el municipio de Nativitas. Las más grandes son: San Miguel del Milagro (29 de septiembre), Quinto Viernes en honor a Jesús de los Tres Caminos (una semana antes del Viernes Santo, en Tepactepec), Santa María de la Natividad (8 de septiembre en la cabecera municipal). En todas las fiestas se ofrece comida, bebida, música, cohetes, danzas, misas colectivas, etc.
Cuadro 24. Maíz, superficie sembrada (hectáreas) y producción, Nativitas, 1960-2008.

Fuente: (a) DGE 1965; (b) INEGI 1991a;

(c) INEGI 2003; (d) INEGI 2008. 


\section{LA RESIGNIFICACIÓN DE LA ENTRADA A LOS MERCADOS DE TRABAJO}

Debido al carácter de la inserción de los pobladores del municipio en mercados laborales flexibles, es difícil clasificarlos de acuerdo con los tres sectores en los cuales oficialmente se contabiliza la PEA: primario, secundario y terciario. De acuerdo con la información recogida en el trabajo de campo en la región, se puede concluir que estos trabajadores forman parte de mercados tan flexibles que participan de los tres sectores a lo largo de su vida laboral; a veces lo hacen simultáneamente, como aquellos que durante la semana están contratados en la industria en las ciudades y el fin de semana regresan al pueblo y se dedican a la economía doméstica. El trabajo de Magazine y Robichaux en Acxotla del Monte, Tlaxcala, ubicado en las faldas del volcán La Malinche, a escasos $20 \mathrm{~km}$ de Nativitas, revela que desde 1930, y con mayor claridad desde 1970, los hombres eran contratados en empresas textiles en Puebla y tiempo después en el Distrito Federal:

pasaban la semana trabajando en fábricas textiles y también en la construcción como peones de albañil. Algunos se fueron quedando en las ciudades, pero los más reprodujeron el patrón de pasar la semana en la ciudad para trabajar en las fábricas, y regresar a su casa y a la familia en el pueblo con todas las obligaciones económicas y sociales que esto implicaba, e implica [...] varios reconocimientos del área [...] revelaron que, en distintos momentos históricos, un gran número de poblados de la región habían sufrido procesos similares (Magazine y Robichaux 2010: 633).

Podemos observar esta misma tendencia en las trayectorias laborales que hemos recopilado en Nativitas, donde el factor común de los trabajadores es la pluriactividad: trabajadores asalariados en la industria (muchas veces fuera de la región), agricultura y actividades pecuarias -en sus propios terrenos o contratándose como jornaleros con sus vecinos, en la entidad o fuera de ella-, atienden un pequeño comercio (café internet, estética, etc.), dan servicio de transporte público, las mujeres se emplean como trabajadoras domésticas en ciudades cercanas; asimismo, se ubican personas que trabajan en instituciones gubernamentales y educativas.

Presentamos a continuación diversos casos que ejemplifican esta diversidad de actividades. Felipe (50 años) es un ejidatario de Nativitas, con bachillerato en el sector tecnológico. Ha trabajado más de 20 años en el mantenimiento de maquinaria de las fábricas textiles que producen la tela para las vestiduras de automóviles y autobuses; además, cultiva en sus tierras maíz para el consumo familiar y forrajes para la crianza de aves y borregos (entrevista en Jesús Tepactepec, Nativitas, junio 2010). 
Óscar (60 años), también ejidatario, desarrolló su vida laboral en la ciudad de México. Una parte de sus ingresos como trabajador industrial la destinó a mejorar tanto su vivienda en el ejido de Nativitas como las condiciones para la producción agropecuaria, a la que se ha dedicado en los últimos años. Así lo relataba: "Yo soy jubilado de la industria automotriz y ahora me dedico a criar vacas, tengo ocho vacas lecheras que me permiten vivir decentemente con mi familia, aquí sólo somos tres, [yo,] mi esposa y mi hijo" (entrevista en Jesús Tepactepec, Nativitas, junio 2010).

Teresa (50 años), esposa de Óscar, es maestra de educación primaria y su hijo es estudiante de bachillerato. Posee dos hectáreas de tierra ejidal que heredó de su padre, en las cuales produce forraje (alfalfa y avena) y maíz que se destina al autoconsumo y para las compostas de pienso que utiliza para alimentar a sus vacas lecheras que son su ocupación principal en los últimos años.

El caso de Mauro (65 años), ejidatario de San Miguel del Milagro, ejemplifica cómo se combinaban las actividades laborales en la industria con la residencia en el ejido y en la ciudad. Trabajó durante 30 años como doblador de láminas en un taller en la ciudad de México durante la semana, los fines de semana regresaba a San Miguel con su familia. Después trabajó una temporada en Puebla. Con sus ganancias pudo comprar las tierras de cultivo que, según su testimonio, le han permitido enviar a sus hijos a la escuela, todos ellos terminaron la secundaria. Nos ha relatado que es ejidatario desde 1970. Se define a sí mismo como campesino, siembra maíz para las 20 vacas lecheras que posee, frijol para la familia, y amaranto porque señala que es el mejor cultivo para la venta (entrevista en San Miguel del Milagro, Nativitas, noviembre 2010).

Eladio (65 años), ejidatario de Nativitas, accedió a diversos mercados de trabajo, pero en el relato que incluimos a continuación destaca la pluriactividad en la industria y en la construcción alrededor del pueblo, tanto de sus hijos y parientes cercanos, quienes, por diversos motivos, no accedieron a tierras de cultivo, como de su propia participación laboral. Asimismo, relata la experiencia migratoria de los nativiteños tanto al interior del país como a Estados Unidos:

Nunca he trabajado en la industria, yo trabajé de chofer en carretera, ya tengo como cinco años que no trabajo en la carretera. Pero muchas personas sí han trabajado en las fábricas, inclusive mis hijos trabajan en las fábricas. A mí no me gustó. Ellos [sus hijos] nada más en sus tiempos libres trabajan en el campo, pero no tienen vacas porque no les da tiempo de atenderlas. Un hijo estudió en el colegio militar de México, cumplió la milicia y se salió, conoció un militar que trabajaba en San Martín, él lo llamó para que trabajara en la planta de Santa Julia, donde hacen cerámica, loseta. El otro trabaja de albañil. La mayoría de jóvenes se van a trabajar a las industrias, si tienen suerte los contratan, ahora es por contrato, antes era de planta, HYLSA y Volkswagen es por contrato y poco tiempo. Como 
sus padres viven y ellos [los hijos] tienen algo de estudio, prefieren irse a la industria y dejar el campo a los padres. Hay mucha migración desde cuando había braceros a Estados Unidos, ahora se van solos, por su cuenta y riesgo. Yo nunca migré, ni mis hijos. Familiares sí, tres hermanos y sobrinos. Un hijo trató de irse, pero no pasó y se regresó, mejor trabaja aquí, gana poco pero sin riesgos. No sé cuántos, pero sí hay muchos. También hay migración a la ciudad de México. Si se casan por allá ya no regresan, vienen cada año a la fiesta patronal del pueblo. Los de Estados Unidos ya no regresan, menos si no tienen documentos. Mi hermano ya no viene, sólo me ha visitado como tres veces y tiene como 25 años por allá. Mandan dinero a sus papás, pero sólo para que la vayan pasando, no invierten (entrevista en Nativitas, octubre 2010).

La ruralidad que actualmente enfrentan las nuevas generaciones como consecuencia de la globalización es diferente a la que relatan los ejidatarios y campesinos que vivieron en el pasado reciente. La desarticulación industrial ha disminuido las ofertas de empleo y la precariedad laboral ofrece ocasionalmente un salario inseguro y efímero. Hasta hace algunos años, la ciudad de Puebla y el Distrito Federal eran destinos privilegiados para los habitantes del municipio. De acuerdo con INEGi (2005), 385 habitantes de cinco años y más del municipio de Nativitas residían en octubre de 2000 en otra entidad del país, entre las que destacan Puebla con 142 personas, el Distrito Federal con 113 y el estado de México con 73. Además de la migración como cambio de residencia, destaca en la región una migración "pendular" de traslados diarios o semanales a las ciudades de Puebla y México (Gutiérrez 2004), migración que ha contribuido por décadas a la economía familiar de las unidades domésticas de muchos pueblos tlaxcaltecas.

Las experiencias migratorias son otro elemento fundamental que constata el cada vez más diverso acceso a los distintos mercados laborales. En casi todas las historias laborales observadas de los pobladores del municipio aparece la migración como una experiencia laboral fundamental. Como resultado de la visita a veinte hogares y de entrevistas realizadas a cincuenta estudiantes de secundaria y bachillerato de las comunidades de Jesús Tepactepec, San Miguel Xochitecatitla, Santo Tomás la Concordia y de la cabecera municipal, es posible constatar la tendencia a la diversificación en el trabajo y en las actividades económicas, la manifiesta falta de empleo y a emigrar permanente o temporalmente hacia la ciudad de México y, como nuevo destino, a Estados Unidos; las ciudades de referencia para los tlaxcaltecas de Nativitas son: New Haven, Connecticut; Los Ángeles y Oxnard, California; y Portland, Oregon. Tal y como se registró en las entrevistas, las actividades en que se ocupan los migrantes son la agricultura y la jardinería en Arizona; diversas labores en el sector servicio de restaurantes, lavacoches y hoteles en Nueva York; fábricas de costura en Los Ángeles; y albañilería en Texas, Chicago y California, lugares donde los tlaxcaltecas son conocidos por su buen hacer. 
En este mismo sentido, es común escuchar de la migración, mayoritariamente indocumentada, de jóvenes varones, pero también mujeres, a diversas ciudades de Estados Unidos, y de manera documentada a campos agrícolas en Canadá mediante el Programa de Trabajadores Agrícolas Temporales (РTAT). ${ }^{153}$ La precariedad laboral local y regional ha desencadenado en las últimas décadas una migración acelerada hacia los países del norte (Binford et al. 2004). ${ }^{154}$

Además, resalta el hecho de que la mayor parte de la población de la entidad se encuentra en edades productivas. ${ }^{155}$ Para el año 2005, aunque gran parte de la población sigue siendo joven, el porcentaje de habitantes entre los 0 y 19 años bajó a $43.83 \%$ y el de 20 a 65 años aumentó a $49.49 \%$, mientras que el de 65 años y más se mantuvo en 6.67 \% (INEGI 2005). Esto permite deducir que, en la medida en que los pobladores jóvenes y adultos en edad productiva de la región no ven satisfechas sus demandas educativas y/o laborales, seguramente pasan a engrosar las filas de los migrantes. Aunque las cifras oficiales sobre la migración internacional de tlaxcaltecas son bajas, todo parece indicar que, tal como acontece en las regiones emergentes de la migración internacional (Durand y Massey 2003), la migración desde esta entidad hacia Estados Unidos y Canadá se intensificará en el mediano plazo.

${ }^{153}$ El Programa de Trabajadores Agrícolas Temporales México-Canadá, conocido por sus siglas PTAT, administrado por la Secretaría del Trabajo y Previsión Social, tiene sus antecedentes el año 1974 cuando se firmó un Memorándum de Entendimiento entre los gobiernos de ambos países. Este programa "recluta, selecciona y promueve la canalización de trabajadores agrícolas con experiencia laboral como jornaleros o campesinos a granjas canadienses, que ofrecen una alternativa de ocupación segura y redituable a los trabajadores del campo sin empleo" (sTPs 2010: 63). En 2009 fueron reclutados 15352 trabajadores mexicanos que fueron a Canadá, de los cuales 1893 eran de Tlaxcala (12.3\%) (Arana 2011). Las provincias canadienses que participan en el Programa fueron: Alberta, Columbia Británica, Isla Príncipe Eduardo, Manitoba, Nuevo Brunswick, Nueva Escocia, Ontario, Quebec y Saskatchewan (Consulado General de México en Toronto 2010).

${ }^{154}$ Para el año 2000, casi 180000 tlaxcaltecas residían en otra entidad y 8541 habían emigrado a Estados Unidos (INEGI 2001); de un total de 203000 hogares tlaxcaltecas, $2.24 \%$ reciben remesas familiares, algún miembro del $2.7 \%$ de las familias reside en Estados Unidos, 0.49 \% tiene migrantes circulares y $0.37 \%$ migrantes de retorno (CONAPo 2000). Según conapo (2000), el índice de intensidad migratoria en la entidad es de 0.73806, por lo que el grado migratorio es considerado bajo; sin embargo, las remesas que recibe el estado de Tlaxcala se incrementan constantemente: para 2003 su monto se elevó a 137.6 millones de dólares, en 2004 fue de 173.2, en 2005 de 212.3, en 2006 de 260.9 y en 2007 alcanzó los 282.1 millones de dólares (Banco de México 2008).

${ }^{155}$ De la población total del municipio de Nativitas, $46.19 \%$ (10 050 personas) tiene entre 10 y 34 años de edad. De acuerdo con la siguiente relación de la población por quinquenio, la edad mediana es de 23 años: de 10 a 14 años, 2 597; de 15 a 19, 2 327; de 20 a 24, 1945, de 25 a 29, 1628 y de 30 a 34, 1553 (INEGI 2005). 
Para el tema que nos ocupa, podemos señalar que la migración y el uso de las remesas no están colaborando a reproducir estilos de vida campesina vinculados al trabajo de la tierra. Por el contrario, los entrevistados que buscan un destino en la migración han declarado que cuando envían dinero lo hacen para invertir en sus viviendas - pensando en su regreso-, pero como medio de vida esperan comprar maquinaria (tractores), un camión, poner un negocio, incluso alguno reconoció la posibilidad de "comprar" una plaza de profesor. La presencia de las remesas se hace evidente en las mejoras en las construcciones, las viviendas en obra y los establecimientos comerciales, entre los que destacan los café internet, las estéticas, las casetas telefónicas y los expendios de bebidas (información de campo, septiembre 2008).

Aun cuando los jóvenes se encuentren en la escuela y tengan algunas posibilidades de continuar sus estudios en la capital del estado, ven su inevitable inserción en el trabajo asalariado de la industria, el comercio y/o el sector servicios a través de la migración. Este hecho fue confirmado por maestros y autoridades escolares, quienes incluso manejan con suma discreción la deserción escolar derivada de los jóvenes que se han ido de migrantes. En las conversaciones con los estudiantes de secundaria de Nativitas se reconocía tener al menos un familiar fuera del país y más de uno empleado fuera de la entidad, de tal manera que en su vida familiar la cotidiana presencia de la migración los hace pensar en su propio destino.

\section{CAMBIOS LABORALES Y NUEVA RURALIDAD}

En las últimas décadas, se observa en Tlaxcala un fenómeno ya estudiado en distintas regiones rurales de América Latina. El incremento de participación de la población en actividades de servicio y comerciales y el aumento de empleos precarios, informales y flexibles refleja la tendencia de los habitantes de Nativitas a ocuparse en la industria, la construcción, las maquiladoras y el turismo. El resultado ha sido, por un lado, una radical modificación del paisaje: ${ }^{156}$

${ }^{156}$ En este sentido, el territorio no solamente se distingue por elementos ambientales, sino que es transformado, creado y apropiado por los seres humanos en una combinación o integración de los aspectos geográficos, físicos, bióticos y antrópicos donde se inscribe la cultura de las sociedades como un conjunto observable que refleja las creencias, prácticas, objetos, diseños y tecnologías de una sociedad en particular y donde ésta produce y reproduce su cultura (Crang 1998: 15-22). Este dinamismo del territorio, concebido entonces como paisaje, es donde se acumula el conjunto de relaciones que representan una historia escrita por procesos del pasado y del presente, un conjunto indisoluble de objetos y sistemas de acciones; por ello una cualidad del paisaje es su transtemporalidad, formas materiales creadas en diferentes momentos que coexisten en el momento actual (Santos 2000: 86-87). 
se ha dado un cambio importante en el uso del suelo de agrícola a residencial, los canales de riego se han convertido en caminos, calles y autopistas y, más grave aún, se usan como desagües, drenajes y ductos de desechos industriales, urbanos y domésticos. Por otro lado, la amplia participación de los sujetos en otros ámbitos de experiencia y de identidad, derivados de la migración y el acceso a mercados de trabajo regionales, en las ciudades -dentro y fuera del país-, ha trastrocado las formas de vestir, las costumbres alimentarias, los gustos musicales y las creencias.

En todo caso, es importante destacar que estos procesos han sido improvisados y, quizás, incompletos; el reemplazo de la centralidad del trabajo agrícola por el asalariado en la industria, el comercio o los servicios no ha significado contratos de trabajo plenos, satisfactorios y estables; el desplazamiento de un paisaje rural por uno urbano no ha devenido en los servicios urbanos necesarios, como la recolección de basura, la seguridad, el suministro constante de agua potable o luz eléctrica, el mejoramiento de las instalaciones educativas o de salud, ni tampoco ha redundado en la calidad de estos servicios.

Para seguir definiendo este espacio social y cultural como sociedad rural, debe tomarse en consideración el dinamismo y la reconfiguración del paisaje y la composición y expectativa de los actores, sin enmarcarlas en una definición rígida limitada a la magnitud y frontera de las localidades, pueblos o ciudades, de tal manera que, en acuerdo con Barkin (2001: 33), podemos decir que se requiere

reexaminar las formas en que los estudiosos y las instituciones oficiales identifican y clasifican lo rural, ya que grandes contingentes de trabajadores del campo y muchas familias campesinas se encuentran en enormes campos de mano de obra migratoria, en pequeñas ciudades o aún en las zonas periurbanas de algunas de las grandes urbes.

Podemos agregar que los poblados rurales, antaño centros de concentración de mercados donde se intercambiaban productos agrícolas, pecuarios, animales, vegetales y algunas artesanías, ejes de la vida económica agraria, se han vuelto núcleos comerciales, donde abundan los llamados cibercafés, las estéticas, las tiendas de abarrotes, verduras, licores, ropa y zapatos, carnicerías, oficinas públicas donde se ofician ayudas estatales o trabajos precarios y flexibles. Asimismo, la sede del ayuntamiento y de las agencias auxiliares ha sustituido las estructuras ejidales, que han dejado de ejercer como centros sociales de expansión del agrarismo, de la lucha por la tierra, de distribución de las aguas de irrigación y como facilitadoras para la comercialización de los productos agrícolas.

La nueva ruralidad permite dar cuenta de nuevas actividades que se desarrollan en estos ámbitos; asimismo, posibilita comprender de manera más amplia los procesos de transforma- 
ción, tomando en cuenta cambios sociales que involucran, esencial y necesariamente, lo rural con lo urbano, lo agrícola con lo industrial y comercial y lo local con lo global (cfr. Carton de Grammont 1999; Delgado 1999; Llambí 2001, 2007; Lara 2001). Para entender mejor esta articulación entre lo local y lo global, Long (1996: 46-59) ha propuesto los términos de "localización" y "relocalización", que remiten al hecho de que esta compleja dinámica de interrelación genera nuevos modos de organización y sobrevivencia económica, nuevas identidades, alianzas y disputas por el espacio y el poder, repertorios culturales y de conocimiento. De forma tal que los elementos globales son "localizados" (territorialmente) y reformulados en el contexto de los conocimientos, organizaciones, agencias y culturas nacionales, regionales o locales. Es decir, los elementos globales adquieren significaciones que atañen a la "relocalización", al resurgimiento de compromisos locales y a la "reinvención" de formas sociales locales que emergen como parte del proceso de globalización.

La noción de nueva ruralidad deviene de procesos de ocupación de zonas rurales tradicionales por actividades industriales o urbanas, los cuales hacen que la actividad agropecuaria no sea la más importante de la vida rural. En otras palabras, los sujetos rurales son los que se transforman con su paso por otras experiencias de vida, de trabajo y de socialización. Las personas continúan habitando las localidades rurales, con sus nuevos repertorios económicos, culturales y sociales. A esto lo llamamos "desagrarización sin desruralización".

Sin negar el hecho de que todos estos fenómenos se enmarcan dentro del llamado modelo neoliberal y, por ende, del proceso de globalización económica, en este trabajo hemos explorado las respuestas y las estrategias alternativas que los actores locales están desplegando en los ámbitos económico, técnico, social, cultural y político para hacer frente a sus consecuencias. En efecto, las comunidades objeto de este análisis han actualizado sistemas tradicionales de organización social, económica y cultural, como un recurso para enfrentar la acentuada exclusión que las afecta, la desarticulación de formas de organización familiar y comunitaria y el deterioro de su entorno laboral y ambiental.

\section{A MANERA DE CONCLUSIÓN}

A contracorriente de lo que pudiera pensarse, la pluriactividad de las familias rurales, campesinas o no, no es resultado directo de los procesos de globalización -si bien este fenómeno se ha acentuado. Desde inicios del siglo xx, el vínculo de la mano de obra en Nativitas con la industria textil de la región evidencia que la movilidad de las poblaciones rurales no es recien- 
te ni corresponde solamente a las migraciones contemporáneas, ligadas a las necesidades del mercado laboral flexibilizado.

Podemos diferenciar, por una parte, una pluriactividad y movilidad poblacional histórica, que corresponde a un modelo nacional de desarrollo cuyo objetivo central fue la industrialización y la ampliación de los mercados internos sobre la base de una producción agropecuaria que satisfacía las necesidades de estos mercados, tanto en términos de materias primas a precios convenientes para la industria como de fuerza de trabajo barata y abundante. Por otra parte, observamos una pluriactividad y movilidad poblacional contemporánea, que corresponde a la globalización de los mercados, a la reorganización del sistema agroalimentario mundial y a la flexibilización de los mercados laborales, que han traído como consecuencia procesos de desagrarización, cambio en el uso de las tierras de cultivo e intensificación de la movilidad de las poblaciones rurales tanto en el interior de México como a Estados Unidos y Canadá.

Aunque estos procesos se han generalizado en el campo mexicano, no son homogéneos. Tal como hemos podido observar en el municipio de Nativitas, a pesar de la contracción del sector primario, éste sigue siendo el más importante generador de empleos. Sin embargo, el grueso de los ingresos familiares proviene del trabajo asalariado y de las actividades comerciales y de servicios. De tal manera que los ingresos producto de actividades agropecuarias que en el pasado fueron centrales, han devenido en complementarios o, en algunos casos, como mantenedores de las poblaciones jubiladas. Se concluye, siguiendo a Carton de Grammont (2006), que la desagrarización no ha implicado la desaparición de las actividades agropecuarias, sino el aumento de las fuentes de ingresos no agrícolas.

Esta diferencia entre un proceso histórico y uno contemporáneo, se manifiesta en un corte generacional. Quienes han concluido su vida laboral, incluso aquellos que tienen experiencias migratorias, ven en las actividades agropecuarias un medio de subsistencia, por lo que se afanan en reproducir formas de producción y organización familiar y comunitaria que corresponden a un estilo de vida marcado por la agricultura. A diferencia de esta generación, los jóvenes se muestran reacios a emplearse en esta actividad y centran sus expectativas en el trabajo asalariado -oficios ocasionales y/o pequeños negocios- en la región o fuera de ella, de manera que las actividades agropecuarias operan como un soporte para las migraciones laborales y para el desarrollo de otras estrategias económicas de las familias. En este sentido, señalamos que las actividades asalariadas y las migraciones laborales se definen por las condiciones del mercado de trabajo y son las que ordenan la vida social y económica de las familias, a diferencia del pasado agrícola.

En este análisis hay tres conceptos clave para dar cuenta de los cambios vividos en las últimas décadas en el municipio de Nativitas: pluriactividad, desagrarización y migración. El 
análisis de los cambios en la región estudiada permite explicar con meridiana claridad que estas transformaciones son consecuencia de etapas históricas del modelo de desarrollo nacional que no pueden entenderse sólo en términos coyunturales. Las peculiaridades del municipio estudiado nos permiten destacar que, aunque es eminentemente rural, estamos frente a nuevas ruralidades, en las cuales el acceso a los mercados flexibilizados de trabajo define, hoy en día, este tránsito hacia una nueva forma de sociedad rural. 


\title{
LA MIGRACIÓN CON FINES LABORALES EN EL CONTEXTO DE LA DIVERSIFICACIÓN DE ACTIVIDADES ECONÓMICAS ENTRE LOS NATIVITEÑOS
}

\author{
María Leticia Rivermar Pérez
}

\section{INTRODUCCIÓN}

\begin{abstract}
7 n 1846, la hambruna liquidó en Irlanda a más de un millón de seres humanos, pero sólo se $\checkmark$ trataba de pobres diablos. No infligió el menor perjuicio a la riqueza del país. El éxodo que la siguió durante dos decenios y que todavía hoy va en aumento, no diezmó -como sí lo hizo la Guerra de los Treinta Años- junto a los hombres a sus medios de producción. El genio irlandés inventó un método totalmente nuevo para proyectar a un pueblo indigente, como por arte de encantamiento, a miles de millas de distancia del escenario de su miseria. Los emigrantes arraigados en Estados Unidos envían anualmente sumas de dinero a casa, medios que posibilitan el viaje de los rezagados. Cada tropel que emigra este año, atrae el próximo año otro tropel de emigrantes. En vez de costarle algo a Irlanda, la emigración constituye uno de los ramos más proficuos de sus negocios de exportación (Marx 1975: 880-881).
\end{abstract}

Valga esta larga cita para ratificar que las migraciones ${ }^{157}$ en la sociedad moderna han sido gestadas por las demandas del capital. Podemos decir, parafraseando a Marx, que en la actuali-

${ }^{157}$ En una primera instancia, definimos la migración como el cambio de lugar de residencia con fines laborales o de estudio. "Esta mera movilización de personas implica una serie compleja de eventos que alteran las relaciones sociales, tanto en las comunidades de origen como en las de llegada, además, implica la construcción de redes sociales que posibilitan dichas movilizaciones y que inciden en una sucesión de cambios en la vida de las comunidades que atraviesan por este fenómeno" (Canabal 2008: 11-12). 
dad el genio capitalista ha seguido proyectando, como por arte de magia, a miles de kilómetros de distancia del escenario de su miseria a la "población excedente", compuesta mayoritariamente por hombres y mujeres jóvenes "incapacitados para trabajar en casa y sin perspectivas" (Bauman 2007: 519). Sólo que, a diferencia del pasado, esta vez van en dirección contraria y sin la ayuda de ejércitos de conquistadores, comerciantes y misioneros (Bauman 2007: 53). Hasta la primera mitad del siglo pasado los flujos migratorios tuvieron como origen Europa y como destino fundamental América, África y Australia; hoy en día los millones de migrantes deambulan del sur al norte y del este al oeste del planeta. ${ }^{158}$

Este hecho es resultado de la reorganización del mercado laboral acaecida en las últimas décadas a nivel mundial, la cual ha traído aparejada una acentuada flexibilización del trabajo y una polarización en el interior de ese mercado: en la cúspide se aglutinan trabajadores con altos grados de calificación, elevados salarios y empleos estables que demandan una serie de servicios ofrecidos por hombres y mujeres originarios de países o regiones asolados por la pobreza, en donde han sido privados de sus tierras, talleres y redes de seguridad colectiva (Bauman 2007: 44). Estos empleos son inestables, de tiempo parcial y demandan escasa calificación, los trabajadores que los ejecutan se ubican en la base del mercado laboral (Sassen 1995).

En este escenario, en los últimos treinta años hemos visto crecer la migración de mexicanos a Estados Unidos e incorporarse a este flujo ya centenario de poblaciones de la denominada región central de la migración ${ }^{159}$ (Durand y Massey 2003). Situación que, además de responder a la reorganización del mercado laboral arriba anotada, obedece a tres razones fundamentales: 1) la pérdida de importancia de la zona metropolitana de la ciudad de México (ZMCM) entre 1970 y 1980 como destino laboral de poblaciones originarias del centro del país (Corona y Luque 1992; Durand y Massey 2003); 2) las crisis económicas de 1982 y 1994, consecuencia de la implantación de políticas de corte neoliberal que han generado la expulsión del mercado laboral de un gran número de trabajadores y la precarización del empleo que se expresa en bajos salarios e inseguridad laboral; y 3 ) la reestructuración de la agricultura que ha propiciado la pérdida de importancia de las actividades agropecuarias, relegándolas al nivel de subsistencia

${ }^{158}$ También se mueven entre las repúblicas de lo que fue la Unión Soviética con destino a Rusia. Estos trabajadores, junto con los habitantes de origen ruso en todo el espacio postsoviético, tal como sucede en otras latitudes del planeta, padecen represalias cuando el Kremlin se enfrenta con los gobiernos de sus lugares de origen (La Jornada 2010: 22).

${ }^{159}$ Esta región está conformada por los estados de Guerrero, Hidalgo, México, Morelos, Oaxaca, Puebla, Querétaro, Tlaxcala y el Distrito Federal (Durand y Massey 2003: 83). 
(Carton de Grammont 2004), por lo que hoy en día se aprecia en los hogares rurales un aumento en la tendencia a vivir de un salario (Canabal 2008: 20).

Sin embargo, aun cuando la producción agrícola ha dejado de garantizar la reproducción de un gran número de esos hogares, no ha sido abandonada del todo. Se ha optado por complementarla con otras actividades económicas -entre las que destacan el empleo precario, el subempleo y el empleo informal tanto en el interior del país como en Estados Unidos y Canadá ${ }^{160}$ - que se han convertido en indispensables para la sobrevivencia de los hogares rurales. Esta diversificación de actividades ha implicado la incorporación de otros miembros de la familia, especialmente mujeres y niños, a la esfera económica y a la migración. Resultado de estos trastrocamientos son los cambios habidos tanto en la organización de la familia como en los espacios socioeconómicos y culturales en los que estas poblaciones habitan (Barros 2007: 173).

El objetivo de este capítulo es analizar la migración de los pobladores del municipio de Nativitas. Para tal fin, en un primer apartado caracterizamos los flujos migratorios de los pobladores de la entidad; en un segundo momento delineamos las características de la migración hacia Estados Unidos; y en las reflexiones finales discutimos críticamente las cifras oficiales sobre la migración de tlaxcaltecas a aquel país.

\section{DE ESTADO EXPULSOR A ENTIDAD RECEPTORA DE POBLACIONES}

$\mathrm{Al}$ intentar conocer el número de tlaxcaltecas que radican en el extranjero, nos enfrentamos con diferencias significativas en las cifras emitidas por diversas instituciones gubernamentales e investigadores: Conapo (s/f) anota que $2.59 \%$ de viviendas en el estado de Tlaxcala recibió remesas en 2010. Esta misma institución -con base en la muestra de $10 \%$ del XII Censo General de Población y Vivienda 2000- señala que sólo 2.7 \% de 203259 hogares encuestados tiene algún miembro radicado en Estados Unidos, lo que representa alrededor de 10000 personas. Ese último porcentaje es muy cercano al de hogares tlaxcaltecas que reciben remesas, $2.24 \%$, manejado por Flores (2009: 13). INEGI (s/fb) refiere que para junio de 2010, 12947 tlaxcaltecas vivían fuera del país. Por último, según las cifras proporcionadas en 2008 por las Oficinas de

160 "En el año reciente la economía informal generó cuatro veces más puestos de trabajo que el sector formal, marca que dejó de ser coyuntural para convertirse en tendencia, reveló este viernes información oficial. Uno de cada tres trabajadores remunerados en el país percibe un ingreso no mayor a dos salarios mínimos, 120 pesos por día, cantidad insuficiente para tener acceso a los bienes más básicos, según datos publicados por el Instituto Nacional de Estadística y Geografía (INEGI)" (La Jornada 2012: 26). 
Atención a Poblaciones en el Extranjero, 107000 tlaxcaltecas residen fuera del país (González 2008: 52-53). Según Conapo (s/f), en el 2010 Tlaxcala se ubicó en grupo de entidades que presentaron grado medio de intensidad migratoria. Más allá de las discrepancias en las cifras, observamos que los desplazamientos de los tlaxcaltecas allende las fronteras nacionales con fines laborales han llegado a ser desde los años noventa una importante estrategia de sobrevivencia de muchos grupos domésticos de la entidad. Al respecto, Mendoza (2006: 125) señala que:

las tasas de crecimiento promedio anual de la población con residencia permanente en Estados Unidos muestran que los estados de la región sur del país, aunque aún no cuentan con grandes cantidades relativas de población viviendo en ese país, han tenido un gran dinamismo migratorio durante la década de los noventa. En particular, resaltan los casos de Tlaxcala, Veracruz, Chiapas, Hidalgo, Puebla y Guerrero.

Una de las explicaciones del crecimiento de la migración internacional de los tlaxcaltecas está relacionada con los cambios en la agricultura de la entidad, que se iniciaron cuando se puso en marcha la revolución verde ${ }^{161}$ en los años sesenta del pasado siglo. Entonces se sustituyó el cultivo de trigo que tenía como destino el mercado nacional por la producción de forrajes que abastece tanto el mercado local como la ganadería familiar. ${ }^{162}$ La situación se complicó aún más para los pequeños productores agrícolas tlaxcaltecas en los años noventa, cuando enfrentaron graves problemas de liquidez: la mayoría llegaron a formar parte de la cartera vencida del Banco Nacional de Crédito Rural (Banural) y de bancos privados.

Quienes no contaban con financiamiento o aquellos que no fueron beneficiados con el reparto agrario, dedicaron sus tierras al cultivo de maíz. ${ }^{163}$ Quizás una de las consecuencias más

${ }^{161}$ La revolución verde es un modelo que nació en Estados Unidos tras las investigaciones para la creación de semillas híbridas, se integró a la agricultura con el fin de obtener mayores rendimientos. En México, la revolución verde se adoptó en los años cincuenta del pasado siglo, cuando se presentó como una vía para la modernización del país, especialmente de las zonas rurales, las que eran vistas como espacios desprovistos de los medios necesarios para alcanzar un desarrollo similar al de las zonas urbanas (Pichardo 2006: 45, 66).

${ }^{162}$ Fueron dos los motivos centrales que propiciaron el viraje de la producción de cultivos tradicionales hacia los de forraje en nuestro país durante la revolución verde: el crecimiento de la demanda de carne en el mercado estadounidense (Pichardo 2006: 65) y la reorientación de la dieta humana hacia un mayor consumo de proteínas cárnicas, lo que modificó sustancialmente los sistemas agroalimentarios mundiales y desencadenó los procesos nacionales de ganaderización (Salas 2002). 2003).

${ }^{163}$ Así, para el año 2000, esta gramínea se sembró en 76 \% de la superficie cultivable de la entidad (INEGI 
notables de estos cambios en el campo tlaxcalteca fue el incremento de la feminización del trabajo asalariado rural, que pasó de $37.3 \%$ en 1990 a $50.2 \%$ en el año 2000, lo que se relaciona con el abandono del campo por parte de los varones y con el sesgo masculino de la migración internacional (Flores 2009: 12-14). Otro de los resutlados notables de estos trastrocamientos es el aumento del empleo asalariado en la industria y en los talleres de maquila ${ }^{164}$ de la región y la creciente importancia que la migración internacional con fines laborales cobra entre los tlaxcaletecas.

En la década de los noventa, como resultado de la firma del Tratado de Libre Comercio para América del Norte (TLCAN) y de las reformas estructurales de corte neoliberal, se puso en marcha un proyecto que convirtió al estado de Tlaxcala en una entidad clave para promover el desarrollo industrial fuera de las ciudades de la frontera norte del país, lo que atrajo inversiones provenientes de Estados Unidos y Canadá. La expansión de las industrias de exportación se dio en coexistencia con la tradicional industria textil asentada en el estado. A pesar de las importantes inversiones foráneas, la exclusión y la pobreza en la entidad continuaron en incremento, originándose un desarrollo desigual en las zonas rurales de Tlaxcala y, con ello, el crecimiento de la migración internacional, especialmente la de carácter indocumentada hacia Estados Unidos (Flores 2009: 13). Esta situación puede ser interpretada a partir de lo planteado por Sassen (1996: 219), para quien las migraciones de larga escala en países en desarrollo, como México, están relacionadas con el impacto de substanciales inversiones extranjeras, cuyo más importante resultado es la ruptura de los tradicionales modos de vida de la gente.

En 1970, Hugo Nutini y Timothy Murphy (1970: 86) llamaron la atención sobre los rápidos cambios en el paisaje de la denominada área poblano-tlaxcalteca, en la que se localiza el municipio de estudio, como resultado de la importante migración hacia los centros urbanos. Sin embargo, en la primera mitad de la década de los ochenta Tlaxcala pasó de ser un estado expulsor a una entidad receptora de población. Entonces un número cada vez mayor de inmigrantes, muchos provenientes de la ciudad de México, se dirigió hacia Tlaxcala, tendencia que se mantuvo hasta los años noventa.

${ }^{164}$ En su momento, Marx (1975: 882) documentó una situación similar entre los agricultores irlandeses: "La competencia de la agricultura practicada con métodos capitalistas oprime progresivamente, en grado mucho más intenso que antes a [los pequeños y medianos arrendatarios, quienes, por consiguiente] suministran de manera constante nuevos reclutas a la clase de asalariados". Sin embargo, no debemos perder de vista que aunque estos procesos no son nuevos, las características de la calificada por Marx como "revolución de la agricultura" y de la expulsión de los campesinos de sus parcelas que trajo aparejada, hoy día adquieren tonos distintos a la luz de las exigencias de la nueva fase de acumulación capitalista (Harvey 1989). 
Desde la primera mitad de la década de los ochenta, el estado de Tlaxcala era receptor activo de pobladores inmigrantes del Distrito Federal [...]. En estos años la población del Distrito Federal disminuyó y la población de Tlaxcala aumentó, incluso a tasas superiores al promedio nacional [...]. La política de desconcentración de la población del centro a la periferia y el terremoto de 1985 [que afectó severamente a la ciudad de México] transformaron las áreas agrícolas tlaxcaltecas en complejas unidades habitacionales: extensas hectáreas dedicadas a la producción agrícola fueron desplazadas para alojar naves industriales (Flores 2009: 12).

Paralela a este crecimiento de la inmigración, se observa una importante emigración laboral de carácter pendular hacia el Distrito Federal, que involucra de manera fundamental a mujeres: Alonso y Marroni (citadas en Flores 2010: 13) encontraron que mujeres provenientes de poblados rurales tlaxcaltecas emigran efímeramente hacia las urbes. El sesgo femenino de esta migración puede explicarse por la mayor facilidad de las mujeres para incorporarse al sector terciario, en donde se ocupan especialmente en actividades informales, entre las que destaca el servicio doméstico (Corona y Luque 1992).

También se sabe de la importante presencia de mujeres tlaxcaltecas en las redes de prostitución nacional. El municipio de Tenancingo, en donde las principales actividades económicas de sus cerca de diez mil habitantes son la industria manufacturera, el comercio, la agricultura y la ganadería, es conocido como uno de los principales importadores de mujeres esclavizadas para fines sexuales. Estas redes de prostitución tienen una ruta muy específica: del Distrito Federal a Veracruz, de Veracruz a Puebla, de Puebla a Tlaxcala, de Tlaxcala otra vez al D. F. y de la capital a Morelia, pasando por Celaya. En el norte del país se encuentra el corredor Tijuana, que va hasta el condado de San Diego en Estados Unidos (La Crónica 2008).

Aunque entre 1970 y 2000 se observan cambios sustanciales en la demografía del estado, el saldo neto migratorio de la entidad sigue siendo negativo: en 2005 Tlaxcala ocupó el lugar 23 entre los estados expulsores de población con un saldo neto migratorio de -1.7. Asimismo, a pesar de la pérdida de importancia de la ZMCM como destino migratorio de las poblaciones del centro del país, para los migrantes de origen tlaxcalteca el estado de México y el Distrito Federal siguen siendo dos destinos privilegiados. Hoy en día la migración de carácter pendular hacia esos territorios sigue siendo una práctica común. Según INEGI (2005), en octubre de 2000, 27990 personas de cinco o más años de edad vivían en una entidad diferente a Tlaxcala, 72.6 \% residían en tres estados: 8605 personas en Puebla, 6245 en el estado de México y 5469 en el Distrito Federal. Tanto la migración intraestatal como la interestatal de los tlaxcaltecas tiene un sesgo masculino: $74.6 \%$ de los migrantes son varones y $25.4 \%$ mujeres, de manera que, al parecer, la migración interna ha funcionado como motor de los desplazamientos de 
tlaxcaltecas hacia Estados Unidos y Canadá (Marchand 2006: 3-8), situación que también han detectado Rivera y Lozano (2006) para el caso de los mixtecos poblanos.

No obstante que en Tlaxcala los desplazamientos poblacionales hacia Estados Unidos son débiles en comparación con los que se generan en estados como Oaxaca, Guerrero e Hidalgo, entre 1970 y 1990 este flujo se incrementó (Espina 2003: 249). De 1960 a 1990 el Distrito Federal, Puebla, Tlaxcala e Hidalgo aumentaron sistemáticamente su participación en la migración internacional, aportación que se caracteriza por dos peculiaridades:

Una, que sus tasas de emigración respecto a sus poblaciones residentes han permanecido por debajo de la media nacional en las tres décadas. Y la otra, que en razón del gran volumen de población que habita en estas entidades ( $18.5 \%$ del total de residentes en el país en 1990), su presencia se incrementó notablemente, tanto en los flujos decenales de emigración (pasando de $2.9 \%$ en los sesenta a $16.5 \%$ en los ochenta), como entre los mexicanos que residen en Estados Unidos ( $2.8 \%$ en 1960 y $12.5 \%$ en 1990) (Corona 1993: 758).

González (2008: 16) anota que son pobladores de la región sur del estado ${ }^{165}$ quienes se trasladan hacia Estados Unidos. En esta zona -conurbada a las ciudades de Tlaxcala y Puebla y parte de la Zona Metropolitana Puebla-Tlaxcala desde 2005- se han instalado grandes corredores industriales que generan empleos eventuales para la población de la región y del vecino estado de Puebla. ${ }^{166} \mathrm{El}$ mismo González refiere que quienes migran a Canadá son originarios de la región centro-poniente-norte, en donde las actividades agropecuarias siguen teniendo un peso importante en la generación de empleos estacionales. Se podría pensar que la presencia de una importante industria de exportación en el sur y una pujante actividad agropecuaria en el centro-poniente-norte retendrían a las poblaciones en edad productiva. Sin embargo, los bajos salarios, la temporalidad de los empleos, la inexistencia de prestaciones sociales, en suma, la

${ }^{165}$ Región conformada por los municipios de Acuamanala, Mazatecochco, Nativitas, Papalotla de X., San Jerónimo Zacualpan, San Juan Huactzinco, San Lorenzo A., San Pablo del Monte, Santa Apolonia T., Santa Catarina A., Santa Cruz Quilehtla, Tenancingo, Teolocholco, Tepetitla de Lardizábal, Tepeyanco, Tetlatlahuca, Xicohtzinco y Zacatelco (González 2008: 84).

${ }^{166}$ Podemos interpretar esta situación a partir de lo dicho por Suárez (2011: 65), para quien la reorganización territorial provocada por los cambios económicos "ha ocasionado la atracción de población y la conurbanización, es decir, un proceso de articulación de una o varias localidades en torno a un centro urbano de rápido crecimiento, proceso que, por la cercanía geográfica entre las localidades, las lleva a integrarse en lo económico y lo político". 
precariedad laboral característica, obligan a hombres y mujeres a desplazarse fuera de la entidad y más allá de las fronteras nacionales en búsqueda de mejores condiciones laborales y de vida. ${ }^{167}$

La migración de tlaxcaltecas a Estados Unidos, que es mayoritariamente indocumentada, se caracteriza por su sesgo masculino: $63.3 \%$ de los migrantes son varones y $36.4 \%$, mujeres; su juventud: alrededor de $62 \%$ de los migrantes tienen entre 20 y 39 años de edad; ${ }^{168}$ y su origen urbano: 84 \% de los migrantes provienen de este entorno (Flores 2009: 13). La mayoría de los tlaxcaltecas que radican en aquel país se ubican en la zona limítrofe de los estados de Idaho y Wyoming. El primero, dado el menor costo de las rentas, ha sido elegido como lugar de residencia y el segundo como lugar de trabajo, donde se emplean de manera fundamental en la industria de la construcción y los servicios. Algunos tlaxcaltecas son reclutados por enganchadores para laborar en los campos agrícolas estadounidenses a través del programa de visas de trabajo temporal H2A. ${ }^{169}$ Un número importante de los migrantes tlaxcaltecas combina el empleo regulado con trabajos no amparados por visa alguna o con estancias superiores a las permitidas; algunos más, después de acumular cierta experiencia, prescinden de los intermediarios oficiales y pactan directamente con empleadores que los han contratado con antelación (Herrera et al. 2007).

Por su parte, la migración de tlaxcaltecas a Canadá es regulada dentro del marco del Programa México-Canadá de Trabajadores Agrícolas Temporales, que se estableció en 1971 con la firma del Memorándum de Entendimiento, administrado por la Secretaría del Trabajo y Previsión Social (STPS). Este programa "recluta, selecciona y promueve la canalización de trabajado-

${ }^{167} \mathrm{Tal}$ como lo ha advertido Suárez (2011: 76) "el desarrollo industrial no representa necesariamente el mejoramiento de las condiciones de vida de la población local".

${ }^{168}$ Según París (2010: 149), la importante migración a Estados Unidos de jóvenes puede estar respondiendo, por un lado, al hecho de que este grupo presenta gran movilidad geográfica y mayores posibilidades de adaptarse a diversas ocupaciones en aquel país y, por otro, a la capacidad para adquirir habilidades en ocupaciones de la más diversa índole. Siguiendo a Michael Kearney (1996), podemos definir a estos trabajadores como "polibius", en tanto tienen una gran capacidad para insertarse en distintos nichos de vida y laborales, que es potenciada por su juventud.

${ }^{169} \mathrm{El}$ Programa de Visas H2A se inició en 1964 al cancelarse el programa Bracero para asegurar el abasto de trabajadores agrícolas en la costa este de Estados Unidos. Entonces se contrataron en especial trabajadores temporales de las Indias Occidentales Británicas (mayoritariamente jamaiquinos). A la luz de la promulgación de la Reforma de Inmigración y Acta de Control (IRCA, por sus siglas en inglés) -mejor conocida entre los mexicanos residentes en Estados Unidos como la Ley Simpson-Rodino en alusión a sus promotores-, a fines de los años ochenta se añadió la visa $\mathrm{H} 2 \mathrm{~b}$ para servicios; en la actualidad, tres cuartas partes de estas visas se otorgan a trabajadores mexicanos (Durand 2006: 54). 
res agrícolas con experiencia laboral como jornaleros o campesinos a granjas canadienses, que ofrecen una alternativa de ocupación segura y redituable a los trabajadores del campo sin empleo" (stps s/f). A través de este programa "desde 1974 miles de mexicanos han desempeñado trabajo agrícola por periodos que van de seis semanas a ocho meses" (Binford et al. 2004: 11).

Los lugares de trabajo de los mexicanos en Canadá se ubican en las provincias de Nueva Escocia, Nuevo Brunswick, Isla Príncipe Eduardo, Alberta, Manitoba, Quebec y Ontario, estas dos últimas reciben $90 \%$ de esos trabajadores (Arana et al. 2009: 62). Preibisch (The NorthSouth Institute s/f) ha señalado que los trabajadores agrícolas extranjeros se han convertido de forma incrementada en parte del tejido social y cultural de las comunidades rurales canadienses, particularmente en Ontario y Quebec, donde se emplean más de 20000 migrantes cada año. En estas dos provincias y en Manitoba se ubica la mayoría de los trabajadores tlaxcaltecas (Binford et al. 2004). Según Pardinas (2008: 39), en 2007 el estado de Tlaxcala ocupó el segundo lugar (17.3\%), después del estado de México (19.25\%) y sobre Puebla (9.42\%), como proveedor de fuerza de trabajo de la agricultura canadiense. Este mismo autor señala que durante 33 años se han contratado 134518 trabajadores; según González (2008: 64), entre 1989 y 2005, 2782 mujeres participaron en este programa.

\section{LOS MIGRANTES DE LA CRISIS}

En el Plan Municipal de Desarrollo 2008-2011 del municipio de Nativitas (H. Ayuntamiento de Nativitas s/f) se refiere que este municipio recibe más personas de las que salen a otras entidades del país: en 1990 la tasa neta de migración fue de 36.5 inmigrantes por cada 1000 habitantes. En 1995, 39.46 \% de los inmigrantes provenían de Puebla, 24.53 \% del Distrito Federal, $16.15 \%$ del estado de México, 12.67 \% de Hidalgo, $4.3 \%$ de Veracruz, $3.53 \%$ de Oaxaca y $9.29 \%$ no especificado. Del otro lado, $35.7 \%$ de quienes emigraron se dirigieron al Distrito Federal, $25.8 \%$ a Puebla, $22 \%$ al estado de México, $2.9 \%$ a Veracruz, $2.1 \%$ a Hidalgo y $11.5 \%$ no especificado.

Llama la atención que en este documento no se reporten migrantes internacionales; sin embargo, y a pesar de que González (2008: 68) ubica a Nativitas entre los municipios que tienen un índice de intensidad migratoria bajo, por información recabada en trabajo de campo sabemos que la migración laboral, mayoritariamente indocumentada, de nativiteños hacia Estados Unidos desde inicios de la década de los noventa, se ha convertido en una importante estrategia de sobrevivencia de muchos hogares y que hoy en día los jóvenes ven en esta migración una vía segura de movilidad social. 
La migración de nativiteños a Estados Unidos se remonta a los años del programa Bracero (1942-1964). Aunque la participación de poblaciones del centro y sur del país en ese programa no fue tan numerosa como la que se reporta en los estados que conforman la región histórica de la migración, ${ }^{170}$ se da cuenta de varones originarios de esas zonas que laboraron temporalmente en los campos agrícolas estadounidenses (Durand y Massey 2003). Para el caso de Tlaxcala, se anota que entre 1942 y 1948 alrededor de 3017 tlaxcaltecas trabajaron en Estados Unidos; en 1957 fueron 2 000; 300 en 1958; 1200 en 1961; 1700 en 1962; alrededor de 2200 en 1963; al menos 400 en 1964 y 1500 en $1965^{171}$ (Revilla 2007).

Desde 1950 algunos hombres en edades productivas oriundos de Nativitas fueron contratados como braceros. Al cancelarse este programa, en 1964, la migración hacia Estados Unidos en este municipio se contuvo - precisamente durante los años en que se inició un proceso de industrialización en la entidad que abrió un importante mercado laboral para los habitantes de la región- reiniciándose a fines de la década de los ochenta, cuando empezó un flujo migratorio indocumentado hacia aquel país, justamente cuando comenzó la flexibilización laboral y la desarticulación de las grandes naves industriales para dar paso a la industria de exportación, con lo que se constriñó la oferta laboral en la región y las condiciones de trabajo se precarizaron.

Como hemos anotado líneas arriba, la precariedad laboral en la entidad es una de las razones que explican la migración internacional contemporánea de tlaxcaltecas. El municipio de estudio no es la excepción. Ahí los bajos salarios y la inseguridad laboral son la norma: en el campo un peón gana 140 pesos al día y en las industrias de la región el salario de quienes ocupan un empleo temporal es de 350 pesos a la semana para quienes inician su contrato, aquellos que tienen mayor experiencia pueden llegar a ganar 3100 pesos quincenales. También se da cuenta de mujeres que realizan trabajo a domicilio para maquiladoras textiles, ${ }^{172}$ a quienes se les paga

${ }^{170}$ Conformada por los estados de Aguascalientes, Colima, Durango, Guanajuato, Jalisco, Michoacán, Nayarit, San Luis Potosí y Zacatecas (Durand y Massey 2003: 73).

${ }^{171}$ Llama la atención que Revilla (2007) proporcione cifras de braceros tlaxcaltecas para 1965, cuando el Programa fue cancelado unilateralmente por el gobierno estadounidense en 1964. No obstante, algunos exbraceros de la Mixteca poblana señalan que todavía en 1965 fueron reclutados como braceros (Cristian Alcalá, comunicación personal). Valdría la pena indagar cuál siguió siendo el papel del Estado mexicano en la contratación de trabajadores agrícolas en ese último año cuando, oficialmente, el convenio signado con el gobierno estadounidense ya se había cancelado.

${ }^{172}$ Las pequeñas maquiladoras y los talleres textiles se han convertido en el principal referente para la mano de obra agrícola y en una importante evidencia de las transformaciones rurales. Martínez y Vallejo 
a destajo (Héctor, entrevista realizada en Santa María Nativitas, Nativitas, junio de 2008). Esta situación pone de manifiesto una de las consecuencias de la restructuración del campo mexicano en las últimas décadas: los pobladores rurales se han visto obligados a diversificar aún más sus actividades. Al respecto, junto con Martínez y Vallejo (2011:36-37) podemos decir que:

La relocalización económica de sectores productivos como la industria, el comercio y los servicios inmobiliarios, entre otros, ha contribuido a la pluriactividad en la medida en que ofrecen nuevos empleos a la población. En algunos casos se puede constatar el éxito de algunos pobladores, quienes realmente han logrado obtener beneficios de estas transformaciones y tener acceso a una mejor calidad de vida. Sin embargo, estos casos son poco usuales; por lo general, la mayoría de los pobladores, hombres y mujeres, se emplea en trabajos poco calificados, mal remunerados y precarios.

El inicio de la migración contemporánea hacia Estados Unidos a fines de los años ochenta en este municipio tuvo como sostén las redes migratorias ${ }^{173}$ establecidas con familiares, conocidos y amigos de la comunidad de San Jerónimo Zacualpan, cabecera municipal de Zacualpan. ${ }^{174}$ Fueron pobladores de esa localidad los primeros en salir, "por eso los mejores polleros son de Zacualpan" (entrevista realizada en San Miguel del Milagro, Nativitas, julio de 2008). Oriundos de San Jerónimo se habían establecido desde una década atrás en New Haven, Connecticut, hacia donde dirigieron sus pasos los primeros nativiteños que cruzaron la frontera norte del país, en donde laboran como lavacoches, en invernaderos y restaurantes. Con el paso del tiempo sus destinos se han diversificado: hoy se les encuentra en Nueva York, donde los

(2011: 50) han señalado en su estudios sobre Los Altos de Morelos y la región de Ixtlahuaca-Atlacomulco en el estado de México que: "El trabajo en la maquila de confección está siendo una alternativa laboral para algunos miembros de las familias 'rurales', las que anteriormente basaban su economía en el cultivo de maíz y, que ante la crisis agrícola, han tenido que generar y adecuar nuevas estrategias de sobrevivencia. Estas estrategias socioeconómicas de sobrevivencia se enmarcan en un contexto de crisis agrícola, de un proceso de urbanización acelerado y disperso y de una reestructuración productiva de la región, es decir, no es un proceso aislado, sino que es consecuencia de la relación de diversos procesos que están transformando el medio 'rural.'

${ }^{173}$ Respecto a las redes sociales: "Fernando Herrera [...] señala que tienen como función facilitar información acerca de las posibilidades de empleo, traslado y sobrevivencia cotidiana, ayudar a resistir el costo del proceso (desempleo, traslado, mantenimiento de la familia), proporcionar contactos con posibles empleadores, hacer tolerable subjetivamente el choque cultural, ayudar a la construcción del imaginario o la representación colectiva, intervenir en el diseño de estrategias individuales y colectivas" (Canabal 2008: 14).

${ }^{174}$ De acuerdo con Conapo, el municipio de Zacualpan tiene un grado de intensidad migratoria medio (González 2008: 69). 
varones se ocupan en restaurantes y las mujeres en maquiladoras textiles; también algunos residen en Los Ángeles, ahí trabajan en los servicios y maquiladoras textiles; en Arizona, lugar en el que laboran en la agricultura y la jardinería; asimismo, se dice que hay gente de Santiago Michac -uno de los pueblos/ejidos del municipio de Nativitas- en Santa Fe, Nuevo México.

La inserción de los migrantes originarios de Nativitas en empleos de baja remuneración que requieren menores calificaciones y se caracterizan por su alta inestabilidad y ser de tiempo parcial responde al hecho de que quienes se ubican en la cima del mercado laboral, como resultado de su alto poder adquisitivo, generan una mayor demanda de trabajo en servicios calificados y de baja calificación que son realizados por poblaciones de inmigrantes, hombres y mujeres, en su gran mayoría jóvenes e indocumentados (Canales 2007: 86-87).

En consonancia con el sesgo masculino de la migración de tlaxcaltecas a Estados Unidos, cuya tasa de migración neta internacional masculina es tres veces mayor que la de las mujeres: -13.5 frente a -3.3 (Conapo 2010), en Nativitas quienes migran al vecino país del norte son fundamentalmente hombres solos. Sin embargo, en la actualidad empieza a ser notoria la migración de mujeres y familias. Al respecto, profesores y directivos de escuelas de secundaria y bachillerato del municipio señalan que el aumento de la deserción escolar en los últimos años es resultado del creciente número de padres que radican en Estados Unidos, quienes, al lograr cierta estabilidad, mandan buscar a esposas e hijos.

El endurecimiento de la política migratoria estadounidense después del 11 de septiembre de 2001 ha tenido graves consecuencias para los mexicanos que se dirigen a ese país en búsqueda de mejores condiciones de vida. Por un lado, el conjunto de estrategias y acciones de control y vigilancia de la frontera de Estados Unidos con México ha obligado a aquellos que pretenden internarse en aquel sin la documentación requerida a hacerlo por regiones más inhóspitas y riesgosas (Anguiano y Trejo 2007; Massey et al. 2009), lo que ha ocasionado, además de la muerte de cientos de migrantes, ${ }^{175}$ el aumento de los costos de los servicios de coyotes y polle-

${ }^{175}$ De acuerdo con cifras recientes, "[s]e estima que más de 4 mil migrantes han muerto atravesando el 'muro' (material y virtual) que separa México de Estados Unidos en el transcurso de los últimos 12 años, o sea 15 veces más que el número de personas muertas atravesando el muro de Berlín en sus 28 años de existencia. Desde el establecimiento de nuevas medidas de control de la frontera por las autoridades norteamericanas, a partir de 2001, el número de muertos ha aumentado dramáticamente para alcanzar la cifra de 473 para el 2005, de los cuales 260 [fallecieron] en el desierto de Arizona" (Federación Internacional de Derechos Humanos 2008: 5). 
ros. ${ }^{176}$ Asimismo, las deportaciones de mexicanos han ido en aumento tanto en la frontera como tierra adentro: en casas y departamentos, calles y lugares de trabajo ${ }^{177}$ (Passel y Cohn 2009).

Otro de los efectos de esta política migratoria ha sido la pérdida de circularidad de la migración de mexicanos (Bustamante 2006; Massey et al. 2009) y de tlaxcaltecas en particular: durante el quinquenio de 1997 a 2002, de 15067 tlaxcaltecas que habían migrado a Estados Unidos, sólo 4496 retornaron (Mendoza 2006: 127). Según Conapo (s/f), en $20101.25 \%$ de las viviendas tenían migrantes circulares del quinquenio anterior y $1.8 \%$ contaban con migrantes de retorno. $\mathrm{Al}$ respecto se dice en Nativitas que antes los migrantes regresaban con frecuencia, pero que hoy la mayoría sólo lo hace esporádicamente para visitar a la familia o asistir a fiestas comunitarias. "La gente que se fue ya no volvió, como la mayoría son indocumentados es muy complicado y caro", señala don Yucundo (entrevista realizada en San Miguel Xochitecatitla, Nativitas, octubre de 2010). También se dice que algunos nativiteños han regularizado su situación migratoria en el vecino país del norte: "Ha de haber como unas 400 gentes de Michac en Estados Unidos. Hay algunos que ya tienen papeles legales, van y vienen" (Alberto Espinoza, Santiago Michac, entrevista realizada en Nativitas, febrero de 2011).

Una consecuencia más de esta política migratoria y de la crisis financiera estadounidense es el decremento del flujo migratorio de mexicanos hacia Estados Unidos: según estimaciones de la Current Population Survey, de marzo de 2008 a marzo de 2009 se reportaron las cifras más bajas de migrantes mexicanos durante la década y sólo alrededor de la mitad del promedio de los dos años anteriores (Passel y Cohn 2009: 3). ${ }^{178}$ En correspondencia con esta situación, en Nativitas se comenta que en los últimos cinco años ha disminuido el número de personas que han emprendido el camino al norte.

${ }^{176} \mathrm{Al}$ respecto Durand (2011) anota: "Las medidas disuasivas emprendidas de manera explícita por Estados Unidos contemplaban incrementar los costos y los riesgos del cruce fronterizo. Y lo lograron. Ahora cuesta 60 mil pesos cruzar la frontera y eso equivale a mil días de salario mínimo, por lo que quedan descartados de la aventura migratoria todos aquellos que ganan el minisalario mexicano de 59 pesos diarios. Incluso aquellos que ganan dos, tres o cuatro salarios mínimos. El cálculo de costo-beneficio ya no sale a cuenta”.

${ }^{177}$ De acuerdo con Jorge Durand (2011), “en el año 2009 [las deportaciones] sumaron 973 mil, de las cuales técnicamente fueron deportados 393 mil y retornados 580 mil. Lo que se ha incrementado son las deportaciones formales (removals), muchas de migrantes con problemas legales. [...] por lo general [los migrantes deportados] no regresan a Estados Unidos porque se pueden enfrentar a la cárcel y a medidas coercitivas severas. Eso de que 'hoy me deportan y mañana me vuelvo a cruzar' es un asunto del pasado".

${ }^{178}$ Según Jorge Durand (2011), la migración indocumentada de mexicanos es la que ha bajado, pero ha crecido notablemente la migración legal: "los que han podido ir a Estados Unidos [en los últimos dos años] lo han hecho con visas H2A y H2B, para el trabajo agrícola y los servicios". 
Por último, vale la pena anotar que, al igual que en otras regiones en donde la migración a Estados Unidos se ha convertido en una de las más importantes estrategias de sobrevivencia de los grupos domésticos, en Nativitas irse al norte representa para muchos jóvenes una opción de vida más atractiva que la educación formal. Al respecto, profesores y autoridades municipales señalan que la migración de los padres hace más difícil que los jóvenes se interesen por la escuela: "Ahora los muchachos se van muy jóvenes, nomás salen de la secundaria, se casan y se van", comenta el presidente de comunidad de San Miguel del Milagro (entrevista realizada en San Miguel del Milagro, Nativitas, julio de 2008). Este hecho refleja la presencia en el municipio de una cultura a partir de la cual los niños y jóvenes ven la migración hacia Estados Unidos como la única fuente de éxito personal (París 2010: 140).

\section{REFLEXIONES FINALES}

Las autoridades gubernamentales estatales y federales han manejado un discurso que resalta el proceso de industrialización del estado de Tlaxcala a partir de los años sesenta, cuando se instalaron en su territorio corredores industriales que, desde sus cifras, han generado un importante número de empleos que no sólo satisface la demanda de las poblaciones locales, sino también ha atraído a poblaciones de entidades vecinas, logrando con ello un abatimiento sustancial de la emigración. Este discurso se manifiesta en las bajas cantidades de emigrantes internacionales que las instancias gubernamentales manejan. Si nos atenemos a esas cifras, podemos llegar a la conclusión de que en Tlaxcala, a diferencia de lo que acontece en el resto del país, el problema del desempleo y/o del empleo precario no existe, por lo que la migración allende las fronteras nacionales es poco significativa.

A contracorriente de estas cifras alegres, Mendoza (2006: 122) anota que entre 1993 y 1996, las altas tasas de desempleo características del Distrito Federal y los estados de Hidalgo, Jalisco, Tlaxcala, Veracruz, México y Zacatecas tendieron a incrementarse. Lo que, desde su punto de vista, sugería la existencia de una relación entre el desempleo de la fuerza de trabajo regional y los movimientos migratorios regionales de la población de esos estados.

Un acercamiento de corte etnográfico, como el que se ha llevado a cabo en la investigación de la cual forma parte este trabajo, nos permite percatarnos de que los empleos -tanto en la industria como en la agricultura- generados en el estado en las últimas décadas, se caracterizan, como en todo el país, por su precariedad y su limitado número. Asimismo, observamos que la reestructuración de la agricultura y la instalación de una industria de exportación en la región 
de estudio han contribuido al abandono de la agricultura como forma de vida y, por ende, a la adopción de diversas estrategias económicas, entre las que destaca la migración tanto al interior del país como allende las fronteras nacionales con fines laborales.

En este escenario, los pobladores de Nativitas tienden a valorar positivamente el trabajo en Estados Unidos y las conductas, actitudes y estilos de vida asociados con ello, dando a lugar a lo que se ha definido como "cultura migratoria" (Kandel y Massey 2002), la que, junto con la crisis económica que padece la mayoría de las familias de este municipio, ha desempeñado un papel importante en el incremento de la migración indocumentada de jóvenes hacia Estados Unidos. Lo referido por Conapo (2010) corrobora este hecho en el sentido de que en Tlaxcala, al igual que en la mayoría de las entidades del país, los jóvenes presentan una dinámica migratoria más intensa que el resto de la población.

Sin embargo, tenemos que tomar en consideración los importantes cambios que se aprecian en la dinámica migratoria de mexicanos hacia Estados Unidos desde el año de 2008. La aguda crisis del sistema financiero internacional ${ }^{179} \mathrm{y}$ el endurecimiento de la política migratoria estadounidense, han tenido efectos transcendentales para los trabajadores mexicanos radicados en Estados Unidos, ${ }^{180}$ quienes ante la inestabilidad de la economía mexicana vieron en la migración al norte una salida a la apremiante situación de sus familias.

El análisis de la forma como los nativiteños están encarando este nuevo escenario es una tarea pendiente que tendremos que llevar a cabo a la brevedad posible. Habrá que responder a importantes preguntas, entre las cuales destacan: ante los inmensos riesgos que entraña cruzar la frontera y la escasez de empleos en la unión americana, ¿cuáles son las estrategias que las familias rurales han adoptado para satisfacer sus necesidades? ¿La migración interna ha repuntado? ¿Los jóvenes se integran rápidamente al empleo informal o, en el peor de los casos, a la delincuencia organizada?

En tanto estos movimientos migratorios responden a las necesidades que impone la presente fase de acumulación capitalista, el gobierno mexicano, en sus diferentes niveles, tiene que dejar de negar una realidad que demanda ser reconocida y, en consecuencia, cambiar el rumbo de las políticas económicas de corte neoliberal adoptadas desde hace ya más de dos décadas. Políticas que han tenido un costo muy alto para la mayoría de los mexicanos, especialmente para los jóvenes, quienes, ante la carencia de oportunidades laborales y educativas en el país, deciden arries-

\footnotetext{
${ }^{179}$ Que ha ocasionado el desempleo de 200 millones de personas a nivel planetario (La Jornada 2011: 27).

${ }^{180}$ Entre los efectos destacan la pérdida del empleo, el descenso de las horas de trabajo, la imposibilidad de obtener una licencia de manejo y, por supuesto, el serio riesgo de ser deportados.
} 
garse a cruzar la frontera norte en búsqueda del "sueño americano" o integrarse a las bandas de la delincuencia organizada, aun a costa de sus propias vidas.

Para finalizar, tal como lo hemos anotado en otros trabajos (Salas y Rivermar 2011:155-156),

podemos decir que la migración y el uso de las remesas no está colaborando a reproducir estilos de vida campesina vinculados al trabajo de la tierra, por el contrario, los entrevistados que buscan un destino en la migración han declarado que vuelven o invierten su dinero en sus viviendas y como medio de vida esperan comprar maquinaria (tractores), un camión, poner una tienda, una carnicería, un pequeño negocio de comida, alguno reconoció la posibilidad de "comprar" una plaza de profesor. 


\title{
ESTRATEGIAS COMUNITARIAS EN NATIVITAS. UNA PLURALIDAD DE PROCESOS SOCIALES
}

\author{
Íñigo González de la Fuente
}

\section{INTRODUCCIÓN}

$\mathrm{E}$ 1 presente capítulo contiene -en forma de propuesta analítica- reflexiones sobre las formas de organización comunitaria en Jesús Tepactepec, localidad perteneciente al municipio de Nativitas, Tlaxcala. Durante el trabajo de campo en los veranos de 2008 a 2010 se ha prestado especial atención a diversos procesos que tienen como eje varias de las cuestiones que estudia la antropología política, concretamente, los denominados sistemas de cargos y su articulación con las formas constitucionales de participación política ${ }^{181}$ Llama la atención que la mayoría de textos sobre estos fenómenos están centrados en comunidades indígenas, frente a la escasa literatura que trata a grupos no indígenas (Bonfil 1988: 238; Robichaux 2007:

${ }^{181}$ En un trabajo anterior (González 2011) he señalado que, siendo Jesús Tepactepec una comunidad urbanizada e industrializada, se está dando una mutua influencia entre los usos y costumbres y las formas constitucionales de participación política. Por un lado, la constitucionalización de la presidencia de comunidad, cargo situado en la cúspide de la jerarquía político-religiosa, ha supuesto la fractura de tal jerarquía que confería antes el mayor prestigio a los fiscales; sin embargo, a pesar de tal modificación, el sistema de cargos ha salido reforzado en tanto la recompensa del salario ha activado la participación de una mayoría de miembros y, consecuentemente, ha reducido la disidencia de los posibles conversos, sobre todo de los miembros que pudieran sentirse atraídos en algún momento de sus vidas por confesiones religiosas distintas a la católica. Por otro lado, la elección a la manera de usos y costumbres asegura, en primer lugar, que los cargos más importantes (los que manejan presupuesto público) sean ocupados por personas con larga experiencia de servicio a la comunidad; en segundo lugar, la rotación anual permite que el acceso a los centros decisorios sea factible para una gran parte de los cooperantes. Es importante subrayar que la asamblea es un filtro, una estrategia para elegir vecinos con largo historial de servicio a la comunidad, lo que reduce el posible impacto de los partidos políticos en su papel de gestores del dinero público. 
25; Korsbaek 2009a: 49). Asimismo, a partir de la experiencia de campo en Jesús Tepactepec se corrobora que, en esta comunidad, la cual puede ser definida como mestiza, ${ }^{182}$ las características propias del sistema de $\operatorname{cargos}^{183}$ están presentes e, incluso, algunas se encuentran fortalecidas.

En este trabajo se plantea una propuesta de análisis antropológico del sistema de cargos que incluye tanto a comunidades indígenas como no indígenas, reconociendo su origen en "la tradición cultural mesoamericana" (Robichaux 2007: 27). En ningún caso se intenta hacer una recopilación de rasgos que se puedan encontrar en cualquier comunidad, tal como hace Korsbaek con su mencionado modelo del "típico sistema de cargos"; más bien, partiendo del reconocimiento del sistema de cargos como una institución esencialmente heterogénea, se sugiere estudiarlo como estructura empírica que se puede observar directamente en el campo. La hipótesis principal de este trabajo plantea que el sistema de cargos alimenta una serie de mecanismos que, en sí mismos, generan prácticas ${ }^{184}$ protagonizadas por los miembros de la comunidad con las siguientes características: permiten entrar y "jugar" al mayor número del total de agentes en una pluralidad de campos; se repiten con mucha frecuencia; sus "reglas de juego" aseguran la distribución rotatoria de las posiciones sociales (aunque solamente de determinados grupos de agentes) y, por tanto, la de los diferentes tipos de capital cuya posesión condiciona el acceso a las recompensas específicas de cada campo (se institucionaliza que la distancia social entre agentes cambie regularmente).

Esta propuesta analítica va a estar estructurada en tres bloques a lo largo del texto. En primer lugar, como marco referencial del estudio se señala la intención de ubicar las prácticas

${ }^{182}$ Utilizando el continuum indio-mestizo de Robichaux (2007: 23), el "polo mestizo" se identifica con "la cultura mexicana nacional".

${ }^{183}$ Los elementos propios de lo que se conoce como el "típico sistema de cargos" son, según Korsbaek (2009a: 41-43): un número de oficios claramente definidos, rotación entre los miembros de la comunidad, orden jerárquico de los cargos, comprende a todos o casi todos los miembros, la no remuneración del servicio que es compensado en forma de prestigio y dos jerarquías separadas, la política y la religiosa.

${ }^{184}$ Las prácticas remiten al esquema para el análisis social de Bourdieu en cuanto a relación dialéctica de las estructuras y los habitus (García Inda 2001: 13; Pinto 2002: 58). El autor trata de superar la oposición entre subjetivismo y objetivismo mediante una construcción analítica que asocia inseparablemente estructuras objetivas - las posiciones probables de los agentes definidas de acuerdo con la posesión de diferentes recursos o especies de capital (económico, cultural, social, simbólico), posesión que condiciona el acceso a los provechos específicos que están en juego en el espacio social- y estructuras incorporadas -las disposiciones duraderas de los agentes "adquiridas por medio de los aprendizajes asociados a una prolongada confrontación con las regularidades del campo" históricamente constituidas (Bourdieu 2001: 22; 2009: 86). 
registradas en torno al sistema de cargos en un continuum de disposiciones capaces de generar comportamientos individualistas en uno de los polos y, en el otro, habitus de conductas colectivistas. En segundo lugar, se apuesta por la explicitación del concepto de comunidad como elemento básico para la observación e interpretación de los sistemas de cargos. Por último, se propone la idea del proyecto comunitario como denominador común de lo observado y leído en cuanto a sistemas de cargos se refiere. Se elude explícitamente el debate sobre las diversas interpretaciones que desde la antropología se han hecho del sistema de cargos, ${ }^{185}$ aunque, lógicamente, aparecerán a lo largo del texto.

\section{EL CONTINNUM INDIVIDUO-COLECTIVO}

A nivel intercultural y holístico se discute en torno a los conceptos de comunidad-individuo (colectivismo-individualismo), tratando de no caer en la idealización ${ }^{186}$ y confusión ${ }^{187}$ de la primera; en este sentido, estamos hablando de "las maneras humanas de convivir organizadamente" (Delgado 2009: 51). Siguiendo a Bonfil (2003: 57 y ss.), podemos decir que uno de los principales objetivos de una comunidad es llevar una vida autosuficiente, "con autonomía".

${ }^{185}$ Sin pretensión de exhaustividad, Korsbaek (2009b: 376-377) y Castro (2000: 503-511) destacan varios modelos teóricos para la explicación del sistema de cargos de tradición mesoamericana: el modelo de nivelamiento -discutido por autores como Eric Wolf, June Nash, Pedro Carrasco, Fernando Cámara, Manning Nash, James Dow, entre otros-, el de estratificación -que sigue las aportaciones de Frank Cancian y de Marvin Harris-, el de redistribución -encabezado por Aguirre Beltrán y Ángel Palerm-, el del control social -planteado en los trabajos de Sol Tax, Ricardo Pozas, María Ana Portal, entre otros-, el de los impactos externos -donde destacan los estudios de Jan Rus y Robert Wasserstrom, Waldemar R. Smith, Hugo Nutini y Barry Isaac, James B. Greenberg-, el de la modernización -en el cual se ubica Bonfil Batalla-, el de la educación informal -sugerido por Ulrich Köhler- y el histórico -donde se posicionan varios de los autores anteriormente citados.

${ }^{186}$ La ideología del "comunalismo moderno" señala la oposición entre comunidad e individuo, "generalmente anteponiendo la comunidad al individuo". En este sentido, se comparte la defensa que Zárate (2009: 69) hace de "una modernidad comunitaria" que acepte "la posibilidad de comunidades desterritorializadas [y] del individualismo al interior de la comunidad conviviendo con el todo comunal".

${ }^{187}$ Delgado (2009: 53) reclama que no se puede confundir "lo común" con "lo colectivo". Lo común "puede ser lo de todos, [...] aquello con lo que todos comulgan [...], y que encierra a sus componentes [de la comunidad] en un orden cosmovisional y organizativo del que ni deben ni sabrían escapar". Por el contrario, lo colectivo "se asocia con la idea de una reunión de individuos que toman consciencia de lo conveniente de su copresencia" y "se organiza a partir de la comunicación [intercambio comunicacional]". 
Para lograr esto, Bonfil destaca, entre otros elementos, la importancia de fomentar relaciones familiares y de comunidad "que permitan ordenar la cooperación de un mayor número de individuos". Esta "continua relación colectiva" tiene una fundamentación en la práctica: en un determinado espacio social, una dinámica de relaciones caracterizada porque 1) todos los agentes entran y "juegan" en ese espacio social, 2) sus posiciones sociales varían por "contrato" 188 entre todos ellos, 3) esta variación se produce frecuentemente, configura un habitus capaz de generar conductas orientadas a la búsqueda del beneficio de la comunidad. En esta dirección, el sistema de cargos sería la estructura que produce y reproduce "la intensa convivencia”. Aunque se insistirá en esta idea a lo largo del capítulo con múltiples ejemplos, se adelanta brevemente uno de ellos: la institución de la fiesta se puede caracterizar como la que propone frecuentes prácticas -frecuencia propiciada por el calendario ritual familiar y comunitario- que cuentan con la participación de una buena parte de los miembros de una familia extensa y/o comunidad, siendo, en ocasiones, unos anfitriones y otros invitados y viceversa, además de otros papeles que se pudieran desempeñar.

En palabras de Bonfil (2003: 68), existe una "perspectiva individualista y acumulativa" ligada a la sociedad occidental capitalista, cuyas leyes son "el cálculo interesado y la competencia sin límites por la ganancia" (Bourdieu 2001: 20). Frente a ella, lo comunitario se fomenta con la relación continua y frecuente entre los miembros de un grupo. Sin caer en esta posición dicotómica, Salas, Rivermar y Velasco (2011:13) prefieren hablar de coexistencia de las disposiciones modeladas por el universo precapitalista - "donde predomina el espíritu de reciprocidad, sociabilidad y espontaneidad" - y las disposiciones capitalistas fundadas en "criterios de cálculo e interés". Se puede explicitar todo esto mediante la ubicación de los fenómenos sociales observados en un continuum de comportamientos tendentes al individualismo y a lo colectivo. ${ }^{189}$

Las disposiciones adquiridas por los agentes estarán impregnadas de los presupuestos individualistas si las prácticas que se repiten incluyen cada vez menos vecinos, en intervalos de

${ }^{188}$ Este concepto alude a "acuerdos mínimos pero suficientes" entre los miembros que, "por supuesto [...] son o pueden ser muy distintos entre sí y hasta incompatibles” (Delgado 2009: 55).

${ }^{189}$ Esta propuesta de continuum pretende ser útil para calibrar las posibles transformaciones en las instituciones comunitarias derivadas de los procesos ligados a la modernización. Tal propuesta no liga, como hacen Nutini e Isaac (citados en Robichaux 2007: 23), comunidades "secularizadas" al polo mestizo, sino que asocia determinados mecanismos institucionales a lo colectivo, frente a otros mecanismos fomentadores de comportamientos individualistas. La propuesta tampoco asume la conclusión de Cámara (2009: 398) de que las "comunidades centrípetas [...] están constituidas por habitantes culturalmente indígenas. [...] En contrario, las comunidades centrífugas, compuestas de buen número de ladinos y/o mestizos [...] aspiran al cambio (modernización y urbanización)”. 
tiempo cada vez mayores, y siempre con idéntica distancia social entre agentes; al contrario, un habitus colectivo se fomenta en el ámbito de la práctica con relaciones cuya lógica sea la presencia frecuente y continua de todos los agentes que comparten un espacio social. ${ }^{190} \mathrm{En}$ este sentido, se plantea la hipótesis de que una de las formas estructurales con las que las sociedades locales de tradición mesoamericana aseguran un habitus colectivista es el sistema de cargos. En todo caso, la propuesta aquí incluida permite registrar una pluralidad de procesos sociales cuyas trayectorias se mueven -en función de cada campo social- entre la revitalización de lo colectivo-local (Salas et al. 2011: 19; Rivermar 2008: 243) y la imposición paulatina del exterior-global.

\section{LA COMUNIDAD}

Una vez enmarcado el presente análisis en el continuum individuo-comunidad, el siguiente paso es definir de forma nítida y concisa qué entenderemos cuando hablamos de comunidad. ${ }^{191}$ Korsbaek (2009a: 32) es uno de los autores que, a la hora de involucrarse en el estudio de los sistemas de cargos, se ha preocupado por definir la categoría de comunidad. Según este autor, se trata de "encontrar una definición precisa y al mismo tiempo operativa del concepto de comunidad".

Una comunidad es "un grupo de gentes en estrecha contigüidad por lo regular en un lugar con fronteras geográficas o políticas reconocidas” (Korsbaek 2009a: 33). En otra obra, Korsbaek define las "seis características" que conforman una comunidad: ${ }^{122}$ "[es...] un proceso [1] llevado a cabo por una colectividad [2], frecuentemente pero no siempre dentro de un marco territorial [3], que tiene coherencia horizontal [4], coherencia vertical [5] e historia [6]" (Korsbaek

${ }^{190} \mathrm{El}$ ejemplo de la desaparición en los últimos años de la institución de la "faena" -la cual regulaba sistemáticamente las prácticas laborales colectivas- en Jesús Tepactepec, la cual se describirá con mayor profundidad en los siguientes epígrafes, confirma tal apreciación: la progresiva asalarización -que lleva pareja el contrato individualizado- de una buena parte de vecinos de Tepactepec ha reducido tales prácticas.

${ }^{191}$ Para una discusión contemporánea del concepto de comunidad, véase Delgado (2009) y Cámara (2009).

${ }^{192}$ Bartolomé (2009: 105-6) propone diez características constitutivas de las comunidades actuales: un territorio asumido como propio [1], el control por parte de los miembros del usufructo de ese espacio [2], una organización política propia [3], cierto nivel de control sobre el proceso de producción [4], una articulación con el mercado de trabajo que conviva con las formas económicas redistributivas y de reciprocidad [5], existencia del trabajo colectivo [6], la posibilidad de vincularse con el Estado de manera colectiva [7], compartir una historia [8], constituir una comunidad ritual en torno a un santo patrono [9] y compartir una religiosidad asumida como propia más allá de las confesiones dominantes [10]. 
2005: 134). Añade que, dando el mencionado carácter operativo al término, lo que las diferencia de las no comunidades no es el tamaño de su población ni tampoco si poseen o no una historia compartida, sino que dispongan de un "proyecto social" en el sentido de "cumplir obligaciones para con la comunidad". Así pues, "el sistema de cargos es la institución que se presta a la formulación de un proyecto social, creando así una comunidad" (Korsback 2009a: 36). Por su parte, Sandoval (2005: 266) anota que los papeles desempeñados en una comunidad mazahua fortalecen el sistema de cargos "con el cumplimiento de tareas y con la participación de todos, haciendo un sistema interactuante y coherente [...] en constante retroalimentación".

A partir de estas propuestas, en este trabajo, cuando se habla de comunidad se entiende al "grupo social articulado por relaciones de cooperación y conflicto" (Muñoz 2008: 175), generalmente territorializado, cuya característica principal es que la mayoría de sus relaciones están canalizadas por instituciones ${ }^{193}$ que promueven la relación directa y constante a todos los niveles socioculturales entre el mayor número de agentes del grupo y con la mayor frecuencia posible -contacto que no deriva necesariamente en una participación más activa de los individuos. ${ }^{194}$ Todo ello sin perder de vista las limitaciones de acceso a determinadas formas de capital que se juegan en el campo: algunas de ellas-las que condicionan el acceso a los provechos específicos e institucionalizan las posiciones inferiores o superiores de los agentes- están vetadas para ciertos grupos de agentes de la comunidad según género, ${ }^{195}$ edad, estado civil, lugar de nacimiento, tipo de propiedad, confesión religiosa, algunas limitaciones físicas o enfermedades como el alcoholismo, entre otros.

Desde esta perspectiva, se parte de la hipótesis de que el sistema de cargos estará presente de forma vigorosa en grupos humanos que quieren y, casi siempre, necesitan ser comunidad, esto es, que cuentan con "proyectos comunitarios". En palabras de Delgado (2009: 56), los componentes de una comunidad quieren serlo cuando se ponen "de acuerdo en lo más importante,

${ }^{193}$ Con el objetivo de facilitar el análisis, se generan categorías de instituciones políticas, sociales, económicas y religiosas; sin embargo, se asume que se podría generar mayor número de éstas y que, en todo caso, tales instituciones funcionan interrelacionadas.

${ }^{194}$ En este sentido, siguiendo a Sullings (2004), se considera que las instituciones sociales -incluidas las comunitarias aquí estudiadas- deben tratar de garantizar "que todo el que quiera pueda participar", en contraposición a garantizar "que todos participen", esto último más ligado a la "vocación por la actividad social" de los ciudadanos más activos.

${ }^{195}$ Existe una incipiente literatura antropológica que prioriza el estudio de los sistemas de cargos desde una perspectiva de género. Trabajos como los de Vizcarra (2002) y Ochoa (2008) destacan la manifiesta dominación androcéntrica que se refleja en la práctica social del sistema de cargos. 
convivir. Lo que ocurre es que ese proyecto [...] no puede ocultar la existencia de estructuras sociales hechas de desigualdad e injusticia".

\section{EL PROYECTO COMUNITARIO}

De acuerdo con nuestro análisis, lo que posibilita que el sistema de cargos esté fuertemente presente en numerosas regiones del territorio mexicano es que sus protagonistas persigan implícita y explícitamente un proyecto de comunidad, esto es, que los miembros de la comunidad -habitantes por lo regular de un lugar con fronteras geográficas o políticas reconocidas ${ }^{196}$ - se doten de instituciones -incluido el sistema de cargos- encaminadas a "garantizarles diversos proyectos comunitarios", como "los dones de vida, salud, bienestar, trabajo, buenas cosechas, lluvias oportunas y suficientes, etc." (Topete 2005: 293).

En este sentido, en tanto la población de Jesús Tepactepec es mayoritariamente mestiza, ${ }^{197}$ destaca que lo que tiene en común con las sociedades indígenas y que hace que todas ellas mantengan con cierto vigor las formas de organización comunitaria es que, efectivamente, sus miembros comparten un proyecto comunitario que se expresa en el sistema de cargos. ${ }^{198}$ Asimismo, se considera relevante el estudio en comunidades como Jesús Tepactepec, la cual se caracteriza por ser una localidad urbanizada, culturalmente heterogénea y notablemente influida por los procesos globales, en el sentido de que ha dejado atrás un pasado agrario centrado en la figura del ejido colectivo que ordenaba la vida económica y era el eje articulador de los procesos sociopolíticos, para dar lugar a una sociedad vinculada a mercados de trabajo flexibles y precarios en los sectores industriales, del comercio y los servicios. Resulta funda-

${ }^{196}$ En torno a la territorialidad como base material de la vida comunitaria, Salas, Rivermar y Velasco (2011: 17-18) señalan el concepto de "comunidad transnacional" para poner en evidencia que, reconociendo que una parte importante de la población rural mexicana está involucrada en flujos migratorios internacionales, la consecuente rearticulación de las relaciones sociales "se ha gestado sobre la base de reglas de juego planteadas por el grueso de la comunidad" de origen.

${ }^{197}$ Afirmación que se sustenta en el criterio lingüístico para definir la adscripción étnica de la población: sólo 98 de los 18463 habitantes (0.53 \%) de 5 y más años que habitaban el municipio de Nativitas en 2000 hablaban náhuatl (INEGi 2003: 25).

${ }^{198}$ Robichaux (2007: 26) refrenda tal percepción de los sistemas de cargos en el suroeste de Tlaxcala: "las estructuras organizativas comunitarias [...] siguen siendo fuertes, son capaces de reproducirse e incluso de expandirse y florecer". 
mental prestar atención a los proyectos comunitarios de poblaciones incorporadas al trabajo industrial y que participan de la economía capitalista. Estos actores sociales redefinen y manipulan las instituciones comunitarias "en función de los conflictos y luchas que mantienen tanto hacia el interior como hacia el exterior de la comunidad" (Zárate 2009: 83).

El objetivo que se persigue en esta investigación es encontrar un mínimo común denominador que nos permita definir un grupo social como comunidad. Este mínimo es justamente que los miembros del grupo quieran y necesiten ser comunidad, que compartan un proyecto comunitario o, lo que es lo mismo, que sus disposiciones estructuren y generen prácticas cuyas propiedades sean simultáneamente la pluralidad, la totalidad, la frecuencia y la rotación. ${ }^{199}$ De acuerdo con este objetivo, la hipótesis principal que ha guiado este trabajo es que un grupo social local tiene proyecto comunitario cuando una gran parte de sus instituciones trabajan como mecanismos (en los campos político, económico, religioso) tendentes, en mayor o menor medida y de acuerdo con variables, a: 1) potenciar prácticas densamente pobladas (variable pluralidad-tendencia al muchos); 2) asegurar la convocatoria del total de miembros de la comunidad en los campos puestos en juego (variable totalidad-tendencia al muchos de todos); 3) fomentar la mayor frecuencia posible de tales prácticas (variable frecuencia-tendencia al menor intervalo temporal posible entre una práctica y otra); 4) propiciar el intercambio de posiciones entre agentes con la frecuencia que haya sido consensuada por el grupo (variable rotación-tendencia a aumentar las posibilidades de que todos los que están legitimados para jugar ${ }^{200}$ puedan ocupar -a lo largo de su historia comunitaria particular- el mayor número de posiciones presentes en el espacio social).

A partir de tal hipótesis, y sin perder de vista el continuum individuo-colectivo, se presentan los siguientes enunciados, a través de los cuales se ha ordenado la información que se expone a continuación: 1) en determinados campos del espacio social que configura la comunidad de Jesús Tepactepec, un habitus colectivista ${ }^{201}$ tendrá más posibilidades de imponerse a un habitus individualista en la medida en que todos los ámbitos de la práctica de ese campo pre-

${ }^{199}$ Pluralidad se refiere a la acepción de "multitud, número grande de algunas cosas, o el mayor número de ellas". Totalidad se refiere a la acepción de "conjunto de todas las cosas o personas que forman una clase o especie". Frecuencia se refiere a la acepción de "repetición mayor o menor de un acto o un suceso" (RAE: 2001).

${ }^{200} \mathrm{La}$ brevedad de estas páginas impide profundizar en la hipótesis -implícita en la sociología de Bourdieu- del sistema de cargos como estructura de violencia simbólica que legitima las relaciones de dominación y la distribución asimétrica de posiciones de poder existentes en los más variados campos (Sidicaro 2008).

${ }^{201}$ Que los comportamientos económicos, políticos, sociales y religiosos de esa comunidad tiendan hacia el reforzamiento de lo colectivo (el beneficio material y simbólico del conjunto frente al beneficio del individuo). 
senten simultáneamente regularidades en cuanto a densidad poblacional (muchos agentes), capacidad de convocatoria (todos los agentes), regularidad en la convocatoria (alta frecuencia) y equilibrio en la distribución de posiciones sociales (rotación asociada a la alta frecuencia); ${ }^{202}$ 2) por el contrario, unas disposiciones individualistas tendrán más posibilidades de imponerse a unas que busquen el beneficio colectivo en la medida que sus prácticas incidan en el hábito y la repetición de relaciones que, coetáneamente, sean escasa y parcialmente pobladas (pocos agentes entran y "juegan"), irregularmente convocadas (baja frecuencia) y con un fuerte desajuste en la distribución de las diferentes especies de capital (posiciones invariables).

Desde luego, estas hipótesis parten del hecho -ya mencionado- de que las comunidades rurales pueden y quieren ser autosuficientes, compartir un proyecto social; en este sentido, la institución que asegura sistemáticamente esa tendencia es el sistema de cargos. Si bien es cierto que, como se verá más adelante, las embestidas modernizadoras -que predominantemente fomentan el individualismo y, en la práctica, reducen la continuidad de los escenarios plurales y totales-, están dando lugar a diversos procesos en función del campo donde entren en juego: por un lado, algunas instituciones comunitarias han ido perdiendo vitalidad poco a poco -incluso hasta desaparecer- y, paralelamente, otras se han mantenido y fortalecido. En el caso concreto de Jesús Tepactepec, en trabajo de campo los habitantes nos han comentado del desuso de la "faena" 203 y el "tequihua" ${ }^{204}$ hace apenas quince años, ${ }^{205}$ mientras que las formas asamblearias de elección siguen en completa vigencia.

${ }^{202}$ Resulta clarificador el comentario de un habitante de Jesús Tepactepec, quien afirma que, producto de la relación continua con los miembros de la comunidad, todos "nos echamos la mano los unos a los otros. [...] Yo soy director de escuela y ayudo a los vecinos a colocar a sus hijos, y ellos me ayudan a mí en otros aspectos" (entrevista realizada en Jesús Tepactepec, Nativitas, julio 2010).

${ }^{203}$ La faena o tequio -entre otros términos- es la expresión utilizada por los pueblos originarios para referirse al trabajo comunitario o trabajo colectivo. Incluye "desde la repartición de tareas o cargos para la realización de festividades, hasta la realización de trabajos que requieren de la participación de numerosas personas en un mismo tiempo" (Romero 2009: 57).

${ }^{204}$ Davinson y Sam (2003: 74) registran en el municipio de Santa Apolonia Teacalco -limítrofe con el de Nativitas- el "tequihua" como la "autoridad" económicamente elegida -libre y directa- encargada de notificar cualquier comunicación surgida de la asamblea tanto a nivel colectivo -el contenido de la comunicación afecta a todos los vecinos de la comunidad- como a nivel individual -por ejemplo, la comunicación de embargo.

${ }^{205}$ Un miembro de la fiscalía de Jesús Tepactepec pensaba que tales instituciones estaban desapareciendo debido a las "estrategias del gobierno, las cuales buscan dividirnos dándonos ayudas para que nos peleemos por ellas" (entrevista realizada en Jesús Tepactepec, Nativitas, julio 2010). 
Interesa entonces caracterizar el sistema de cargos como conjunto de estrategias que: asegura -a nivel económico, político, religioso- prácticas en las cuales una mayoría de agentes de un grupo social puedan participar activamente; que tales prácticas se ejecuten con la mayor frecuencia posible; y que tal mayoría tenga la seguridad de que, tarde o temprano, podrá ocupar las distintas posiciones del campo, estén o no estos papeles ubicados en la cúspide jerárquica. Las razones que empujan al proyecto de comunidad son varias y han sido profusamente estudiadas por la antropología, aunque finalmente lo que interesa destacar en el presente texto es el análisis del sistema de cargos como mecanismo que genera y mantiene estrategias que fomentan lo colectivo.

\section{ESTRATEGIAS DE LO COLECTIVO}

Para tratar de corroborar las hipótesis sugeridas en las páginas anteriores, se han seleccionado varios de los mecanismos institucionales que han sido analizados por la literatura antropológica y que hemos registrado etnográficamente en Jesús Tepactepec y otras comunidades de Nativitas ${ }^{206}$ en las que el sistema de cargos continúa vigente. Con el objetivo de facilitar el análisis, hemos categorizado esos mecanismos como presentes en cuatro campos: políticojudicial, económico, religioso y social, los cuales están fuertemente interrelacionados entre sí; en este sentido, el sistema de cargos es fundamental ya que potencia varias de estas estrategias paralela, simultánea y frecuentemente.

De esta manera, todos los procesos "de esos pequeños mundos de sociabilidad sobre los cuales se construye la comunidad” (Muñoz 2008: 175) tratan de responder a la pregunta de cómo el sistema de cargos vigoriza lo colectivo frente a lo individual -restricción, pero no cancelación, del interés individual- y cómo se mantiene el proyecto comunitario. En la práctica, se sostiene que tales estrategias tienen en común que, con el sistema de cargos como vehículo y principal garante, aseguran sistemáticamente la relación frecuente y el intercambio de posiciones entre el mayor número posible de miembros de una comunidad. En todo caso, también se presta atención a las posibles embestidas globalizadoras que estén sufriendo las estrategias de lo colectivo, las cuales, por un lado, pueden llevar al debilitamiento y desaparición de éstas o, por otro, derivar en una articulación de los mecanismos tradicionales con las instituciones moder-

${ }^{206}$ El municipio de Nativitas cuenta con 16 localidades (trece pueblos-ejidos; un barrio; dos colonias exhaciendas) que funcionan mediante la figura de "presidente de comunidad". 
nizadoras de manera que aquellos salgan fortalecidos. ${ }^{207}$ Finalmente, su desaparición no implica que no existan tales estrategias de lo colectivo, sino que, precisamente, habla de una imprevisibilidad en la configuración de habitus ${ }^{208}$ con dispares resultados.

\section{CAMPO POLITICO-JUDICIAL}

Son cuatro los mecanismos institucionales político-judiciales sobre los que se trabaja con las variables de pluralidad, totalidad, frecuencia y rotación: las asambleas, el cargo político de "presidente de comunidad", la comandancia y el embargo. Todas las posibles prácticas generadas por tales mecanismos están garantizadas, como se describirá a continuación, a través del sistema de cargos, siendo el primero de ellos la forma de elección de los oficios, los dos siguientes son cargos propiamente dichos y el último, un sistema judicial tradicional asociado a varios cargos.

Las asambleas son el mecanismo de consulta, debate, decisión y elección de la comunidad de Jesús Tepactepec y se encuentra presente en otras numerosas regiones de México. Pueden categorizarse en asambleas ordinarias -incluida la asamblea general- y asambleas extraordinarias. Las primeras son un espacio donde participa una mayoría de la comunidad tanto en la toma de decisiones como en la organización de numerosas actividades -incluidas las de los campos político y religioso- que competen a toda la comunidad. En Tepactepec es la asamblea general la que, cada 31 de diciembre, propone de entre sus miembros, en primer lugar, a tres candidatos a presidente, para después elegir por mayoría simple a uno de ellos (situándose los asambleístas detrás del candidato al que apoyan), quien no puede rechazar su elección. Los dos candidatos no elegidos podrán serlo en futuras convocatorias. Las asambleas extraordinarias se convocan para situaciones que no pueden esperar al ciclo ordinario -anual en caso de la asamblea general-, aunque no suelen ser habituales; se convocan cuando la situación roza lo insostenible. ${ }^{209}$

${ }^{207}$ Se asume que el estudio del impacto de los fenómenos ligados a la globalización en las instituciones comunitarias demanda un análisis pormenorizado de cada caso. Aun así, se entiende que merece la pena relacionar, como se hace a continuación, cada mecanismo con fenómenos sobradamente trabajados por las ciencias sociales.

${ }^{208}$ Está implícita la idea de "circularidad" del habitus, en el sentido de que "a la regla sucede la estrategia", es decir, al mecanismo institucional productor de regularidades objetivas de comportamiento -sistema de cargos- sucede el sistema de disposiciones - prácticas colectivistas- que "se ajusta de manera desigual a otras condiciones" (Pinto 2002: 44-45).

${ }^{209}$ Una de las últimas asambleas extraordinarias de Jesús Tepactepec tuvo lugar en 2010 y fue promovida para relegar del cargo de fiscal a su ocupante, a quien se le acusó de haber cometido un desfalco en las cuentas de la festividad principal. 
Desde esta perspectiva, la asamblea general se concibe como un conjunto de relaciones del espacio social comunitario en el cual, cada año (variable frecuencia), un mayor número del conjunto de miembros (variables pluralidad y totalidad) puede opinar, elegir, ser elegido y decidir sobre las cuestiones que afectan a la comunidad tanto a nivel político como religioso y que, además, tales agentes pueden participar activamente en las diferentes posiciones que se ponen en juego: orador, candidato elegible, candidato elegido, elector, organizador, vigilante, etc. (variable rotación).

El mecanismo asambleario recibe influencias modernizadoras desde las formas constitucionales de elección, principalmente del voto nominal secreto como mecanismo individualizado de elección. En el caso de Tepactepec, se puede afirmar que ambos mecanismos se articulan positivamente e, incluso, comentan en el pueblo que en los últimos años el número de participantes en las asambleas ha crecido debido a que los cargos principales (fiscal y presidente auxiliar) manejan presupuestos considerables. ${ }^{210} \mathrm{~A}$ pesar de ello, la mayoría de las veces, quienes ocupan los cargos deben abandonar, por el periodo correspondiente, su trabajo y muchas de sus actividades productivas cotidianas.

En este sentido, el cargo político de "presidente municipal auxiliar" -segundo mecanismo institucional referido- se encarga tradicionalmente de la esfera cívica de la comunidad. Este cargo se constituye, politológicamente hablando, como centro público de decisión política, esto es, como órgano representativo y/o ejecutivo en el cual se formulan, elaboran y aplican "las opciones genuinamente cruciales que sí afectarán inevitablemente la vida del conjunto de la comunidad política" (Spencer 2004: 60). A nivel local, estos centros implican "disputas entre las distintas facciones [...] y, quizás, conflictos entre los distintos titulares de los cargos locales, como en el caso de las autoridades seculares y las religiosas" (Gledhill 2000: 201).

Siguiendo los pasos de la presente investigación, se puede afirmar que tal cargo puede ser ocupado anualmente (frecuencia) por todos aquellos miembros que participen activamente en las actividades de la comunidad (totalidad y pluralidad): se selecciona aquel candidato que tiene todo un historial de cargos menores en la comunidad, sistema que asegura la rotación de

${ }^{210}$ Aguirre Beltrán (1991: 39) defiende la mayor democratización que históricamente representan las formas de gobierno indígena frente a los patrones culturales occidentales, debido a que "un número mayor de individuos desempeñaban, en el tiempo, funciones de gobierno". En el caso concreto de esta investigación, no se pretende discutir sobre si las formas colectivas son más democráticas que las individuales, interesa rescatar de Aguirre la concreta vinculación entre comunidad y participación de un mayor número de miembros. Explicitado en hipótesis, cuanto mayor número de individuos miembros de un grupo interactúen -y con la mayor frecuencia posible-, mayores posibilidades habrá de que sus comportamientos tiendan al beneficio colectivo. 
posiciones en las sucesivas prácticas dadas en la comunidad a lo largo de su existencia. Este filtro asambleario reduce el posible impacto de los partidos políticos tanto en la selección de candidatos afines como en su papel de gestores del dinero público. Uno de los últimos casos que vienen a demostrar este dispositivo de control es el de un exfiscal de Tepactepec, quien explícitamente quiso llegar de inmediato a presidente de comunidad, lo cual provocó que la asamblea sancionara sus pretensiones eligiéndole para el cargo menor de campanero, truncando así, momentáneamente -o quizás para siempre-, sus ambiciones políticas. En todo caso, los habitantes también reconocen que algunos asambleístas eligen candidatos en función de su pertenencia partidaria, dándose la tendencia a elegir presidentes de comunidad afines al alcalde en turno, con la idea que han expresado algunos pobladores de que es más "conveniente para el pueblo".

En otro orden de cosas, el cargo político principal está siendo transformado formalmente por la asignación de un presupuesto público, el cual no ha supuesto en Tepactepec un debilitamiento del puesto sino más bien lo contrario: ha activado la participación de un mayor número de miembros. En todo caso, la presidencia de comunidad ha controlado constantemente un presupuesto considerable debido a la renta de espacios para la colocación de pequeños puestos comerciales durante las ferias más importantes de la comunidad.

Siguiendo con el análisis del campo político-judicial comunitario, el cargo de "comandante" está presente en numerosas localidades como figura a la que se encomienda la vigilancia y seguridad pública de la comunidad, especialmente del presidente auxiliar. ${ }^{211}$ Se trata de un cargo menor que puede ser ocupado anualmente por alguno de los miembros activos de la comunidad para el cuidado de todos: "los policías somos todos", comenta el presidente de la contigua comunidad de San Miguel del Milagro (entrevista realizada en San Miguel del Milagro, Nativitas, julio de 2008). Usualmente, estos policías-comandantes son los encargados de distribuir los citatorios a cada jefe de familia y evitar que ningún miembro quede sin ser avisado de, por ejemplo, las asambleas.

Aunque se trata de un mecanismo excepcional, Davinson y Sam (2003) describen como elemento político-judicial la práctica del embargo en Santa Apolonia Teacalco, ${ }^{212}$ comunidad contigua a Jesús Tepactepec. Se le denomina "embargo" al sistema por el que los habitantes se obligan a sí mismos a pagar las cooperaciones exigidas por el pueblo. El sistema consiste en embargar los bienes de un poblador que se niegue o no pueda pagar una cooperación econó-

${ }^{211}$ El equipo de cargos que acompaña anualmente al presidente de comunidad está formado por personas afines en parentesco y amistad, quienes usualmente se apoyan unos a otros en las asambleas para distribuirse los cargos en el transcurso de los años.

${ }^{212}$ En 1995 la comunidad de Santa Apolonia Teacalco se separó de Nativitas y se convirtió en municipio. 
mica, de las que tratará el siguiente apartado. En líneas generales, el embargo se inicia con la reunión de "los hombres del pueblo" (adultos y/o casados por el rito católico) junto con las autoridades. El jefe de manzana -cargo igualmente rotatorio- en donde se ubican los bienes del embargado le solicita que pague la deuda y, en caso de negarse, se procede al embargo: se acude a la casa del vecino y se requisa entonces cualquier tipo de bienes que éste posea, pero que cubra el monto de la deuda. Los autores destacan que tal sistema "no acepta excepciones" (totalidad) en lo que supone una representación "del derecho de la comunidad por encima del individuo".

\section{CAMPO ECONÓMICO}

Dos son los mecanismos institucionalizados que pueden, a nivel económico, fomentar lo colectivo frente a lo individual: los trabajos comunitarios y las cooperaciones. El primero forma parte de la organización laboral de las comunidades y está muy relacionado con la jerarquía civil; el segundo está asociado -entre otros aspectos- con el entramado del ceremonial religioso.

Los trabajos comunitarios, denominados de muy diferentes maneras según la región (faenas, tequios, fajinas, fatigas, tandas), son mecanismos de trabajo colectivo en "los que participan obligatoriamente todos [énfasis nuestro] los varones ${ }^{213}$ adultos de la comunidad" y que "se usan para obras públicas, como la construcción y el mantenimiento de caminos, la edificación de escuelas, la reparación de templos y otros edificios comunales" (Bonfil 2003: 61).

Concretamente, en la comunidad de Jesús Tepactepec se puede observar un progresivo debilitamiento de este tipo de instituciones, las cuales, a decir de los pobladores, han dejado de funcionar hace apenas quince años: "canijo que no quería ir, se la hacía con cemento". En opinión del equipo fiscal de Tepactepec, estas formas de trabajo colectivo eran "una forma de relacionarse, de colaborar, de sentirse más identificado con los otros" y si se han debilitado ha sido por "las costumbres de las ciudades" (entrevistas realizadas en Jesús Tepactepec, Nativitas, julio de 2010). En este mismo sentido, el presidente de comunidad de Tepactepec en 2009 afirmaba que antes se daban más las faenas, pero ahora "ha cambiado la forma de vivir en el campo; la gente tiene otro empleo y no tienen tiempo" (entrevista realizada en Jesús Tepactepec, Nativitas, agosto de 2009).

Sin duda, los procesos modernizadores que mayor impacto han tenido en el trabajo comunitario son los de urbanización y asalarización. Con Bonfil (2003: 61) podemos decir que la

${ }^{213}$ Las mujeres -familiares y amistades de "los varones adultos"- participan preparando los alimentos que se distribuyen entre los participantes del trabajo. 
noción de salario impacta directamente en la idea de trabajo colectivo, el cual "no se paga, se retribuye, se adquiere la obligación de hacer lo mismo que otros [una mayoría de todos] hicieron por uno [rotación], cuando llegue el momento [frecuencia]".

Las cooperaciones son un mecanismo presente en todas las dimensiones de la vida social comunitaria (política, religiosa, familiar) que tienen como principal cometido socializar ${ }^{214}$ los ingresos de un determinado grupo por medio de contribuciones monetarias y/o especies. Jesús Tepactepec tiene un total de 990 habitantes (Serrano 2008: 76), cuyos aproximadamente 300 jefes de familia cooperan regularmente sufragando los diversos gastos asociados con las esferas política y religiosa del sistema de cargos ("tengo propiedad", "ya te casaste, ya cooperas"). Desde el punto de vista político, las cooperaciones pueden financiar un trabajo colectivo y, sobre todo, asegurar la entrada de servicios comunitarios, como el agua. Las cooperaciones más numerosas tienen como principal objetivo sufragar el calendario ritual católico; y existen las cooperaciones muy cotidianas entre familiares para celebrar algún acontecimiento relevante.

A continuación se expone el mecanismo conjunto cooperación-comisión para poder aplicar las variables manejadas a lo largo del texto. Las cooperaciones, a través de las comisiones (las cuales serán estudiadas como mecanismo social más adelante) generadas para cada una, permiten que varios vecinos que se van rotando (una comisión en Jesús Tepactepec suele estar formada por seis miembros: presidente, secretario, tesorero y tres vocales) visiten cada una de las casas, es decir, a todos los vecinos de la comunidad y, además de enterarse con relativa premura de los habitantes que han emigrado, se han separado de sus parejas o que pasan por graves dificultades económicas, solicitan la cooperación monetaria. Estas visitas, que tienen como finalidad recaudar las cooperaciones, se producen en Tepactepec como mínimo ocho ${ }^{215}$ veces al año (frecuencia), generándose auténticos censos tanto de pagadores como de deudores. De hecho, estas últimas listas se exponen en el atrio de la iglesia del pueblo, para hacer público qué cabezas de familia no realizan una determinada contribución. Además de la implí-

${ }^{214}$ Socializar se refiere a la acepción de "transferir" los ingresos "particulares" a un "órgano colectivo" (RAE: 2001)

${ }^{215}$ 1) Año nuevo, 2) Carnaval, 3) fiesta del Quinto Viernes de Cuaresma, 4) Semana Santa, 5) Domingo de Pascua, 6) día del niño (30 de abril), 7) Virgen de la Ascensión (15 de agosto), 8) Virgen de la Natividad (8 de septiembre). Además, también están obligados a cooperar los ejidatarios el día de san Isidro Labrador (15 de mayo); los celadores el día de la Preciosa Sangre de Cristo y los vecinos en las posadas que se llevan a cabo en las calles del pueblo donde está ubicada su vivienda. Si además se tiene en cuenta que algunas de estas fiestas necesitan del servicio de tres comisiones diferentes (cohetes, bebida y música) y que cada comisión consta de seis miembros, se puede deducir que cada cabeza de familia participa de alguna comisión en intervalos relativamente cortos de tiempo. 
cita sanción social que conlleva tal publicidad, la fiscalía de Jesús Tepactepec tiene sus propios mecanismos punitivos: mientras no paguen, los miembros no tienen derecho a los servicios de la iglesia (eucaristías para bautizos, comuniones, quince años, etc.). Si de cualquier manera alguien continúa sin saldar su deuda, la comunidad -a través de las asambleas- le elige para ocupar un puesto en alguna de las comisiones durante el siguiente año, como una manera de contribuir/pagar con trabajo.

A pesar del fuerte impacto que han recibido por la gran cantidad de población que ha tenido que emigrar a Estados Unidos, Canadá y otros estados de la República Mexicana (especialmente al Distrito Federal y Puebla) y, en menor medida, por los convertidos a otra fe religiosa quienes han dejado de contribuir, las cooperaciones se siguen dando para llevar a cabo proyectos comunitarios (Salas et al. 2011: 17); aun quienes han migrado siguen enviando sus cooperaciones a través de representantes -casi siempre pertenecientes a su familia. ${ }^{216}$

CAMPO RELIGIOSO

La dimensión religiosa de la mayoría de las comunidades indígenas y no indígenas de la región mesoamericana con sistema de cargos pasa por el análisis del calendario ritual católico, el cual está organizado por los cargos religiosos (fiscalía de cinco miembros en el caso de Jesús Tepactepec: fiscal, mayor, portero y dos campaneros). Dentro de este ciclo ceremonial resulta obligado acercarse al sistema de mayordomías como mecanismo fomentador de prácticas colectivas y como "estructura que dialoga con las formas locales de autoridad, al grado que los cargos y las mayordomías son a menudo términos que se confunden" (Millán 2005: 227).

Las fiestas católicas permiten que la frecuencia de convivencia de una gran parte de los vecinos (pluralidad y totalidad) sea continua a lo largo de todo el año (en el municipio de Nativitas se puede asistir a una fiesta cada día del año). ${ }^{217}$ Esto incluye las peregrinaciones a otras comunidades, procesiones, arreglo y aseo de las iglesias (recolección de flor, arcos florales), bendiciones de autos, etc. Un mecanismo de singular interés -especialmente para lo que se expone en estas páginas- es el de la capilla de la adoración perpetua, sita en la comunidad que da nombre al municipio: se trata de un escenario de interacción - un pequeño centro religioso

${ }^{216}$ Rivermar (2008: 151) registra para el caso de los migrantes de la comunidad de Xoyatla, Puebla, un aumento significativo de la participación activa en el sistema de cargos de los varones mayores de sesenta años y de las mujeres como representantes de los migrantes que viven en Estados Unidos.

${ }^{217}$ Medina (2009: 136) percibe igualmente que "los pueblos del sur de la ciudad de México tienen más fiestas que días tiene el año". 
católico contiguo a la parroquia- que debe contar con la presencia de mínimo un miembro de la comunidad durante los 365 días del año, las 24 horas del día.

Mención aparte merecen las prácticas que tienen como protagonistas miembros de varias comunidades, por ejemplo las peregrinaciones o las procesiones intercomunitarias (recogida de leña de miembros de Jesús Tepactepec a Santa Apolonia Teacalco). Salas (2010: 152-154) reconoce en las peregrinaciones una red territorial de relaciones sociales que hace referencia a un sistema de invitación y asistencia a las fiestas de los santos patrones de los pueblos limítrofes o lejanos, y que constituyen un mecanismo que permite fortalecer las relaciones comunitarias del entorno regional, como las que se han construido en las peregrinaciones desde y hacia el vecino pueblo de San Miguel del Milagro. En términos parecidos se expresaban algunos vecinos de Tepactepec cuando, al hablar de las comunidades que les visitan anualmente -Santa Catarina del Monte o Santa Inés Tecuexcomac, entre otras-, comentan que quieren que los visitantes "pasen por todas las casas", lo cual sirve "para que te conozcan" -sobre todo si acompañas a los peregrinos como miembro de la fiscalía- y quizás puedas conseguir un empleo o "se prestan a los intereses políticos". ${ }^{218}$

A pesar del fuerte impacto que el ceremonial está recibiendo del calendario laboral ligado a la productividad (ocio y tiempo libre asociados a los fines de semana y periodos vacacionales), tales instituciones conservan todo el vigor de anteriores épocas, lo cual está relacionado en Jesús Tepactepec con la imagen del padre Jesús de los Tres Caminos, una de las que, junto con San Miguel del Milagro, más visitas, limosnas y donaciones recibe en la región.

Resulta fundamental introducir en este punto la figura de los mayordomos (para el caso de Tepactepec hay que hablar de cargos religiosos de apadrinamiento). A pesar de que gran parte de los festejos se sufragan por medio de las contribuciones económicas de una mayoría de miembros de la comunidad, lo cual supone toda una forma de "colectivismo de aportación monetaria y de reciprocidad ritual" (Sandoval 2005: 270), el sistema de mayordomías es otra expresión fundamental del ceremonial comunitario. A diferencia de las fiestas pagadas entre todos los cooperantes, los mayordomos asumen gastos que, en muchos casos, están por encima de sus posibilidades económicas; en este sentido, los mayordomos suelen ser los miembros de la comunidad a los que menos mal les ha ido económicamente respecto al resto del grupo. ${ }^{219}$

${ }^{218}$ Salas (2010: 153) registra 134 peregrinaciones el año 2009 en la comunidad vecina de San Miguel del Milagro, reconociendo igualmente que la visita es devuelta por una comisión "durante el siguiente año, o en el momento en que éstos [los otros pueblos] celebren su fiesta patronal".

${ }^{219}$ Sandoval (2005: 272) explica tal comportamiento como una forma "de evitar la acumulación económica que conlleve a diferencias sociales y de poder [...] Ésta es la exigencia de una formación cultural cuyo valor 
Se trata por tanto de una institución de carácter selectivo "ya que llegar a la cúspide de la jerarquía comunitaria sólo es privilegio de unos cuantos” (Millán 2005: 227).

La comunidad de Jesús Tepactepec no tiene mayordomos propiamente dichos, pero cuenta con varios padrinazgos eclesiásticos, entre los que destaca el padrino de "la Acostada del Niño Dios", ${ }^{220}$ cuyos gastos, según varios pobladores, rondan el millón de pesos. ${ }^{221}$ Concretamente, ha de sufragarse durante dos días ( 23 y 24 de diciembre) comida, bebida, música y cohetes para una multitud entre miembros de la comunidad y visitantes.

\section{CAMPO SOCIAL}

Esta cuarta dimensión contiene varios mecanismos que se caracterizan por estar presentes en el resto de las dimensiones trabajadas. Se toman en consideración tres instituciones fundamentales: las comisiones y/o comités, el compadrazgo y las fiestas.

Las comisiones y/o comités son fundamentales en el funcionamiento cotidiano de las comunidades. Son un núcleo integrado por un número determinado de personas que tiene como fin el auxilio a los responsables de organizar actividades tanto políticas (se encargan del agua potable, la escuela, las obras públicas, etc.) como religiosas. De hecho, recordando la interconexión existente entre comités y cooperaciones, "el modelo de obligatoriedad de la cooperación en el sistema de cargos religiosos se ha extendido a lo civil. De alguna manera u otra, nadie [totalidad] escapa de la cooperación comunitaria" (Robichaux 2007: 24). Según lo observado y registrado en Jesús Tepactepec, los miembros han de rotar por la mayoría de comisiones para poder llegar a ser presidente de comunidad. Según el tesorero de la comisión de aguas de Tepactepec, quienes tienen interés de llegar pronto a la cúspide jerárquica utilizan las comisiones, de manera que "al que habla mucho en las asambleas, hay que darle un hueso [comisión]” (entrevista realizada en Jesús Tepactepec, Nativitas, julio de 2010).

El compadrazgo o parentesco ritual fomenta la existencia de figuras que puedan sustituir a los parientes biológicos en caso de ausencia (viudez, separación, divorcio, emigración, etc.). Este tipo de parentesco se destaca en este nivel ya que, siguiendo a Bonfil (2003: 58), "permite ordenar la cooperación de un mayor número de individuos [pluralidad] para ciertas tareas en las que los

originario es la socialización, muy diferente a la exacerbada individualización y acumulación de dinero que rige la vida del mundo occidental".

${ }^{220}$ Destaca de esta celebración que los padrinos pueden ser personas que no pertenecen a la comunidad.

${ }^{221}$ En el tiempo de la investigación, 12 pesos mexicanos equivalían a un dólar estadounidense. 
miembros de la unidad doméstica resultan insuficientes", tareas en las que se incluye las relacionadas con el sistema de cargos. ${ }^{22}$

Resulta extraordinariamente convincente para la presente propuesta el número de padrinazgos que Nutini y Bell (1981) tienen registrados únicamente para el estado de Tlaxcala. Ni más ni menos que 27 formas de compadrazgo entre las que destacan el bautizo, la comunión, la confirmación, los quince años de las niñas, el matrimonio y las diferentes graduaciones escolares; menos utilizadas, pero que siguen funcionando, se encuentran el apadrinamiento de una ordenación sacerdotal, de los tres años de un niño o niña, de las bodas de plata y oro; más específicas de Tlaxcala -aunque presentes en otros estados, como Puebla- son la Parada de Cruz de Entierro, la Acostada del Niño Dios, la Coronación de la Santísima Virgen, la Coronación del Sagrado Corazón de Jesús, la Sacada a misa, etc. En definitiva, si tenemos en cuenta que "si no hay comida ni bebida, no hay fiesta", identificamos una cantidad ingente de prácticas que, como característica destacada, multiplican exponencialmente las relaciones entre individuos y grupos, además de alimentar la economía local. En este contexto, el sistema de cargos es una estructura fiable que fomenta y mantiene relaciones de parentesco, amistad y compadrazgo, las cuales aseguran, entre otras cosas, la consolidación de redes de ayuda mutua.

La fiesta es una de las instituciones más presentes en las comunidades. Constituye un espacio fundamental para "las prácticas de sociabilidad en espacios públicos" (Sandoval 2005: 272), y estimula la participación y refuerza la solidaridad entre los diversos individuos (Bonfil 2003: 61). Las fiestas que se celebran en una comunidad pueden diferenciarse entre fiestas familiares ligadas a los ritos de paso de los miembros de una familia extensa (bautizos, comuniones, confirmaciones, graduaciones, cumpleaños, aniversarios, quince años y hasta velorios) y a las cuales también suele estar invitada parte de la comunidad, amigos, parientes y compadres; y fiestas comunitarias ligadas al ciclo ceremonial católico, que son sufragadas, como se ha visto anteriormente, por la misma comunidad a través de cooperaciones o por alguien -mayordomo o padrino- con más recursos que la media de la población.

En primer lugar, las fiestas familiares son una plataforma que genera y mantiene vínculos de parentesco, compadrazgo y amistad. En una familia extensa, destacan las celebraciones anuales de los cumpleaños del cabeza de familia masculino y la preparación del mole en paralelo a la fiesta grande del 8 de septiembre. Siendo ocho el número de hijos, 28 el de nietos y nueve el de bisnietos, tales celebraciones concentran una mayoría de la familia. A priori, todos los

${ }^{222}$ Ya en su obra Cholula: la ciudad sagrada en la era industrial, Bonfil (1988) señalaba la importancia que el sistema de cargos "tiene en fortalecer las relaciones de parentesco y en propiciar el establecimiento de relaciones de compadrazgo". 
cabezas de familia -casados- cooperan equitativamente para comprar los alimentos y bebidas que se utilizarán en la fiesta; además algún miembro de la familia hace un esfuerzo mayor para contratar el servicio de un mariachi. Igualmente, señalamos el caso de la fiesta de quince años de niñas del vecino municipio de Santa Apolonia Teacalco. Destaca en la organización de la celebración el número de "padrinos" que costean la fiesta: los padrinos de bautizo -que tienen que estar casados por el rito católico- se comprometen a pagar el vestido para la fiesta; los padres pagan la comida y pueden aceptar cooperaciones de otros familiares, especialmente en animales; algunos familiares pagan la bebida y en caso de que se agote, se hace una cooperación para comprar más. Otros familiares, amigos y compadres se encargan de "apadrinar" la decoración de la iglesia, el salón y sus arreglos, el cojín, las medallitas, las zapatillas, el mariachi, el conjunto musical, las invitaciones, los recuerdos, la corona y un largo etcétera.

Interesa rescatar de este ejemplo -además de su interrelación con el mecanismo económico de la cooperación y el gran número de pequeños negocios locales que dependen de este tipo de celebraciones- el número de participantes o, en otras palabras, la tendencia a que la fiesta tenga el mayor número de invitados posible ${ }^{223}$ (pluralidad), incluidos el conjunto de miembros de la propia comunidad (totalidad), los cuales se encontrarán en la posición de anfitriones (rotación) cuando vivan una situación pareja -que alguna hija cumpla quince años- (frecuencia): "tienes que invitar a todos los que te invitaron". 224

En segundo lugar, las fiestas comunitarias destacan y son reconocidas porque siempre van acompañadas de comida, bebida, música, juegos pirotécnicos o cohetes, danzas y bailes populares, misas colectivas, toritos, jaripeos, concursos deportivos, etc., ello "a pesar de los intentos de gobernantes y sacerdotes por erradicarlas" (Sandoval 2005: 272). Como se ha comentado en el rubro destinado al ciclo ceremonial católico, los gastos de las fiestas pueden correr por cuenta de toda la comunidad y/o de los mayordomos, quienes cambian -rotan- de fiesta en fiesta (frecuencia). En ellas se dan todo tipo de relaciones entre las que destaca el intercambio de alimentos y bebidas con familiares, compadres y amigos. Frecuentemente, las fiestas familiares y comunitarias se desarrollan coetáneamente y comparten protagonistas, llegándose a dar en algunas localidades las instituciones de la "tornafiesta": posteriormente a los días principales

${ }^{223}$ Los propios informantes correlacionan "el prestigio" y "tener recursos" con conseguir el mayor número de invitados: “¡Hay gente que cierra la calle y te hace bailazo!”, comentaba un vecino sobre la última boda a la que asistió (entrevista realizada en Jesús Tepactepec, Nativitas, julio de 2010).

${ }^{224}$ Este hecho está relacionado con el prestigio que los anfitriones logran al organizar fiestas tan concurridas, capital simbólico que el cabeza de familia - un varón- puede convertir a medio o largo plazo en otras formas de capital. 
de la fiesta comunitaria -cuando se produce la mayor afluencia de visitantes-, los residentes organizan otra comida de menor importancia entre los familiares. La tornafiesta también se acostumbra en las fiestas familiares: "la tornaboda".

Las frecuentes fiestas propician entonces habitus colectivos explicados de las diferentes maneras que lo hace la antropología, pero siempre bajo la premisa de ser prácticas en las que pueden participar todos: fomentan la cohesión social ya que se reúnen todos (Montes y Galinier, citados en Castro 2000: 510); son un mecanismo de control social porque nadie escapa de la cooperación (Robichaux 2007: 24); frenan la acumulación de poder en cualquier individuo o grupo (Chance y Taylor, citados en Castro 2000: 506); legitiman las diferencias de riqueza porque todos pasan por "el servicio en el sistema de cargos", etc. (Cancian 1989: 176-177).

Sin duda, el mayor impacto modernizador que recibe la fiesta como institución comunitaria proviene de las nuevas necesidades de ocio y tiempo libre asociadas con los altos niveles de productividad de las sociedades industriales. Desde hace décadas, las transacciones intergrupales entre anfitriones e invitados -basadas predominantemente en intercambios recíprocos y redistributivos- se están viendo desplazadas por la generación de "territorios turísticos" (Nash 1989: 80 ), cuya característica esencial es la progresiva mercantilización de las relaciones -interacciones y/o transacciones- entre anfitriones e invitados (relaciones que recuperan al individuo -el turista- como figura central y que no contemplan la rotación pactada de papeles).

\section{REFLEXIONES FINALES}

A lo largo del texto hemos descrito y definido, a partir de la literatura antropológica y las experiencias etnográficas, diferentes mecanismos institucionalizados que se pueden encontrar en buena parte de las comunidades rurales y algunos barrios urbanos del territorio mexicano de tradición mesoamericana. Todos estos espacios están, de una u otra manera, relacionados con la institución del sistema de cargos, al que consideramos articulador de cada uno de esos mecanismos. Si bien es cierto que cada uno de ellos pudiera funcionar autónomamente o incluso lo hace en ocasiones, también es verdad que la presencia del sistema y su propia inercia produce y reproduce tales mecanismos, los cuales, desde el punto de vista que se ha querido traer a colación en este texto: 1) propician prácticas en las que puede participar activamente la mayoría de miembros de la comunidad, 2) procuran que tales prácticas tengan la mayor frecuencia posible y 3 ) fomentan el intercambio de posiciones, lo cual, por un lado, permite que los miembros de la comunidad participen en los campos desde todos los papeles posibles 
y, por otro, genera ciudadanos activos que hacen que el sistema nunca pierda vigor a pesar de las embestidas de los fenómenos ligados a la globalización.

Estas reflexiones no buscan ni generalizar ni presentar los sistemas de cargos como mecanismos de cohesión social; al contrario, esta apreciación no significa de ninguna manera la falta de conflictos entre los miembros de la comunidad. En otras publicaciones de esta investigación, hemos destacado cómo el proyecto ético-político de comunidad permite la articulación de "grupos considerables de personas" a través de "reglas de convivencia social" que, sin embargo, no eliminan ni borran las diferencias socioeconómicas y culturales (Salas et al. 2011: 18).

La directa, necesaria y deseada interacción, considerando los dispositivos que también la hacen obligatoria, viene a justificar implícita y explícitamente lo que hemos denominado "proyecto comunitario" o, en otras palabras, el mínimo común denominador de algunas comunidades rurales mexicanas, sean éstas de población mayoritaria y étnicamente originaria, sean de población mestiza (en ningún caso existen grupos totalmente homogéneos): sus miembros quieren y necesitan pertenecer a la comunidad, o lo que es lo mismo, creen en el continuo contacto con las personas con las que conviven como generador, las más de las veces, de beneficio colectivo frente y/o articulado al beneficio individual propio de las sociedades modernas. Todo ello bajo la premisa de que cuantas más ocasiones un individuo comparta prácticas con sus vecinos, mayores posibilidades habrá de que "los unos nos ayudemos a los otros" en la búsqueda de un empleo, la cooperación para una celebración o el apoyo para llegar a los Estados Unidos como nuevo emigrante.

Es muy difícil conjeturar cómo evolucionará el sistema de cargos en el cambiante contexto socioeconómico y político en el que se desenvuelven las comunidades rurales del México del siglo XXI. Las transformaciones sociales derivadas de la globalización y de la modernidad han penetrado tan profundamente en la vida social, política, económica y religiosa de las comunidades que sería lo más fácil pensar en que éstas pueden desaparecer o transformarse hasta perder sus características esenciales y básicas que las definen. Sin embargo, hemos demostrado en este trabajo que las personas siguen agrupándose en territorios, que se relacionan a través de instituciones que generan, mantienen y, en documentados casos, potencian estrategias de cooperación que coexisten con las de conflicto, de manera que las comunidades no sólo persisten, sino que en algunos aspectos su comportamiento se ha fortalecido. Finalmente, podemos concluir destacando la pluralidad de procesos sociales existente en Jesús Tepactepec, procesos abiertos y flexibles enfrentados, por un lado, a experiencias tan desestructurantes de la comunidad -como las migraciones y las dispersiones poblacionales a través de diferentes mercados- $y$, por otro, a experiencias integradoras que, a modo de resistencia, mantienen los proyectos de la colectividad. 


\title{
CARTOGRAFÍA DE NATIVITAS
}

\author{
Celia López Miguel
}

$\mathrm{E}$

1 objetivo central de este capítulo es mostrar cartográficamente las principales divisiones territoriales del estado de Tlaxcala (1848-2010) y cambios espaciales del municipio de Nativitas (1999-2010). Cabe destacar el valor de la metodología empleada para la reconstrucción de los mapas antiguos. Éstos se han georreferenciado, es decir, se les han asignado coordenadas tomando como base un mapa con las coordenadas correctas y proyección geográfica; se han digitizado, lo que significa convertirlos de formato analógico a digital; y se han diseñado a partir de varias fuentes cartográficas, descripciones y recorridos de campo con GPS (Sistema Global de Posicionamiento). La georreferenciación se realizó utilizando los softwares Ilwis 3.x y ArcGis 9.2, los cuales son sistemas de información geográfica (sIG).

La importancia de los mapas originales en este trabajo no sólo radica en que sean lo más exactos en cuanto a los límites de cada fecha, sino que también cuenten con una localización aproximada de los asentamientos establecidos desde la época colonial hasta el México independiente. Los mapas antiguos del estado de Tlaxcala, ya georreferenciados, se sobrepusieron en cartografía actual; esto con el fin de observar y conocer los cambios de las divisiones territoriales a través del tiempo.

Para el caso del municipio de Nativitas se trabajó con ortofotos, fotografías aéreas tomadas desde un avión con corrección geométrica, de dos fechas (1999 y 2010), y mediante interpretación visual en pantalla se reconocieron áreas de cambios de uso del suelo. El tema de las haciendas se abordó desde el punto de vista histórico y cartográfico ya que la distribución espacial nos permitió hacer la relación con uso de los recursos naturales (suelo y agua) de las zonas cercanas a las haciendas.

La georreferenciación y ubicación de los corredores y parques industriales en un mapa nos permite interpretar y entender el tema de la contaminación de los ríos por desechos industriales. Con los recorridos de campo se agrega al mapa obtenido de fuentes documentales un valor de exactitud. 
Los mapas temáticos se integran a este capítulo para tener una visión general del estado y del municipio, este último grosso modo ya que la escala de esta cartografía temática es 1:250 000. La visualización de estos mapas permite observar y conocer la ubicación de tierras ejidales, el valle Texmelucan y el territorio donde tiene su origen el río Atoyac, la localización y geología del municipio de Nativitas en la subcuenca Puebla-Tlaxcala, y la disposición de aguas subterráneas y escurrimientos superficiales. El capítulo se subdivide en cinco apartados: el primero reúne desde los primeros mapas del estado de Tlaxcala y la evolución de su división administrativa desde 1848 hasta la actualidad (mapas 1-4); el segundo apartado permite conocer la conformación territorial de Nativitas (mapas 5-9); el tercero refiere a las haciendas de Tlaxcala y Nativitas de finales del siglo XIX (mapas 10-12); luego se describe la ubicación de los corredores industriales del valle Puebla-Tlaxcala (mapas 13-14) y finalmente una sección de mapas temáticos (mapas 15-21).

TLAXCALA (1848-2010)

Mapa 1. Mapa antiguo: División territorial de Tlaxcala, 1848. Tres partidos: de Tlaxco, Tlaxcala y Huamantla. La superficie comprende 400 leguas cuadradas. Una ciudad, 109 pueblos, 18 barrios, 168 haciendas, 94 ranchos, ocho molinos de trigo, dos ferrerías y una fábrica de tejido de lana. De este mapa se extrajo (por medio de la digitización dentro de un SIG) la información de la planicie, ranchos, pueblos, haciendas y división de partidos, dicha información se utilizó para sobreponerse en otros mapas que se mostrarán más adelante.

Método de Georreferenciación: la figura del plano del territorio de Tlaxcala ("figura" ya que no tenía coordenadas ni proyección) que se tenía en papel se "escaneó" a alta resolución 300 dpi en formato .tif. El mapa en formato digital se importó dentro un SIG (Ilwis). Con éste se le asignaron coordenadas por medio del método esclavo-maestro; es decir, se tomó como referencia el mapa topográfico actual del estado de Tlaxcala para asignarle coordenadas al plano, tomando como referencia los ríos, vías de comunicación y cuerpos de agua. Con el plano - con coordenadas- se hizo una corrección geométrica con el método del "vecino más cercano". Con este proceso se pasó de una figura a un mapa georreferenciado y corregido geométricamente. 


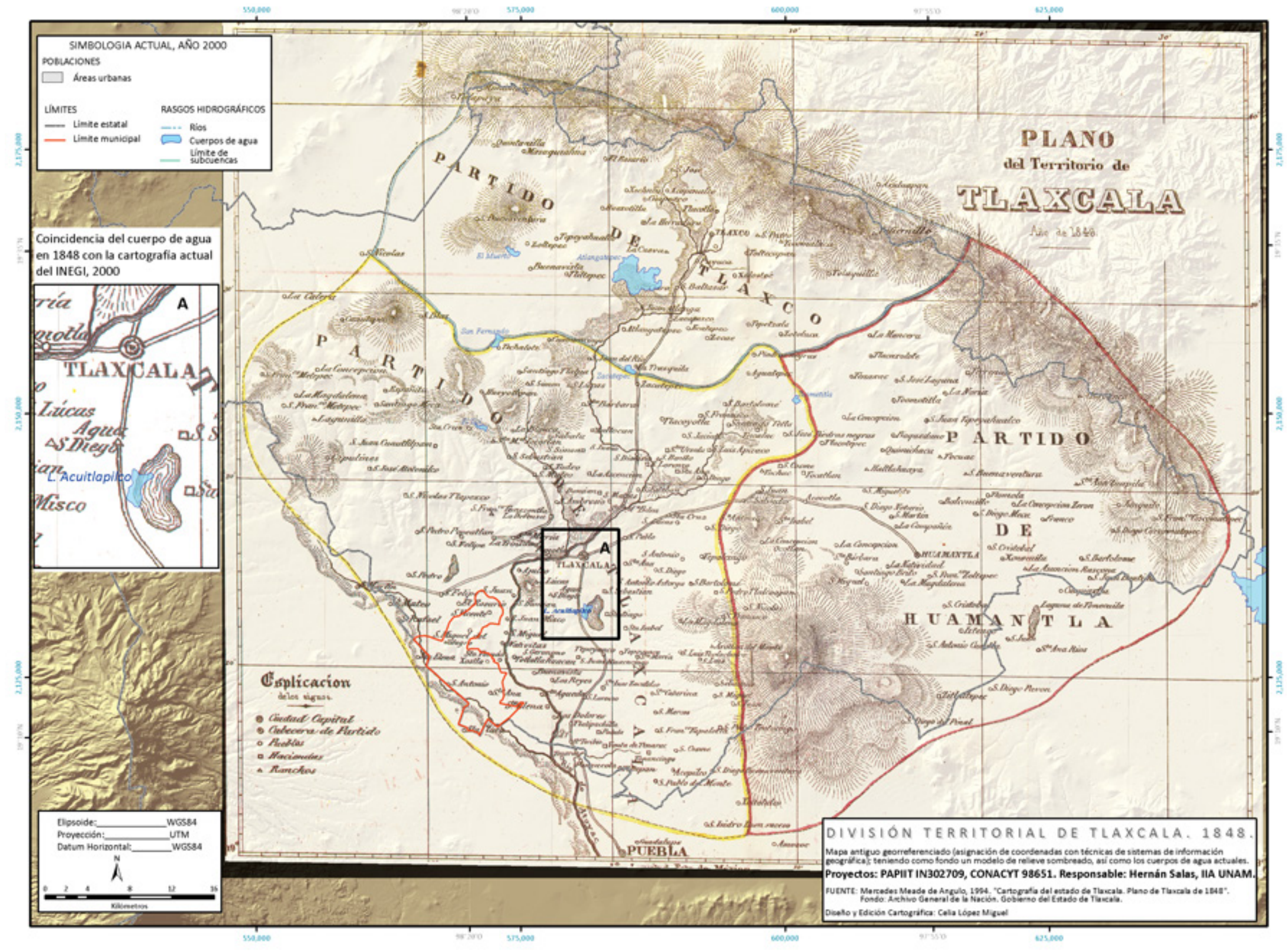


Mapa 2. Sobreposición de las divisiones territoriales del estado de Tlaxcala (en 1848) sobre el modelo de relieve sombreado (MDRS). El MDRS corresponde a la cartografía actual del estado y se utilizó como fondo para ver la correspondencia "casi exacta" del relieve actual con el del mapa de 1848. En este mapa también se cartografiaron de manera puntual los pueblos, ranchos, ciudades, cabeceras y haciendas, así como la división de los partidos. 


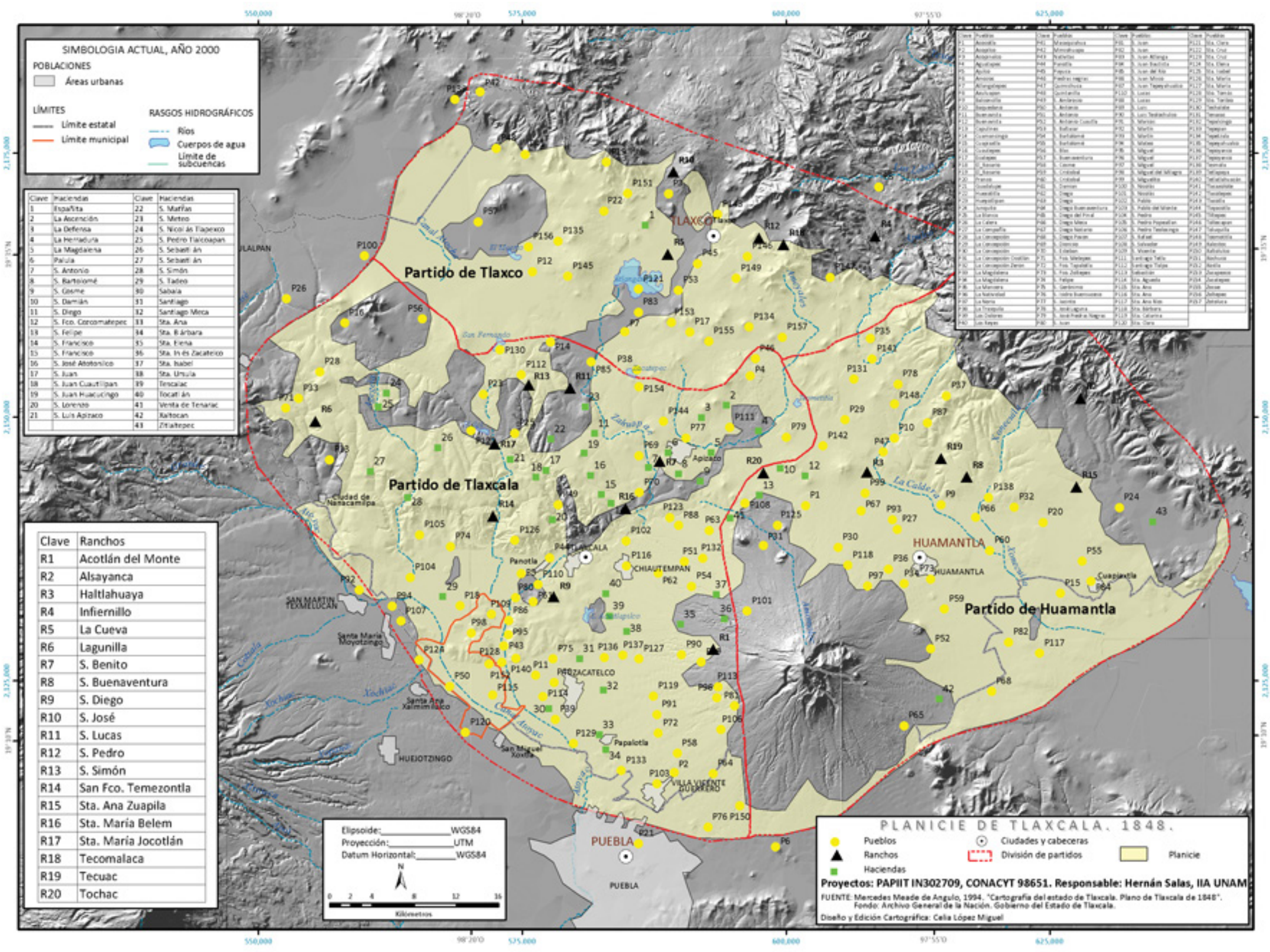


Mapa 3. División territorial de Tlaxcala. 1848-1881. Tlaxcala en 1848 tenía tres partidos: Tlaxcala, Tlaxco y Huamantla; para 1881 se dividió en seis distritos: Cuauhtémoc, Hidalgo, Juárez, Morelos, Ocampo y Zaragoza, subdivididos en 33 municipalidades. El concepto de "municipalidad" es una categoría político-

administrativa utilizada en la Colonia. Este mapa se reconstruyó a partir de la lista de municipios publicada en Galicia (2010), "Rasgos generales de funcionamiento del sistema hídrico y el desarrollo socioeconómico en el ambiente acuático de la planicie Tlaxcala, subcuenca Puebla-Tlaxcala. Siglos xvixx". Con la división de distritos se acerca más a la conformación espacial actual del estado de Tlaxcala. 


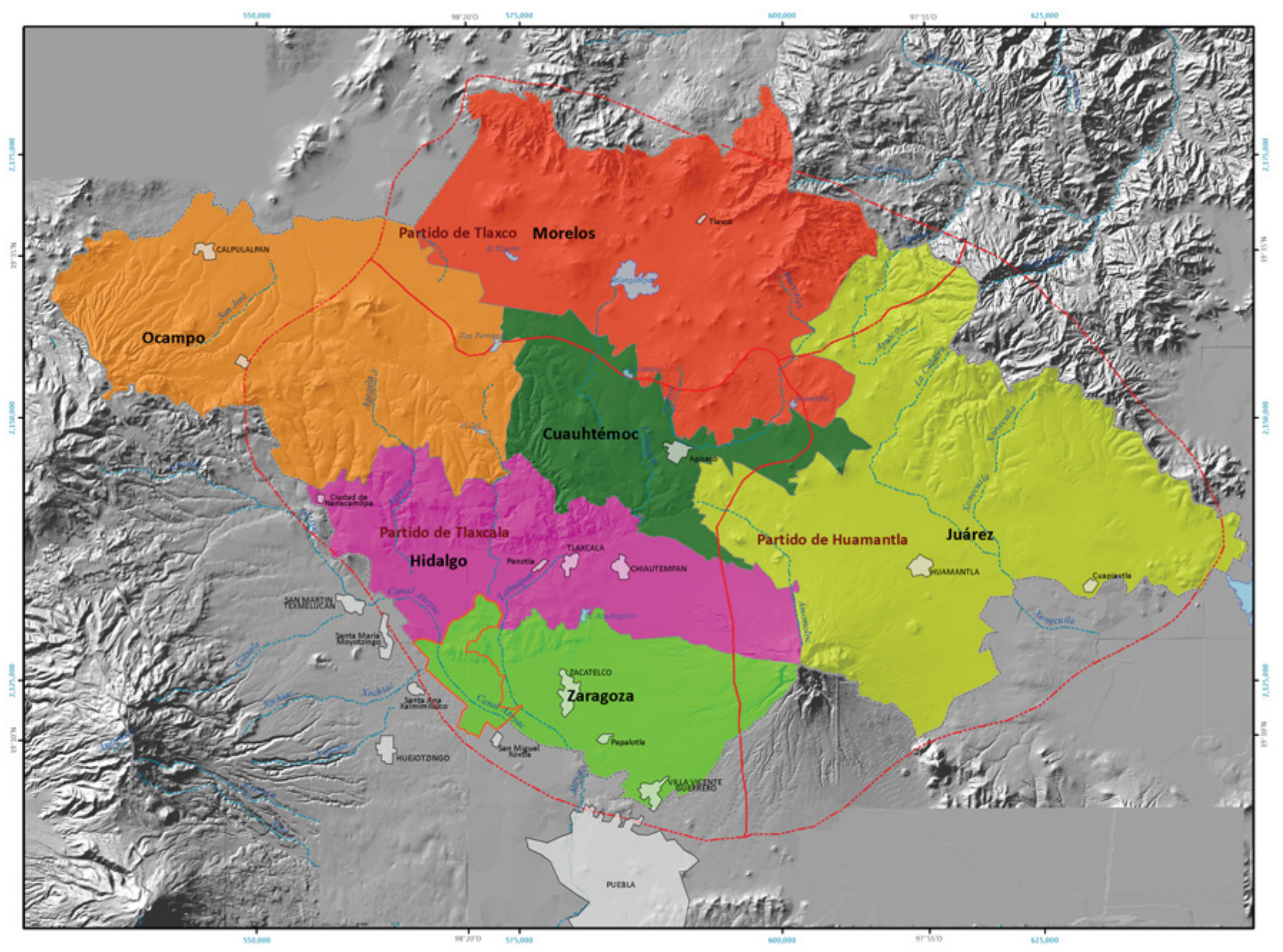


Mapa 4. División territorial actual de Tlaxcala. Sobrepuesto con la información del mapa 3; con esto se puede saber qué municipios actuales pertenecen a partidos y distritos que ordenaban el territorio a fines del siglo xix. Tlaxcala, para el 2010, contaba con una superficie de $3991 \mathrm{~km}^{2}$ y 60 municipios. 


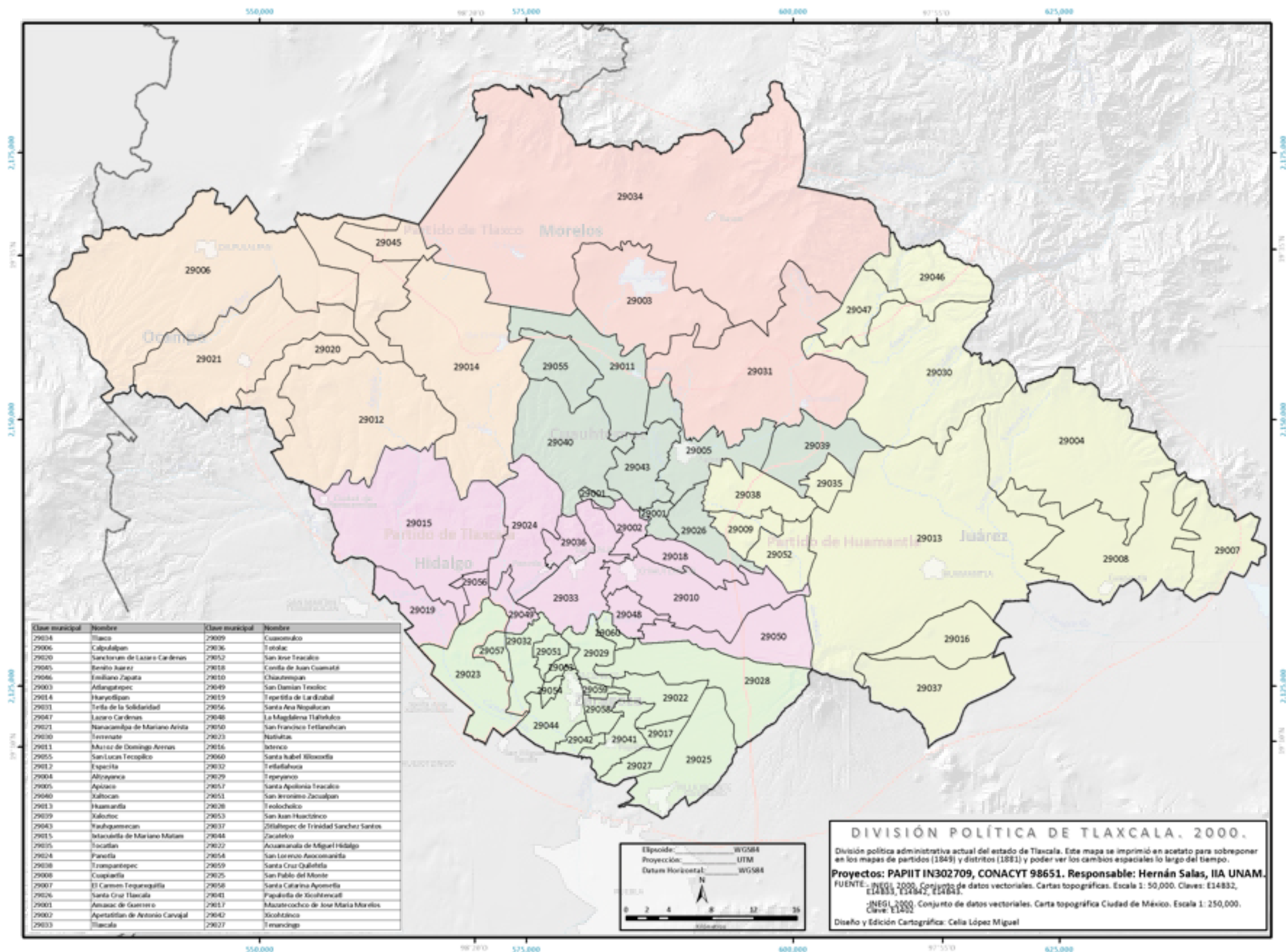


NATIVITAS, TLAXCALA (1999-2010)

Mapa 5. Localización del municipio de Nativitas con las 13 comunidades de estudio. Se trabajó con la base de datos vectorial digital del INEGI del año 2000. 


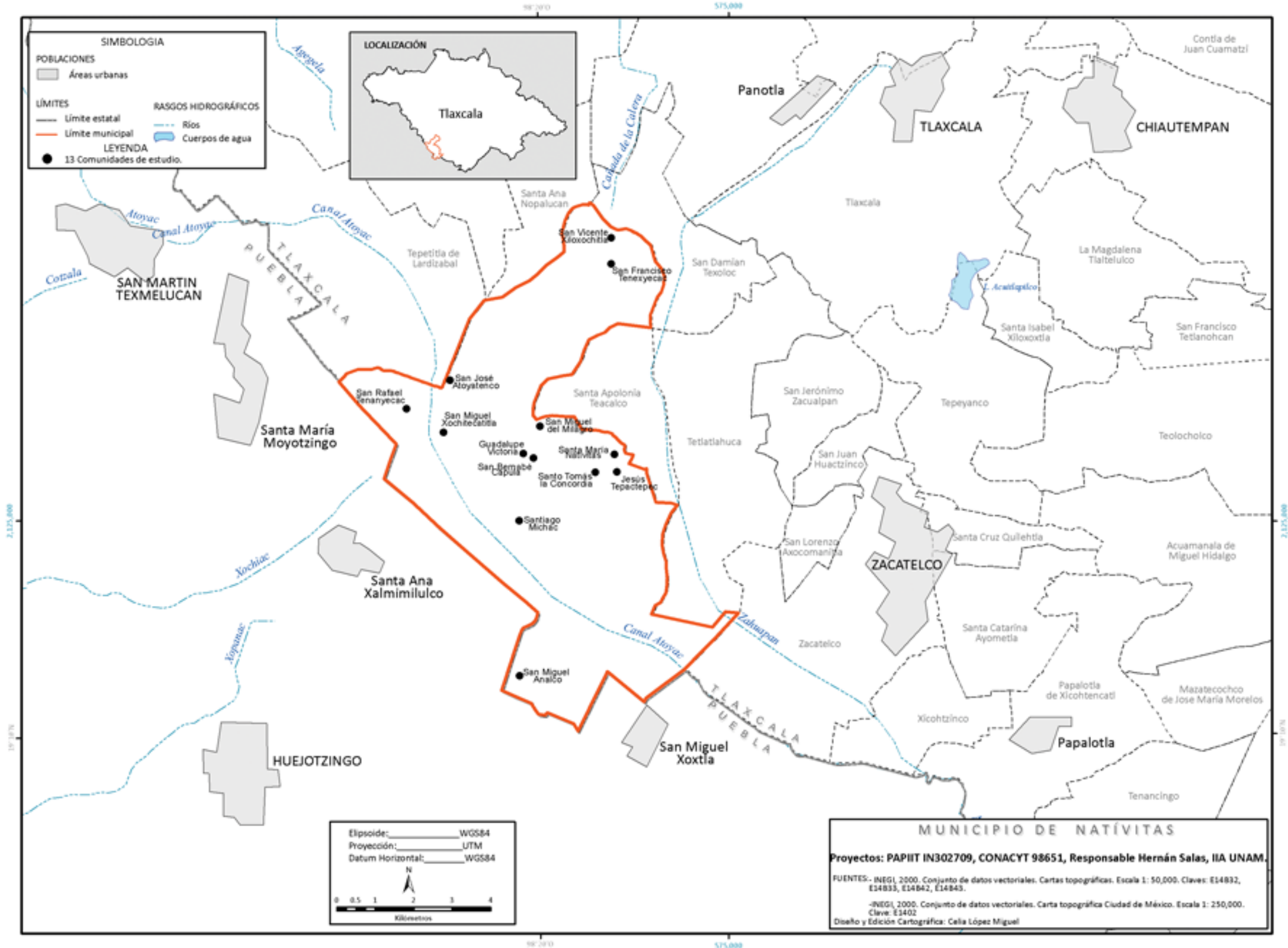


Mapa 6. Ubicación de las zonas de cambios (color amarillo) dentro del municipio de Nativitas. Para identificar estos cambios se trabajó con ortofotos (fotografías aéreas tomadas desde una plataforma y corregidas geométricamente) de dos fechas: 1999 (en escala de grises) y 2010 (a color). Se hizo una interpretación visual para identificar estas zonas de cambios, asociadas con el crecimiento urbano. En los siguientes mapas se ejemplificarán tres casos. 


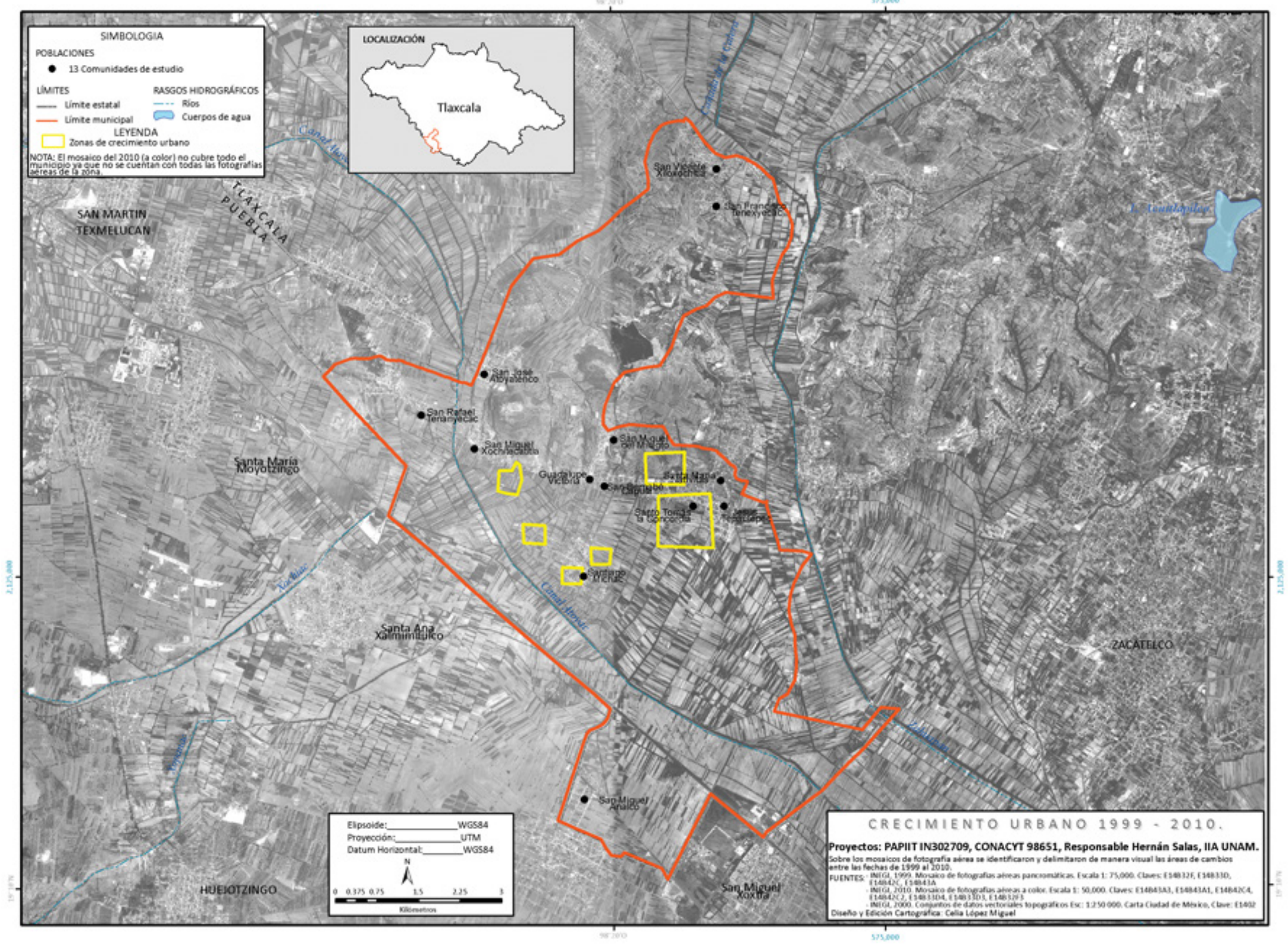


Mapa 7. Ejemplo 1. San Miguel Xochitecatitla. Ubicación de las zonas de cambios, identificadas con líneas punteadas color magenta. 


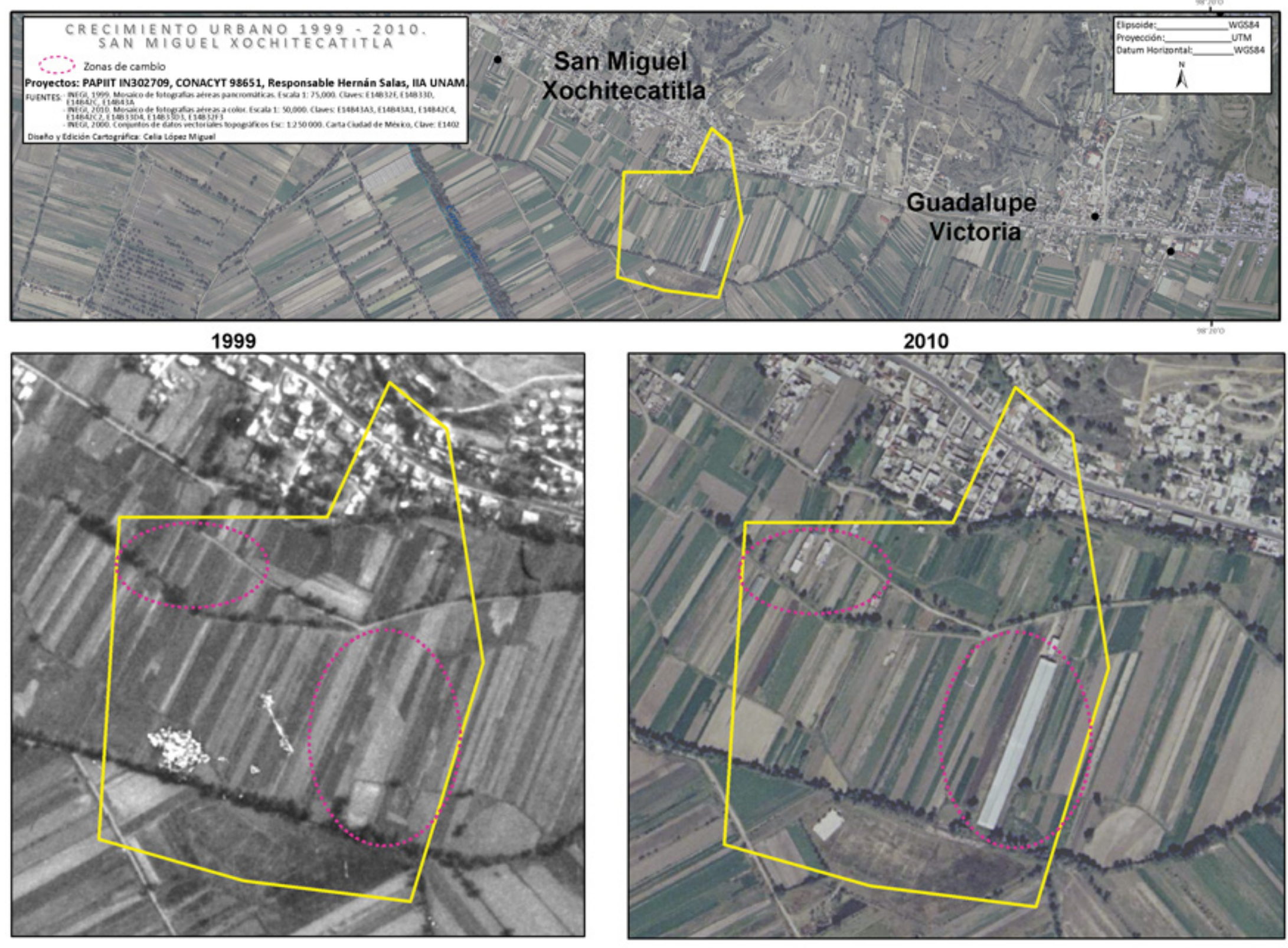


Mapa 8. Ejemplo 2. Santiago Michac. Ubicación de las zonas de cambios, identificadas con líneas punteadas color magenta. Para el caso de Santiago Michac se encontraron tres áreas: A, B y C. 

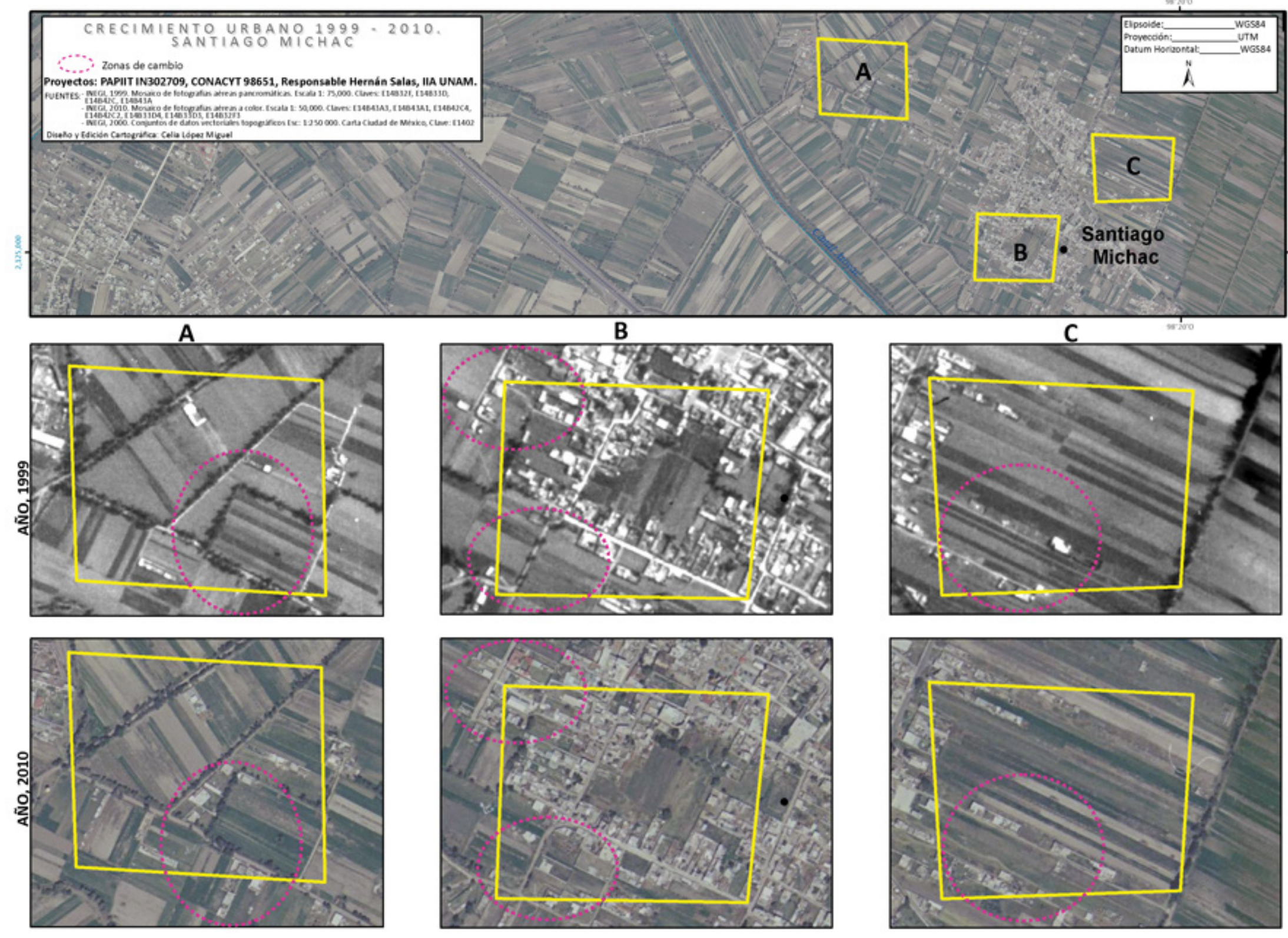
Mapa 9. Ejemplo 3. Santo Tomás la Concordia. Ubicación de las zonas de cambios, identificadas con líneas punteadas color magenta. 

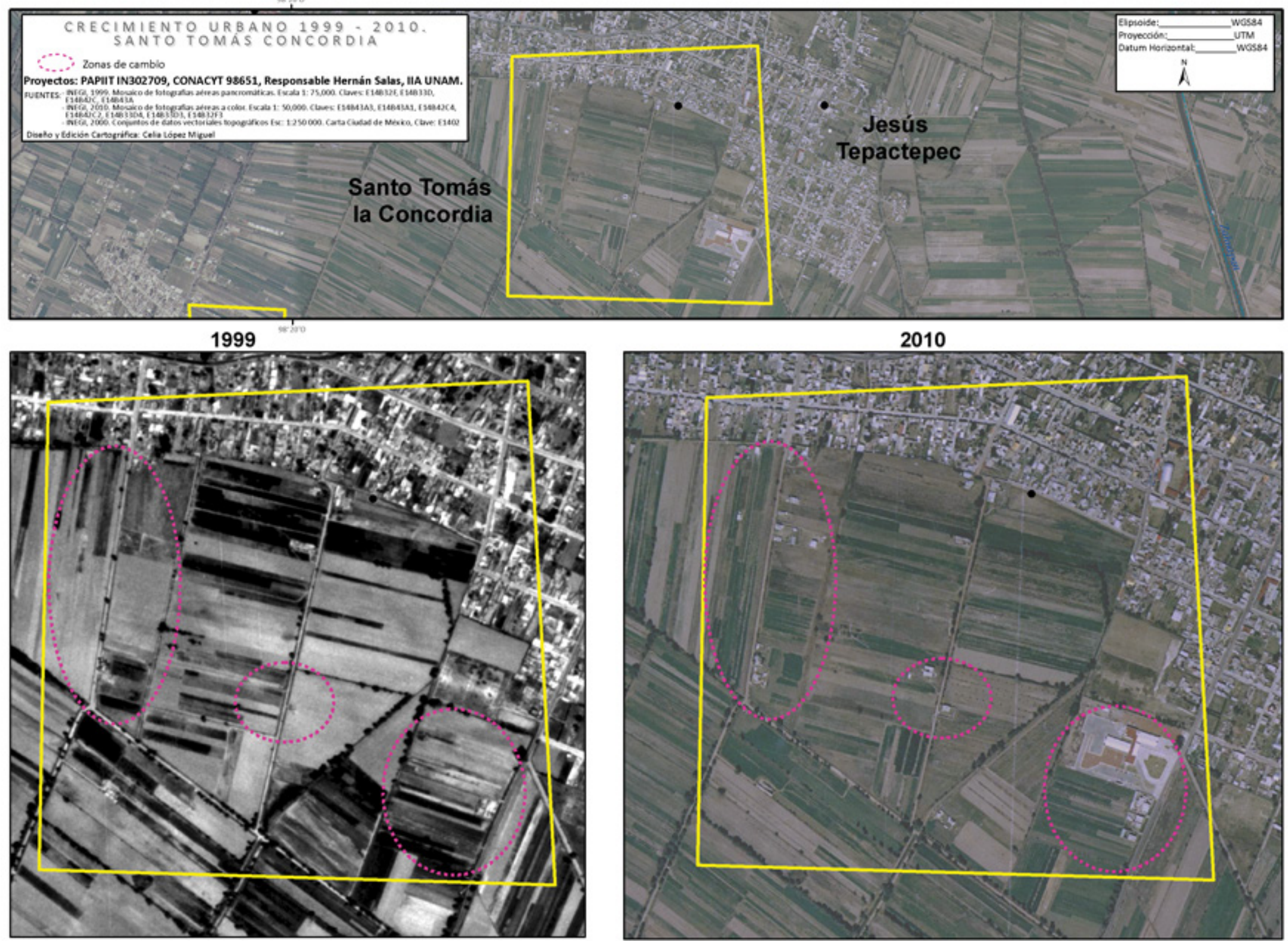
HACIENDAS DE TLAXCALA Y NATIVITAS

Mapa 10. Plano (dibujo) del estado de Tlaxcala con la ubicación de las haciendas, vías de comunicación y fábricas, 1881. Tomado del Museo de la Memoria de Tlaxcala. 


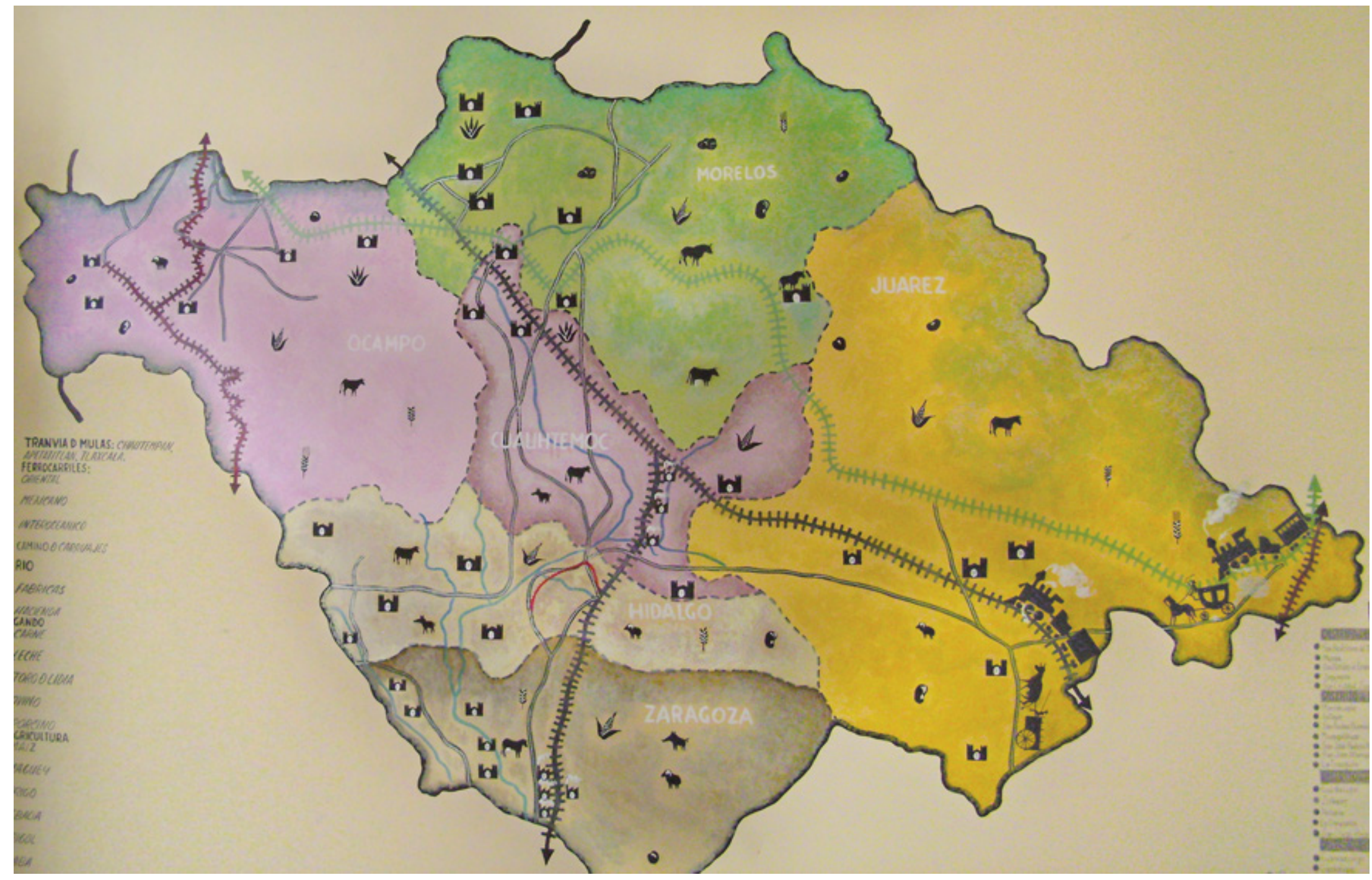


Mapa 11. Mapa georreferenciado de las haciendas en 1881. Seis Distritos, siete fábricas y 32 haciendas; esta información está sobrepuesta en un MDRs en color sepia y con información topográfica actual del estado. 


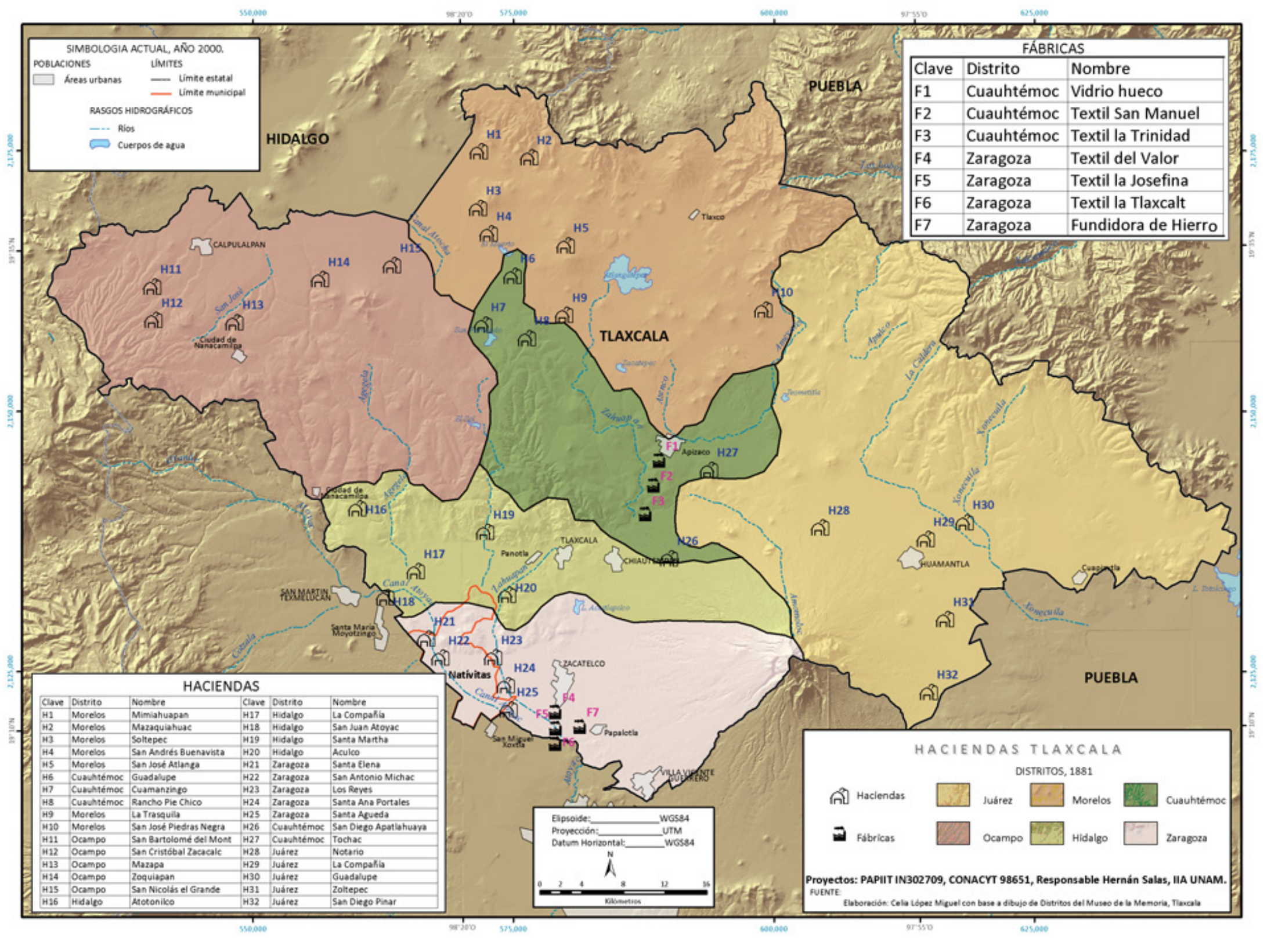


Mapa 12. Ubicación de las haciendas (siete) dentro del municipio de Nativitas, 2010. La ubicación se obtuvo mediante el uso del GPS en un recorrido de campo que también está representado en el mapa (línea magenta punteada). 


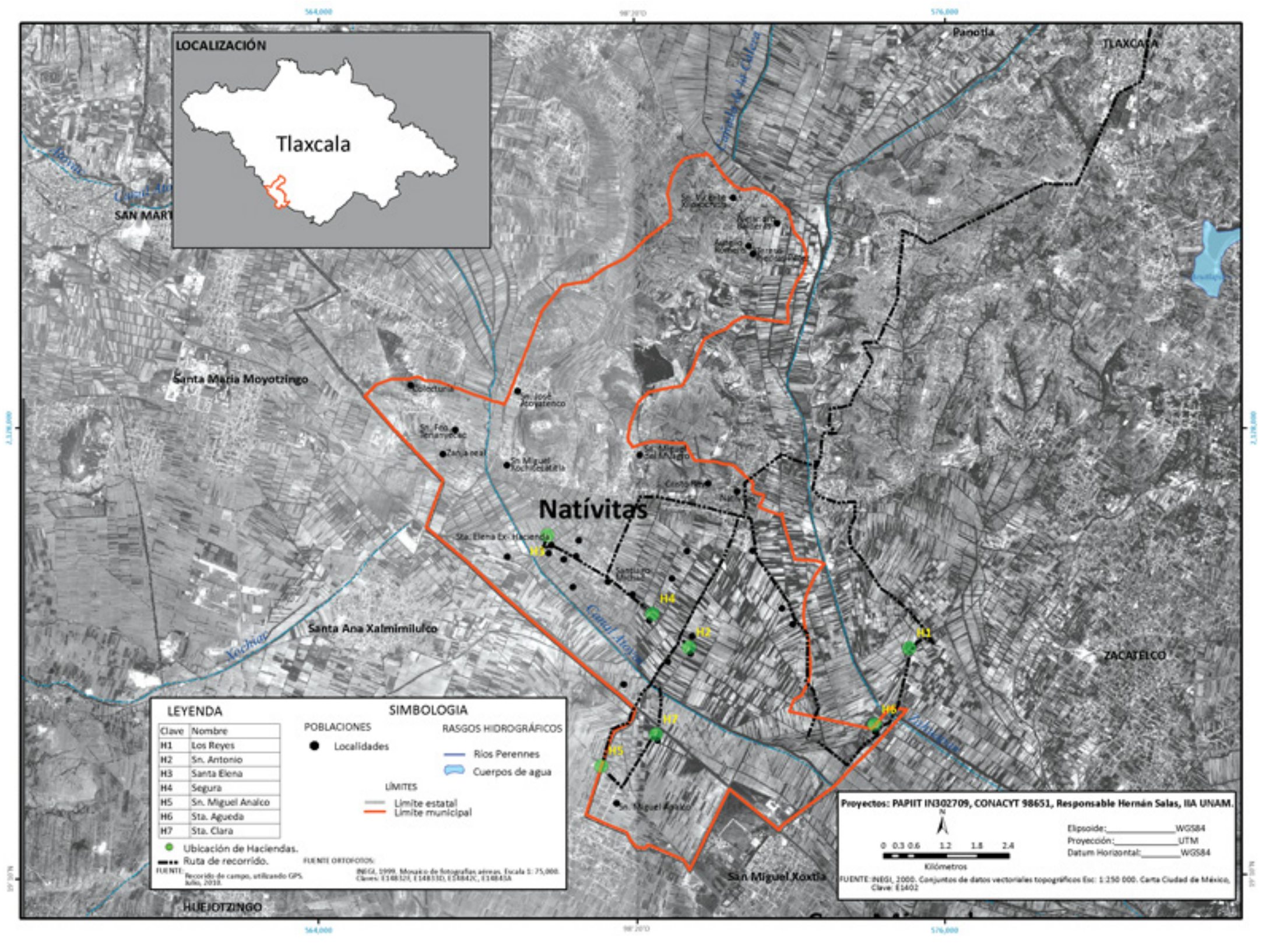


INDUSTRIA EN TLAXCALA Y NATIVITAS

Mapa 13. Ubicación de los corredores y parques industriales. Para realizar este mapa se partió de información de mapas (sin coordenadas) en formato .pdf. Se georreferenciaron y posteriormente se editaron sobre un mapa topográfico del INEGI para tener puntos de referencia en la identificación de la ubicación de las industrias. 


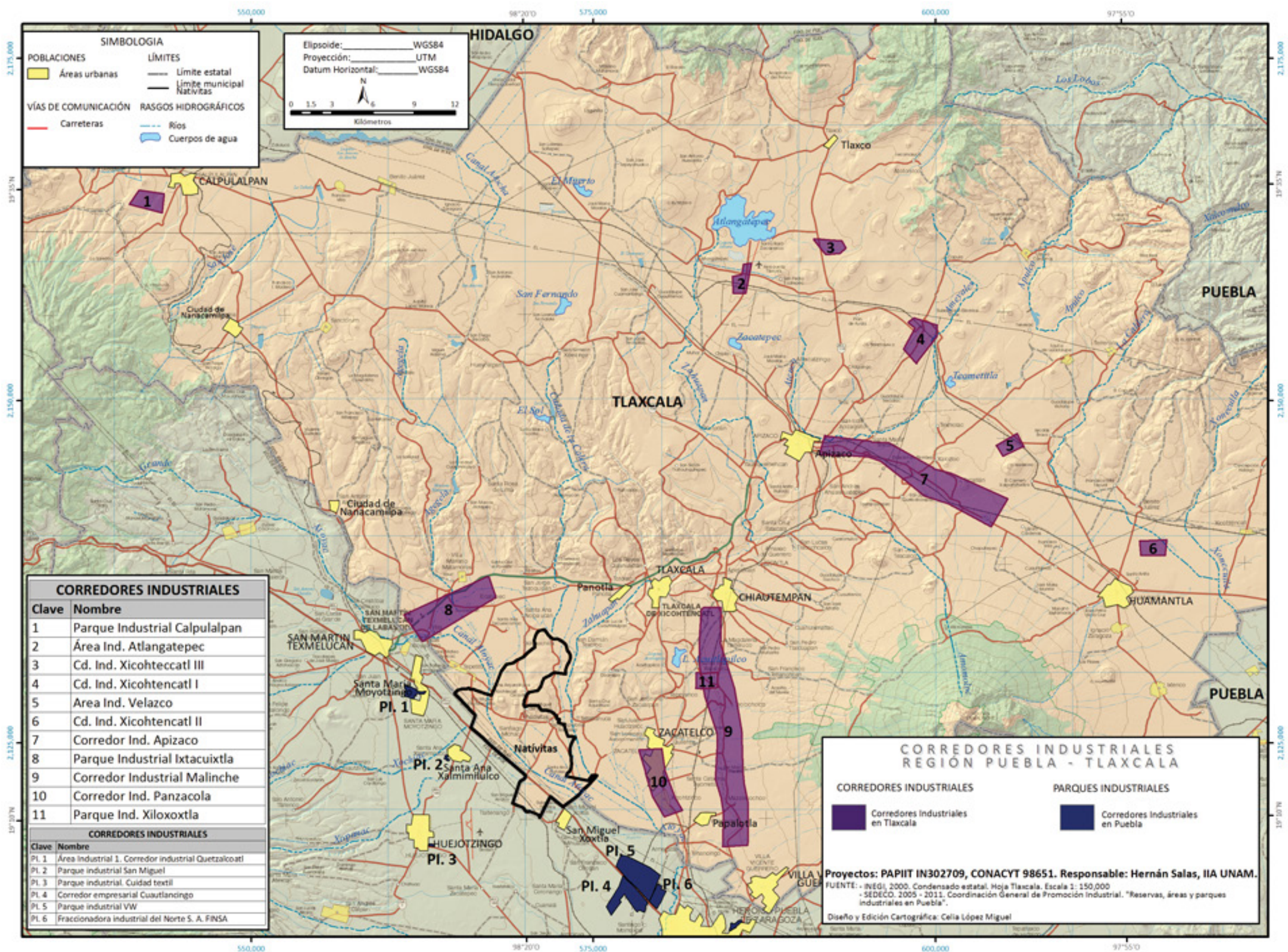


Mapa 14. Ubicación de los corredores industriales (los más cercanos al municipio de Nativitas) y parque industrial de Ixtacuixtla. Dentro del parque industrial de Ixtacuixtla se cartografiaron los tipos de industrias y sus nombres. 


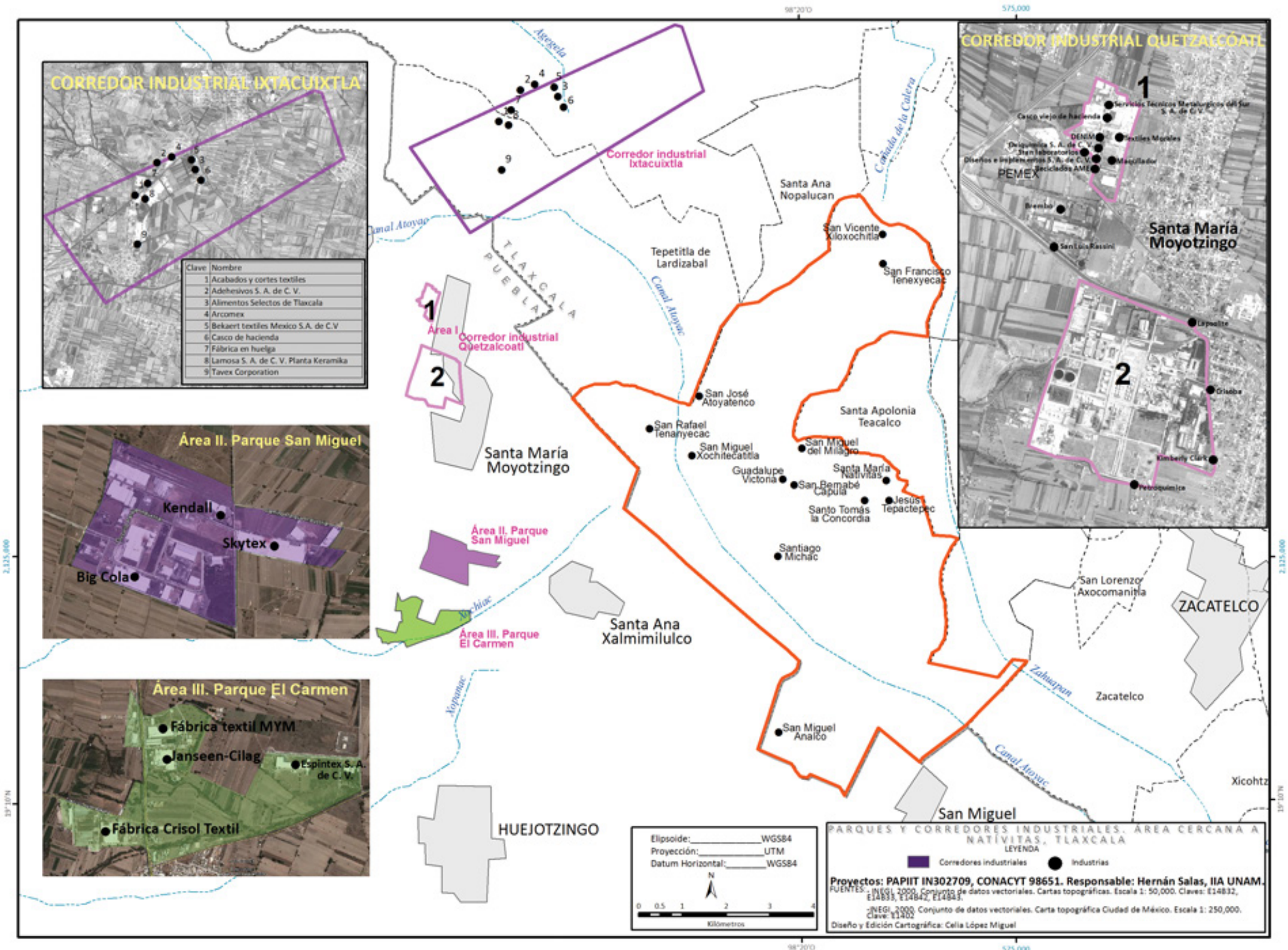




\section{CARTOGRAFÍA TEMÁTICA DE NATIVITAS}

Mapa 15. Núcleos ejidales. Este mapa se trabajó con información proporcionada por el Registro Agrario Nacional (Dirección de Catastro Rural) de la Secretaría de la Reforma Agraria. La información en formato de AutoCAD se importó dentro del sIG ArcGIS y se editó sobre una ortofoto. 


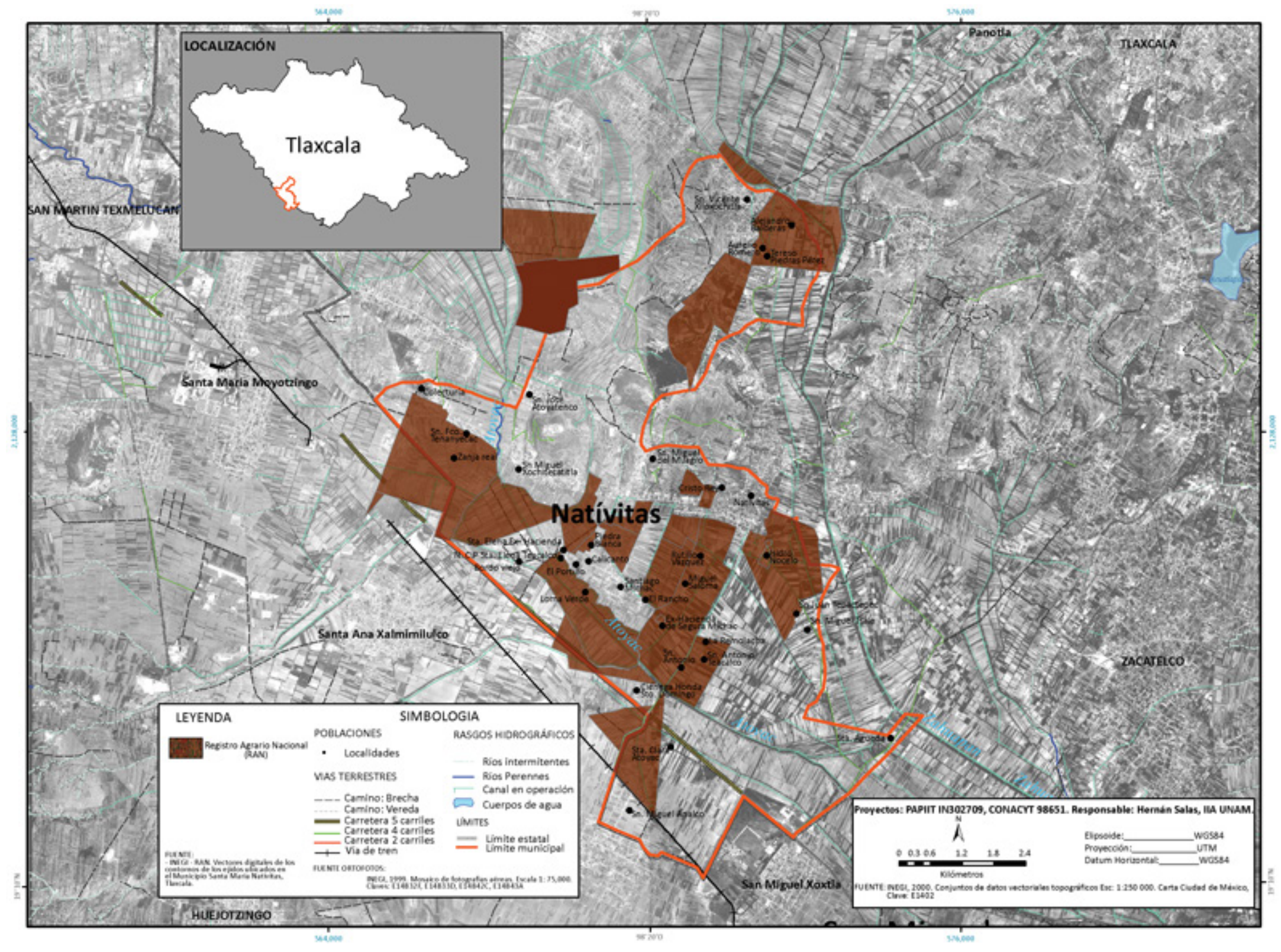


Mapa 16. Mapa de la cuenca de México, el eje volcánico, el valle de San Martin Texmelucan y Nativitas, escala 1:250 000 del INEGI, Carta Topográfica. 


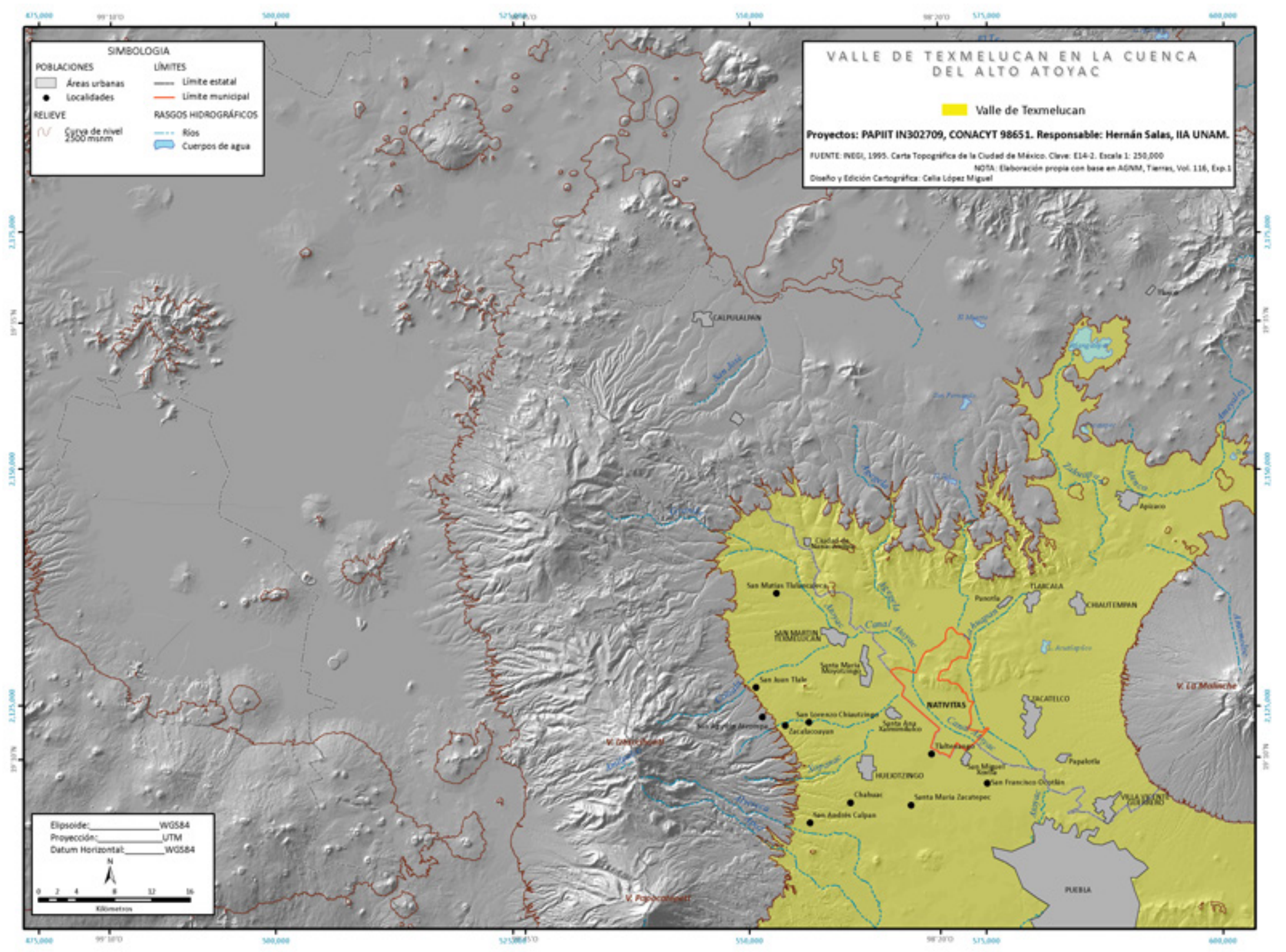


Mapa 17. Mapa de las subcuencas Puebla-Tlaxcala, la escala de trabajo de esta cartografía es 1: 250000 del INEGI. El municipio de Nativitas se encuentra entre las cuencas del río Atoyac-San Martín Texmelucan y el río Zahuapan. 


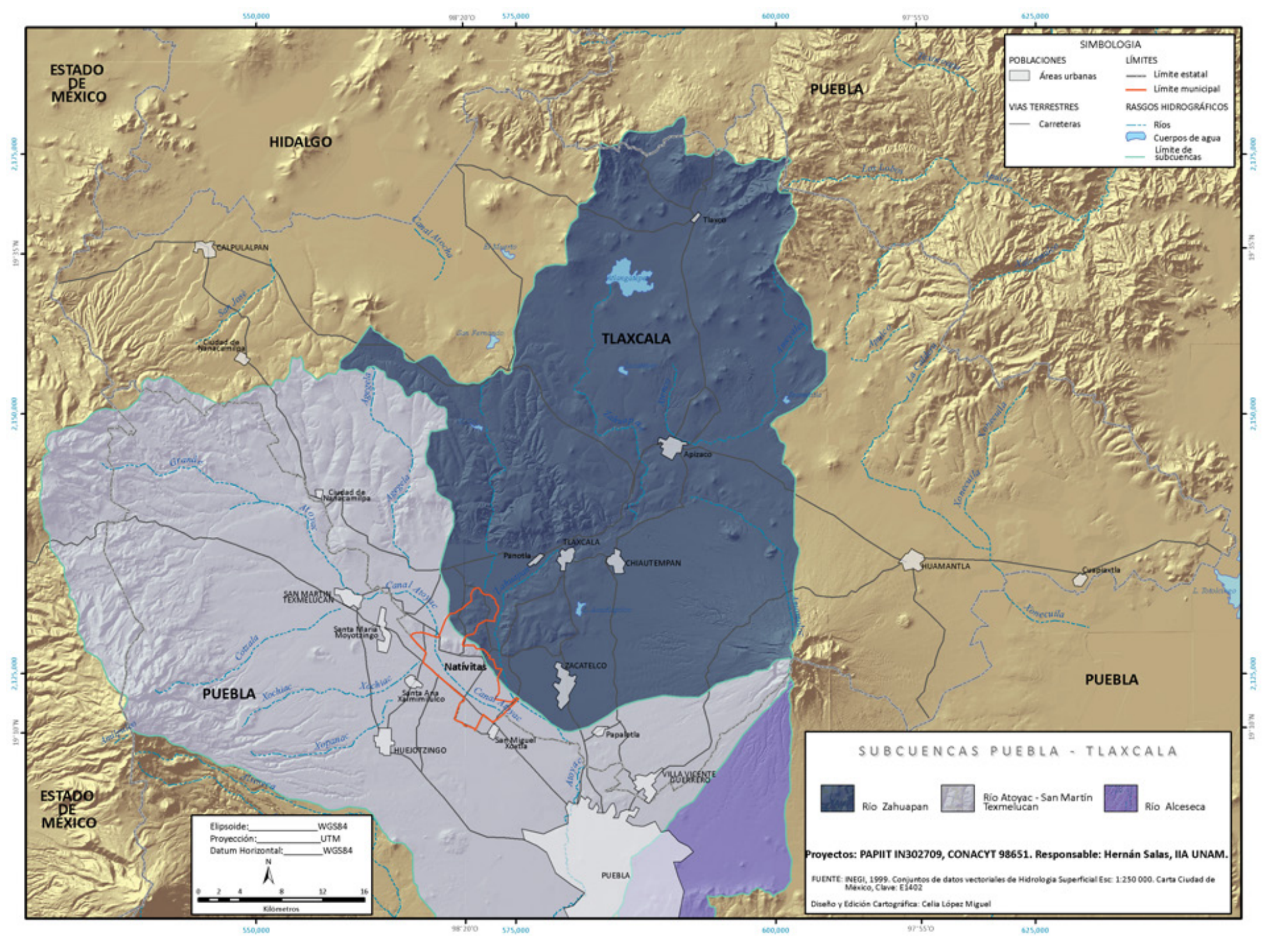


Mapa 18. Mapa geológico, la escala de trabajo de esta cartografía es 1:250 000 del INEGI. La roca de las partes altas del municipio de Nativitas son tobas intermedias y las partes que corresponden a la planicie

son depósitos aluviales. Como información de referencia se dejaron los límites de las subcuencas, con fines de interpretación y descripción del mapa. 


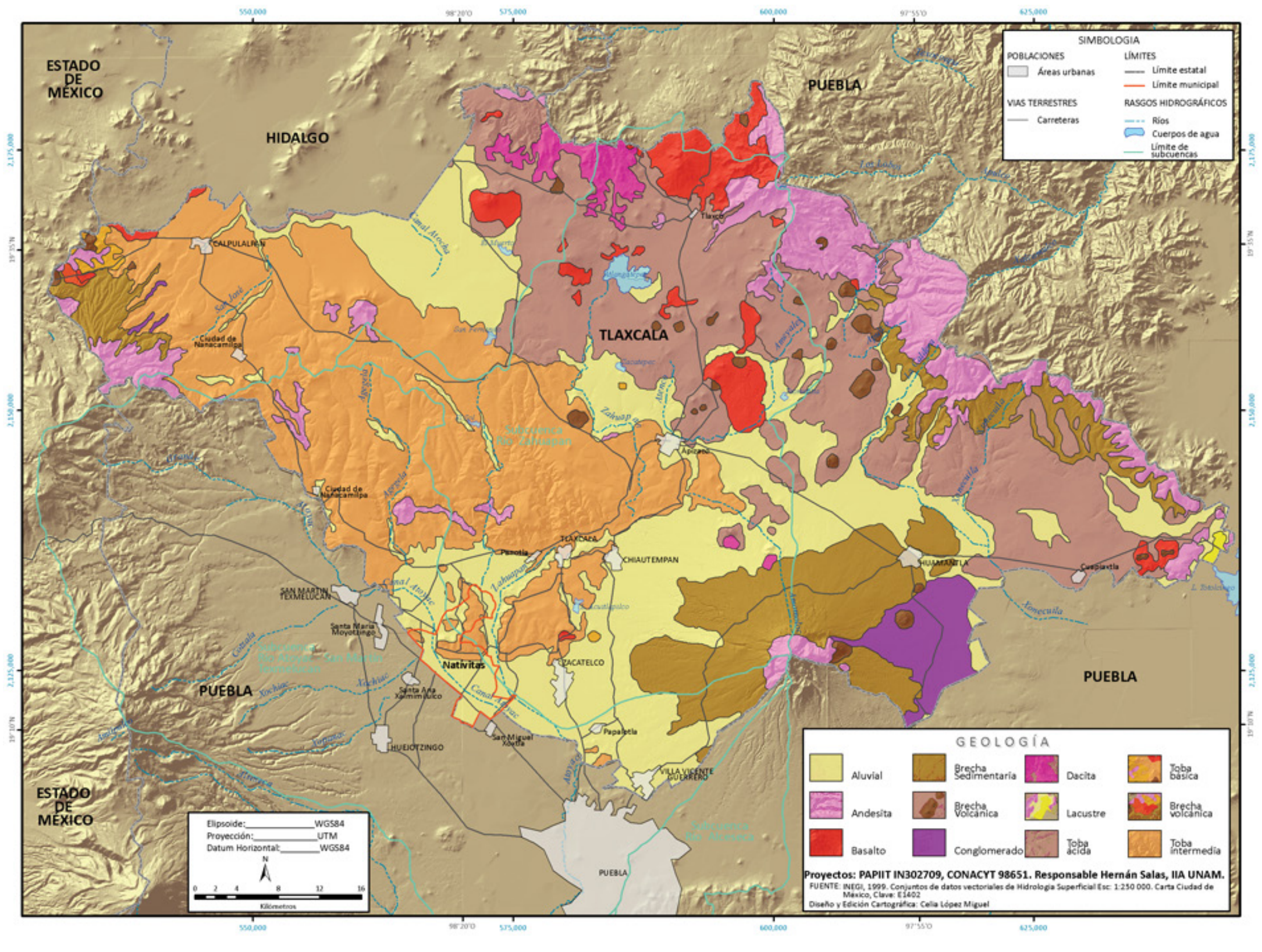


Mapa 19. Mapa de agua subterránea UE. Dentro del municipio de Nativitas se localizan dos pozos de uso doméstico y uno sin uso. Se debe tomar en cuenta que estamos hablando de una cartografía con muy poco detalle $1: 250000$ 


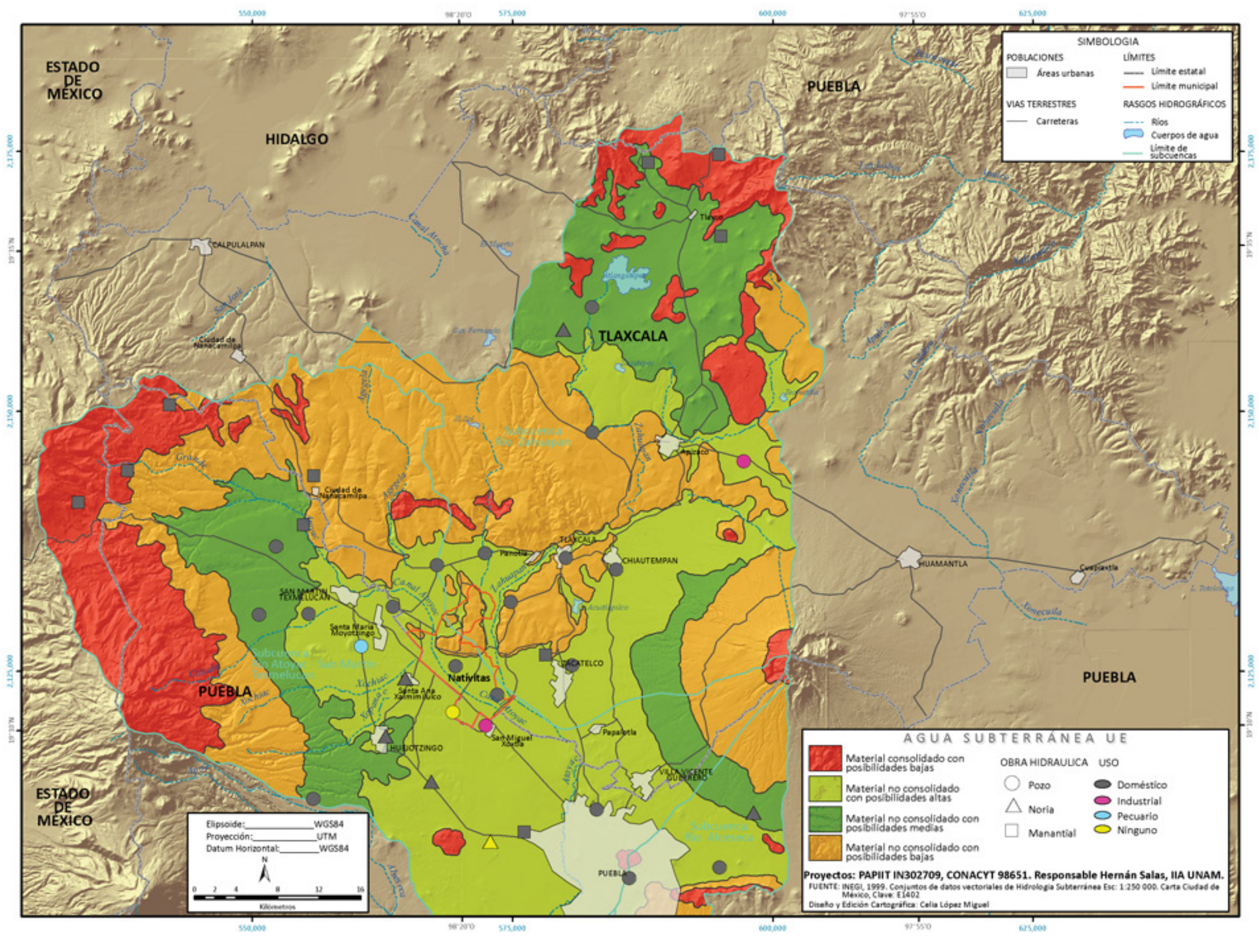


Mapa 20. Mapa de agua subterránea VE. El municipio de Nativitas se localiza dentro de un área de veda. 


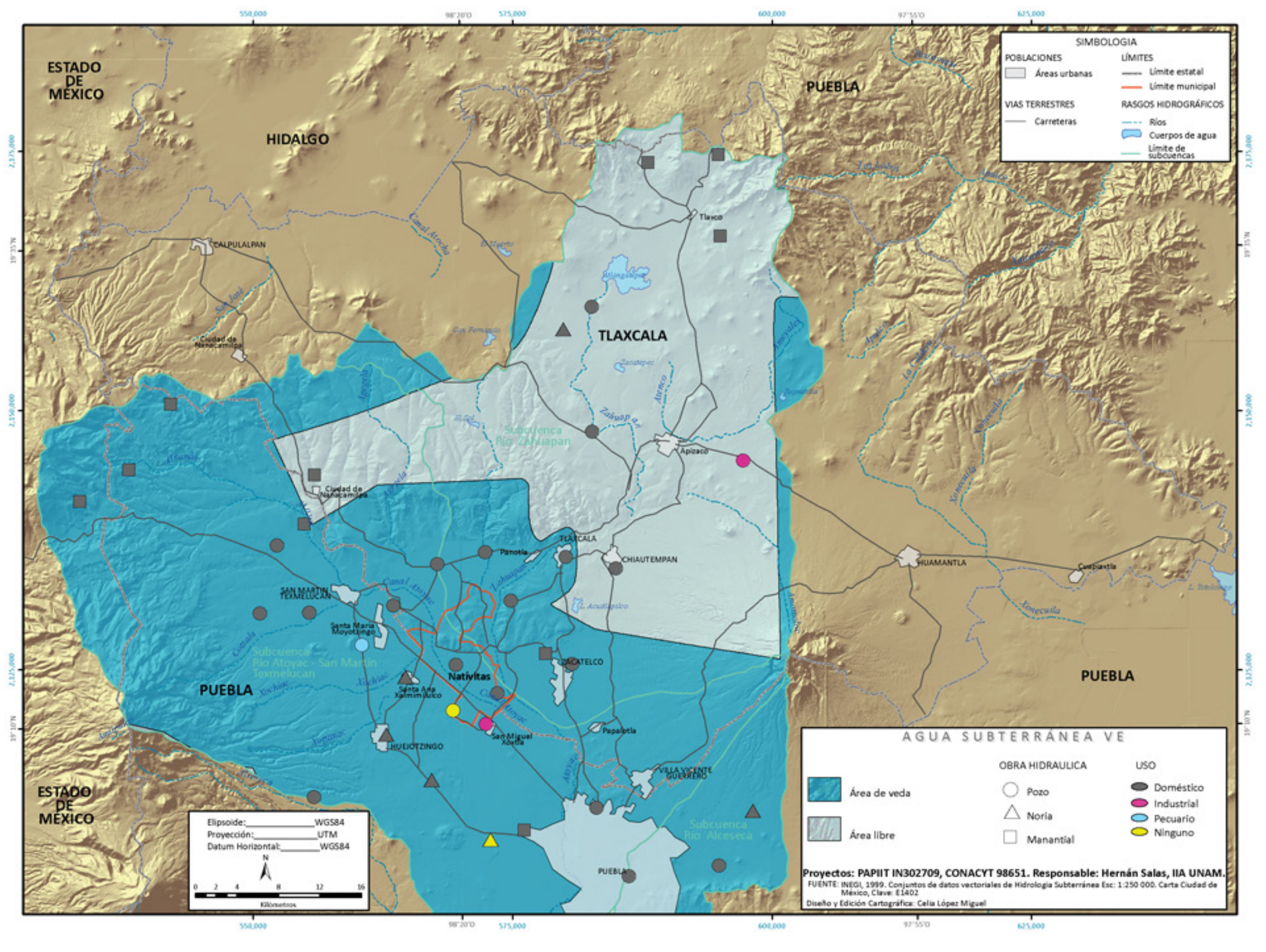


Mapa 21. Mapa de agua superficial EE. El municipio de Nativitas se localiza dentro de un área con un coeficiente de escurrimiento del 10 al $20 \%$. 


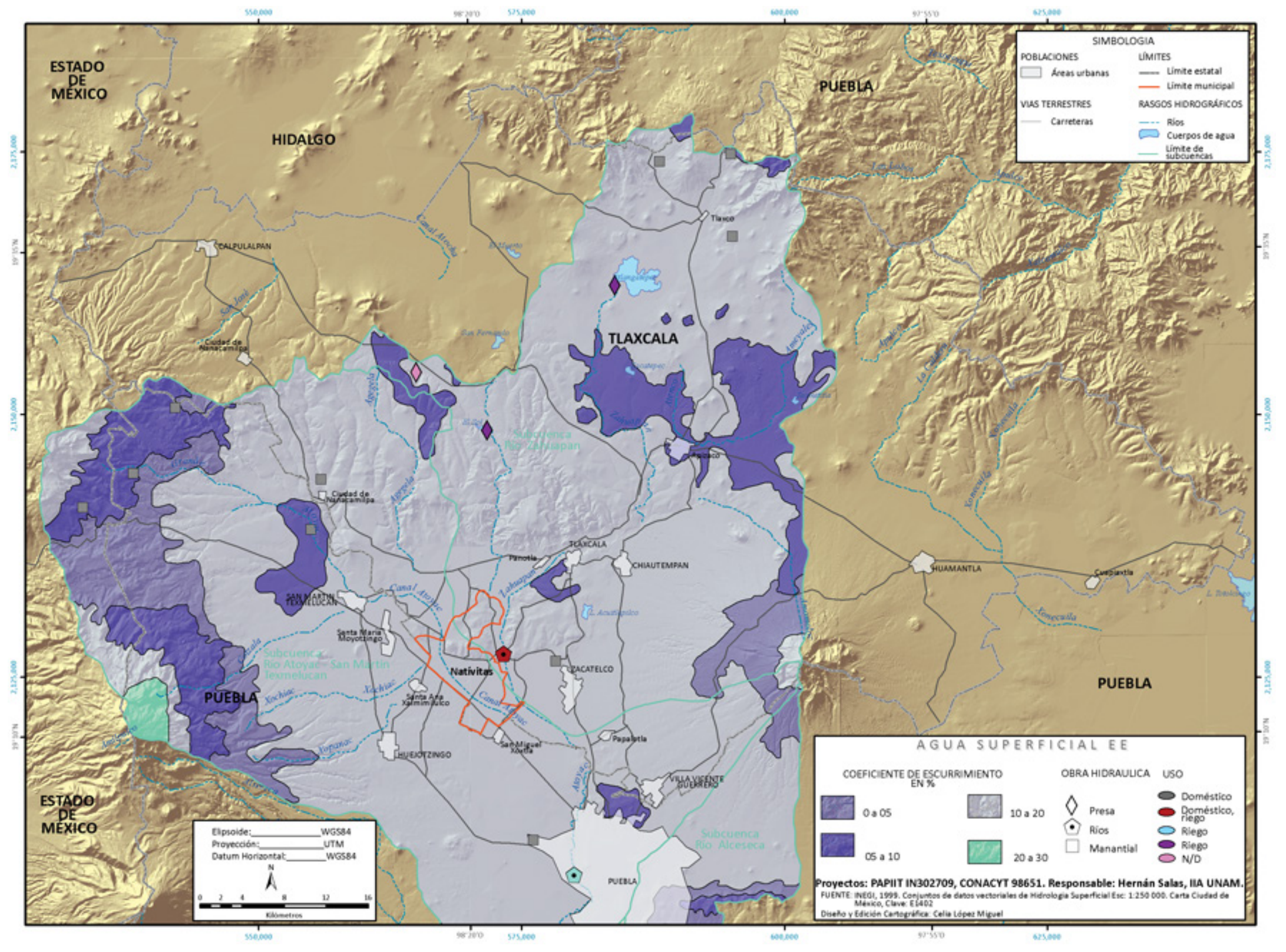





\section{ÍNDICE DE FIGURAS, CUADROS Y MAPAS}

\section{FIGURAS}

Figura 1. Canales, lagunas, chinampas y manantiales termales en la planicie del suroeste de Tlaxcala. Subcuenca Puebla-Tlaxcala. Época prehispánica-siglo XIx

Figura 2. Profundidad del nivel freático y dirección de los flujos de agua subterránea. Subcuenca Puebla-Taxcala, 1972-1973

Figura 3. Diagrama con la territorialidad y fronteras en el momento del contacto, valle de Texmelucan

Figura 4. Nativitas en la zona metropolitana Puebla-Tlaxcala (ZMPT 2005) y área de mercado de la hacienda Segura Michac durante la última administración (1960)

Figura 5. Superficie sembrada y cultivo por año censal en el estado de Tlaxcala (1956-2007) 108

Figura 6. Superficie sembrada y cultivo por año censal en el municipio de Nativitas (1956-2007) .... 109

Figura 7. Población total de Nativitas de 1990-2010 120

\section{CUADROS}

Cuadro 1. Población por distritos y municipalidades del estado de Tlaxcala a fines del siglo xix ....... 25

Cuadro 2. Obispado de Puebla. Distribución geográfica de la producción de trigo en fanegas, 1602-1624

Cuadro 3. Obispado de Puebla. Distribución geográfica del valor del diezmo líquido (en reales) 1675-1694

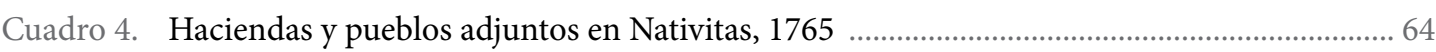

Cuadro 5. Población de la Municipalidad de Nativitas (1901). 
Cuadro 6. Caminos, ganado e inventario vehicular en Nativitas (1901) ...................................................... 68

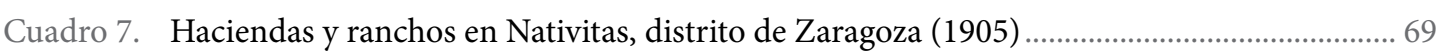

Cuadro 8. Haciendas en el partido de Nativitas, Tlaxcala, 1712 ……………………………………..... 76

Cuadro 9. Pueblos favorecidos de afectaciones a haciendas en el valle de Nativitas, 1917-1937 .......... 77

Cuadro 10. Número de haciendas y ranchos en Tlaxcala, 1712-1930 ........................................................ 80

Cuadro 11. Variables y condiciones en la región sur de Tlaxcala en la etapa revolucionaria de 1910 ...... 82

Cuadro 12. Padrón y afectaciones a la hacienda Segura Michac,

su aportación territorial y económica ....................................................................................... 87

Cuadro 13. Superficie total y relativa por cultivo en Nativitas, 2009 ............................................................ 109

Cuadro 14. Ganado y recursos pecuarios en Nativitas ................................................................................ 111

Cuadro 15. Promedio por década de la superficie cosechada (ha) de trigo 1940-1988 .......................... 124

Cuadro 16. Superficie cosechada (ha) de alfalfa y trigo en Nativitas y Tlaxcala para el periodo de 1950-2007

Cuadro 17. Superficie de labor ejidal y de propiedad privada en Nativitas, 1950-2007 ........................... 132

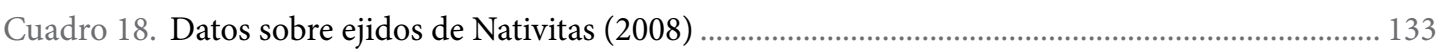

Cuadro 19. Información sobre ejidatarios y personas que ocupan los ejidos en Nativitas ..................... 134

Cuadro 20. Población municipal de la región afectada por la contaminación del río Atoyac ................. 152

Cuadro 21. Evolución de la PEA (porcentaje) en el estado de Tlaxcala (1980-2010) ............................... 171

Cuadro 22. Evolución de la PEA (total y porcentaje) en el municipio de Nativitas (1980-2010) ............ 172

Cuadro 23. Superficie sembrada (hectáreas), Nativitas, ciclo 1996-97, 2001-02 y año 2008 .................. 175

Cuadro 24. Maíz, superficie sembrada (hectáreas) y producción, Nativitas, 1960-2008 ......................... 176

MAPAS

Mapa 1. Mapa antiguo: División territorial de Tlaxcala, 1848 .............................................................. 227

Mapa 2. Sobreposición de las divisiones territoriales del estado de Tlaxcala (en 1848) sobre el modelo de relieve sombreado (MDRS) 
Mapa 3. División territorial de Tlaxcala. 1848-1881 .................................................................... 231

Mapa 4. División territorial actual de Tlaxcala _............................................................................ 233

Mapa 5. Localización del municipio de Nativitas con las 13 comunidades de estudio .................... 235

Mapa 6. Ubicación de las zonas de cambios territoriales dentro del municipio de Nativitas .......... 237

Mapa 7. Ejemplo 1. San Miguel Xochitecatitla. Ubicación de las zonas de cambios ........................ 239

Mapa 8. Ejemplo 2. Santiago Michac. Ubicación de las zonas de cambios ..........................................2241

Mapa 9. Ejemplo 3. Santo Tomás la Concordia. Ubicación de las zonas de cambios ...................... 243

Mapa 10. Plano (dibujo) del estado de Tlaxcala con la ubicación de las haciendas, vías de comunicación y fábricas, 1881 ................................................................................ 245

Mapa 11. Mapa georreferenciado de las haciendas en 1881 ............................................................. 247

Mapa 12. Ubicación de las haciendas (siete) dentro del municipio de Nativitas, 2010 ...................... 249

Mapa 13. Ubicación de corredores y parques industriales ................................................................ 251

Mapa 14. Ubicación de corredores industriales (los más cercanos al municipio de Nativitas) y parque industrial de Ixtacuixtla .................................................................................. 253

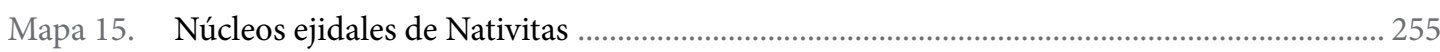

Mapa 16. Mapa de la cuenca de México, el eje volcánico, el valle de San Martin Texmelucan

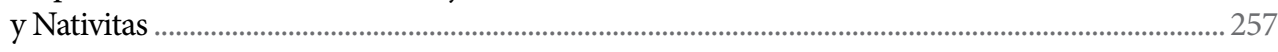

Mapa 17. Mapa de las subcuencas Puebla-Tlaxcala _....................................................................2 259

Mapa 18. Mapa geológico, subcuenca Puebla-Tlaxcala ....................................................................... 261

Mapa 19. Mapa de agua subterránea UE valle de Tlaxcala .............................................................. 263

Mapa 20. Mapa de agua subterránea VE planicie de Tlaxcala ..........................................................2.265

Mapa 21. Mapa de agua superficial del municipio de Nativitas ..........................................................2 267 


\section{BIBLIOGRAFÍA}

\section{Авоites, Luis}

1999 "Relación sociedad-naturaleza desde la historia de los usos del agua en México (1900-1940)", Bernardo García M. y Alba González J. (comps.), Estudios sobre historia y ambiente en América I, El Colegio de México, Instituto Panamericano de Geografía e Historia, México: 173-190.

\section{Aeppli, Hans}

1972 Mapa de los suelos de la cuenca Puebla-Tlaxcala, Franz Steiner (El proyecto México de la Fundación Alemana para la investigación científica, 8), Stuttgart.

\section{Agrogeología y Secretaría de Recursos Hidráulicos}

1973 "Estudio Geohidrológico preliminar de los valles de Puebla (Alto Atoyac), en el estado de Puebla y del río Zahuapan (Alto Atoyac), en el estado de Tlaxcala”, tomo 1, Secretaría de Recursos Hidráulicos, México.

\section{Aguirre, Gonzalo}

1991 Obra antropológica, IV. Formas de gobierno indígena, Fondo de Cultura Económica, México.

\section{AKRAM-LOHDi, Haroon y CRISTÓBAl KaY}

2009 "The agrarian question. Peasants and rural change", A. Haroon Akram-Lodhi y Cristóbal Kay (eds.), Peasants and Globalization. Political Economy, Rural Transformation and the Agrarian Question, Routledge, Abingdon, Nueva York: 3-34.

2010 "Surveying the Agrarian Question (Part 2): Current Debates and Beyond", Journal of Peasant Studies, 37 (2): 255-284.

\section{Albores, Beatriz y Johanna Broda (coords.)}

1997 Los graniceros, cosmovisión y meteorología indígena de Mesoamérica, El Colegio Mexiquense, Universidad Nacional Autónoma de México, México. 


\section{Anderson, Nels}

1975 Sociología de la comunidad urbana, Fondo de Cultura Económica, México.

\section{Anguiano, María Eugenia y Alma Paola Trejo}

2007 "Vigilancia y control en la frontera México-Estados Unidos: efectos en las rutas del flujo migratorio internacional", Papeles de Población, 51: 45-75.

\section{ANónimo}

1906 "El establo y criadero de la hacienda de Santa Águeda", La Antigua República, Semanario de Política, Variedades y Anuncios. Destinado preferentemente a defender y fomentar los intereses generales del Estado Libre y Soberano de Tlaxcala, Quinta Época, 78,29 de julio.

\section{Araghi, Farshad}

2009 "The Invisible Hand and the Visible Foot. Peasants, Dispossession and Globalization", A. Haroon Akram-Lodhi y Cristóbal Kay (eds.), Peasants and Globalization. Political Economy, Rural Transformation and the Agrarian Question, Routledge, Abingdon, Nueva York: 111-147.

\section{Arana, María, José Rodríguez y Guillermo Carrasco}

2009 "La migración de jornaleros agrícolas tlaxcaltecas a Canadá: un sistema complejo", Agricultura, Sociedad y Desarrollo, 6 (1): 61-79.

\section{Arana, SOCORro}

2011 “Trabajadores migrantes, agrícolas y temporales de Tlaxcala a Canadá: un grupo vulnerable", ponencia presentada en el II Seminario sobre migración de tlaxcaltecas hacia Estados Unidos y Canadá, El Colegio de Tlaxcala, Tlaxcala.

\section{Arias, Patricia}

2009 "La pluriactividad rural a debate", Hubert Carton de Grammont y Luciano Martínez (comps.), La pluriactividad en el campo latinoamericano, Facultad Latinoamericana de Ciencias Sociales Ecuador, Quito: 171-205.

\section{Art, Henry W.}

1993 The Dictionary of Ecology and Environmental Science, Henry Holt and Company, Nueva York. 


\section{Atoyac Zahua pan y Calidad de Vida y Centro “Fray Julián Garcés”}

2009 Situación del derecho a la salud en México y Centroamérica. Justiciabilidad y exigibilidad en los casos de daños a la salud por contaminación en los estados de Tlaxcala y Puebla, Atoyac Zahuapan y Calidad de Vida, Centro "Fray Julián Garcés", Tlaxcala.

\section{BANCO DE MÉXICO}

2008 [en línea] "Indicadores económicos y financieros. Balanza de pagos", Instituto Nacional de Estadística, Geografía e Informática, <http://www.inegi.gob.mx/est/contenidos/espanol/rutinas/ept.asp?t=rem01\&c=7970\&e=29> [consulta: 1 de agosto de 2008].

\section{BARKIN, DAVID}

2001 “La nueva ruralidad y la globalización”, E. Pérez y M. A. Farah (comps.), La nueva ruralidad en América Latina, tomo II, Pontificia Universidad Javeriana, Bogotá: 21-40.

\section{Barros, Magdalena}

2007 "The Mexican Peasantry and the Ejido in the Neo-liberal Period", D. Bryceson, C. Kay y J. Mooij (eds.), Disappearing Peassantries? Rural Labour in Africa, Asia and Latin America, Intermediate Technology Publication, Londres: 159-175.

\section{BARTOlOmé, Miguel}

2009 "Una lectura comunitaria de la etnicidad en Oaxaca", Miguel Lisbona (coord.), La comunidad a debate. Reflexiones sobre el concepto de comunidad en el México contemporáneo, El Colegio de Michoacán, Universidad de Ciencias y Artes de Chiapas, Zamora: 101-119.

\section{BAUMAN, ZygmunT}

2007 Tiempos líquidos. Vivir en una época de incertidumbre, Tusquets, Barcelona.

\section{BECK, ULRICH}

2006 La sociedad del riesgo. Hacia una nueva modernidad, Paidós Ibérica, Barcelona.

\section{BERIAIN, JOSETXO (COMP.)}

1996 Las consecuencias perversas de la modernidad, Anthropos, Barcelona. 
Bernal, María Elena y Ángel Julián García

2006 "El altepetl colonial y sus antecedentes prehispánicos", Federico Fernández Christlieb y Ângel Julián García Zambrano (coords.), Territorialidad y paisaje en el altepetl del siglo XVI, Fondo de Cultura Económica, Instituto de Geografía, Universidad Nacional Autónoma de México, México: 31-113.

\section{Binford, Leigh, Guillermo Carrasco, Socorro Arana y Soledad Santillana}

2004 Rumbo a Canadá. La migración canadiense de trabajadores agrícolas tlaxcaltecas, Universidad Autónoma de Tlaxcala, Sistema de Investigación Ignacio Zaragoza, Tlaxcala.

\section{Boehm de LAMEIRAs, BRigitTe}

2003 "Transformación del paisaje industrial y urbano en el occidente de México: los proyectos de la familia Cuesta Gallardo durante el porfiriato", ponencia presentada en $51^{\circ}$ Congreso Internacional de Americanistas, Santiago de Chile.

\section{BONFIL, GUILLERMO}

1988 Cholula. La ciudad sagrada en la era industrial, Benemérita Universidad Autónoma de Puebla, Puebla.

2003 México profundo: una civilización negada, Grijalbo, México.

\section{Bonnal, Philippe, Pierre Marie Bosc, Mario Díaz y B. Losch}

2004 "Multifuncionalidad de la agricultura y nueva ruralidad: ¿reestructuración de las políticas públicas a la hora de la globalización?”, Edelmira Pérez et al. (comps.), Desarrollo rural y nueva ruralidad en América Latina y la Unión Europea, Pontificia Universidad Javeriana, Bogotá: 19-41.

\section{BOUQUET, EMMANUELle}

1999 "Mercado de tierras ejidales en Tlaxcala. Formalidad e informalidad del cambio institucional”, Estudios Agrarios, 11: 67-106.

\section{Bourdieu, Pierre}

2001 Las estructuras sociales de la economía, Manantial, Buenos Aires.

2009 El sentido práctico, Siglo Veintiuno, México. 


\section{BRAUDEL, FERNAND}

1986 La historia y las ciencias sociales, Alianza, México.

1989 El mediterráneo: el espacio y la historia, Fondo de Cultura Económica, México.

2002 "Geohistoria: la sociedad, el espacio y el tiempo", Fernand Braudel, Las ambiciones de la historia, Crítica, Barcelona: 53-89.

\section{BRITO, BALTAZAR}

2011 Huexotzingo en el siglo XVI. Fragmentación de un altepetl mesoamericano, tesis, Facultad de Filosofía y Letras, Universidad Nacional Autónoma de México, México.

\section{Broda, Johanna, Stanislaw Iwaniszewski y Arturo Montero (coords.)}

2001 La montaña en el paisaje ritual, Universidad Nacional Autónoma de México, Benemérita Universidad Autónoma de Puebla, Instituto Nacional de Antropología e Historia, Consejo Nacional para la Cultura y las Artes, México.

\section{BRYCESON, DEBORAH}

2007 "Peasant Theories and Smallholder Policies: Past and Present", Deborah Bryceson, Cristóbal Kay y Jos Mooij (eds.), Disappearing Peasantries? Rural Labour in Africa, Asia and Latin America, Intermediate Technology Publications, Londres: 1-36.

\section{BustamANTE, JORGE}

2006 "La migración indocumentada de México a Estados Unidos; la dialéctica de la vulnerabilidad y los derechos humanos", ponencia presentada en el Simposio Internacional La vulnerabilidad de los migrantes internacionales, Monterrey, 3 y 4 de noviembre.

\section{Busto, Emiliano}

1880 Estadística de la República Mexicana, tomo III, Ignacio Cumplido, México.

\section{BuvE, RAYMOND}

1975 "Peasant movements, caudillos and Landreform during the Revolution (1910-1917) in Tlaxcala, Mexico", Boletín de Estudios Latinoamericanos y el Caribe, 18 (18): 112-152.

1979 "Movilización campesina y reforma agraria en los valles de Nativitas, Tlaxcala (19171923): Estudio de un caso de lucha por recuperar tierras habidas durante la revolución armada”, Elsa Cecilia Frost, Michael C. Meyer y Josefina Zoraida Vázquez (comps.), El trabajo y los trabajadores en la historia de México, El Colegio de México, University of Arizona Press, México: 533-565. 
1986 "La Revolución mexicana: el caso de Tlaxcala a la luz de las recientes tesis revisionistas", Historia y sociedad en Tlaxcala. Memorias del Primer Simposio Internacional de Investigaciones Socio-Históricas sobre Tlaxcala, Gobierno del Estado de Tlaxcala, Instituto Tlaxcalteca de Cultura, Universidad Autónoma de Tlaxcala, Universidad Iberoamericana, Tlaxcala: 119-134.

1989 "Agricultores, dominación política y estructura agraria en la Revolución Mexicana: el caso de Tlaxcala (1910-1918)", Revista Mexicana de Sociología, II (2): 181-236.

2010 Amores y odios compartidos. Puebla y Tlaxcala (1800-1920), Ediciones de Educación y Cultura, Benemérita Universidad Autónoma de Puebla (Colección Especial Bicentenario), Puebla.

\section{Calva, José Luis}

1993 La disputa por la tierra: la reforma del artículo 27 y la nueva ley agraria, Fontamara, México.

\section{CAMAcho, Gloria}

1998 Repartimientos y conflictos por el agua en los valles de Atlixco e Izúcar, Puebla, tesis, Centro de Investigaciones y Estudios Superiores en Antropología Social, México.

\section{Cámara, Fernando}

2009 "Epílogo. Sociedades, comunidades y localidades", Leif Korsbaek y Fernando Cámara (eds.), Etnografía del sistema de cargos en comunidades indígenas del Estado de México, MC Editores, México: 375-414.

\section{Canabal, Beatriz}

2008 Hacia todos los lugares... Migración jornalera indígena de la Montaña de Guerrero, Universidad Autónoma Metropolitana-Xochimilco, Secretaría de Asuntos Indígenas del Gobierno del Estado de Guerrero, Universidad Intercultural de los Pueblos del Sur, Centro de Investigaciones y Estudios Superiores en Antropología Social, México.

\section{Canales, Alejandro}

2007 "Los inmigrantes latinoamericanos en Estados Unidos: inserción laboral con exclusión”, A. Canales (ed.), Panorama actual de las migraciones en América Latina, Universidad de Guadalajara, Asociación Latinoamericana de Población, Guadalajara: 81-116. 


\section{Cancian, Frank}

1989 Economía y prestigio en una comunidad maya. El sistema religioso de cargos en Zinacantan, Instituto Nacional Indigenista, México.

\section{Carrasco, Pedro}

1976 “Los linajes nobles del México Antiguo", Pedro Carrasco, Johanna Broda et al., Estratificación social en la Mesoamérica prehispánica, Instituto Nacional de Antropología e Historia, México: 19-36.

\section{Carton de Grammont, Hubert}

1999 Agricultura de exportación en tiempos de globalización, Juan Pablos, México.

2004 "La nueva ruralidad en América Latina", Revista de Sociología, 66, Número Especial: 279-300.

2006 [en línea] "La nueva estructura ocupacional en los hogares rurales mexicanos: de la Unidad Económica Campesina a la Unidad Familiar Pluriactiva (versión preliminar)", VII Congreso Latino-Americano de Sociología Rural, Asociación Latinoamericana de Sociología Rural, <http://www.alasru.org/cdalasru2006/22\%20GT\%20 Hubert\%20C.\%20de\%20Grammont.pdf> [consulta: 11 de julio de 2008].

2009 “La desagrarización del campo mexicano", Convergencia, 50: 13-55.

\section{Carton de Grammont, Hubert y Luciano Martínez}

2009 “Introducción”, Hubert Carton de Grammont y Luciano Martínez (comps.), La pluriactividad en el campo latinoamericano, Facultad Latinoamericana de Ciencias Sociales Ecuador, Quito: 8-18.

\section{Carton de Grammont, Hubert y Luciano Martínez (comps.)}

2009 La pluriactividad en el campo latinoamericano, Facultad Latinoamericana de Ciencias Sociales Ecuador, Quito.

\section{Castro, Pablo}

2000 "El gobierno indígena en Cozoyoapan: un acercamiento político de la estructura de cargos comunitarios”, Héctor Tejera (coord.), Antropología política. Enfoques contemporáneos, Plaza y Valdés, México: 503-524. 


\section{Centro de Información Empresarial del Estado de Puebla (Ciep)}

s/f [en línea] "Parques industriales del Estado de Puebla", Centro de Información Empresarial del Estado de Puebla, <www.ciepuebla.com.mx/pdf/infra_pin.pdf> [consulta: agosto de 2011].

\section{Cesín, Alfredo, Benito Ramírez, Mario Aliphat y Daniel Martínez}

2010 "Producción de forraje y ganadería lechera en el suroeste de Tlaxcala, México", Tropical and Subtropical Agroecosystems, 12: 639-648.

Cesín, Alfredo, Mario Aliphat, Benito Ramírez, José Herrera y Daniel Martínez

2007 "Ganadería lechera familiar y producción de queso. Estudio en tres comunidades del municipio de Tetlatlahuca en el estado de Tlaxcala, México", Técnica Pecuaria en México, 45 (1): 61-76.

\section{Chance, John K. Y William B. Taylor}

1987 "Cofradías y cargos: una perspectiva histórica de la jerarquía cívico-religiosa mesoamericana”, Antropología. Boletín Oficial del Instituto Nacional de Antropología e Historia, 14: 1-24.

\section{Chevalier, François}

1975 La formación de los latifundios en México. Tierra y sociedad en los siglos XVI y XVII, Fondo de Cultura Económica, México.

\section{Comisión Nacional del Agua (Conagua)}

2005 Estadísticas del agua en México 2005, Comisión Nacional del Agua, México.

\section{Consejo Nacional de Población (Conapo)}

2000 [en línea] "Resultados principales del índice de intensidad migratoria México-Estados Unidos, nivel nacional 2000", Consejo Nacional de Población <http://www. conapo.gob.mx/work/models/CONAPO/migracion_internacional/intensidad_migratoria/anexoA.pdf> [consulta: 11 de julio de 2008].

2010 [en línea] "Situación actual de los jóvenes en México", Consejo Nacional de Población, <http://www.conapo.gob.mx/index.php?option=com_content\&view=article\& $\mathrm{id}=446 \&$ Itemid $=15>$ [consulta: 25 de abril de 2011]. 
[en línea] "Intensidad migratoria a nivel estatal y municipal", Consejo Nacional de Población, <http://www.conapo.gob.mx/publicaciones/intensidad_migratoria/texto/IIM_Estatal_y_municipal.pdf> [consulta: 18 de abril de 2012).

\section{Consulado General de México en Toronto}

2011 [en línea] "Programa de trabajadores agrícolas temporales México-Canadá", Consulado General de México en Toronto, <http://www.consulmex.sre.gob.mx/esp/programadetrabajadoresagricolas.asp $>$ [consulta: 27 de enero de 2011].

\section{Corona, Reina y José LUQUe}

1992 "Cambios recientes en los patrones migratorios a la Zona Metropolitana de la Ciudad de México, zмcm”, Estudios Demográficos y Urbanos, 7, 2-3 (20-12): 575-586.

\section{CORONA, RODOLFo}

1993 "Migración permanente interestatal e internacional, 1950-1990", Comercio Exterior, 43 (8): 750-762.

\section{Crang, Mike}

1998 Cultural Geography, Routledge, Nueva York.

\section{Cuéllar, Crisanto}

1935 Juan Cuamatzi. Indio tlaxcalteca, precursor de la Revolución mexicana: apuntes para la historia, Talleres Tipográficos de Efrén Suárez, México.

1961 Domingo Arenas, caudillo agrarista, Difusión Cultural del Estado de Tlaxcala, Tlaxcala.

\section{Davinson, Guillermo y Magdalena Sam}

2003 El embargo: una forma de cumplir las normas en dos pueblos de Tlaxcala, Universidad Autónoma de Tlaxcala, Tlaxcala.

\section{Delgado, JAVier}

1999 "La nueva ruralidad en México", Investigaciones Geográficas, 39: 82-93.

\section{Delgado, Manuel}

2009 "Espacio público y comunidad. De la verdad comunitaria a la comunicación generalizada", Miguel Lisbona (coord.), La comunidad a debate. Reflexiones sobre el concepto de comunidad en el México contemporáneo, El Colegio de Michoacán, Universidad de Ciencias y Artes de Chiapas, Zamora: 39-59. 


\section{Dirección Nacional de Estadística (DGE)}

1930 I Censo Agrícola Ganadero, Dirección de Censos de los Estados Unidos Mexicanos, México.

1956 III Censo Agrícola, Ganadero y Ejidal 1950, Tlaxcala, Secretaría de Economía, Dirección General de Estadística, México.

1965 IV Censo Agrícola, Ganadero y Ejidal 1960, Tlaxcala, Secretaría de Industria y Comercio, Dirección General de Estadística, México.

1970 V Censo Agrícola, Ganadero y Ejidal 1970, Tlaxcala, Dirección General de Estadística, México.

\section{DURAND, JORGE}

2006 Temas de migración. Programas de trabajadores temporales. Evaluación y análisis del caso mexicano, Secretaría de Gobernación, Consejo Nacional de Población, México.

2011 "Migración a la baja", La Jornada, 17 de julio de 2011: 19.

\section{Durand, Jorge y Douglas S. Massey}

2003 Clandestinos. Migración México-Estados Unidos en los albores del siglo XXI, Universidad Autónoma de Zacatecas, Miguel Ángel Porrúa, México.

\section{DYCKERHOFF, URSULA}

1988 "La región del Alto Atoyac en la historia: la época prehispánica", Hanns Prem (ed.), Milpa y hacienda. Tenencia de la tierra indígena y española en la cuenca del Alto Atoyac, Puebla, México, (1520-1650), Fondo de Cultura Económica, Centro de Investigaciones y Estudios Superiores en Antropología Social, México: 18-34.

\section{ENCYCLOPAEDIA BRITANICA}

2012 [en línea] "Hinterland", Encyclopaedia Britanica Online, <http://www.britannica. com/EBchecked/topic/266517/hinterland> [consulta: 12 de diciembre de 2012].

Escalante, Roberto, Horacio Catalán, Luis Miguel Galindo y Orlando Reyes

2007 "Desagrarización en México: tendencias actuales y retos hacia el futuro", Cuadernos de Desarrollo Rural, 4 (59): 87-116.

\section{Escobar, Arturo}

1998 La invención del Tercer Mundo. Construcción y deconstrucción del desarrollo, Norma, Santa Fé de Bogotá. 
ESPINA, ANGEL

2003 Emigración e integración cultural. Antropología en Castilla y León e Iberoamérica, V, Universidad de Salamanca, Salamanca.

\section{Estado de Tlaxcala}

1881 Carta del Estado de Tlaxcala mandada a formar por su gobernador el Sr. Don Mariano Grajales y delineada por P. Almazán, Archivo General del Estado de Tlaxcala, Tlaxcala.

\section{exyco, Comisión Nacional del Agua y Secretaría de Agricultura y Recursos \\ Hidráulicos}

1990 "Estudio de actualización geohidrológica del acuífero del valle de Puebla, para abastecimiento de agua a la ciudad de Puebla, Pue., México.

\section{Fabila, Gilberto, Alfonso Fabila, Manuel Mesa y Óscar Soberón}

1955 Tlaxcala. Tenencia y aprovechamiento de la tierra, Centro de Investigaciones Agrarias, México.

\section{Federación Internacional de Derechos Humanos (FIDH)}

2008 Estados Unidos-México. Muros, abusos y muertos en las fronteras. Violaciones flagrantes de los derechos de los migrantes indocumentados en camino a Estados Unidos, Federación Internacional de Derechos Humanos, 488/3, París.

\section{Flores, Aurelia}

2009 "Género y migración en dos sistemas de organización de la tierra en Tlaxcala, México", Agricultura, Sociedad y Desarrollo, 6 (1): 1-31.

\section{Flores, Sergio}

1993 Estructura territorial en la zona metropolitana de la ciudad de Puebla, Sociedad Mexicana de Planificación, Benemérita Universidad Autónoma de Puebla, Universidad Nacional Autónoma de México, México.

\section{GALICIA, Esther}

2009 “Topografía, geología y clima en la cuenca Alto Atoyac. Factores determinantes del funcionamiento de los sistemas de flujo de agua subterránea", Rosalva Loreto (coord.), Agua, poder urbano y metabolismo social, Instituto de Ciencias Sociales y 
Humanidades “Alfonso Vélez Pliego", Benemérita Universidad Autónoma de Puebla, México: 25-45.

2010 "Rasgos generales de funcionamiento del sistema hídrico y el desarrollo socioeconómico en el ambiente acuático en la planicie Tlaxcala, subcuenca Puebla-Tlaxcala. Siglos XVI-Xx", ponencia presentada en el II Congreso Nacional RETAC-Conacyt $\mathrm{La}$ investigación del agua en México: avances, deficiencias y retos a superar, Centro Regional de Investigaciones Multidisciplinarias, Universidad Nacional Autónoma de México, Cuernavaca, agosto.

\section{GÁlVEZ, GuAdAluPe}

2009 [en línea] “Clausura gobierno local la planta Oxiquímica en San Martín”, Diario Milenio, 14 de abril de 2009, <http://impreso.milenio.com/node/8559748> [consulta: 29 de enero de 2010].

\section{García, BeAtriz}

2009 Historia de la visión territorial del Estado mexicano. Representaciones político-culturales del territorio, Universidad de Guadalajara, Universidad Nacional Autónoma de México, México.

\section{García Cubas, Antonio}

1903 Atlas metódico para la enseñanza de la geografía de la República Mexicana, Imprenta Munguía, México.

\section{García IndA, ANDRÉs}

2001 "Introducción. La razón del derecho: entre habitus y campo", Pierre Bourdieu, Poder, derecho y clases sociales, Desclée, Bilbao: 9-60.

\section{GAYOL, ROBERTO}

1994 [1909] Dos problemas de vital importancia para México. La colonización y el desarrollo de la irrigación Tlaxcala, Instituto Mexicano de Tecnología del Agua, Centro de Investigaciones y Estudios Superiores en Antropología Social, México.

\section{GEO MÉXICO}

2004 Perspectivas del medio ambiente en México, Programa de las Naciones Unidas para el Medio Ambiente, Secretaría de Medio Ambiente y Recursos Naturales, México. 


\section{GEOTECNOLOGÍA}

1997 “Actualización del estudio geohidrológico de los acuíferos del Valle de Puebla", informe final, tomos I, III y VII, Sistema Operador de Agua Potable y Alcantarillado del Municipio de Puebla, México.

\section{Giordano, Carlos}

2011 "Las haciendas de la provincia de Tlaxcala en la Nueva España durante el siglo xvirI", Bibliographica Americana, 7: 112-135.

\section{GLEDHILL, JOHN}

2000 El poder y sus disfraces. Perspectivas antropológicas de la política, Bellaterra, Barcelona.

\section{Gómez, Francisco Javier}

1998 Tanto que costó. Clase, cultura y nueva ley agraria en un ejido, Instituto Nacional de Antropología e Historia, México.

\section{GonzÁlez de la Fuente, Í̃̃̃go}

2011a "El sistema de cargos en una sociedad local urbanizada, industrializada y mestiza", Hernán Salas, Leticia Rivermar y Paola Velasco (eds.), Nuevas ruralidades. Expresiones de la transformación social en México, Instituto de Investigaciones Antropológicas, Universidad Nacional Autónoma de México, Juan Pablos, México: 165-181.

2011 b "Comunidad, sistema de cargos y proyecto social. Una propuesta analítica de sociedades locales en México", AIBR. Revista de Antropología Iberoamericana, 6 (1): 81-107.

\section{González de la Fuente, Í̃̃igo y Hernán Salas}

2012 "Community Projects in the Era of Globalization: The Case of a Local Rural Society in Mexico", Anthropological Notebooks, 18 (1): 41-64.

\section{GonzÁlez Jácome, Alba}

1991 "Evolución de la industria textil en Tlaxcala. Siglo xix y primera mitad del xx", Alba González Jácome (comp.), La economía desgastada. Historia de la producción textil en Tlaxcala, Universidad Autónoma de Tlaxcala, Universidad Iberoamericana, México: $12-42$.

1999 "El paisaje lacustre y los procesos de desecación en Tlaxcala, México", Bernardo García M. y Alba González J. (comps.), Estudios sobre historia y ambiente en Améri- 
ca I, El Colegio de México, Instituto Panamericano de Geografía e Historia, México: 191-218.

2002 "Paisajes del pasado: Los canales del suroeste de Tlaxcala, México", Bernardo García M. y María del Rosario P. (comps.), Estudios sobre historia y ambiente en América II, El Colegio de México, Instituto Panamericano de Geografía e Historia, México: 203-221.

2006 "El ambiente y la agricultura en Tlaxcala durante el siglo xvI", Perspectivas Latinoamericanas, 3: 19-46.

2008 Humedales en el suroeste de Tlaxcala. Agua y agricultura en el siglo xx, Universidad Iberoamericana, México.

\section{GonZález, Adrián}

2008 Migración y pobreza: remesas, condiciones de vida y trayectorias laborales de migrantes tlaxcaltecas en Estados Unidos y Canadá, El Colegio de Tlaxcala, Gobierno del Estado de Tlaxcala, Tlaxcala.

\section{GONZÁLEZ, ISABEL}

1969 Haciendas y ranchos de Tlaxcala en 1712, Instituto Nacional de Antropología e Historia, México.

\section{Granados, Diódoro y Rocío TAPIA}

1990 Comunidades vegetales, Universidad Autónoma Chapingo (Colección Cuadernos Universitarios, Serie de Agronomía, 19), Chapingo.

\section{Guevara, Jorge}

1991 "La identidad étnica de los olmecas-xicalancas", Historia y Sociedad en Tlaxcala. Memorias del IV y V Simposios Internacionales de Investigaciones Socio-Históricas sobre Tlaxcala, 1988 y 1989, Gobierno del Estado de Tlaxcala, Instituto Tlaxcalteca de Cultura, Universidad Autónoma de Tlaxcala, Universidad Iberoamericana, México: 132-135.

\section{GutiérRez, Silvano}

2004 "Características de la emigración pendular femenina como estrategia de sobrevivencia. El caso de las mujeres de Santa Ana Nopalucan, Tlaxcala”, Danú Fabre, Amelia Molina y Carlos Rodríguez (coords.), Investigación y desarrollo regional en ciencias 
sociales y humanidades. Hidalgo, Puebla y Tlaxcala, Praxis, Universidad Autónoma de Hidalgo, México: 173.

\section{H. Ayuntamiento de Nativitas}

s/f H. Ayuntamiento de Nativitas, <http://www.nativitas.gob.mx/work/sites/Tlaxcala/ resources/.../nativitasweb.swf $>$ [consulta: 19 de junio de 2011].

\section{HARVEY, DaVid}

1989 The Condition of Postmodernism. An Inquiry into the Origin of Cultural Change, Cambridge University Press, Cambridge.

2005 The New Imperialism, Oxford University Press, Nueva York.

2006 "Neo-liberalism as Creative Destruction", Geografiska Annaler, Series B, Human Geography, 88 (2): 145-158.

\section{HERnÁndez, J. LuIS Y R. MALdonado}

1991 Estudio geohidrológico del valle de Puebla, Pue., tesis, Facultad de Ingeniería, Universidad Nacional Autónoma de México, México.

\section{Hernández Lara, Oscar Gerardo}

2011 De la hacienda a la cabecera municipal. Geohistoria de las transformaciones socioeconómicas y territoriales en Nativitas, Tlaxcala, 1924-2010, tesis, Instituto de Investigaciones Dr. José María Luis Mora, México.

\section{HeRnández, María de Lourdes}

2011 "Conflictos por el agua en la microcuenca Atoyac-Zahuapan", Raúl Jiménez G. y María de L. Hernández (coords.), Zahuapan: río-región-contaminación, El Colegio de Tlaxcala, Tlaxcala: 233-252.

\section{HERnÁNDEZ, RAMSÉS y MARgarita LOERA}

2008 "El templo cristiano y su conexión con el Tlalocan mesoamericano", Historias, (70): 23-38.

\section{Herrera, Fernando, Óscar Calderón y Leticia Hernández}

2007 "Redes que comunican y redes que enclaustran: evidencia de tres circuitos migratorios contrastantes”, Migración y Desarrollo, 8: 3-23. 


\section{Hewitt de Alcántara, Cynthia}

1988 La modernización de la agricultura mexicana, 1940-1970, Siglo Veintiuno, México.

\section{HoBSBAw M, ERIC}

1998 La historia del siglo xx, Crítica, Grijalbo Mondadori, Buenos Aires.

\section{Instituto NaCional de Estadística, Geografía e INFOR mática (INEGi)}

1980 X Censo General de Población y Vivienda de 1980, Instituto Nacional de Estadística, Geografía e Informática, México.

1981a VI Censo Agrícola, Ganadero y Ejidal (Tlaxcala), Resumen General, (resultados muestrales a nivel nacional y por entidad federativa), Instituto Nacional de Estadística, Geografía e Informática, México.

1981b Tabulados Básicos. Estados Unidos Mexicanos. X Censo General de Población y Vivienda, Instituto Nacional de Estadística, Geografía e Informática, México.

1982a X Censo General de Población y Vivienda. Estado de Tlaxcal, volumen 1, tomo 29, Instituto Nacional de Estadística, Geografía e Informática, México.

1982b X Censo General de Población y Vivienda. Estado de Puebla, volumen 1, tomo 21, Instituto Nacional de Estadística, Geografía e Informática, México.

1991a VII Censo Agrícola, Ganadero y Ejidal (Tlaxcala, República Mexicana), Instituto Nacional de Estadística, Geografía e Informática, Aguascalientes.

1991b Tabulados Básicos. Estados Unidos Mexicanos. XI Censo General de Población y Vivienda, 1990, Instituto Nacional de Estadística, Geografía e Informática, Aguascalientes.

1995 Conteo de Población y Vivienda 1995, Instituto Nacional de Estadística, Geografía e Informática, Aguascalientes.

1996 Cartas Topográficas (conjunto datos vectoriales) E14B32, E14B33, E14B42 y E14B43, escala 1:50,000, Instituto Nacional de Estadística, Geografía e Informática, Aguascalientes.

1999 Modelo digital de elevación, escala 1:50,000 (ciudad de México), Instituto Nacional de Estadística, Geografía e Informática, Aguascalientes.

2001 Tabulados Básicos. Estados Unidos Mexicanos. XII Censo General de Población y Vivienda, 2000, Instituto Nacional de Estadística, Geografía e Informática, Aguascalientes.

2003 [CD-ROM] Sistema para la consulta de los cuadernos estadísticos municipales, Gobierno del Estado de Tlaxcala, copladeT, México. 
2005 II Conteo de Población y Vivienda, Instituto Nacional de Estadística, Geografía e Informática, Aguascalientes.

2007 Síntesis Metodológica del Censo Agrícola-Ganadero, Instituto Nacional de Estadística, Geografía e Informática, Aguascalientes.

2008 [en línea] México en cifras, información nacional, por entidad federativa y municipios (Nativitas, Tlaxcala), Instituto Nacional de Estadística y Geografía, Aguascalientes, $<$ http://www.inegi.org.mx/sistemas/mexicocifras/default.aspx?ent=29> [consulta: 28 de enero de 2011].

2009 [en línea] México en cifras, información nacional, por entidad federativa y municipios (Nativitas, Tlaxcala), Instituto Nacional de Estadística y Geografía, Aguascalientes, $<$ http://www.inegi.org.mx/sistemas/mexicocifras/default.aspx?ent=29> [consulta: 2 de septiembre de 2011].

2010a Anuario estadístico de Tlaxcala, Gobierno del Estado de Tlaxcala, Aguascalientes.

2010b [en línea] Censo de Población y Vivienda 2010, Instituto Nacional de Estadística y Geografía, Aguascalientes, <http://www.censo2010.org.mx> [consulta: 3 de octubre de 2011].

s/fa [en línea] Compendio de Información Geografica Municipal, Instituto Nacional de Estadística y Geografía, Aguascalientes, <http://mapserver.inegi.org.mx > [consulta: 1 de febrero de 2010].

$\mathrm{s} / \mathrm{fb}$ [en línea] Instituto Nacional de Estadística y Geografía, <http://www.inegi.org.mx > [consulta: 2 de junio de 2011].

\section{Instituto Nacional para el Federalismo y el Desarrollo Municipal (inafed)}

s/f [en línea] "Nativitas", Enciclopedia de los Municipios y Delegaciones de México, Instituto Nacional para el Federalismo y el Desarrollo Municipal, México, <http:// www.e-local.gob.mx/work/templates/enciclo/tlaxcala/mpios/29023a.htm $>$ [consulta: 5 de enero de 2012].

\section{JIMÉNEZ, GABRIEL}

2005 Modelo de flujo y transporte de masa en el acuífero del valle de Puebla (zona Puebla), tesis, Instituto de Geofísica, Universidad Nacional Autónoma de México, México.

\section{Kandel, William y Douglas S. Massey}

2002 "The culture of Mexican Migration: A Theoretical and Empirical Analysis", Social Forces, 80 (3): 981-1004. 


\section{KAy, Cristóbal}

2007 "Latin America's Agrarian Transformation: Peasantization and Proletarianization", Deborah Bryceson, Cristóbal Kay y Jos Mooij (eds.), Disappearing Peasantries? Rural Labour in Africa, Asia and Latin America, Intermediate Technology Publications, Londres: 123-138.

\section{Kearney, Michael}

1996 Reconceptualizing the Peasantry: Anthropology in Global Perspective, Westview, Boulder.

\section{KLOPPENBURG, JACK}

2004 [1988] First the Seed: The Political Economy of Plant Biotechnology, Cambridge University Press, Cambridge.

\section{KORSBAEK, LEIF}

2005 "Historias de vida en una comunidad indígena del estado de México: el caso de San Francisco Oxtotilpan”, Hilario Topete, Leif Korsbaek y Mariana Sepúlveda (eds.), La organización social y el ceremonial, MC editores, México: 131-164.

2009a "El sistema de cargos en San Francisco Oxtotilpan”, Leif Korsbaek y Fernando Cámara (eds.), Etnografía del sistema de cargos en comunidades indígenas del Estado de México, MC Editores, México: 207-231.

2009b "Los peligros de la comunidad indígena y sus defensas", Ra Ximhai. Revista de Sociedad, Cultura y Desarrollo Sustentable, 5 (3): 373-385.

\section{LA CRÓNICA}

2008 [en línea] Edición del 18 de junio, La Crónica, <http://www.cronica.com.mx/nota. php?id_nota=367900> [consulta: 18 de junio de 2008].

\section{LA JORNADA}

2009 [en línea] Edición del 13 de mayo, La Jornada, <http://www.lajornadadeoriente. com.mx/2009/05/13/puebla/mun103.php> [consulta: 30 de enero de 2012].

2010 Edición del 4 de febrero.

2011 Edición del 25 de septiembre.

2012 Edición del 11 de febrero. 


\section{Landa, María Elena}

1987 Los tributos de Huexotzingo en el siglo XVI, INAH-Puebla, Puebla.

\section{LANZ, JOSÉ TRINIDAD}

1982 Legislación de aguas en México (estudio histórico legislativo de 1521-1981), Consejo Editorial del Estado de Tabasco, Villahermosa.

\section{LARA, SARA}

2001 "Análisis del mercado de trabajo rural en México en un contexto de flexibilización", Norma Giarracca (comp.), ¿Una nueva ruralidad en América Latina?, Consejo Latinoamericano de Ciencias Sociales, Buenos Aires: 363-382.

lara V., Alicia, Elías García A. y Alejo Aguilar R.

2004 "Casos médicos y estudios biológicos", Eduardo Morales Sierra (coord.), Ambiente y derechos humanos, Centro "Fray Julián Garcés", Tlaxcala: 67-71.

\section{LESSER Y ASOCIADOS}

1982 "Estudio geohidrológico en la zona río Atoyac, estado de Puebla", Secretaría de Asentamientos Humanos y Obras Públicas, México.

\section{Limón, ELENA}

1991 "La clase alta indígena en Tizatlán en el siglo xvi", Historia y sociedad en Tlaxcala. Memorias del IV y V Simposios Internacionales de Investigaciones Socio-Históricas sobre Tlaxcala, Gobierno del Estado de Tlaxcala, Instituto Tlaxcalteca de Cultura, Universidad Autónoma de Tlaxcala, Universidad Iberoamericana, México: 183-191.

\section{LIPSETT, SONYA}

1999 To Defend Our Water with the Blood of Our Veins. The Struggle for Resources in Colonial Puebla, The University of New Mexico Press, Albuquerque.

\section{Lira, Miguel N.}

1932 Corrido de Domingo Arenas, Fábula, México.

\section{LLAMBí, Luis}

2001 "Globalización, ruralidad, nueva ruralidad y desarrollo rural", La nueva ruralidad en América Latina, tomo II, Pontificia Universidad Javeriana, Bogotá. 
2007 “Global-Local Links in Latin America’s New Ruralities", Deborah Bryceson, Cristóbal Kay y Jos Mooij (eds.), Disappearing Peasantries? Rural Labour in Africa, Asia and Latin America, Intermediate Technology Publications, Londres: 176-191.

\section{LONG, NORMAN}

1996 "Globalización y localización: nuevos retos para la investigación rural", S. Lara y M. Chauvet (coords. del vol.), H. Carton de Grammont y H. Tejera (coords. grals.), La sociedad rural mexicana frente al nuevo milenio, vol. I: La inserción de la agricultura mexicana en la economía mundial, Plaza y Valdés, Instituto Nacional de Antropología e Historia, Universidad Autónoma Metropolitana-Azcapotzalco, Universidad Nacional Autónoma de México, México: 35-74.

\section{Lugo HubP, José ET AL.}

1989 Diccionario geomorfológico, Universidad Nacional Autónoma de México, México.

\section{Luna Morales, César}

1993 Cambios en el aprovechamiento de los recursos naturales de la antigua ciénega de Tlaxcala, Universidad Autónoma Chapingo, Chapingo.

\section{MACIP, RICARDO (ED.)}

2009 Sujetos Neoliberales en México, Benemérita Universidad Autónoma de Puebla, Puebla.

\section{Magazine, Roger y David Robichaux}

2010 “Neoliberalismo y nuevas economías en Tlaxcala y Texcoco, ¿una nueva ruralidad?", Antonio Escobar, Fernando I. Salmerón, Laura R. Valladares y Guadalupe Escamilla (coords.), Reformas del Estado. Movimientos sociales y mundo rural en el siglo XX en América Latina, Universidad Nacional Autónoma de México, El Colegio de México, Instituto Nacional de Antropología e Historia, Centro de Investigaciones y Estudios Superiores en Antropología Social, Universidad Iberoamericana, Universidad Autónoma Metropolitana, Colegio de Etnólogos y Antropólogos Sociales, El Colegio de Michoacán (Cátedra Interinstitucional Arturo Warman), México: 621-661.

\section{Mann, Susan y James Dickinson}

1978 "Obstacles to the Development of a Capitalist Agriculture", Journal of Peasant Studies, 5 (4): 466-81. 


\section{Marchand, Marianne H. (COORD.)}

2006 Tlaxcala. ¿Migración o desarrollo local?, Consejo Nacional de Ciencia y Tecnología, Gobierno Constitucional del Estado de Tlaxcala, Universidad de las Américas-Puebla, México.

\section{Marín Tamayo, Fausto et al.}

s/f "Puebla a través de los siglos: panorama histórico de la ciudad", México (inédito).

\section{MARRONI, GLORIA}

1995 "Los campesinos del centro del país en tiempo de competencia: el caso del trigo", Cuadernos del CIISDER, 1: 1-25.

\section{Martínez, Estela y JANett Vallejo}

2011 "Las nuevas relaciones rural-urbanas y mercados de trabajo en Morelos y el Estado de México", Hernán Salas, Ma. Leticia Rivermar y Paola Velasco (eds.), Nuevas ruralidades. Expresiones de la transformación social en México, México, Instituto de Investigaciones Antropológicas, Universidad Nacional Autónoma de México, Juan Pablos, México: 29-57.

\section{Martínez, Hildeberto}

1984 Tepeaca en el siglo XVI. Tenencia de la tierra y organización de un señorío, Secretaría de Educación Pública, Centro de Investigaciones y Estudios Superiores en Antropología Social (Ediciones de la Casa Chata, 21), México.

1994 Codiciaban la tierra. El despojo agrario en los señoríos de Tecamachalco y Quecholac (Puebla, 1520-1650), Centro de Investigaciones y Estudios Superiores en Antropología Social, México.

\section{Martínez, LuCiano}

2009 "La pluriactividad entre los pequeños productores rurales: el caso ecuatoriano", Hubert Carton de Grammont y Luciano Martínez (comps.), La pluriactividad en el campo latinoamericano, Facultad Latinoamericana de Ciencias Sociales Ecuador, Quito: 81-101.

\section{MARX, KARL}

1975 El Capital, tomo I, vol. 3, Siglo Veintiuno, México. 
Massey, Douglas S., Karen A. Pren y Jorge Durand

2009 "Nuevos escenarios de la migración México-Estados Unidos. Las consecuencias de la guerra antiinmigrante", Papeles de Población, XV (61): 101-128.

\section{Mazabel, Davison}

2007 "Las disputas por el agua en el valle de Texmelucan, Puebla, México a fines del siglo XVII”, Agricultura, Sociedad y Desarrollo 4 (2): 165-191.

\section{McCarthy, James y Scott Prudham}

2004 "Neoliberal Nature and the Nature of Neoliberalism", Geoforum, 35: 275-283.

\section{Medina, ANDrÉs}

2009 "Las comunidades corporadas del sur del Distrito Federal. Una primera mirada etnográfica", Miguel Lisbona (coord.), La comunidad a debate. Reflexiones sobre el concepto de comunidad en el México contemporáneo, El Colegio de Michoacán, Universidad de Ciencias y Artes de Chiapas, Zamora: 135-160.

\section{Medina, ARístides}

1983 La iglesia y la producción agrícola en Puebla 1540-1795, El Colegio de México, México.

\section{Mendoza, Jorge EduARdo}

2006 "Determinantes macroeconómicos regionales de la migración mexicana", Migraciones Internacionales, 3 (4): 118-145.

\section{Miehlich, GunTER}

1988 “Fisiografía de la región”, Hanns Prem, Milpa y hacienda. Tenencia de la tierra indígena y española en la cuenca del Alto Atoyac, Puebla, México, (1520-1650), Fondo de Cultura Económica, Centro de Investigaciones y Estudios Superiores en Antropología Social, México: 8-18.

\section{Millán, SAúl}

2005 "Los cargos en el sistema”, Hilario Topete, Leif Korsbaek y Mariana Sepúlveda (eds.), La organización social y el ceremonial, MC Editores, México: 217-238.

\section{Montero, Arturo}

2001 "Buscando a los dioses de la montaña: una propuesta de clasificación ritual”, Johanna Broda, Stanislaw Iwaniszewski y Arturo Montero (coords.), La montaña en el paisaje 
ritual, Universidad Nacional Autónoma de México, Benemérita Universidad Autónoma de Puebla, Instituto Nacional de Antropología e Historia, Consejo Nacional para la Cultura y las Artes, México: 23-47.

\section{Montero, Regina, Luis Serrano, Antonio Araujo, Víctor Dávila, Johny Ponce,}

\section{Rafael Camacho, Eduardo Morales y Alejandra Méndez}

2006 "Increased Cytogenetic Damage in a Zone in Transition from Agricultural to Industrial Use: Comprehensive Analysis of the Micronucleus Test in Peripheral Blood Lymphocytes", Mutagénesis, 21 (5): 335-342.

\section{Morales, Eduardo}

2004 "Conclusiones", Eduardo Morales Sierra (coord.), Ambiente y derechos humanos, Centro "Fray Julián Garcés", Tlaxcala: 79-81.

2010 "Casos de daño a la salud por contaminación en los estados de Tlaxcala y Puebla", Mariana Pérez Argüelles (coord.), Cinco miradas sobre el derecho a la salud. Estudios de caso en México, El Salvador y Nicaragua, Fundar, Centro de Análisis e Investigación, México: 231-290.

\section{Morales, Ma. Eugenia}

1999 "Aprovechamiento de los ríos Zahuapan y Atoyac para el riego de la Hacienda Santa Ana Portales", Boletín del Archivo Histórico del Agua, 5 (15): 27-31.

\section{MuÑoz, Christian}

2008 "La reinvención de la comunidad: cambio social y estrategias de adaptación en el México rural. Un caso de estudio", Kirsten Appendini y Gabriela Torres-Mazuera (eds.), ¿Ruralidad sin agricultura?, El Colegio de México, México: 171-192.

\section{NASh, DenNison}

1989 "El turismo considerado como una forma de imperialismo", Valene L. Smith (coord.), Anfitriones e invitados. Antropología del turismo, Endymion, Madrid: 69-91.

\section{Navarro, Inés y Eduardo Morales}

2004 "Descripción del problema", Eduardo Morales Sierra (coord.), Ambiente y derechos humanos, Centro "Fray Julián Garcés", Tlaxcala: 15-25. 


\section{Navarro, Inés, Erasmo Flores y Rita Valladares}

2004 "Evaluación ambiental y epidemiológica para identificar factores de riesgo a la salud por contaminación del río Atoyac, México”, ponencia presentada en el XXIX Congreso interamericano de ingeniería sanitaria y ambiental, Forjando el Ambiente que Compartimos, San Juan, Puerto Rico, agosto.

\section{NorTh, Douglas}

1990 Institutions, Institutional Change, and Economic Performance, Cambridge University Press, Cambridge.

\section{Nutini, Hugo y Berry Bell}

1981 Ritual Kinship, the Structure and Historical Development of the Compadrazgo System in Rural Tlaxcala, Princeton University Press, Princeton.

\section{Nutini, Hugo y Timothy Murphy}

1970 "Labor Migration and Family Structure in the Tlaxcala-Puebla Area, Mexico", W. Goldschmithd y H. Hoiyer (eds.), The Social Anthropology of Latin America. Essays in Honor of Ralph Beals, Latin American Center, University of California, Los Ángeles: 80-103.

\section{OCHOA, TERESA}

2008 "La dominación masculina en el sistema tradicional de cargos: el caso de San Jerónimo Amanalco, municipio de Texcoco, México", Primavera, 4 (1): 1-18.

\section{Palerm, Jacinta}

2009a [en línea] "Distritos de riego en México, algunos mitos", Jacinta Palerm y Tomás Martínez (eds.), Aventuras con el agua. La administración del agua de riego: historia y teoría, Colegio de Postgraduados, Texcoco: 277-327, <http://jacintapalerm.hostei. com/AVENTURAS_10_Mitos_D_de_R.pdf> [consulta: 26 de febrero de 2012].

2009b "Prólogo", Davison Mazabel, Agua y colonización, División de Ciencias Sociales y Humanidades, Universidad de Guanajuato.

\section{Paleta, Guillermo}

2008 Industrialización, lucha agraria y cambio social en una comunidad del ex Distrito de Cholula, Puebla, 1915-1930, tesis, Universidad Nacional Autónoma de México, México. 


\section{Pardinas, Juan E.}

2008 Los retos de la migración en México. Un espejo de dos caras, Comisión Económica para América Latina y el Caribe (Serie Estudios y Perspectivas, 99), Organización de las Naciones Unidas, México.

\section{Passel, JefFrey y D’Vera Cohn}

2009 “Mexican Immigrants: How Many Come? How Many Leave?", Pew Hispanic Center, Washington.

\section{París, María Dolores}

2010 "Youth Identities and the Migratory Culture among Triqui and Mixtec Boys and Girls", Migraciones Internacionales, 5 (4): 139-164.

\section{Pérez, César y René VAldivieso}

1990 La industrialización en Tlaxcala, 1970-1985: el caso de la cuenca Atoyac-Zahuapan, Tlaxcala, tesis, Universidad Iberoamericana, México.

\section{Perrault, Thomas y Patricia Martin}

2005 "Geographies of Neoliberalism in Latin America", Environment and Planning, 37: 191-201.

\section{Perrow, Charles}

1999 Normal Accidents. Living with High-Risk Technologies, Princeton University Press, Princeton.

\section{Pichardo, Beatriz}

2006 “La Revolución Verde en México”, Agraria, 4: 40-68.

\section{Pinto, Louis}

2002 Pierre Bourdieu y la teoría del mundo social, Siglo Veintiuno, México.

\section{Prem, Hanns}

1988 Milpa y hacienda. Tenencia de la tierra indígena y española en la cuenca del Alto Atoyac, Puebla, México, 1520-1650, Fondo de Cultura Económica, Centro de Investigaciones y Estudios Superiores en Antropología Social, México. 
RAMírez RANCAÑo, MARio

1990 El sistema de haciendas en Tlaxcala, Consejo Nacional para la Cultura y las Artes, México.

1988 "Huelgas de los peones del campo en las haciendas de Tlaxcala", Secuencia, 10: 5-32.

\section{Real Academia Española (RAe)}

2001 [en línea] Diccionario de la Lengua Española, Real Academia de la Lengua Española, Madrid, <www.rae.es/rae.html> [consulta: 10 de enero de 2012].

\section{REDFIELD, ROBERT}

1960 The Little Community and Peasant Society and Culture, University of Chicago Press, Chicago.

\section{Registro Agrario Nacional (RAN)}

2008 [en línea] "Municipios Tlaxcala”, Procuraduría Agraria, <http://www.pa.gob.mx> [consulta: 14 de febrero de 2010].

\section{RENDón, RiCARDO}

1996 Breve historia de Tlaxcala, Fondo de Cultura Económica, El Colegio de México, México.

\section{Restrepo Fernández, IVÁn y José SÁnchez Cortés}

1972 La Reforma Agraria en cuatro regiones. El Bajío, Michoacán, La Laguna y Tlaxcala, Secretaría de Educación Pública (sep Setentas, 63), México.

\section{REVilla López, Ulises}

2007 La migración transnacional de Oaxaca y Tlaxcala: las organizaciones de migrantes en Estados Unidos, Fondo Indígena, La Paz.

\section{Reyes, Candelario}

1961 Biografía de Juan Cuamatzi, Tlahuicole, Tlaxcala.

\section{RICHARDSON, HARRY}

1973 Economía Regional, Vicens Vives, Barcelona. 


\section{Rivera, Liliana y Fernando Lozano}

2006 "Los contextos de salida urbanos y rurales y la organización social de la migración", Migración y Desarrollo, 6: 45-101.

\section{Rivermar, María Leticia}

2008 Etnicidad y migración internacional. El caso de una comunidad nahua en el estado de Puebla, Benemérita Universidad Autónoma de Puebla, Puebla.

\section{RoBICHAUX, DAVID}

2006 "Nahuas de Tlaxcala (México) en el mundo globalizado: reflexiones a partir de 30 años de trabajo de campo", Iberoforum, 2 (1): 1-15.

2007 “Identidades cambiantes: 'indios' y 'mestizos' en el suroeste de Tlaxcala”, Osvaldo Romero et al. (comps.), Cultura, poder y reproducción étnica en Tlaxcala, México, Universidad Autónoma de Tlaxcala, Tlaxcala: 17-64.

\section{Rodríguez, JuAn Carlos y Hernán SAlas}

2010 "La nueva ruralidad. Una propuesta conceptual desde la antropología política y espacial", Roberto Hernández y Luis Pezo (eds.), La ruralidad chilena actual, aproximaciones desde la Antropología, CoLibris, Santiago: 45-77.

\section{Romero, María Teresa}

2009 "Antropología y pueblos originarios de la ciudad de México. Las primeras reflexiones", Argumentos, 22 (59): 45-65.

\section{ROSEBERRY, WILLIAM}

1991 “Los campesinos y el mundo", Stuart Plattner (ed.), Antropología económica, Alianza, Consejo Nacional para la Cultura y las Artes, México: 154-176.

2002 “Understanding Capitalism-Historically, Structurally, Spatially", David Nugent (ed.), Locating Capitalism in Time and Space: Global Restructurings, Politics, and Identity, Stanford University Press, Stanford: 61-79.

\section{Salas, Hernán}

2002 Antropología, estudios rurales y cambio social. La globalización en la región lagunera, Instituto de Investigaciones Antropológicas, Universidad Nacional Autónoma de México, México. 
2010 "La territorialización de las redes de pertenencia social: un caso de religiosidad popular en Nativitas, Tlaxcala", Rodrigo Luiz Simas de Aguiar, Jorge Eremites de Oliveira y Levi Marquez Pereira (eds.), Arqueologia, etnologia e etno-história em Iberoamérica, Universidade Federal da Grande Dourados, Dourados: 143-157.

\section{Salas, Hernán y Leticia Rivermar}

2011 "Nuevas ruralidades en el sur de Tlaxcala", Hernán Salas, Leticia Rivermar y Paola Velasco (eds.), Nuevas ruralidades. Expresiones de la transformación social en México, Instituto de Investigaciones Antropológicas, Universidad Nacional Autónoma de México, Juan Pablos, México: 139-163.

\section{Salas, Hernán, Ma. Leticia Rivermar y Paola Velasco (eds.)}

2011 Nuevas ruralidades. Expresiones de la transformación social en México, Universidad Nacional Autónoma de México, Instituto de Investigaciones Antropológicas, Juan Pablos, México.

\section{Salas, Hernán y Paola Velasco}

2010 "Deterioro ambiental y calidad de vida en una población rural del sur de Tlaxcala", ponencia presentada en la 70th Annual Meeting Society for Applied Anthropology, Mérida, Yucatán, 24 al 27 de marzo.

\section{Salazar, Celia}

1993 Problemática del agua en Tehuacán, época colonial, 1610-1730, tesis, Facultad de Filosofía y Letras, Universidad Nacional Autónoma de México, México.

\section{Saldaña, Pilar y Ma. Antonieta Gómez}

2006 "Caracterización de fuentes puntuales de contaminación en el río Atoyac, México", ponencia presentada en el XXX Congreso interamericano de ingeniería sanitaria y ambiental, Punta del Este, noviembre.

\section{SÁNCHEZ, MARTín}

2001 "Las disputas por el agua en el Bajío mexicano a fines del siglo xviII", Relaciones, 87 (XXII): 159-174. 


\section{SANDERSON, STEven E.}

1990 La trasformación de la agricultura mexicana: estructura internacional y política del cambio rural, Alianza, México.

\section{SANDOVAL, EduARdo}

2005 "La organización social indígena mazahua", Hilario Topete, Leif Korsbaek y Mariana Sepúlveda (eds.), La organización social y el ceremonial, MC Editores, México: 261-280.

\section{SAntos, Milton}

2000 La naturaleza del espacio. Técnica y tiempo. Razón y emoción, Ariel, Barcelona.

\section{SASSEN, SASKIA}

1995 "Immigration and Local Labor Markets", A. Portes (ed.), The Economic Sociology of Immigration. Essays on Networks, Ethnicity, and Entrepreneurship, Russell Sage Foundation, Nueva York: 87-127.

1996 "Immigration Policy toward Mexico in a Global Economy", D. G. Gutiérrez (ed.), Between Two Worlds. Mexican Innmigrants in the United States, Scholarly Rosources (Jaguar Books on Latin America, 15) Wilmington: 213-227.

\section{Secretaría de Agricultura, Ganadería, Desarrollo Rural,}

Pesca y Alimentación (sagarpa)

2009 "Servicio de información agroalimentaria y pesquera", Secretaría de Agricultura, Ganadería, Desarrollo Rural, Pesca y Alimentación, México.

\section{Secretaría de Desar rollo Industrial de Puebla (sdip)}

s/f [en línea] "Reservas, áreas y parques industriales en Puebla", Coordinación General de Promoción Industrial, <http://www.sedeco.pue.gob.mx/seapi/infraestructura/index.htm> [consulta: febrero de 2010].

\section{Secretaría de la Reforma Agraria}

1998 La transformación agraria: origen, evolución, retos, testimonios, Secretaría de la Reforma Agraria, México. 
Secretaría de Medio Ambiente y Recursos Naturales (semarnat)

2007 [en línea] "Agenda Ambiental del Estado de Tlaxcala 2007", Secretaría de Medio Ambiente y Recursos Naturales, <http://www.semarnat.gob.mx/.../tlaxcala/.../Agenda\%20Ambiental\%202007.pdf> [consulta: 1 de febrero de 2010].

\section{Secretaría del Trabajo y Previsión Social (stps)}

2010 [en línea] "Cuarto informe de labores de la Secretaría del Trabajo y Previsión Social", Secretaría del Trabajo y Previsión Social, <http://www.stps.gob.mx/bicentenario_ plantilla/4to_info/4o_Informe_version_digital.pdf> [consulta: 28 de enero de 2011].

s/f [en línea] "Anexos", secretaría del Trabajo y Previsión Social, <www.stps.gob.mx/ ANEXOS/TERCER\%20INFORME\%20STPS.pdf> [consulta: 28 de enero de 2011].

\section{Serra, Mari Carmen y Jesús Carlos Lazcano}

2011 Vida cotidiana. Xochitécatl-Cacaxtla, días, años, milenios, Instituto de Investigaciones Antropológicas, Universidad Nacional Autónoma de México, México.

\section{SerRANO, JUAN}

2008 Yancuitlalpan -en la tierra nueva- Nativitas. Monografía histórica municipal, $\mathrm{H}$. Ayuntamiento de Nativitas, Nativitas.

\section{SIDICARO, RICARDO}

2008 "La sociología según Pierre Bourdieu", Pierre Bourdieu y Jean-Claude Passeron, Los herederos. Los estudiantes y la cultura, Siglo Veintiuno, México: I-XXXII.

\section{SMith, NeIL}

2009 “Toxic Capitalism”, New Political Economy, 14 (3): 407-412.

\section{Solano, Francisco}

1984 Cedulario de tierras. Compilación de legislación agraria colonial (1497-1820), Universidad Nacional Autónoma de México, México.

\section{Solís-Oba, Miran, Javier Almendáriz y Gustavo Viniera-González}

2008 "Biotechnological Treatment for Colorless Denim and Textil Wastewater Treatment with Laccase and ABTS", Revista Interamericana de Contaminación Ambiental, 24 (1): 5-11. 


\section{SOPHOCLEOUS, Marios}

2002 "Interactions Between Groundwater and Surface Water: the State of the Science", Hydrogeology Journal, 10: 52-67.

\section{SPENCER, JONATHAN}

2004 "La democracia como sistema cultural. Escenas de las elecciones de 1982 en Sri Lanka", Aurora Marquina (comp.), El ayer y el hoy: lecturas de Antropología Política. El futuro, volumen II, Universidad Nacional de Educación a Distancia, Madrid: 53-74.

\section{SuÁrez, SUSANA}

2011 "Globalización y transformaciones socioterritoriales en el ámbito rural: puntualizaciones sobre una nueva ruralidad", Hernán Salas, María L. Rivermar y Paola Velasco (eds.), Nuevas ruralidades. Expresiones de la transformación social en México, Instituto de Investigaciones Antropológicas, Universidad Nacional Autónoma de México, Juan Pablos, México: 59-81.

\section{SUllings, GUILlermo}

2004 "Introducción a la democracia real", Aurora Marquina (comp.), El ayer y el hoy: lecturas de Antropología Política. El futuro, volumen II, Universidad Nacional de Educación a Distancia, Madrid: 75-104.

Tello, Enriqueta, Tomás Martínez-Saldaña, Israel Sandré y Alberto Xelhuantzi

2010 "Reconstrucción histórica de la intervención del estado en el control oficial para el uso y manejo del agua en San Miguel Xochitecatitla, Tlaxcala", Ra Ximbai, Revista de Sociedad, Cultura y Desarrollo Sustentable, 6 (2): 169-185.

\section{Terrazas, Óscar}

2005 La ciudad de los caminos: el caso del corredor Puebla-Tlaxcala, Gobierno del Estado de Tlaxcala, Consejo Nacional de Ciencia y Tecnología, Universidad Autónoma Metropolitana-Azcapotzalco, México.

\section{The NorTh-South Institute}

s/f [en línea] North South Institute, <http://www.nsi-ins.ca/english/pdf/Exclusion_Inclusion_Migrant.pdf> [consulta: 2 de junio de 2011]. 


\section{Topete, HiLa Rio}

2005 "El poder, los sistemas de cargos y la antropología política", Hilario Topete, Leif Korsbaek y Mariana Sepúlveda (eds.), La organización social y el ceremonial, MC Editores, México: 281-303.

\section{TORRES, GABriela}

2009 "La territorialidad rural mexicana en un contexto de descentralización y competencia electoral”, Revista Mexicana de Sociología, 71 (3): 453-490.

\section{Tortolero, Alejandro}

2000 El agua y su historia. México y sus desafíos hacia el siglo XXI, Siglo Veintiuno, México.

Тóтн, J.

2000 "Las aguas subterráneas como agente geológico: causas, procesos y manifestaciones", Boletín Geológico y Minero, 111 (4): 9-26.

\section{Trautmann, Wolfgang}

1981 Las transformaciones en el paisaje cultural de Tlaxcala durante la época colonial. Una contribución a la historia de México bajo especial consideración de aspectos geográficoeconómicos y sociales, Franz Steiner, Stuttgart.

\section{Tyrakowski Findeiss, Konrad}

2003 "Historia colonial en detalle: progreso y decadencia de la España Chiquita, del pueblo de Santa María Nativitas Yancuitlalpan en Tlaxcala (México)", Revista Española de Antropología Americana, 33: 157-181.

\section{Valencia-Quintana, Rafael, Stefan Waliszewski, José Gómez-Olivares, Juan}

SUÁREZ Y JUANa SÁNCHEZ

2011 "Evaluación de Riesgos por exposición a contaminantes ambientales presentes en las aguas del Sistema Hidrológico Atoyac-Zahuapan”, Raúl Jiménez G. y María de L. Hernández (coords.), Zahuapan: río-región-contaminación, El Colegio de Tlaxcala, Tlaxcala: 79-100.

\section{Valladares, Rita, Erasmo Flores e Inés Navarro}

2005 "Estudio de la calidad del agua residual que descarga al río Atoyac: comunidades, ONG e investigadores unidos", ponencia presentada en el II Encuentro Participación de la mujer en la ciencia, León, Guanajuato, mayo. 


\section{VAllejos, Arturo}

2005 "Los conflictos ambientales en una sociedad mundializada. Algunos antecedentes y consideraciones para Chile”, Revista Líder, 13 (10): 193-214.

\section{VARGAS, ERNESTO}

1995 Seis ensayos sobre antiguos patrones de asentamiento en el área maya, Instituto de Investigaciones Antropológicas, Universidad Nacional Autónoma de México, México.

Velasco, Luis A.

1998 Geografía y estadística de la Republica Mexicana, XI, Geografía y estadística del estado de Tlaxcala (versión facsimilar del original publicado en 1892), Gobierno del Estado de Tlaxcala, Tlaxcala.

\section{Villalobos-Pietrini, Rafael, Ana Rosa Flores-MárQuez}

Y SANDra Gómez-Arroyo

1994 "Cytogenetic Effects in Vicia Faba of the Polluted Water from Rivers of the Tlaxcala Hydrological System, Mexico", Revista Internacional de Contaminación Ambiental, $10(2): 83-88$.

\section{VIZCARRA, IVONNE}

2002 "Las otras 'Santas del Sustento' en la fiesta de San Miguel la Labor: una (re)construcción social de género en el sistema de cargos", Eduardo Sandoval, Hilario Topete y Leif Korsbaek (eds.), Cargos, fiestas, comunidades, Universidad Autónoma del Estado de México, Toluca: 197-206.

\section{WOLF, ERIC}

1955 "Types of Latin American Peasantry: A Preliminary Discussion", American Anthropologist, 57 (3): 452-471.

\section{ZÁrate, Eduardo}

2009 "La comunidad imposible. Alcances y paradojas del moderno comunalismo", Miguel Lisbona (coord.), La comunidad a debate. Reflexiones sobre el concepto de comunidad en el México contemporáneo, El Colegio de Michoacán, Universidad de Ciencias y Artes de Chiapas, Zamora: 61-85. 


\section{ARCHIVOS CONSULTADOS}

Archivo General de la Nación México (agnM).

Archivo Histórico del Agua (AHA).

Archivo Histórico del Estado de Tlaxcala (AHET).

Archivo Histórico Parroquial Santa María Nativitas, Tlaxcala (AHPNT).

Registro Agrario Nacional, Tlaxcala (RAN-T).

\section{PÁGINAS DE INTERNET CONSULTADAS}

http://afectadosambientales.blogspot.com/

http://impreso.milenio.com

http://www.boell-latinoamerica.org

http://www.ciepuebla.com.mx

http://www.sanluisrassini.com/

http://www.sedeco.pue.gob.mx/seapi/infraestructura/index.htm 


\section{SOBRE LOS AUTORES}

Hernán Salas Quintanal es investigador en el Instituto de Investigaciones Antropológicas de la UNAM. Es doctor en Antropología (UNAM), maestro en Ciencias Sociales (FLACSO) y licenciado en Antropología Social (Universidad de Chile). Es miembro del Sistema Nacional de Investigadores y de la Academia Mexicana de Ciencias. Es profesor en los posgrados en Antropología (UNAM) y en Estudios Regionales (Instituto Mora) y en la Licenciatura en Desarrollo y Gestión Intercultural (FFyL). Es coordinador del Seminario Permanente "Antropología y nuevas ruralidades" (IIA-UNAM) y responsable de los proyectos de investigación: Continuidades y transformaciones socioeconómicas y culturales en el municipio de Nativitas, Tlaxcala. ¿Hacia la conformación de una nueva ruralidad? (PAPIIT-UNAM) y Repensar lo rural (Conacyt). Entre sus publicaciones destacan Antropología, estudios rurales y cambio social. La globalización en la región lagunera (UNAM 2002); con Estela Martínez y Susana Suárez (coords.), La globalización del sistema lechero en La Laguna: Estructura productiva, desarrollo tecnológico y actores sociales (UnAM, Porrúa 2003); con Cristina Oehmichen (eds.), Migración, diversidad y fronteras culturales (UNAM 2011); con Leticia Rivermar y Paola Velasco (eds.), Nuevas ruralidades: expresiones de la transformación social en México (UNAM, Juan Pablos 2011); El río Nazas, la historia de un patrimonio lagunero (UNAM, 2011; premio Fray Bernardino de Sahagún 2012).

Ma. Leticia Rivermar Pérez es doctora en Antropología, pertenece al sNi nivel I, es profesora-investigadora del Instituto de Ciencias Sociales y Humanidades "Alfonso Vélez Pliego" de la BUAP. Entre sus publicaciones más destacadas se encuentran: Etnicidad y migración internacional. El caso de una comunidad nahua del estado de Puebla, (BUAP 2008); con Blanca Laura Cordero Díaz (comps.), El norte como destino. Circuitos migratorios Puebla-Estados Unidos, (BUAP 2008); con Ma. Eugenia D’Aubeterre Buznego (eds.), Migraciones en la Huasteca poblana. Actores y procesos, (ICSYH, BUAP 2011); con Hernán Salas y Paola Velasco (eds.), Nuevas ruralidades expresiones de la transformación social en México, (IIA, UNAM, Juan Pablos 2011). 
Esther Galicia Hernández es maestra en Arquitectura-Urbanismo por la Universidad Nacional Autónoma de México (1997) y Arquitecta por la Benemérita Universidad Autónoma de Puebla (1985). Actualmente realiza la tesis para obtener el Doctorado en Geografía por la UNAM. Es autora del artículo "Sistemas de irrigación y sistemas de flujos de agua superficial y subterránea en la cuenca Alto Atoyac, 1950-2000” (2009) y ha publicado como capítulos de libro: “Topografía, geología y clima en la cuenca Alto Atoyac. Factores determinantes del funcionamiento de los sistemas de flujo de agua subterránea" (2009) y "La integración de un territorio al dominio de la ciudad. El caso del ejido de San Baltazar Campeche, Puebla. 1923-1991" (2009). Sus temas de investigación son: sistemas de flujo de agua subterránea en la subcuenca PueblaTlaxcala; condiciones históricas de funcionamiento del sistema hídrico y los procesos de apropiación-distribución del agua en el territorio.

Davison G. Mazabel Domínguez es doctor en Antropología por la UnAM. profesor-investigador de la Universidad de Guanajuato (Campus Celaya-Salvatierra, Departamento de Estudios Sociales). Es miembro del sNI, autor del libro Agua y Colonización. Las disputas por el agua en el valle de Texmelucan (2009) y coautor de los libros La dimensión social de la sustentabilidad en sistemas hidroagrícolas (2010) y Agua, cultura y desarrollo (2011). Ha publicado diversos artículos en revistas nacionales y extranjeras sobre historia agraria, sustentabilidad social y organización social para el manejo del agua. Es miembro del Cuerpo Académico Desarrollo Regional y Sustentabilidad de la Universidad de Guanajuato. Forma parte de la Red de Investigadores Sociales sobre Agua (RISSA) y de la Red de Desarrollo Sostenible y Medioambiente (REDESMA).

Guillermo Paleta Pérez es doctor en Antropología por la UnAM, investigador de la Unidad Académica de Estudios Regionales de la Coordinación de Humanidades de la UNAM en Jiquilpan, Michoacán. Es miembro del SNI, nivel I. Su línea de investigación es antropología rural y territorio. Entre sus publicaciones recientes se encuentran: "Territorios y ruralidades: jornaleros agrícolas en el cultivo de zarzamora en el valle de Los Reyes, Michoacán, México" en la Revista de Antropología Experimental de la Universidad de Jaén, España (2012); "Reorganización territorial y conurbación entre Sahuayo y Jiquilpan, Michoacán” en Estudios Michoacanos XIV del Colegio de Michoacán (2011); "Notas sobre el paisaje y transformaciones rurales en localidades de la ciénega de Michoacán" en Sociedad y culturas regionales. Problemas locales, miradas globales (UNAM 2011). 
Óscar Gerardo Hernández Lara es licenciado en Planeación Territorial por la Universidad Autónoma del Estado de México (UAEmex) y maestro en Estudios Regionales por el Instituto de Investigaciones Dr. José María Luis Mora. Actualmente es alumno del Doctorado en Geografía de la UNAM. Tiene un diplomado en "Desarrollo regional: metodologías, diagnóstico y aplicaciones" otorgado por el Instituto de Investigaciones Económicas de la UNAM. Ha impartido ponencias en eventos organizados por la UAM-Iztapalapa, la UAEMex, la AMER y la UNAM y asignaturas en los niveles de licenciatura y bachillerato en la UAEMex. Cuenta con publicaciones para el Instituto de Investigaciones Dr. José María Luis Mora y la Facultad de Planeación Urbana y Regional de la UAEMex. Líneas de interés: procesos urbano-rurales, estudios rurales y regionales: turismo, envejecimiento y migración.

Rubén Luna Castillo es maestro en Estudios Regionales por el Instituto Dr. José María Luis Mora, generación 2007-2009. Es licenciado en Antropología Social por la Escuela Nacional de Antropología e Historia, generación 2001-2004. Su última publicación: "La Sierra Tarahumara: una historia de resistencia y continuidad", revista Cuadernos de Posgrado, segunda edición, del Instituto Mora. Ha laborado como consultor en el proyecto "Evaluación de los programas de fomento de la Secretaría de la Reforma Agraria", Proyecto UTF/MEX/098 (Organización de las Naciones Unidas para la Agricultura y la Alimentación [FAO] 2011); como investigador en los proyectos "Caracterización e identificación de comunidades indígenas" y "Evaluación diagnóstica de la administración pública en comunidades indígenas" (CDI-CIESAS2011). Es miembro del seminario Antropología y nuevas ruralidades del Instituto de Investigaciones Antropológicas (UNAM).

Paola Velasco Santos es doctora en Antropología por la UnAM (2014), maestra en Estudios Regionales por el Instituto de Investigaciones José María Luis Mora (2007) y licenciada en Antropología con especialidad en Antropología Cultural por la Universidad de las Américas Puebla (2005). Actualmente colabora en los proyectos Continuidades y transformaciones socioeconómicas y culturales en el municipio de Nativitas, Tlaxcala (PAPIIT 302709) y Repensar lo rural y el concepto de Nueva Ruralidad como propuesta para entender las transformaciones contemporáneas en el Valle Puebla Tlaxcala (Conacyt CB-98651). En el 2009 recibió el premio 2007-2008 a la "Mejor investigación del campo mexicano" otorgado por la Asociación Mexicana de Estudios Rurales (AMER) por la tesis de maestría titulada "Entre el cambio y 
la permanencia. Formas actuales de ruralidad en la región sociocultural de Cholula, Puebla". Es coeditora del libro Nuevas ruralidades. Expresiones de la transformación social en México (2011), publicado por unAm y Juan Pablos y autora de un capítulo del mismo libro llamado "Cambios, reacomodos y permanencias en San Andrés Cholula, Puebla: la construcción de una forma actual de ruralidad”.

Íñigo González de la Fuente es docente e investigador de la Universidad de Cantabria (España). Es doctor en Antropología (2008) y maestro en Estudios Latinoamericanos (2004) por la Universidad de Salamanca y licenciado en Sociología por la Universidad del País Vasco (1997). Es profesor de diferentes materias de grado y posgrado en la Facultad de Educación en su Universidad, además ha sido profesor invitado de posgrado en la Universidad de Salamanca y en la unAm. Sus temas de investigación son: juventud, diversidad cultural y participación política. Entre sus publicaciones destacan el libro Antropología de la participación política (2010), el capítulo de libro "Cultura e interacción social en Bolivia: el caso de la ciudad de El Alto" (2011) y el artículo "Comunidad, sistema de cargos y proyecto social. Una propuesta analítica de sociedades locales en México" (2011).

Celia López Miguel es licenciada en Geografía egresada de la Facultad de Filosofía y Letras de la Universidad Nacional Autónoma de México (UnAM). Recibió la medalla Gabino Barreda por el mejor promedio de la generación 93-97. Se tituló con mención honorífica y su tesis fue premiada por la Sociedad Mexicana de Geográfica y Estadística como la mejor tesis del año 2000. Su formación académica después de la licenciatura ha consistido en cursos, tanto nacionales como internacionales, de especialización en manejo de Sistemas de Información Geográfica, GPS y en el proceso de edición, diseño y producción cartográfica digital. Se ha desempeñado como profesora de Sistemas de información geográfica a nivel licenciatura. Como parte de su producción científica ha colaborado en artículos publicados en revistas indexadas nacionales e internacionales. Actualmente es Técnica Académica Asociada "C" Definitiva de Tiempo Completo del Centro Regional de Investigaciones Multidisciplinarias (CRIM) de la UNAM. 


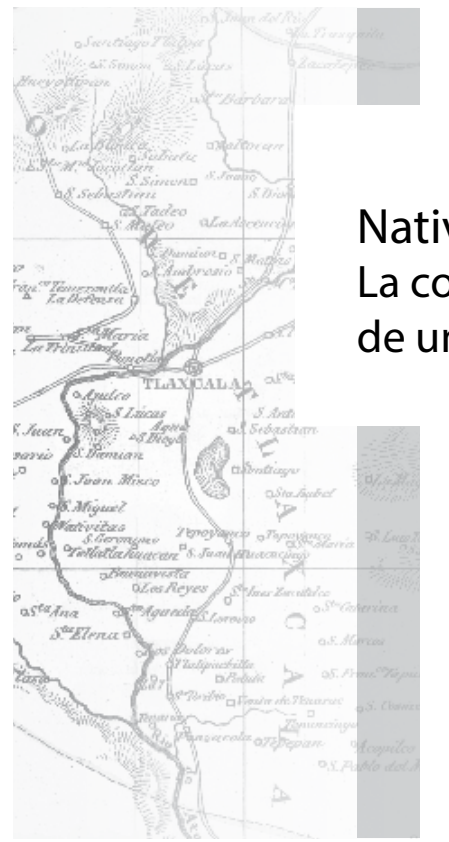

Editado por el Instituto de Investigaciones Antropológicas de la UNAM, se terminó de imprimir el 30 de junio de 2014, en los talleres de ART Graffiti Sistema Gráfico, calle Concepción Beistegui № 1562, Col. Narvarte, Del. Benito Juárez, México, D. F., C.P. 03020; Flor Moyao hizo la composición en tipo Minion Pro y Trajan Pro

15/18, 11/13 y 9/11 puntos; la corrección estuvo a cargo de René Uribe y Adriana Incháustegui. La edición consta de 500 ejemplares impresos en offset, en papel couché de $135 \mathrm{~g}$, encuadernación rústica y estuvo al cuidado de Ada Ligia Torres. 


\section{Nativitas, Tlaxcala.}

\section{La construcción en el tiempo} de un territorio rural

Nativitas, al sur del estado de Tlaxcala, es uno de los municipios más antiguos del estado, enclavado en el centro del valle poblano tlaxcalteca, se caracteriza por la calidad de sus tierras y la abundancia de agua para labores agropecuarias. En este libro se reúne un amplio acervo de información para comprender su historia agrícola, los cambios económicos, socioculturales y territoriales.

La obra contiene estudios etnográficos e históricos que analizan el reparto agrario, el proceso de industrialización, las transformaciones de los mercados laborales, las migraciones, el deterioro ambiental, la reorganización de los grupos domésticos y de la vida comunitaria; asimismo, presenta una amplia cartografía de la región. La publicación de estos materiales busca difundir las problemáticas que aquejan a los nativitenses y tlaxcaltecas y, al mismo tiempo, explicar las bases de la reproducción material y simbólica y los comportamientos de las sociedades rurales en la actualidad.

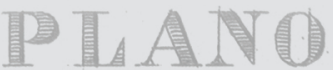

del Territorio de

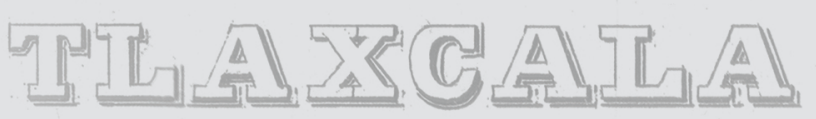

Ario de 1848 .

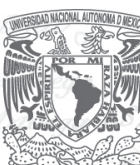

